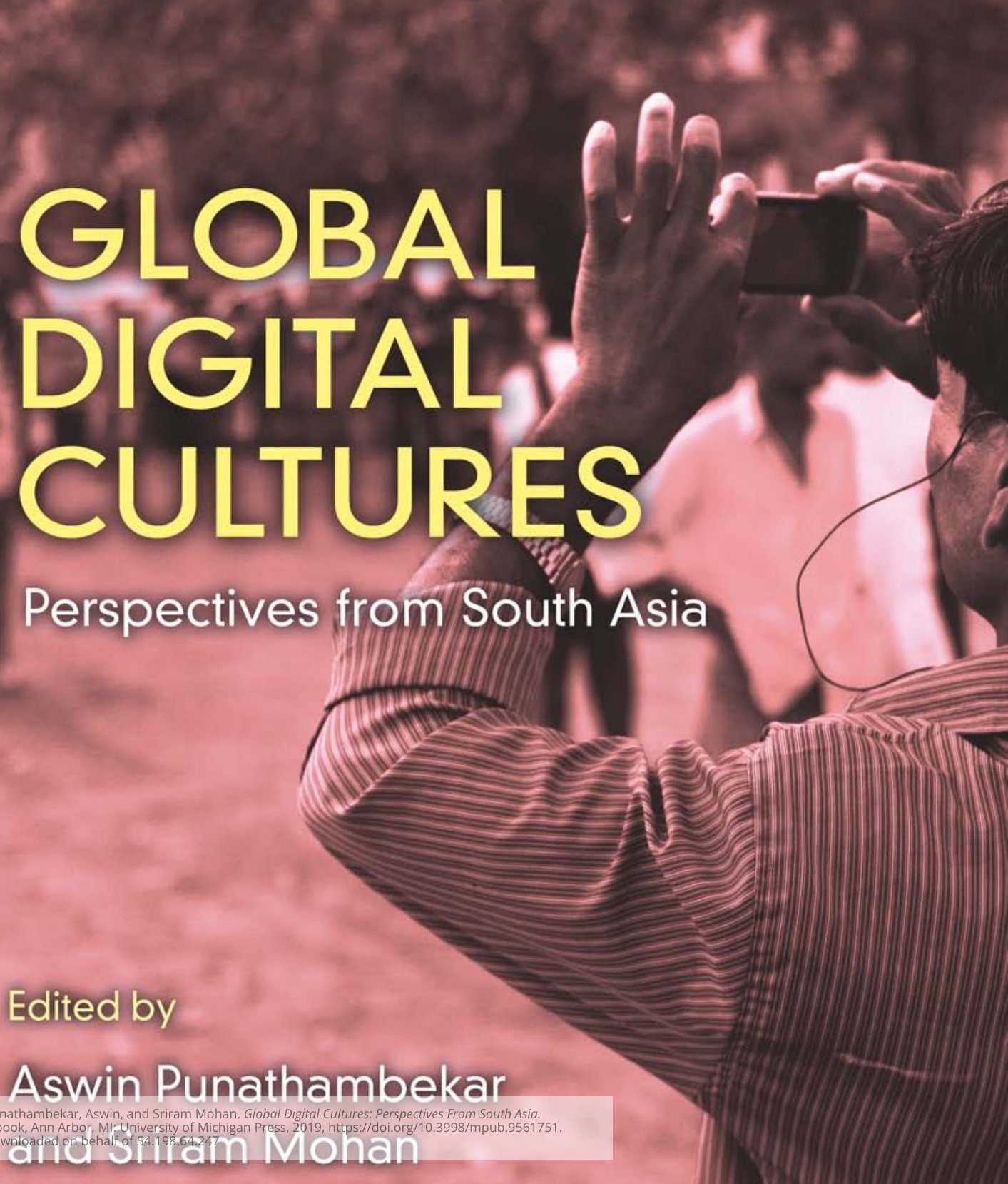


Global Digital Cultures 


\title{
Global Digital Cultures
}

Perspectives from South Asia

\author{
ASWIN PUNATHAMBEKAR AND \\ SRIRAM MOHAN, EDITORS
}

UNIVERSITY OF MICHIGAN PRESS • ANN ARBOR 
Copyright (C 2019 by Aswin Punathambekar and Sriram Mohan All rights reserved

This book may not be reproduced, in whole or in part, including illustrations, in any form (beyond that copying permitted by Sections 107 and 108 of the U.S. Copyright Law and except by reviewers for the public press), without written permission from the publisher.

Published in the United States of America by the University of Michigan Press

Manufactured in the United States of America

Printed on acid-free paper

First published June 2019

A CIP catalog record for this book is available from the British Library.

Library of Congress Cataloging-in-Publication data bas been applied for.

ISBN: 978-0-472-I3140-2 (Hardcover : alk paper)

ISBN: $978-0-472-$ I 253 I-9 (ebook) 


\section{Acknowledgments}

The idea for this book emerged from conversations that took place among some of the authors at a conference on "Digital South Asia" at the University of Michigan's Center for South Asian Studies. At the conference, there was a collective recognition of the unfolding impact of digitalization on various aspects of social, cultural, and political life in South Asia. We had a keen sense of how much things had changed in the South Asian mediascape since the introduction of cable and satellite television in the late 1980 os and early I990s. We were also aware of the growing interest in media studies within South Asian studies, and hoped that the conference would resonate with scholars from various disciplines across the humanities and social sciences. As it turned out, the conference exceeded our expectations and it became clear to us that a volume of essays on digital media and culture in South Asia could, in fact, contribute to a broader academic and public conversation about digital cultures worldwide.

This would not have happened without the encouragement and support of Farina Mir. As the Director of the Center for South Asian Studies at Michigan, Farina has created a brilliant and generous community of scholars and students. We have learned a great deal from our interactions with a wide-ranging group of South Asianists at Michigan, and while we cannot name everyone here, we are particularly grateful to Will Glover, Matthew Hull, Ram Mahalingam, Madhumita Lahiri, and Mrinalini Sinha for their advice and encouragement.

This book is also part of a larger project on 'Global Digital Cultures' that we are coordinating through the Global Media Studies Initiative housed in the Department of Communication Studies at Michigan. We are grate- 
ful to the International Institute for supporting our efforts through an Enterprise Grant, and current and former chairs of the Department of Communication Studies-Susan Douglas, Robin Means Coleman, and Nojin Kwak-for their enthusiastic support. The conference itself would not have been a success without stellar panel chairs, respondents, and notetakers. We would like to thank Madhumita Lahiri, Ram Mahalingam, Kentaro Toyama, Joyojeet Pal, Lia Wolock, and Vishnupriya Das in particular. This project benefited greatly from the sharp insights and advice of colleagues including Katherine Sender, Megan Ankerson, Dan Herbert, Sarah Murray, Pavitra Sundar, Amanda Lotz, and Jean Christophe Plantin. Draft versions of the book's introductory chapter were also discussed at the Media Studies Research Workshop, and we are thankful to Amanda Lotz and Annemarie Navar-Gill for launching and sustaining this crucial forum.

Finally, we would like to thank Mary Francis and her colleagues at the University of Michigan Press for their enthusiastic support, engagement, and editorial care. 


\section{Contents}

Introduction: Mapping Global Digital Cultures

Aswin Punathambekar and Sriram Moban

\section{Part One: Infrastructures}

ONE: Politics of Algorithms, Indian Citizenship, and the Colonial Legacy

Payal Arora

Two: Digital Television in Digital India

Shanti Kumar

THREE: Imagining Cellular India: The Popular,

the Infrastructural, and the National

Rabul Mukberjee

FOUR: Bridging the Deepest Digital Divides:

A History and Survey of Digital Media in Myanmar

Daniel Arnaudo

\section{Part Two: Platforms}

FIVE: Dating Applications, Intimacy, and Cosmopolitan

Desire in India

Vishnupriya Das

SIX: Anomalously Digital in South Asia: A Peri-Technological

Project for Deaf Youth in Mumbai

Shruti Vaidya and Kentaro Toyama 
SEVEn: The Making of a Technocrat:

Social Media and Narendra Modi

foyojeet Pal

EIGHT: Twitter as Liveness: \#ShamedInSydney and the

Paradox of Participatory Live Television

I 84

Sangeet Kumar

\section{Part Three: Publics}

NINE: The Remediation of Nationalism:

Viscerality, Virality, and Digital Affect

Purnima Mankekar and Hannab Carlan

TEN: Clash of Actors: Nation-Talk and Middle-Class

Politics on Online Media

Sabana Udupa

eleven: Private Publics: New Media and Performances

of Pakistani Identity from Party Videos to Cable News

Mobina Hashmi

Twelve: The Man on the Moon: A Semiotic Analysis

of Scopic Regimes in Bangladesh

$26 \mathrm{I}$

Muhammad Nabil Zuberi

THirteen: Media and Imperialism in the Global Village:

A Case Study of Four Malalais

280

Wazhmab Osman

Contributors

Index

$30 \mathrm{I}$

Digital materials related to this title can be found on the Fulcrum platform via the following citable URL: https://doi.org/10.3998/mpub.9561751 


\section{Introduction}

Mapping Global Digital Cultures

\section{Aswin Punathambekar and Sriram Mohan}

Fuly Boys (Sonti 2006), a documentary film about a software company in Bangalore that develops content for mobile phones (e.g., games and movie clips), opens on a gleaming, high-tech office space in which five young men discuss strategy for their latest software project. We learn that the headquarters of this company, July Systems, is in Santa Clara, California, and that many of the engineers and executives leading the product development office in Bangalore have lived and worked in Silicon Valley before moving back to India.

In exploring the cultural and business logics at work in this software company, the film focuses largely on the office interiors and situates the team's work routines within a transnational network involving tech capitals in India, the United States, and Western Europe. Glimpses of the world outside the office-shots of a noisy streetscape crowded with vehicles and pedestrians - cut quickly to an air-conditioned interior with a tastefully designed break room, neatly ordered cubicles, and a gleaming restroom with a waiting area that has a comfortable couch and a television set. In this swanky interior space, one that seems completely disembedded from the rest of the city, the founder and chief executive officer (CEO) Rajesh Reddy declares that people like him are "geography agnostic." Other men working in the company also wax eloquent about entrepreneurial energies being unleashed and, on the whole, offer explanations of India's digital 
revolution that rest on stories of individual talents and merit. Of course, Reddy-like figures are hardly unique to South Asia and emerge in accounts of digital culture in China, Ghana, and other parts of the world as well. ${ }^{1}$

If this kind of narrative of global mobility, seemingly unburdened by any economic, political, or sociocultural factors reveals one imaginary of the digital, another comes into view in the American television comedy Silicon Valley. In an episode titled "Daily Active Users," we get a rare glimpse into the world of click-farms located in, as one article bluntly put it, "some third world country (think India or Bangladesh)" (Edwards 20r6). Toward the end of the episode, a scene of a phone conversation involving the marketing manager of a digital platform start-up asking for "one thousand users every day for the next week" cuts to a shot of a South Asian man waking up in a shared hostel. As he gets ready for work and winds his way through bustling streets on his bicycle, electric wires, cables, air conditioners, and other banal things that make up life in urban South Asia come into view. Just as the nameless man sits down in front of a computer and we imagine a lone user in a dimly lit cybercafe, the camera zooms out to reveal a cavernous warehouse filled with hundreds of men and women working assiduously to generate and boost the number of daily active users, clicks, likes, tweets, and impressions for global digital companies.

Such starkly contrasting narratives and representations offer the dominant imaginaries for understanding digital cultures outside the Anglophone West-tech capitals, unfettered mobility, an expanding middle class, and the support of a neoliberal state, or, on the other hand, as sites for cheap and low-level software testing, call centers, pirate networks, and click-farms. Either way, geography and time seem to become irrelevant as do the historical, political-economic, and social dimensions of the media infrastructures, platforms, and varied user-practices that define digital cultures anywhere in the world today. If the jet-setting software entrepreneurs in Fuly Boys imagine a "flat world" à la Thomas Friedman, American television's take on contemporary digital culture conceives of the rest of the world largely in terms of immense distance and difference.

Steering clear of these distressingly familiar modes of apprehending a world marked by all manner of technological, financial, and cultural flows and frictions, this book analyzes the emergence and development of online cultures and, more broadly, the unfolding impact of digitalization in South Asia as constitutive of our global and digital present. Delinking the Internet from its North Atlantic trajectory, we argue that the digital revolution marks a decidedly global shift with distinct yet connected histories 
and inevitably different trajectories, meanings, and effects depending on which part of the world one looks from. Positioning South Asia as part of an ongoing global transformation rather than as an exception or a site of cultural variation, we show that as with other moments of media transition, digital cultures in varied national and regional contexts are also shaped by transnational circulations of ideas, people, technologies, and capital, and are caught up in deeper histories than popular or academic discourses care to admit.

Building on what Guobin Yang (20I 5) calls "deep internet studies," this book brings together a diverse group of scholars to examine the role of digital media technologies in reconfiguring the social, cultural, and political contours of South Asia and its diaspora. Collectively, we examine digital cultures in South Asia by situating the development of digital infrastructures, platforms, and users/publics within regional and global contexts while retaining a keen awareness of how the particularities of national, regional, and border-spaces open up opportunities to generate more nuanced accounts of how the digitalization of cultural production, consumption, and circulation are remaking our world.

Since the early 2000 s, state and private investments in digital infrastructures (and communication technologies more generally) have led to deepening access to the Internet and a vibrant digital culture across South Asia. With the second largest number of Internet users in the world and growing exponentially as users go online via widely available smartphones with inexpensive data packages, it is no exaggeration to suggest that users across South Asia and the South Asian diaspora will play a critical role in shaping the trajectory of digital platforms, cultures, and politics in the coming years. ${ }^{2}$ Indeed, the meteoric growth of local language Internet users-just in the Indian context, from 42 million in 20 I I to 234 million by 2016 -also signals the emergence of vernacular practices that challenge our Anglocentric understandings of digital cultures ("Indian Languages-Defining India's Internet" 20I7). South Asia thus serves not so much as a strictly defined geographic region, but rather as a site from which to examine the intersections of local, national, regional, interregional, continental, and global forces that shape contemporary digital culture(s).

Playing up the global and interconnected nature of the development of digital cultures seems all the more important at this historical conjuncture when digital studies programs are securing both institutional space and legitimacy not only in the American, European, and Australian academies but also in increasingly well-resourced universities in Asia. In the 
academic marketplace, scholars in a number of disciplines have come to regard digitalization as key to understanding the present. As Gere (2008, I 5) suggests, "To speak of the digital is to call up, metonymically, the whole panoply of virtual simulacra, instantaneous communication, ubiquitous media and global connectivity that constitutes much of our contemporary experience." The emphasis on all things digital is reflected in the proliferation of journals devoted to the study of digital media, the formation of new scholarly associations (the Association of Internet Researchers, for example), and the emergence of new divisions and interest groups within established and powerful scholarly organizations such as the Society for Cinema and Media Studies and the International Communication Association. The ferment surrounding the study of digitalization implies not only diverse theoretical and methodological perspectives but also a growing compartmentalization of digital studies in different disciplines across the humanities and the social sciences.

In relation to this ferment, we wish to position the study of digital cultures in relation to global media studies, an interdisciplinary formation that takes seriously the multiplicity of media cultures as a way to combat the universalizing tendencies of Anglo-American discourse (Parks and Kumar 2003). If the phenomenal expansion of television during the r980s and I990s sparked heated debates over how the globalization of media and communication was transforming societies, then Kraidy (20I7) is surely right to ponder if it is time now to rewrite the term as "global digital cultures." This not only entails reframing our understandings of media and cultural imperialism, dependency, heterogeneity, resistance, cosmopolitanism, and hybridity but also contending with keywords and concepts including precarity, data, affect, circulation, and sharing that have acquired new valences in an era of digitalization. ${ }^{3}$ As Ted Striphas and others have pointed out, the word culture itself "has taken on new inflections . . . many of which embody its association with digital computational tools" (2016, 78). Situated within this broader media studies terrain, this book makes the case that regionally grounded studies of digital media are crucial for laying a strong historical foundation for understanding how digitalization is reshaping culture and communication in the 2 ist century.

\section{Approaching Global Digital Cultures}

One way to approach a topic as maddeningly broad as digital cultures is to start by acknowledging the historicity of, say, the Internet in specific 
national and regional contexts. We could thus begin by narrating the story of the Internet from the mid-I990s when digital communication infrastructures and devices began to acquire greater visibility with the launch of dial-up access in major metropolitan centers across South Asia. Of course, this was initially limited to a very small number of people, but by the early zooos cybercafés had become as integral to the urban environment as public telephones.

The growing prominence of the Internet and other digital media technologies was linked to a discernible shift in national imaginaries that saw governments and market forces in South Asia and across the Global South come to regard digital infrastructures as central to national development. And nowhere was this new imaginary more pronounced than in "vision" documents produced by global consultancy firms such as KPMG and McKinsey that aligned the goals set by international organizations like the World Summit on Information Society with those of national governments that had embraced neoliberal market reforms as the path to globalization. This trajectory has been well documented in the Indian context including in accounts by Sundaram (2000) and Chakravartty (200I) who map how the personal computer and the network became iconic to new visions of progress in the late twentieth and early twenty-first centuries. As Chakravartty (2004) shows, this was the period when the fabled correlation between science and the state unraveled, and a move was made toward "combining the discourse of techno-nationalism with the logic of markets" (236).

The idea that robust digital infrastructures held the key to a nation's fortunes in the 2 Ist century is by no means limited to the Indian context and in fact, emerges as commonsensical to state and market actors across South Asia. For instance, "Digital Bangladesh," an initiative promoted by the Awami League regime as a part of its Vision 202 I development goals, places the digital at the center of the state's ambitions for the nation's place in the global order (Zaman and Rokonuzzaman 2014; Bashar 2017). This is also the foundational premise of large-scale citizen data and biometric identity projects undertaken by India (Unique Identification Authority of India) and Pakistan (National Database and Registration Authority) initiatives that are part of a longer political history of enumeration and identification in postcolonial nations. ${ }^{4}$ Further, when we reflect on the history of information and communication technologies in South Asia and other non-Western regions, we also see how dominant paradigms of modernization that informed efforts to harness media (radio and television, 
most prominently) for developmental purposes since the I950s continued into the digital era as well. Perhaps more crucially, we can discern how user practices very quickly supersede the imaginations that shaped information and communication technologies for development (ICTD) interventions.

Consider the experience that one of us had while observing computer and Internet use at info kiosks in a semirural part of the state of Tamilnadu in south India. Less than a 45-minute bus ride from a large coastal town, these info kiosks were part of an ambitious ICTD initiative funded by a major Indian nongovernmental organization (NGO) in partnership with a global development agency. When a project coordinator discovered that a group of young men had been using the computers in the info kiosk to use software for activities related to a fan club devoted to a film star, the kiosk was closed for a few days. If the young men could not understand that these kiosks were for their munnetram (progress) and valarchi (growth or development), the kiosk would be shut down permanently and set up in a neighboring village where people understood and appreciated its value. From the perspective of the predominantly urban and middle-class professionals overseeing this development project as well as the leaders of the village panchayat (local council), watching films and toying around with Microsoft Paint to design a fan club poster were activities to be frowned upon and disciplined. ${ }^{5}$

Looking back now, we are struck by the fact that academics and policy makers in ICTD circles during the late I 990 and early 2000 s could not anticipate that their particular desires and anxieties about the digital divide would be rendered quaint in less than a decade. ${ }^{6}$ In 2002 , public telephone booths were the primary means of long-distance communication. By 2004, when one of us returned to Tamilnadu for a second round of field research, portents of the mobile phone transforming the communication landscape were there for all to see. Project managers and kiosk operators had begun communicating predominantly via SMS, and conversations with young men at info kiosks revolved around casting votes for contestants on this or that reality TV program. Investments in mobile network infrastructure, new and inexpensive feature phones, and an increasingly competitive telecommunications sector had made mobile communication accessible for a growing proportion of people in semirural areas and, in the process, ensured that the development-oriented info kiosk and other such ICTD interventions were no longer the only point of entry into the digital world.

If we step out of the development communication frame, we can also detect the outlines of a history of user practices that have creatively negoti- 
ated technological, financial, and sociocultural constraints and affordances that every platform-from USENET newsgroups, chat portals, and SMS to blogging services, social networking sites, and smartphone-oriented instant messengers-necessarily arrives with. ${ }^{7}$ Indeed, most online platforms have been sites where everyday uses and creative expressions have, at times, intersected with and reshaped the political in new and unpredictable ways. The 2007 lawyers' strike in Pakistan, the anticorruption movement in India in 20I I-I2, the Shahbag protests in Bangladesh in 20I3, and the mobilization of anti-Muslim and anti-Tamil sentiment in Sri Lanka over the past decade are but the most prominent and recent instances when the defining role of digital and mobile media technologies and practices in the political domain have become apparent.

While certainly limited in both historical and geographic scope, any such attempt at outlining trajectories of digital infrastructures, platforms, and their role in shaping economies, polities, and cultures does help us reflect on the incredible pace of change that marks the digital and more generally, all media, in regions like South Asia. But more importantly, such accounts suggest that even as we acknowledge the newness that is striking and worth careful study, we need to move away from well-worn narratives of speed and time-of Asian, African, or Latin American societies "catching up" to the developed West or leapfrogging the industrial era to join the digital present. The contributions in this book all underscore the importance of situating ourselves in particular places and times as a way to escape the dominant scholarly and popular tendency to cast the digital outside the North Atlantic region as elsewhere and elsewhen: that is, outside the proper and well-worn paths of technological development. For this is where we inevitably end up when we begin with well-intentioned attempts to internationalize Internet studies and pay attention to strikingly different trajectories of the Internet and, more generally, digital media in the nonWestern world.

To be sure, we do not question the importance of attending to the implications of the Internet no longer being a predominantly English-speaking technoscape. Goggin and McLelland (2009) are right to argue that despite the global diffusion of the Internet, we are yet to "systematically chart what is now most salient and significant about the Internet: its great cultural and linguistic variety" (5). However, this call for internationalization is a familiar one to media scholars who have struggled against the methodological nationalism that has haunted film and television studies and is now casting a shadow in the emergent domain of digital studies as well. As Lotte 
Hoek's work on South Asian film cultures so powerfully demonstrates, "The shared historical roots, institutional beginnings, aesthetic vocabularies, technological preferences, and competitive forces of South Asia" all reveal the limits and dangers of relying on the nation-state as a container $\left(20 I_{3}, 8\right)$. If our efforts to internationalize digital studies always begin outside the Anglophone West, we will have little choice but to reproduce what Anita Chan (2OI3) calls "digital universalism," an imaginary that positions elite tech centers (Silicon Valley) and Western Anglophone cultures as the purveyors of digital futures that the rest of the world will, in the fullness of time, merely imitate and adapt. ${ }^{8}$

So instead of offering up an account of difference from one region of the world, our goal here is to understand the ongoing digitalization of media, communication, and culture in South Asia as part and parcel of global transformations. We take our cue from Kavita Philip (2016, 276) who has argued eloquently for moving away from notions of "core and periphery, originality and diffusion" and to better understand the "heterogeneous temporal and transnational dynamics" that shape contemporary tech cultures. What, then, do we stand to gain by positioning the "digital" between two powerful keywords- "global" and "culture"- that have animated the study of media in different disciplines?

\section{Situating Digital Cultures: A Global and Intermedia Framework}

First, a focus on global interconnections allows us to acknowledge and account for digital media as having emerged from and as part of processes of economic and cultural globalization that have unfolded since the late I970s. ${ }^{9}$ We are less concerned about defining limits on what constitutes the "digital" than with insisting on an implicit recognition that digital media anywhere in the world are caught up in a world-historical process in which social, cultural, and economic exchanges are transnational, multidirectional, and driven by a multipolar and predominantly capitalist media system.

The work that media scholars have done in integrating insights from political economy, cultural geography, and cultural studies to understand the complex spatial dynamics of media production and circulation during the global turn of the I980s and ' 90 os thus remains pertinent to the study of digital formations (Curtin 2003; Govil 2009; Massey I994; Sassen 2002). By the early I990s, when the multinodal media world that we are familiar with today was beginning to take shape, David Morley and Kevin Robins argued that a "social theory that is informed by the geographi- 
cal imagination" $(1995,6)$ was crucial to understanding changes in media and communication. Surveying the political and economic transformations that had transformed national economies across the world since the late I970s, they focused in particular on the increasingly complex spatial relations that the mobility of capital had engendered as the "essential context for understanding the nature and significance of developments in the media industries" (6).

This perspective helps us see that the spatial coordinates of the digital in a particular place in the world will always exceed the boundaries of specific cities, regions, or nations. In fact, it would be ludicrous to examine the formation and global impact of Silicon Valley by remaining within the boundaries of the United States. After all, San Francisco's emergence as a global tech hub cannot be grasped without mapping its connections with other nodes of finance, technology, and human capital such as Bangalore, Shenzen, and Accra (Avle 20I4). At the same time, there can be no doubt that digital media are increasingly central to the production of a meaningful sense of cultural belonging and locality for people the world over. Understanding the dynamics of digital cultures, then, calls for a renewed focus on the changing relations between economy, culture, and space without privileging the national as the dominant, pregiven, and uniformly imagined framework and scale of analysis, while remaining attentive to the creative ways in which nation-states have exerted control over digital infrastructures, platforms, and users. ${ }^{10}$

Second, a global and cultural perspective foregrounds the fact that digital cultures are shaped by distinct and at times disjunct temporalities within the same nation-space (Appadurai 2000). It is worth reminding ourselves that the digital turn during the late I990s and early 2000 s was defined as much by the ups and downs of venture capital backed dot-com economies in cities like Mumbai and Bangalore in India as by ICTD projects bankrolled by organizations including the World Bank and the United Kingdom's Department for International Development. An emphasis on the temporal dimensions of technological and institutional change assumes even greater importance in the context of postcolonial media cultures given that at a quite basic level, the digital cannot be seen as neatly following on after broadcasting, film, and television and video cultures. As Sundaram $(2013$, I 2$)$ points out, the I980s and I990s in India were marked by a "frenetic media multiplicity" when cassette culture, color television, VCRs, cable and satellite broadcasting, and the Internet all arrived with hardly any temporal gaps. The story unfolds along similar lines in Pakistan as well. In 
a richly detailed account of new television genres and their impact on political culture, Hashmi (2OI2) recounts that in less than a decade after the ban on private media ownership was lifted in the early 2000 , there were a total of 54 satellite channels, more than 50 radio stations, I 5 I dailies, and 68 monthly publications in place.

The study of digital cultures on a global scale thus cannot simply adopt medium-specific trajectories and their attendant disciplinary boundaries in the Anglophone West. The story of digital media in South Asia is, on the one hand, about the phenomenal expansion of communication infrastructures since the mid-I990s. In the span of a decade, industry discourse in the digital and mobile media sectors shifted from educating new consumers about devices and data services to a generation "born for the Internet."11 And the ups and downs of state censorship and regulation notwithstanding, the digital media economy has become tightly integrated with the advertising, marketing, print, film, radio, and television industries across the subcontinent. Moreover, the interwoven nature of the arrival of different technologies and media forms-for instance, the uptake of color television and the desktop computer during the mid-1980s-suggests histories of intermediality and media convergence that do not register in mainstream scholarship on digital media.

Indeed, this is precisely the historical amnesia that John Caldwell cautioned against when he argued for an approach to digital media and technoculture as "historical formations animated by continuities as much as invention" $(2000,3)$. Caldwell's historicizing impulse-to situate the social and cultural logics of digital media in relation to histories of electronic and broadcasting media - is one we embrace here to avoid framing global digital cultures within the familiar straitjackets of technological novelties that travel the world from some select centers to various peripheries or as inaugurating a decisive break from other media forms.

Third, a focus on global cultural dynamics allows us to think more expansively about digital media as part of the ceaseless remediation of public cultures across South Asia and other regions. Instead of relying on a series of binaries and ruptures-between zeroes and ones, between the digital study of texts and the study of digital texts, between the Internet and other media forms, and so on- a focus on publics and public cultures foregrounds processes of mediation and the continual production of a "zone of cultural debate" (Appadurai and Breckenridge r 996,5 ). In their influential formulation, Appadurai and Breckenridge pointed out that public culture(s) could take many forms and identified cinema, television, sport spectatorship, and museums as creating a densely interlinked and interocu- 
lar arena in countries like India. While this critical reworking of "publics," "publicity," and "public sphere(s)" inspired numerous studies of media cultures in an era of economic liberalization and cultural globalization across the postcolonial world (Larkin 2008; Mankekar 1999; Mazzarella 2003), we have yet to fully grasp the implications of the current phase of digital culture, one marked as much by vibrant participatory cultures as it is by state and corporate surveillance and data mining practices. ${ }^{12}$

As we pointed out earlier, the terms and debates about globalization and culture have hardly been resolved. But instead of casting those debates as belonging to the quaint world of radio, film, and television, we would do well to revisit and recast them. This is not to suggest that we simply revive discussions of media imperialism-as-cultural homogenization in the era of globally dominant digital platforms (Google, YouTube, Facebook, and so forth). And we are not advocating for a return to the at-times celebratory accounts of cultural hybridity and cosmopolitanism either. Rather, we need sustained engagement with the emergence of new public cultures in relation to digital media, by taking into account the connections between, say, social media and satellite broadcasting that transform the production and circulation of news, entertainment, and other media genres (Alexander and Aouragh 20I4; Sangeet Kumar, this volume).

Such an intermedial approach is crucial for engaging with the implications of algorithmic processes that now structure the production, circulation, and consumption of various cultural forms (Striphas 2015). But, again, instead of approaching the algorithmic production and curation of culture as marking a clean break, we would argue that digital media cultures the world over are best understood as the product of combustible encounters between emergent data-driven and algorithmic processes, on the one hand, and representational logics that continue to hold sway in the news and entertainment media industries, on the other. To grasp these dynamics calls for engagement with theoretical paradigms and methods that grapple with the specificities of digital infrastructures and platforms while continuing to draw on media and cultural studies scholarship focused on representation, identity, culture, and power.

\section{A Framework for Studying Global Digital Cultures: Infrastructures, Platforms, and Publics}

Drawing inspiration from Julie D'Acci's (2004) circuit of media study, a heuristic developed for a cultural and materialist analysis of global television, we develop an analytic framework here that allows us to study global 
digital cultures as formed at the intersections of infrastructures, platforms, and publics. Of course, it is conceptually daunting to draw neat boundaries around a specific media infrastructure, platform, or a particular formation of a public. And although all the authors focus on a specific infrastructural dimension (for example, the digitalization of Indian television) or the operations of a particular platform company (Tinder, for instance), the analyses reveal how digital infrastructures and platforms evolve in complex interaction with other media ecologies, and how publics and politics are shaped by these changes. More broadly, we approach the three organizing concepts as pointing to a set of porous and interlinked sites, and suggest that they are best understood by taking an integrated, conjunctural approach that accounts for the economic, political, and sociocultural forces at work in each site. In what follows, we engage with recent scholarship on media infrastructures, platforms, and mediated publics before providing an overview of the book.

\section{Infrastructures}

"Which developing nations have interesting tech stories at the moment?" In the summer of 2017 , a podcaster posed this question on Hacker News, a news aggregation website focused on digital technology and entrepreneurship. The most upvoted response was titled "India I Telecom I I roM subscribers on-boarded in Ioo days" (erbdex 20I7). The user in this case was referring to Reliance Jio, an Indian mobile network operator that launched ${ }_{4} \mathrm{G}$ services in September 2016 and claimed to have orchestrated the fastest ramp-up by any mobile network operator anywhere in the world, with I 6 million new subscribers added within the first month (Indian Express 2016).

In what was subsequently termed by the press as a "data war" (Business Standard India 2017), Jio's entry into the telecom market was marked by the slashing of prices and an explosive rise in data consumption. ${ }^{13}$ The response on Hacker News summarized some of these record-breaking developments and ended with yet another stunning claim-"this infrastructure [emphasis ours] as the physical layer coupled with the fact that India has $40 \% \mathrm{YoY}^{14}$ growth rate in Internet penetration ... has opened up a fintech opportunity in a $\$ 50 \mathrm{~B}$ market that $\mathrm{BCG}^{15}$ and Google estimate ... to be in the tune of $\$ 500 \mathrm{~B}+$ by $2020 "$ (erbdex 20I7). The language of layers and market opportunities animating such responses point to the centrality of digital media infrastructures in shaping new imaginaries of development, progress, and economic growth. 
The question of media infrastructures that undergird digital cultures, however, has not received the kind of scholarly attention accorded to audiences, films and television programs, industries and institutions, and even policy and regulation. Even in non-Western contexts, where infrastructure(s) are marked by their hypervisibility, scholars have tended to ignore the profound impact that a whole range of communication infrastructures- towers, cables and wires, devices, repair practices, ${ }^{16}$ and so on-has had on processes of mediation. In focusing on infrastructures as key sites for understanding global digital cultures, this book joins the recent infrastructural turn in media studies and other cognate disciplines including science and technology studies, anthropology, and critical information studies (Parks and Starosielski 20I5; Larkin 2008; Peters 2015; Graham and Marvin 200I).

Following Larkin $(2013,328)$, who understands infrastructure as "built networks that facilitate the flow of goods, people, or ideas and allow for their exchange over space," the chapters in this book foreground the imaginaries and contingencies that digital infrastructures unleash as they become a part of everyday life in South Asia. Infrastructures are composed of both technical, material things (e.g., mobile phones, SD [Secure Digital] cards, set top boxes, satellites) and the "soft" cultural practices that shape the formation of social collectivities and the circulation of media objects, ideas and so on. Further, where digital media in South Asia is concerned, we are yet to fully grasp their historicity in terms of postcolonial states' infrastructural dispositions, the aesthetic and affective power that infrastructures wield in public culture (e.g., dams, highways, cinema halls, cell phone towers), and, crucially, the layering and convergences of different media infrastructures. Indeed, once we look past the technical and systems-level aspects of infrastructures, it becomes clear that grasping the emergence of digital media as infrastructural to contemporary social, cultural, political, and economic worlds calls for paying attention to the role of imagination-the fantasies, desires, and anxieties about the present and future that provoke, as Larkin puts it, "such deep affectual commitments, particularly, but not only, in developing societies" (2013,332).

We cannot do justice here to the rich scholarship on infrastructures and work through ideas of scale, relationality, affect, and other issues that Parks and Starosielski (2015) and others have elaborated as critical for understanding media infrastructures in particular. However, approaching the Internet as an infrastructure (Sandvig 2013) encourages us to take into account its built and constructed nature, the ongoing environmental im- 
pacts including everything from devices to cloud servers (Hogan 2015), its political potentials (Aouragh and Chakravartty 2016), and, of course, the manifold ways that identity work (along caste and gendered lines, for example) now happens (Gray 2009; Brock 201 2; Nakamura 2002).

Building on this scholarship and beginning with the understanding that global digital cultures are structured by profoundly uneven power relations, the chapters in this book align with the conceptual shift from infrastructure to infrastructuring that Niewöhner (2015) has proposed. What this allows us to do is focus on the work of producing, maintaining, repairing, and reusing digital infrastructures as an ongoing and continual assembling of technologies, business logics, organizational structures, state practices, and crucially, competing imaginaries. For our purposes, this conceptual and methodological shift enables us to situate digital infrastructures in relation to a longer history of the production of techno-citizens, particularly state-run media projects across the subcontinent (Abraham and Rajadhyaksha 20I 5; Arora and Arnaudo, this volume). ${ }^{17}$ Further, infrastructuring highlights the challenges of drawing clear conceptual boundaries around a particular media infrastructure. Intersections with other media forms and systems are crucial as the formation of public cultures cannot be understood without carefully tracing the ways in which existing media infrastructures and digital systems are entwined. For instance, the history of media practices involving videocassette recorders (VCRs) and color televisions in the subcontinent is one that involves tapes spooled with ballpoint pens as much as 8-bit cartridges and "video" computers. ${ }^{18}$

Finally, a focus on infrastructuring as an ongoing process helps us explore how a range of platforms are mobilized in specific instances of political work and, in some contexts, begin to acquire the veneer of infrastructures themselves (Plantin et al. 20I8). From the perspective of nation-states, infrastructuring is as much about enabling and sanctioning some performances of citizenship (e.g., getting a biometric identity card for yourself) as it is about actively disconnecting entire regions from global Internet and mobile infrastructures (for instance, in the recent spate of media blackouts in Kashmir). ${ }^{19}$

\section{Platforms}

That a handful of digital platforms have become gateways to everyday social life and to the worlds of commerce and politics was the animating concern for José Van Dijck's keynote address at the annual conference of the 
Association of Internet Researchers in 20I6. Building on Gillespie's (20 I0) foundational work on the politics of platforms, Van Dijck (2016) raised the possibility of developing and sustaining public values in platform societies, where public expression is increasingly hosted and organized by digital intermediaries. Given the influence that platforms like Google, Facebook, Twitter, and Amazon now wield on a global stage, Van Dijck's framing of digital platforms as public goods marked an important addition to debates on "platform capitalism" (Srnicek 2016) and "platform imperialism" (Jin 2013). While such attempts to outline the role of technology companies and digital intermediaries as global economic actors in capitalist modes of production are valuable, they seldom allow for granular, experiential engagement with state, industry, and user practices coalescing on these platforms.

In fact, as Plantin et al. (2018) point out, media scholars' early interest in digital platforms emerged in part from what they afforded user communities in terms of connection, creativity, customization, and exchange, usually evidenced through the rise of "Web 2.0" in the mid-2ooos. The excitement around these possibilities was tempered by calls to pay attention to the political economy of these platforms, that is, their ability to profit from vast quantities of data generated through their use, and their increasing influence in determining and shaping legitimate use. Van Dijck and Poell (2015) even assert that the reshaping of public and private communications by social media platforms' commercial imperatives amounts to a transformation of the political economy of the media landscape. But even a sweeping definition of political economy, as the "study of control and survival in social life" (Mosco 2009, 24-25), does not make space for the full range of moral and cultural resources mobilized on and by these digital platforms every day.

This is further complicated by the tensions between studying platforms as computational systems designed and controlled by a few and approaching them as bridges between independently developed and maintained communities of practice. As Brock (forthcoming 2019) argues, critical political economy scholars attempt to account for some of the possibilities that lie at these intersections but continue to undervalue the linkages between desire and user practice. Drawing on Jean-François Lyotard, he adopts a libidinal economy approach, urging scholars interested in digital culture to think about jouissance as the enjoyment of use and contending that the libidinal energies accrued through use-as-"play" drive the operations of digital media platforms. These different approaches to studying digital platforms, 
their uses, their maintenance, and their influence, however, are united in their focus on practices by various actors, indexing dynamic webs of historical, cultural, political, socio-technical, and commercial concerns.

If, following Uricchio (2003), we approach media as cultural practices that envelop technologies, texts, and institutions, then the questions about public values and social good in the age of Google and Facebook must be framed in relation to the affordances of networked media platforms and what states, corporations, and users actually do with them. Further, recentering enduring concerns like localization in computational platforms reveals the tensions between the "global" and the "local," and how these tensions continue to be negotiated by policy makers, industry actors, and users across the world on a day-to-day basis.

As we contend with platforms moving from one cultural and industrial context to another, Gillespie's (2010) approach to understanding platforms as being composed of four interlinked semantic categories-architectural, computational, figurative, and political-is useful to understanding technological considerations and processes of localization. In this regard, our understanding of localization, hybridity, and the circulation of formats in relation to film and television is a helpful basis (Kraidy 2005; Kumar 2005; Shahaf 20I4; Waisbord 2004). Scholarship on MTV's hybrid avatars across the world has shown that localization is a far more complex process involving cultural translations and exchanges that can at times be politically fraught (Fung 2006; Cullity 2002). These accounts also foreground how localization is a multiscalar process whereby shifts in industrial and managerial logics (for instance, producing content locally) go hand in hand with highly charged representational moves that build on and often challenge dominant norms, values, and aspirations in relation to class, caste, gender, and sexuality (Kumar and Curtin 2002; Mankekar 2004). Thinking about localization would allow us to understand, for instance, the cultural shifts that Tinder as a "dating" app needs to straddle in the Indian market (see Das, this volume) or how Facebook becomes shorthand for the Internet at large in Myanmar (see Arnaudo, this volume). Indeed, when assessed in relation to this longer media and cultural history, it is evident that platform localization cannot be merely about local language implementation, subtitling, or technological tweaks that respond to concerns like data speeds and cost.

YouTube's trajectory in Pakistan-from its entry as a global platform in 2006 , its censorship and outright ban in 2008 , the protracted civil society struggle, and, finally, the lifting of the ban after the launch of a local version 
in 2016-offers an instructive case in platform localization that has global effects. Following the republication of caricatures of the Prophet Muhammad and the reproduction of purportedly non-Islamic content on YouTube in 2008 , the Pakistani state ordered local Internet providers to block access to the platform, with a configuration error then shutting off the site to users across the world for a couple of hours.

Such moments of breakage reiterate how a collection of regional Internets come together to support the discursive and socio-technical arrangement of the Internet as a global network. Digital intermediaries like YouTube are increasingly central to scholarly efforts to read the "coming together" of such regional webs rather than the "taking apart" of a global monolithic network of networks. A culturally grounded approach is crucial if we are to ensure that the study of digital media remains alive to regional characteristics and histories while being responsive to transnational exchanges and relays (Venegas 2009). Further, thinking through the lens of platform localization nuances understandings of the enmeshing of algorithmic and representational politics, and their volatile and uncertain implications.

For instance, the lack of a localized YouTube implementation (and consequently, the lack of control experienced by the state in its efforts to monitor and moderate content) was repeatedly mobilized as the reason for the blanket ban on the platform in Pakistan. The tensions between the state's impulse to censor content that it deemed blasphemous and Pakistani civil society's opposition to such heavy-handed control of digital and news media then played out through persistent calls to reinstate platform access. A key example here is \#KholoBC (kholo meaning "open" and BC being an acronym for an expletive), a campaign opposing state censorship and content regulation on the Internet. Sparked by a "viral" rap song featuring comedian Ali Gul Pir and rapper Adil Omar, \#KholoBC indexed a range of discontents about the limiting of the freedom of expression in Pakistan using religion and national security as smokescreens, culminating in a call to action specifically focused on removing the YouTube ban. ${ }^{20}$ \#KholoBC also involved a video shot on the streets of Karachi featuring a person wearing a YouTube-branded cube walking the streets holding a sign reading "hug me if you want me back." Men and women are shown approaching the friendly cube for hugs, as cries of "I love YouTube" and "God, please open YouTube" punctuate the soundtrack.

The routinization of practices that come to define digital media platforms and the sociality that sometimes exceed the platform and spill over 
into public life are, in the first instance, carefully engineered. The thoroughgoing "datafication" and "commodification" of every social interaction we have online is undoubtedly a concern that states and various civil society groups worldwide are grappling with. But as the chapters in this book show, the "coded structures" (Van Dijck 2013) that shape our interactions are more than just technical and commercial ones. Moreover, when we situate digital platforms within a broader media matrix in regions like South Asia and the ongoing and contested blurring of boundaries between personal, public, and private realms, the question of how and when publics cohere cannot be answered by focusing solely on one specific platform and its technological affordances. Rather, examining political cultures marked by networked and mobile publics that shift shape as events unfold involves taking into account processes of media convergence and tracing how particular artifacts (e.g. GIFs, memes, and sound bites), ideas, and discourses move across media platforms, gather publics, and mediate the political.

\section{Publics}

No account of public political discourse in contemporary South Asia is possible or complete without accounting for the role of digital media and processes of media convergence. Since the mid-2ooos, scholars in multiple disciplines have focused on the many astonishing instances of digitally mediated activism around the world, asking what constitutes meaningful participation (Papacharissi 20I4; Jenkins 2006; Postill 2014; Yang 2009; Qiu 20I4; Kraidy and Mourad 20I0; Zayani 20I5). Mapping the world of networks, hashtags, memes, sonic cues, and their complex circulation across media systems, this scholarship has been valuable for understanding new forms of mediation that now lie at the center of political life.

Of course, the current phase of social media-fueled political participation is not without precedent. E-mail listservs and bulletin boards were foundational to the formation of transnational "cyberpublics" during the I99os that intersected with various social and political movements in South Asia including the right-wing Hindutva movement (Rai I995), the formation of new feminist and queer collectives, and environmental justice groups (Gajjala and Gajjala 2008; Shahani 2008). What is clear now, however, is that the qualifier "cyber" no longer seems necessary to understand the role of digital media in shaping the formation of publics around various issues. That said, in every instance of popular participation that intersects with and spills over into the political, popular, and academic discourse ends 
up focusing on the strictly political dimensions and the implications that such moments and zones of participation hold for our understanding of the tenets of normative political theory. ${ }^{21}$

Departing from the well-worn tradition of appraising whether this or that communication platform is conducive to activities that fit within norms of rational discourse in public domains, the chapters in this book probe how digital media use on a routine, daily basis might help us discern new imaginations of the "political" that are emerging in South Asia and across the world. ${ }^{22}$ It is only when we comprehend how digital media use and everyday life are braided together that we can meaningfully pose questions about political impact and, in the process, develop more complex and textured accounts of publics that cohere in and through the digital. Consider, if only briefly for now, two events that unfolded in parts of South Asia that have been roiled by political conflict for well over three decades now.

In early 2016, fears of ethnic tension arose once again in Sri Lanka as graffiti marked the walls and gates of some Muslim-owned homes in Negugoda, a densely populated suburb of Colombo. The words "Sinha Le" ("lion's blood") were spray-painted in Sinhalese, as a sign of Sinhala Buddhist dominance in the island nation. This was not the first time that Sinha Le had found its ways into the streets of the Sri Lankan capital. A more stylized logo, featuring the sword-bearing lion from the national flag and the word le colored red to denote blood, had already started appearing in stickers on buses and motorcycles (including police motorcycles). Photos of the stickers circulated on social media, with some Sinhala Buddhist youth even drawing the symbol on their arms and posting selfies on platforms like Facebook, Twitter, and Instagram. As civil society groups expressed concern about the campaign indexing intimidation of and intolerance toward ethnic and religious minorities in Sri Lanka, mainstream news media outlets continued to track its rapidly growing popularity and its links to the efforts of ultranationalist groups like the Bodu Bala Sena. When Sinha Le is situated amid long-standing concerns around majoritarian angst, perceived dispossession, and ethnic purity, its global resonance becomes immediately apparent. But in tracing the circulation of the logo on digital media and tracking how it gets embodied and integrated into the built environment, it is possible to see how ideas like Sinha Le enter digital culture, gather publics, and transmute the terms of politics.

For a different and fleetingly hopeful imagination of the political, consider the events surrounding the third season of the reality television program Indian Idol. In September 2007, as the contest reached the final stages, 
news reports began focusing attention on how people in the northeast Indian state of Meghalaya had cast aside decades-old separatist identities to mobilize support for finalist Amit Paul. While some fans set up websites and blogs to generate interest and support from the rest of the country and the diaspora, others formed a fan club and facilitated efforts by a range of groups and organizations to sponsor and manage public call offices (PCOs) in different parts of Meghalaya, distribute prepaid mobile phone cards, and set up landline voting booths. Recognizing the ways in which these activities were beginning to transcend long-standing ethnic, religious, linguistic, and spatial boundaries, state legislators and other politicians soon joined the effort to garner votes for Amit Paul, with the chief minister D. D. Lapang declaring Amit Paul to be Meghalaya's "brand Ambassador for peace, communal harmony and excellence." It seemed that this campaign around a reality television program could set the stage for a remarkable refashioning of the sociocultural and political terrain in Meghalaya.

In both these instances, focusing on the explicitly political was understandable given the intensity and seemingly intractable nature of ethnic conflicts in these parts of the world. However, instead of evaluating these kinds of mobilization solely through the question of "effects," we could ask: What happens when such phases of participation fade away? What are the cultural and political implications of zones of participation that last a few weeks or months at best? The answers are more likely to be found in the terrain of daily life, which, in turn, forces us to rethink our understanding of "public" and "public life" in ways that are not beholden to Habermasian ideals (see Hashmi, Mankekar and Carlan, in this volume). Avoiding the theoretical impulse to explain such moments of participatory culture solely in relation to the realm of formal politics is crucial if we are to understand why and how the everyday-ness of watching a reality TV show and sending a text message or putting a sticker on a motorcycle and circulating that image via Instagram becomes deeply meaningful.

Without a doubt, the question of digital platforms' democratic and demotic aspects - the ongoing debate over the extent to which digital platforms shape news and information flows (e.g., rumors, fake news)-is a crucial one. We know that such moments of participation are never entirely autonomous from the interests of the state, media corporations, and various religious, political, and civil society groups with their own vested interests. What such cases suggest is the potential for quotidian digital media use to move beyond a particular media event or location into other 
times and spaces to generate, in the process, an altogether new kind of public that does intersect with broader civic and political issues and movements. For it is worth keeping in mind that the world of "public life" is not limited to questions of citizenship or civic engagement but, in fact, can be better understood through the lens of sociability, which suggests not just willingness to talk and engage with others but also the desire for shared experiences (Barker 2008; Weintraub and Kumar 1997). Spaces of everyday interaction such as the street corner, balconies and verandahs, the public phone booth, the cybercafé, and, now, WhatsApp and Facebook groups have been, as Shanti Kumar (2010, 23) points out, "spaces of sociability that are neither public nor private in the liberal-economic sense of state versus market forces, or in the civic sense of communitarian responsibilities and citizenship, but constitutes the heart of public life" across South Asia.

Progressive ideals and expectations about participatory culture(s) encouraging and informing civic/political engagement in conflict-ridden situations are well and good, but only if they are grounded in an understanding of and deep appreciation for what an immense challenge it is to create and sustain spaces of sociability. Pakistani activist Sabeen Mahmud fought to create precisely this sort of community space when she started The Second Floor, a coffee shop in Karachi that also doubled up as a discussion forum for activists, artists, and academics. In April 20I 5, when a prominent university canceled an event titled "Unsilencing Balochistan," citing pressure from the government, Mahmud invited many of the same speakers, largely Baloch activists, to The Second Floor (or T2F). As the discussion about the "disappearing" of thousands of Baloch nationalists wrapped up with a question-and-answer session, Mahmud thanked everyone and left $\mathrm{T}_{2} \mathrm{~F}$ in her car, only to be shot dead soon after by armed motorcyclists at a traffic signal.

In the weeks that followed, global news media outlets carried multiple stories about the threat to free speech in Pakistan and Mahmud's role in fighting for accountability, pluralism, and secularism. Tributes flowing in from activists and journalists touched upon these achievements, but also thanked her for imagining $\mathrm{T}_{2} \mathrm{~F}$ as a space to conduct hackathons, organize film screenings, discuss poetry, and have conversations about the growing centrality of digital media in Pakistani culture and politics. One of Mahmud's greatest contributions, it appeared, was to have created a space for sociability that wove the digital into Karachi's urban culture and, in the process, imagined new relationships between media, culture, and the political. 


\section{Scope of the Book}

Global Digital Cultures is organized into three parts. The first section joins a broader debate on the emergence of media infrastructures as key sites for the exercise of state and corporate power, the production of citizenship in a digital era, and a new kind of technopolitics that users are increasingly embroiled in whether or not they like it. In doing so, these essays also focus on the link between infrastructures and imaginaries, and explore how farreaching infrastructural changes hinge on cultural mediations of technological and institutional shifts.

State-sponsored identity projects-be it Aadhaar in India or the National Database and Registration Authority in Pakistan - are arguably the best sites from which to begin exploring how the promises of big data are being mobilized to design new information infrastructures that fundamentally alter state-market-civil society relations. Payal Arora's chapter in this section thus explores the biometric identity project in India by first situating it in relation to colonial histories of information gathering and surveillance as well as caste and communal dynamics that have shaped the state's approach to governance in the postcolonial era. Outlining technological shifts beginning in the mid-20oos, in particular the swift expansion of mobile communication and the convergence of old and new media systems, Arora argues that projects like Aadhaar are one part of a larger scale datafication of political communication including the rapidly evolving landscape of broadcast television and the creative data-driven uses of social media platforms by politicians.

Arora's emphasis on media convergence is taken up in next chapter in which Shanti Kumar examines the digitalization of television following a major policy decision in $20 \mathrm{I}$ that made it mandatory for analog cable TV networks to switch over to a new Digital Addressable System by 20I4. Tracking policy and industry discourse surrounding this policy decision, Kumar shows how digital addressability was offered up as the dataoriented solution that would solve the television industry's long-standing woes regarding audience metrics and advertising in particular. Moving past well-worn critiques of how such moves only serve to consolidate industry power in a capitalist media economy, Kumar situates television's digital transition within the discourse of "Digital India" that has come to define the right-wing Bharatiya Janata Party government's agenda. At a broader level, Kumar's essay reveals the value of bringing a historically grounded television studies approach to illuminate the workings of emergent digital platforms and their affordances. 
Concerned with the emergence of new technologies, and the many desires, anxieties, and uses that swirl around them, Rahul Mukherjee explores the cultural meanings of mobile technology by beginning with mainstream advertising and Bollywood films. Through close, thematic readings of landmark advertisements and filmic depictions of mobile phone use over the course of a decade, Mukherjee outlines how a range of media industry professionals imagined and crafted the very idea of a cellphone "user." Delving into the world of informal and pirate networks, Mukherjee shows how vernacular mobile phone use emerges at the intersection of key mediating personas (mobile phone shop owners), specific technologies (small and portable micro-SD cards), and practices of circulation and sharing that remain largely invisible and illegible in digital studies scholarship. Finally, Mukherjee explores public controversies stemming from deep-seated anxieties (cellular radiation, for instance) to foreground the "affective encounters between human bodies and infrastructures" that mark our engagement with new communication technologies.

In the final chapter in this section, Daniel Arnaudo offers a critical survey of the development of digital media in Myanmar and specifically the emergence of a networked public sphere in relation to the transition toward a democratic political system. Outlining the control and censorship regimes in place for several decades (196I-20IO), this essay identifies the formation of the Burmese Internet in exile as having laid the foundation for the modern, largely mobile Internet culture that is now in place. Not surprisingly, the development of digital media in contemporary Myanmar is symptomatic of wider conflicts that structure political culture, particularly along ethnic, religious, and gendered lines. Moreover, the development of mobile and digital infrastructures in Myanmar reveals the profoundly unequal relations of power that shape digital cultures and, in particular, the dominance that platforms like Facebook wield. In a context marked by low literacy levels, low levels of ICT use, and poor regulatory oversight, initiatives such as Facebook Zero (offered by Telenor starting in 20I4), which allowed individuals to use Facebook without using their data, result in an exceedingly narrow view of being online and indeed, what the Internet is.

The second section of this book thus focuses on the relations between digital infrastructures and specific platforms, and in particular the range of industry and user practices indexing social, cultural, economic, and political concerns ranging from intimacy to immigration. The section begins with Vishnupriya Das's chapter tracing how local and international smartphone-based dating apps like TrulyMadly and Tinder mediate possibilities for intimacy in urban India. Through close readings of texts like 
brand-sponsored online videos and television commercials, and in-depth interviews with industry actors, Das situates the politics of desire and discovery—both social and sexual-in notions of "dating" mobilized by these platforms. Her work points to the importance of such platforms in negotiating the pleasures and anxieties of gendered performances of sexuality and selfhood.

Shruti Vaidya and Kentaro Toyama's chapter broadens the remit of the platform-oriented study of digital media by examining the personalization of hearing aids and the everyday experiences of deaf young adults. By providing students of a Mumbai-based nonprofit academy with such digital devices and encouraging some of them to decorate and personalize their devices in collaboration with an artist, Vaidya and Toyama unravel how designing for display, instead of designing for discretion, can affect one's relationship with the hearing aid. Their work attempts to remedy the omission of day-to-day negotiations with disability as a focus area for those interested in the emergence of digital devices as key platforms for selfexpression and the reinforcement of identity. Joyojeet Pal examines another dimension of self-presentation, surveying the use of Twitter as a channel for political branding in the case of Indian politician Narendra Modi. Pal argues that Modi was able to project himself as a tech-savvy leader and signal a careful embrace of modernity through his tweets, thereby wresting control of the narrative from mainstream news media outlets. In doing so, $\mathrm{Pal}$ also draws attention to how platforms such as Twitter help embody notions of entrepreneurial uplift into technoscience-based promises of social transformation.

In the final chapter in this section, Sangeet Kumar evaluates the attempts to produce audience interactivity via Twitter on television news channels in India and focuses on how networked publics on social media platforms can torpedo the goals of institutionally imagined participatory viewing. In examining hashtag wars as a terrain of audience engagement and discursive struggle, Kumar shows how the immediacy and simultaneity afforded by platforms like Twitter can reshape television's "liveness" and speak back to notions of convergence mobilized by media industries.

In the next section on publics, the chapters trace the impact that digital media, their complex entanglements with established media systems and, crucially, the ongoing blurring of lines between the personal, the private, and the public have had on political culture(s) across South Asia. Purnima Mankekar and Hannah Carlan's chapter focuses on convergences between digital platforms and other media (television in particular) to analyze how 
the arrest of a student leader in Delhi contributed to the virulent and deeply affective form of nationalism that has come to define Indian public culture. Tracing the movement of news, images, and sounds across media platforms, they draw attention to the circulation of specific affective responses (e.g., a set of tweets, a particular newscast) as fueling the broader public conversations about national identity. Drawing on a rich body of feminist scholarship, Mankekar and Carlan develop a more expansive understanding of the idea of remediation and show that the convergence of old/new media and the intertextualities that shape contemporary public cultures the world over lead to a thoroughgoing reconfiguration of HinduIndian nationalism.

Sahana Udupa's chapter continues this focus on acrimonious debates about nation and national belonging on social media in urban India. Defining confrontational verbal cultures as "online nation-talk," Udupa argues that such talk contributes to the development of nationalism as an exclusivist ideology. Analyzing discursive continuity and disjuncture in the nation-talk mobilized by middle-class actors on Twitter around a specific hashtag (\#ModiInsultsIndia), Udupa shows how self-proclaimed liberals and Hindu nationalists make claims about what the nation ought to mean and to whom.

Middle-class publics in Pakistan becomes the focus for Mobina Hashmi's chapter in which she examines a range of Pakistani online publics to ask how the performance and presentation of Pakistani identities is shaped by a negotiation between norms of private and public behavior. Situating her analysis of online publics in the historical context of two earlier forms of Pakistani media publics - the official state-centric version produced by PTV (Pakistan Television Corporation) from the I960s to the early I990s, and the early years of the postliberalization media explosion-Hashmi shows that new online publics are, by contrast, messy and varied. Exploring official websites of television channels such as Aaj TV and Geo News, blogs linked with newspapers such as the Friday Times, and amateur videos of weddings, dance parties, encounters with sex workers, and a range of discussion forums, Hashmi details how these online spaces publicize the intimate and private spaces of conversation, opinion, and socializing.

Muhammad Nabil Zuberi develops thematic readings of a set of manipulated images that went "viral" and provoked radically different responses during an episode of political violence in Bangladesh in 2013. The focus here is on a particular manipulated image of Allama Sayeedi, a charismatic Islamic orator and a popular leader sentenced to death by the Bangladeshi 
government for war crimes committed during 197r. Zuberi explores the reasons the image produced such different responses from people who had a common history, religion, and nationality, as well as the role that digital media played in reconfiguring the boundaries between fact and fiction in contemporary political culture.

Finally, Wazhmah Osman explores the circulation of pictures of Afghan and Pakistani women in the aftermath of $9 /$ I I and critically evaluates their framing as victims and as contentious symbols of nationhood. Through a case study of four Af-Pak women activists, all named Malalai, she shows how these images are mobilized by local and international power elites who often benefit, materially and culturally, from the conflict and instability in the region at the expense of human rights.

\section{Conclusion}

Since media and communication studies began in the 1970s, its object of study has changed in fundamental ways. Media were, at first, thought almost wholly within the frame of the nation-state, its national politics and culture. Since then, the diffusion of continuing technological innovations, driven by the world economy, has changed the media landscape beyond recognition, producing the digital and globalized world that we inhabit today. Drawing inspiration from Appadurai and Breckenridge's (1995) statement on global modernity, we have worked with the premise that the digital is now everywhere, it is simultaneously everywhere, and it is interactively everywhere. But it is not only everywhere, it is also in a series of somewheres, and it is through one such somewhere, South Asia, that this volume engages with the cultural dimensions of digitalization.

In conversation with recent efforts to grapple with the global character of the Internet and the plurality of digital cultures (Goggin and McLelland 2017), our goal here has been to bring together scholars with a shared interest in the rise of digital and mobile media technologies, the ongoing transformation of established media industries, and emergent forms of digital media practice and use that are reconfiguring sociocultural, political, and economic terrains across the Indian subcontinent. It goes without saying that the media landscape in a region like South Asia is simply too vast and diverse for any one book to carefully map. ${ }^{23}$ Moreover, the India-centricity of South Asian studies remains a challenge. However, we do hope that, collectively, the chapters here map considerable new terrain and set the stage for more regionally grounded explorations of global digital cultures. 


\section{Notes}

I. See Avle and Lindtner (2016).

2. According to various reports that track Internet use across the world, South Asia accounts for 615 million users. See, for instance, "Internet Usage in Asia" (2018). Further, 74 percent of the Internet user population reside in the Global South, including Asia (48.7\%), Africa (I0.9\%), Latin America (I0.5\%), and the Middle East (3.9\%). Only $26 \%$ of the world's Internet users live in the Global North: Europe (1 7\%), North America (8.3\%), Oceania (0.7\%) ("Internet Users in the World" 2018).

3. See Peters (20r6b).

4. See Breckenridge (2005) for debates on South Africa's HANIS (Home Affairs National Identification System) Project.

5. Referring to ICTD projects in India, Mazzarella (2010, 783) argues that "although the discourse of development helped to legitimize the Internet as an 'appropriate technology,' its emphasis on functional solutions also helped to obscure the Internet's more ambiguous emergent potentials."

6. The newer forms of digital inequality unleashed by these transformations, however, continue to remain on the research agenda of scholars across disciplines. See Robinson et al. (2015).

7. For pathbreaking work on queer life-worlds in the digital era in Asia, see Shahani (2008), Dasgupta (2017), and Yue (2012). Also see Risam (2015) and the special issue on 'Gender, Globalization and the Digital' in Ada: A Fournal of Gender, New Media \& Technology.

8. It is becoming increasingly clear that our understanding of digital culture(s) in Anglo-American contexts has been structured by the specificities of White technoculture. As Faye Ginsburg (2006) points out in her account of digital media practices in indigenous communities, "concepts such as the digital age have taken on a sense of evolutionary inevitability, thus creating an increasing stratification and ethnocentrism in the distribution of certain kinds of media practices, despite prior and recent trends to de-Westernize media studies" (I 29).

9. For a more detailed account of digital culture emerging as a response to the demands of mid-2oth century warfare and Cold War politics, see Gere (2008). Elton and Carey (2OI3) also point out that online services were being imagined in several countries besides the United States. Benjamin Peters's (20 i6a) rich account of the Soviet Union's plans to build a nationwide computer network also reveals the importance of decentering the United States when it comes to writing global Internet histories.

Io. In an important study, $\mathrm{Wu}$ and Taneja (2016) show that the world's Internet traffic flows have become increasingly "regionalized" rather than tied to Anglophone media capitals and circuits.

I I. See, for instance, this advertisement for MTS, a prominent telecom player in multiple national and regional markets: https://www.youtube.com

I 2. See Philip (2005). Also see Schwarz and Eckstein (2014) for a wide-ranging set of essays on the issue of pirate media cultures and global modernity.

I 3. One gigabyte (GB) of high-speed Internet data was made available for as low 
as 76 cents, making it the world's cheapest Internet data plan. Consequently, total mobile Internet data consumption in the country reportedly skyrocketed from 0.2 billion GB per month pre-Jio to I.2 billion GB per month, with Jio subscribers alone using up to I billion GB (Bhattacharya 20I7). This is also said to have led to a massive surge in the use of the Internet for video streaming (Akolawala 20I 7 ).

I4. Year over year (YOY), in this context, refers to the comparison of Internet penetration at one particular time period with that of a similar time period, on an annualized basis.

I 5. BCG refers to the Boston Consulting Group, a management consulting firm with offices worldwide.

I6. For more on cultures of recycling, repair, and reuse, see Sundaram (2010).

I 7. For scholarly accounts of state-run media projects, see Roy (2007) on the Films Division of India, Mankekar (I999) and Rajagopal (200I) on state-run television in India, Hashmi on television in Pakistan (2O 2 ), and Abu-Lughod (2004) on television and nationhood in Egypt.

i8. Further, given the dominance of textual and visual approaches to understanding media cultures, it is hardly surprising that the sonic dimensions of the digital turn have received comparatively less attention. We outline the importance of bringing a sound studies perspective to South Asian media studies in an essay focused on sonic cues and political cultures (Punathambekar and Mohan 20I7). Also see the Sounding Out blog for a series on gendered soundscapes in South Asia, curated by Monika Mehta and Praseeda Gopinath (https://soundstudiesblog.com).

I9. See Rao (2016).

20. See http://pakistanforall.org for more details on this media campaign.

$2 \mathrm{r}$. For an overview of scholarship on publics and politics in relation to the digital, see the annotated bibliography on "Networked Publics: Inter-Asian Perspectives" by Padma Chirumamilla, available online at http://tvri.ssrc.org-content/ uploads/2016/11/InterAsia_Padma_Chirumamilla_Annotated_Bibliography-CMreview.pdf

22. Among the various theoretical frameworks that have been developed to describe transformations in South Asian public culture, and particularly where ongoing changes in media and communications are concerned, perhaps the most influential one has been Appadurai and Breckenridge's statement on public culture in India (1995). There is now a rich body of scholarship that has built on critiques of Habermas's original theorization of the public sphere (see, for example, Warner 2005), particularly in relation to mediated public cultures in a range of postcolonial societies. It is beyond the scope of this introduction to review the scholarship on media, publics, and politics in the South Asian context, but our contributors draw on a range of work in this tradition in mapping how digitization poses new challenges to this area of study (Mankekar I999; Cody 20 I I; Rajagopal 2009).

23. Given that the foundation of "South Asian" media studies is largely English and Hindi-language centric film and television in India and the Indian diaspora in the United Kingdom and North America, if all we produce are Indian accounts of the digital in South Asia, we will miss making connections across places and spaces that do not feature prominently in contemporary geopolitical maps. We regard this anthology as part of wider efforts to think regionally. See, for instance, Banaji (2OI I). Further, there have been a number of interventions in the past two decades 
in the humanities and the social sciences to take seriously historical networks of exchange that do not recenter North Atlantic perspectives. One such influential formation is the Inter-Asia framework, which approaches Asia as a dynamic and interconnected formation spanning Central Asia, East Asia, South Asia, Southeast Asia, the Middle East (including Turkey), and Russia. See, for instance, Kuan Hsing-Chen's Trajectories: Inter-Asia Culture Studies and various projects under the InterAsia program of the Social Science Research Council (https://www.ssrc.org). For a detailed consideration of the media studies-area studies impasse in relation to the study of digital cultures, see Lamarre (2017). Also see Shome and Hegde (2002) on the importance of acknowledging that we all write from somewhere as a way to decenter Anglo-American scholarship.

\section{References}

Abraham, Itty, and Ashish Rajadhyaksha. 2015. "State Power and Technological Citizenship in India: From the Postcolonial to the Digital Age." East Asian Science, Technology and Society 9 (I): 65-85.

Abu-Lughod, Lila. 2004. Dramas of Nationhood: The Politics of Television in Egypt. Chicago: University of Chicago Press.

Akolawala, Tasneem. 20I 7. "Reliance Jio Claims It's the World's Largest Mobile Data Network.” NDTV Gadgets36o (blog). July i 8. https://gadgets.ndtv.com

Alexander, Anne, and Miriyam Aouragh. 20I4. "Egypt's Unfinished Revolution: The Role of the Media Revisited." International Fournal of Communication 8: $890-915$.

Aouragh, Miriyam, and Paula Chakravartty. 2016. "Infrastructures of Empire: Towards a Critical Geopolitics of Media and Information Studies." Media, Culture \& Society 38 (4): 559-75.

Appadurai, Arjun. 2000. "Grassroots Globalization and the Research Imagination." Public Culture I 2 (I): I-I9.

Appadurai, Arjun, and Carol A. Breckenridge. I 995. "Public Modernity in India." In Consuming Modernity: Public Culture in a South Asian World, edited by Carol A. Breckenridge, I-20. Minneapolis: University of Minnesota Press.

Avle, Seyram. 20I4. "Articulating and Enacting Development: Skilled Returnees in Ghana's ICT Industry." Information Technologies \& International Development IO (4): I-I 3 .

Avle, Seyram, and Silvia Lindtner. 20r6. "Design(Ing) 'Here' and 'There': Tech Entrepreneurs, Global Markets, and Reflexivity in Design Processes." In Proceedings of the 2016 CHI Conference on Human Factors in Computing Systems, 2233-45. New York: ACM.

Banaji, Shakuntala, ed. 20 I r. South Asian Media Cultures: Audiences, Representations, Contexts. London: Anthem Press.

Barker, Joshua. 2008. "Playing with Publics: Technology, Talk and Sociability in Indonesia." Language \& Communication 28 (2): I $27-42$.

Bashar, Reazul. 20 I 7. "Bangladesh Creating Policy Vision, Facilitating Private Sector Investment in SDGs: Sheikh Hasina.” BDNews24.Com. September $2 \mathrm{I}$, 20I 7. https://bdnews24.com 
Bhattacharya, Ananya. 20 I 7. "To Stay Ahead, India's Upstart Telecom Provider Is Giving Away Free 4G-Enabled Phones.” Quartz, July 2 r. https://qz.com

Breckenridge, Keith. 2005. "The Biometric State: The Promise and Peril of Digital Government in the New South Africa." Fournal of Southern African Studies $3 \mathrm{I}$ (2): $267-82$.

Brock, André. 201 2. "From the Blackhand Side: Twitter as a Cultural Conversation." Fournal of Broadcasting \& Electronic Media 56 (4): 529-49.

Brock, André. Forthcoming. "Distributed Blackness: African American Cyberculture." Unpublished book manuscript.

Business Standard India. 201 7. "No End to Data Wars: Reliance Jio Free Offers to Continue for I 2-I 8 Months," April 26. https://www.business-standard.com

Caldwell, John, ed. 2000. Electronic Media and Technoculture. New Brunswick, NJ: Rutgers University Press.

Chakravartty, Paula. 200 I. "Flexible Citizens and the Internet: The Global Politics of Local High-Tech Development in India." Emergences: Fournal for the Study of Media \& Composite Cultures I I (I): 69-88.

Chakravartty, Paula. 2004. "Telecom, National Development and the Indian State: A Postcolonial Critique." Media, Culture \& Society 26 (2): 22 7-49.

Chan, Anita Say. 2013. Networking Peripheries: Technological Futures and the Myth of Digital Universalism. Cambridge, MA: MIT Press.

Cody, Francis. 20 I I. "Publics and Politics." Annual Review of Anthropology 40 (I): $37-52$.

Cullity, Jocelyn. 2002. "The Global Desi: Cultural Nationalism on MTV India." Fournal of Communication Inquiry 26 (4): 408-25.

Curtin, Michael. 2003. "Media Capital: Towards the Study of Spatial Flows." International Fournal of Cultural Studies 6 (2): 202-28.

D'Acci, Julie. 2004. "Cultural Studies, Television Studies, and the Crisis in the Humanities." In Television after TV: Essays on a Medium in Transition, edited by Lynn Spigel and Jan Olsson, 4I 8-45. Durham, NC: Duke University Press.

Dasgupta, Rohit K. 201 7. Digital Queer Cultures in India: Politics, Intimacies and Belonging. New Delhi: Routledge India.

Edwards, Matt. 20r6. "The Scene from HBO's Silicon Valley That Everyone Should Be Talking About." Smash Cut Culture (blog). June 2 I, 2016. http:// smashcutculture.com

Elton, Martin C. J., and John Carey. 2013. "The Prehistory of the Internet and Its Traces in the Present: Implications for Defining the Field." In The Oxford Handbook of Internet Studies, edited by William H. Dutton. Oxford: Oxford University Press.

erbdex. 20I 7. "I IоM Subscribers On-Boarded in Ioo Days." Hacker News. https:// news.ycombinator.com

Fung, Anthony. 2006. “'Think Globally, Act Locally': China's Rendezvous with MTV." Global Media and Communication 2 (I): 7 I-88.

Gajjala, R., and V. Gajjala. 2008. South Asian Technospaces. New York: Peter Lang.

Gere, Charlie. 2008. Digital Culture. London: Reaktion Books.

Gillespie, Tarleton. 20 Iо. "The Politics of 'Platforms." New Media \& Society I 2 (3): $347-64$. 
Ginsburg, Faye D. 2006. "Rethinking Documentary in the Digital Age." Cinema fournal 46 (I): I 28-33.

Goggin, Gerard, and Mark McLelland. 2009. "Internationalizing Internet Studies: Beyond Anglophone Paradigms." In Internationalizing Internet Studies, edited by Gerard Goggin and Mark McLelland, 3-I 7. London: Taylor \& Francis.

Goggin, Gerard, and Mark McLelland. 2017. The Routledge Companion to Global Internet Histories. Routledge Media and Cultural Studies Companions Series. London: Routledge.

Govil, Nitin. 2009. "Wind(Fall) from the East." Television of New Media ıо (I): $63-65$.

Graham, Steve, and Simon Marvin. 200 . Splintering Urbanism: Networked Infrastructures, Technological Mobilities and the Urban Condition. London: Routledge.

Gray, Mary L. 2009. Out in the Country: Youth, Media, and Queer Visibility in Rural America. New York: NYU Press.

Hashmi, Mobina. 20 r 2. "At the Limits of Discourse: Political Talk in Drag on Late Night Show with Begum Nawazish Ali." South Asian History and Culture 3 (4): 5II-3I.

Hoek, Lotte. 20I3. Cut-Pieces: Celluloid Obscenity and Popular Cinema in Bangladesh. South Asia across the Disciplines. New York: Columbia University Press.

Hogan, Mél. 20 I 5. "Data Flows and Water Woes: The Utah Data Center." Big Data of Society 2 (2): I-I 2.

Indian Express. 2016. "Reliance Jio 4G Claims It Crossed I6 Million Subscribers in First Month," October 9. http://indianexpress.com

"Indian Languages-Defining India's Internet." 20I 7. KPMG India and Google. https://home.kpmg.com/in/en/home/insights/2017/04/indian-language-internet-users.html

"Internet Usage in Asia." 2018. Internet World Stats. https://www.internetworldstats.com/stats3.htm.

"Internet Users in the World." 20r 8. Internet World Stats. https://www.internetworldstats.com/stats.htm

Jenkins, Henry. 2006. Convergence Culture: Where Old and New Media Collide. New York: NYU Press.

Jin, Dal Yong. 2013. "The Construction of Platform Imperialism in the Globalization Era." TripleC: Communication, Capitalism \& Critique. Open Access fournal for a Global Sustainable Information Society I I (I): I45-72.

Kraidy, Marwan M. 2005. Hybridity, or the Cultural Logic of Globalization. Philadelphia: Temple University Press.

Kraidy, Marwan M. 2017. "Convergence and Disjuncture in Global Digital Culture-an Introduction." International fournal of Communication I I: 3808-I8.

Kraidy, Marwan M., and Sara Mourad. 2oro. "Hypermedia Space and Global Communication Studies Lessons from the Middle East." Global Media Fournal 8 (I6).

Kumar, S. 2005. Gandhi Meets Primetime: Globalization and Nationalism in Indian Television. Pop Culture and Politics Asia PA. Urbana: University of Illinois Press.

Kumar, Shanti. 20 Io. "Globalization, Media Privatization, and the Redefinition of the 'Public' in Indian Television." BioScope: South Asian Screen Studies I (I): 2 I25 . 
Kumar, Shanti, and Michael Curtin. 2002. "'Made in India' in between Music Television and Patriarchy." Television \& New Media 3 (4): 345-66.

Lamarre, Thomas. 20 1 7. "Platformativity: Media Studies, Area Studies." Asiascape: Digital Asia 4 (3): 285-305.

Larkin, Brian. 2008. Signal and Noise: Media, Infrastructure, and Urban Culture in Nigeria. Durham, NC: Duke University Press.

Larkin, Brian. 2013. "The Politics and Poetics of Infrastructure." Annual Review of Anthropology 42 (I): 327-43.

Mankekar, Purnima. I 999. Screening Culture, Viewing Politics: An Ethnography of Television, Womanhood, and Nation in Postcolonial India. Durham, NC: Duke University Press.

Mankekar, Purnima. 2004. "Dangerous Desires: Television and Erotics in Late Twentieth-Century India." Fournal of Asian Studies 63 (2): 403-3 I.

Massey, Doreen. I994. Space, Place, and Gender. Minneapolis: University of Minnesota Press.

Mazzarella, William. 2003. Shoveling Smoke: Advertising and Globalization in Contemporary India. Durham: Duke University Press.

Mazzarella, William. 20ıо. "Beautiful Balloon: The Digital Divide and the Charisma of New Media in India." American Ethnologist 37 (4): 783-804.

Morley, David, and Kevin Robins. I995. Spaces of Identity: Global Media, Electronic Landscapes and Cultural Boundaries. London: Routledge.

Mosco, Vincent. 2009. The Political Economy of Communication. London: SAGE.

Nakamura, Lisa. 2002. Cybertypes: Race, Ethnicity, and Identity on the Internet. New York: Routledge.

Niewöhner, Jörg. 201 5. "Anthropology of Infrastructures of Society." In International Encyclopedia of the Social \& Behavioral Sciences, edited by James D. Wright, 2nd ed., I I 9-25. Oxford: Elsevier.

Papacharissi, Zizi. 20I4. Affective Publics: Sentiment, Technology, and Politics. Oxford: Oxford University Press.

Parks, Lisa, and Shanti Kumar, eds. 2003. Planet TV: A Global Television Reader. New York: NYU Press.

Parks, Lisa, and Nicole Starosielski, eds. 20 I 5. Signal Traffic: Critical Studies of Media Infrastructures. Urbana: University of Illinois Press.

Peters, Benjamin. 20I6a. How Not to Network a Nation: The Uneasy History of the Soviet Internet. Cambridge, MA: MIT Press.

Peters, Benjamin, ed. 20I6b. Digital Keywords: A Vocabulary of Information Society and Culture. Princeton: Princeton University Press.

Peters, John Durham. 2015. The Marvelous Clouds: Toward a Philosophy of Elemental Media. Chicago: University of Chicago Press.

Philip, Kavita. 2005. "What Is a Technological Author? The Pirate Function and Intellectual Property." Postcolonial Studies 8 (2): I99-2 I 8.

Philip, Kavita. 2016. "Telling Histories of the Future: The Imaginaries of Indian Technoscience." Identities 23 (3): 276-93.

Plantin, Jean-Christophe, Carl Lagoze, Paul N. Edwards, and Christian Sandvig. 2018. "Infrastructure Studies Meet Platform Studies in the Age of Google and Facebook." New Media \& Society 20 (I): 293-3 I0. 
Postill, John. 20I4. "A Critical History of Internet Activism and Social Protest in Malaysia, I998-20 г г." Asiascape: Digital Asia I (I-2): 78-го3.

Punathambekar, Aswin, and Sriram Mohan. 201 7. "A Sound Bridge: Listening for the Political in a Digital Age." International Fournal of Communication I I.

Qiu, Jack Linchuan. 20 I4. "'Power to the People!': Mobiles, Migrants, and Social Movements in Asia." International Fournal of Communication 8: I6.

Rai, Amit S. I995. "India On-Line: Electronic Bulletin Boards and the Construction of a Diasporic Hindu Identity." Diaspora: A fournal of Transnational Studies $4(\mathrm{I}): 3 \mathrm{I}-57$.

Rajagopal, Arvind. 200 I. Politics after Television: Hindu Nationalism and the Reshaping of the Public in India. Cambridge: Cambridge University Press.

Rajagopal, Arvind, ed. 2009. The Indian Public Sphere: Readings in Media History. New Delhi: Oxford University Press.

Rao, Ankita. 20 I 6. "Two Months of Internet Blackouts Have Taken a Toll on Kashmir." Motherboard, August 29. https://motherboard.vice.com

Risam, Roopika. 201 5. "Introduction: Gender, Globalization and the Digital." Ada New Media, no. 8 (November). https://adanewmedia.org

Robinson, Laura, Shelia R. Cotten, Hiroshi Ono, Anabel Quan-Haase, Gustavo Mesch, Wenhong Chen, Jeremy Schulz, Timothy M. Hale, and Michael J. Stern. 2015. "Digital Inequalities and Why They Matter." Information, Communication \& Society I 8 (5): 569-82.

Roy, Srirupa. 2007. Beyond Belief: India and the Politics of Postcolonial Nationalism. Durham, NC: Duke University Press Books.

Sandvig, Christian. 20I 3. "The Internet as Infrastructure." In The Oxford Handbook of Internet Studies, edited by William H. Dutton. Oxford: Oxford University Pres. http://www.oxfordhandbooks.com

Sassen, Saskia. 2002. "Locating Cities on Global Circuits." Environment and Urbanization $\mathrm{I} 4$ (I): I3-30.

Schwarz, Anja, and Lars Eckstein, eds. 2014. Postcolonial Piracy: Media Distribution and Cultural Production in the Global South. London: Bloomsbury Academic.

Shahaf, Sharon. 20I4. "Homegrown Reality: Locally Formatted Israeli Programming and the Global Spread of Format TV." Creative Industries Fournal 7 (I): 3-I8.

Shahani, Parmesh. 2008. Gay Bombay: Globalization, Love and (Be)Longing in Contemporary India. New Delhi: SAGE.

Shome, Raka, and Radha S. Hegde. 2002. "Postcolonial Approaches to Communication: Charting the Terrain, Engaging the Intersections." Communication Theory I 2 (3): 249-70.

Sonti, Gautam. 2006. July Boys. Watertown, MA: Documentary Educational Resources.

Srnicek, N. 20r6. Platform Capitalism. Oxford: Wiley.

Striphas, Ted. 201 5 "Algorithmic Culture." European Fournal of Cultural Studies I 8 $(4-5): 395-4$ I 2 .

Striphas, Ted. 20I6. "Culture." In Digital Keywords: A Vocabulary of Information Society and Culture, edited by Benjamin Peters. Princeton Studies in Culture and Technology. Princeton: Princeton University Press. 
Sundaram, Ravi. 2000. "Beyond the Nationalist Panopticon: The Experience of Cyberpublics in India." In Electronic Media and Technoculture, edited by John Caldwell, 270-294. New Brunswick, NJ: Rutgers University Press.

Sundaram, Ravi. 20ıо. Pirate Modernity: Delhi's Media Urbanism. London: Routledge.

Sundaram, Ravi. 2013. No Limits: Media Studies from India. New Delhi: Oxford University Press.

Uricchio, William. 2003. "Historicizing Media in Transition." In Rethinking Media Change: The Aesthetics of Transition, edited by David Thorburn and Henry Jenkins, 23-38. Cambridge, MA: MIT Press.

Van Dijck, José. 2013. The Culture of Connectivity: A Critical History of Social Media. Oxford: Oxford University Press.

Van Dijck, José. 20 i6. \#AoIR zo r 6: Opening Keynote "The Platform Society" by fosé van Dijck. https://www.youtube.com

Van Dijck, José, and Thomas Poell. 2015. "Social Media and the Transformation of Public Space." Social Media + Society I (2): I-5.

Venegas, Cristina. 2009. "Thinking Regionally: Singular in Diversity and Diverse in Unity." In Media Industries: History, Theory, and Method, edited by J. Holt and A. Perren, I 20-3 I. Malden, MA: Wiley.

Waisbord, Silvio. 2004. "McTV: Understanding the Global Popularity of Television Formats." Television \& New Media 5 (4): 359-83.

Warner, Michael. 2005. Publics and Counterpublics. New York: Zone Books.

Weintraub, Jeff, and Krishan Kumar, eds. I997. Public and Private in Thought and Practice: Perspectives on a Grand Dichotomy. Chicago: University of Chicago Press.

Wu, Angela Xiao, and Harsh Taneja. 2or6. "Reimagining Internet Geographies: A User-Centric Ethnological Mapping of the World Wide Web." Fournal of Computer-Mediated Communication 2 I (3): 230-46.

Yang, Guobin. 2009. The Power of the Internet in China: Citizen Activism Online. New York: Columbia University Press.

Yang, Guobin, ed. 201 5. China's Contested Internet. Copenhagen: NIAS Press.

Yue, Audrey. 20 r 2. "Mobile Intimacies in the Queer Sinophone Films of Cui Zi'en." Journal of Chinese Cinemas 6 (I): 95-108.

Zaman, Hasanuzzaman, and Rokonuzzaman. 2014. "Achieving Digital Bangladesh by $202 \mathrm{I}$ and Beyond: Background Paper for the 7 th Five Year Plan $(7 \mathrm{FYP}) . "$ Planning Commission, Ministry of Planning, Bangladesh.

Zayani, Mohamed. 201 5. Networked Publics and Digital Contention: The Politics of Everyday Life in Tunisia. New York: Oxford University Press. 
PART I

\section{Infrastructures}




\title{
Politics of Algorithms, Indian Citizenship, and the Colonial Legacy
}

\author{
Payal Arora
}

In the last decade, much research has focused on the impact of digital media technologies within the political sphere. Social media is a game changer in the way governments engage with their citizens and big data is a key instrument in the understanding and the shaping of political audiences. Having lived through Barack Obama's first campaign, the so-called Twitter revolution, and Trump's Facebook campaign, few people today would question that data politics is the new norm. Datafication has moved from data gathering to strategic filtering and segmenting, relating political clusters to social issues (Burns 2015). However, much of this research is concentrated on advanced industrialized countries, negating the global South, 60 percent of whose residents have incomes below the poverty line (Arora 2016b).

One of the persistent concerns is social inequality, seen as a major hindrance to political participation, suppressing the voices of the poor in policy making (Verba, Schlozman, and Brady 1995). In the last five years, affordable mobile technologies and a plethora of prepaid cell phone plans have brought much of this citizenry into the digital sphere for the first time. Today, even the poor are digitally connected. For instance, in India, 6.5 million cell phones are sold every month. Besides mobile phones, the government has promoted access to the Internet via its community information centers, digitally connecting all of its 600,000 villages (Arora 2016a). These 
efforts have served as an important digital platform to launch e-governance initiatives, connecting citizens to local and national government schemes online. Given the failing social systems in such terrain, it is no wonder there is much faith in this algorithmic leapfrogging of current bureaucracies, including the conventional mechanisms of political communication.

We need not look further than the ambitious Biometric Identity Project in India which provides a unique identification number (UID) to every citizen through a consolidation of I.2 billion of its citizens' fingerprints, 2.4 billion iris scans, and I.2 billion photographs (Sarkar 20I4). This project has received much media attention, with discourse leaning toward the empowerment of the marginalized. R. S. Sharma, secretary of the Department of Electronics and Information Technology in India, declared that "digital India is not for rich people ... it is for poor people" (Toness 20I4, para. 3). Media sources such as the BBC provide further endorsement where "[the poor] with no proof to offer of their existence will leapfrog into a national online system, another global first, where their identities can be validated anytime anywhere in a few seconds" (Rai 2012, para. 2). An expressed vision by leaders spearheading this initiative is that this project can serve as a platform for numerous mobile applications to create transparency, openness, and a two-way communication between political representatives and their people. At the time of this writing, the UIDAI project has come under intense criticism from academics, journalists, and civil society groups (Abraham and Rajadhyaksha 2015).

While these new events and visions promise a more energized political sphere in India, there is still a dearth of scholarship on how big data shapes citizenship in the Global South, particularly for those at the margins. To gauge the impact of big data within the realm of politics in India, we need to attend to the social context within which these technologies are developed and implemented, and the actors behind the designing and deploying of these tools. This chapter argues that we cannot indiscriminately apply existing Western data-based frameworks to this emerging political public. By embedding the argument in the case study of India and its contemporary sociopolitical ecology, several factors come into play. The colonial heritage of information infrastructures, the communal and caste politics unique to much of the South Asian region impacting the old and new mass media systems, and a development legacy of welfare schemes tied to political group representation must be considered to create a more tailored understanding of data politics in this underexamined region. 


\section{Political Audiences in the Big Data Era}

Big data has disrupted the traditional conceptualization of political audiences. A popular perspective is that big data fosters new ways of entrenching political group membership through algorithmic clustering. Pariser (2OI I) calls this the "information bubble" or "filter bubble"-a continuous exposure to like-minded worldviews envisioned to create a monolithic and even more divisive political public. While this concept has captured the popular imagination and persisted over a decade, there are surprisingly few studies that substantiate this notion with empirical evidence. Few studies point to how social media disrupts conventional channels of audience interaction with political agencies. For instance, Maireder, Weeks, Zúñiga, and Schlögl (20 I 7) empirically analyzed the extent to which political actors connect with diverse audiences on these digital networks. They found that language, geo-identity, and political orientation are key factors in influencing such connective action. Also, nongovernmental organizations and activists are more likely to reach diverse audiences as compared to conventional political organizations on digital platforms. However, to date, the extent to which the digital sphere deters diverse political networks remains understudied.

On the other side of the spectrum is the belief that we are experiencing postmodern politics that is "less centered, less easily contained and brokered" (Axford and Huggins 200I, 23; De Mul 20 I 5). This signifies a serious shift from modern politics of representation of fixed identities, primarily through political parties, to an era of micropolitics based on issues and interests that often transcend traditional social relations. The ability of personalization has enabled big data to move beyond the usual suspects of sociological construction in examining political audiences: age, location, past political affiliation, race, and education. A recent report from Netflix on big data analytics of their audiences has a provocative conclusion that their usual categories of geography, age, and gender need to be "put in the garbage heap" (Morris 2016, para 2). The company found that it was far more useful to group people by common taste and that "the variation within any population group is much wider than the collective difference between any two groups" (para 3).

In other words, broad categories like race or location cannot be reliable in assessing audience preferences. The question remains how this applies to political audiences and whether conventional divides such as the Global 
North-South, or the West and the "Rest" are less relevant in this big data era. Would marginalized groups across borders share common political tendencies and grievances as compared to other groups within their own nations? To illustrate, if we look at the hashtag publics of the 'blacklivesmatter' twitter campaign, we see global digital flows of engagement and empathy between black communities in Baltimore and those in Palestine that have been targets of systemic racism (Endong 2018). This creates a temporal digital political cluster across borders. Another example is the state surveillance systems of welfare mothers in the United States and the digital monitoring systems of refugees entering Europe. Both welfare mothers and refugees experience and express acute privacy violations that can justify a bridging between these two disparate groups. In essence, there is more commonality in the struggle for the right to privacy between these disadvantaged groups than with populations in their own local confines.

Postmodern politics as such liberates us from the imagined boundaries of conventional affiliation, but at a cost. This kind of pluralism can undermine chronically marginalized groups that may require continued targeted intervention to legitimize their voices. Take caste politics in India. Dalits and other lower-caste groups have faced historical and insurmountable prejudice compared to other member groups entrenched in poverty. The dilemma posed here is to continue to cluster them with other low-income groups or to give them special privileges due to historically discriminatory practices. These decisions influence how we digitize these publics, consolidating their identity online for simplified governance. Another instance is the casual usurping of the colonial discourse to describe new forms of exploitation such as user-generated "free" labor. This unifying effort is a double-edged sword. It can in fact undermine neocolonized subjects that have long withstood the brunt of these destructive legacies.

Marginalization and social justice, while neglected in the early days of big data, is now gaining significant traction. From obsessing about the size of the data, we are moving toward issues of diversity, agency, and inclusion through digitization (Taylor 2017 ). The politics of algorithms is essentially the politics of representation. Marginalization is particularly important in the policy arena, where political action can be triggered by insights drawn from algorithmically mediated data (Samarajiva and Lokanathan 2016). People and problems not represented in the data are often neglected. In other words, the attention to political causes and groups are becoming more contingent on their digital visibility. In India, where the vast majority 
have only recently gained access to the digital sphere, it begs the question of who is representing India's vast populace via these data-based public constructions.

This situation is further inflamed by the emergence of bots, web robots that serve as automated scripts to perform repetitive actions that allow for an unprecedented degree of synthesis in compiling, sorting, and analyzing data on the Internet. In other words, they are "amalgamations of code that mimic users and produce content" (Woolley and Howard 20I6, para. I). In the political sphere, the rise of political bots has created a new layer of computational propaganda on social life, gaining a newfound influence on the shaping of public opinion. This has shifted conversations over the last two decades about datafication, challenging assumptions of algorithmic neutrality and authenticity of citizen representation online.

Prominent scholars such as Helen Nissenbaum have been advocating for inscribing values in the design of today's information infrastructures to counteract systemic manipulation and obstruction of universal human rights through technical innovations. While today, scholars for the most part are on board with the principle of technology embodying values, it continues to be tremendously difficult to reify this through the conscious engineering of these systems. Take, for instance, feminist bots, a growing movement to counter gender bias online in the values in the design field. The challenge arises even prior to the technical embedding, as we need to decide whose version of feminism gets to be inscribed. By default, Western notions of feminism become the normative value system imposed on the rest of the world, creating the unintended marginalization of other women's voices across the borders.

Clearly, there is a disjuncture between intent and practice. In the West, big data from poverty mapping is used to heighten the efficiency of service delivery to underserved populations. Yet this very information can be used against these neglected demographics through "redlining," the refusal by companies to cater to them due to the possibility of losses. Given that big data can also map ethnic and racial identity to these geographic areas far more precisely than conventional data collection methods, this can be deemed unconstitutional. As big data becomes more accurate in identifying and discriminating against political audiences, legal systems stand as protective measures to check such algorithmic discrimination. However, most regions of the global South, including India, provide little legal recourse to citizens when their data has been compromised or used against them to 
further alienate them (Arora 20r6b). Hence, when constructing political audiences today, we need to pay heed to this spectrum of unresolved challenges to create a more equitable digital political sphere.

\section{Datafication of Politics beyond the West: Factors to Consider}

Datafication is defined as "transforming a phenomenon into a quantified format that allows it to be measured and analyzed" (Mayer-Schönberger and Cukier 20I3, 78). Most of the big data tools used today are designed to harvest vast amounts of data on each individual, with the implicit assumption of constant connectivity within data rich environments. However, as we shift gears to the "data poor" and "dumb phone" of the global South, we cannot assume that what we scrape from the big data feed in these contexts gives us adequate insight into the complex lives of the poor, in this case, in India.

\section{The Colonial Heritage of Information Infrastructures, Welfare, and Communal Politics}

The Biometric Identity Scheme or "Aadhaar" project is popularly framed as unprecedented in connecting India's historically marginalized citizenry to the government. Big data is intended to liberate rather than confine. Liberation is from corruption where welfare benefits valued at approximately 60 billion dollars are siphoned off by middlemen using fake identities, leaving the anonymous poor helpless in the face of such acts (Arora 20I6b). However, this apparatus of empowerment is built on information infrastructures with a deep colonial lineage. Information and control after all have a longstanding relationship (Beniger 2009). During the mid-I 9 th century, to police colonies, the British pioneered biometric surveillance through fingerprinting (Thomas 2014). The fear of an uprising was a constant motivator to identify and track their "unruly" subjects. To mask its intrusiveness, fingerprints were sold to the public as an efficient way to access services such as the pension system. It is not a coincidence that the biometric identity project was initiated to track Bangladeshi migrants coming into India, but is marketed as an empowering tool for the marginalized majority.

Furthermore, the British colonial administration leveraged the existing ethnic and caste politics in their colonies including in India through their "divide and rule" policy. By creating privileged positions within the political structure along lines of caste, they perpetuated and deepened caste 
divisions that pervaded postindependence. For instance, data on land records in Karnataka not just captures information about tenancy and the type of land titles, but also the age, caste, political registration, and religion of owners and tenants (Raman 2012). While caste politics continue to pervade the Indian political sphere, the power dynamics are shifting somewhat. Indian politics is immersed in the game of giving special favors to scheduled castes and tribes and "other backward castes" in exchange for votes (Sharma 20I4). Hence, citizens have a high stake in being digitized as one of these special categories. This enables them to maximize state benefits such as access to coveted government jobs and university positions through the quota systems in place.

The problem with digitizing political audiences in India along lines of caste is that it does not take into consideration the dynamism of such groupings. For instance, the collective political bargaining of caste groups in India typically happens by promising group loyalty and alliances to particular political parties. However, contrary to conventional assumptions of caste groups being divided, the Dalits (the "low caste") have repeatedly partnered with the Brahmins (the "high caste") to strengthen their bargaining position with political parties (Mitra 2015). Hence, intercaste hierarchy and evolving political arrangements between caste groups create a challenge in the digitization of these group identities and the linkage to special state benefits.

Further, current day realities defy conventional notions of caste and class as being mutually exclusive. Numerous protests by Jats (a long-privileged group of land-owning peasants) have pressurized the Indian government to include them in the "Other Backward Caste" category so they can be guaranteed university places and government jobs. The Jats have taken to the streets in large numbers, causing ongoing social unrest as they find themselves excluded and alienated from the growing digital economy in India. Another example is the "female Brahmins" as a category—while high caste, they are often deeply vulnerable as they are more bounded by social rigidities than females of lower castes. Yet, given they are Brahmin, they will likely to be demarcated as exempt from the traditionally exploited gender group.

Hence, the digitization of the Indian citizen promises to freeze privilege along lines of communal politics strengthened during the British Raj over two centuries. In light of this, open government movements and projects such as the biometric identity scheme fail to consider the constructed nature of data and the mobility within the caste system. Hence, information 
justice can be improved by identifying the reproduction of social privilege within conventional data sets to prevent its transfer to new forms of datafication. In other words, what is required is a "set of moral inquiries that can be used to evaluate the justness of data practices, and another exploring the practices and structures that a social movement promoting information justice might pursue" (Johnson 20I4, 266).

Lastly, in this social media era, there is much expectation of political audiences being active agents rather than passive consumers of political messages. Of course, this is not to imply that just because audiences are now participating in the political game, they can thereby affect the political process. Contrary to the optimism expressed by the likes of Saskia Sassen and Ashis Nandy on grassroots politics radically reconstituting political institutions in places like India, a more reserved stance should be taken. Datta (2015) argues that big data continues to be in the hands of the Indian elite for the most part, and thereby is more likely to serve the interests and agendas of this reigning segment. In the context of digitization, the elite and upper class and upper castes continue to find ways of manipulating the data-based systems to their favor through a combination of political lobbying and pressuring of governments to tailor the biometric machine to the needs of the upper classes and castes.

\section{The Old and New Mass Media and Political Ideology}

It is well known that mass media is a critical tool for the government to communicate with their political audiences. The advantage of social media, however, is its ability to tailor political messages to diverse audiences simultaneously and to track responses and sentiments through big data. Given the omnipresence of mobile phones in the Global South including in India, one would assume that political communication has shifted from the television to the mobile phone and has opened up to diverse political views. On the contrary, the "old" media systems continue to exist and even thrive as in the case of India. Communal and language politics play a key role in the shaping of political communication through Indian media systems that appear to carry over to the digital sphere.

The Indian broadcasting industry has changed dramatically in the last two decades due to the privatization and liberalization policies of their media systems. Today, the Indian mass media industry comprises 300 television channels, reaching I 2 million households, including the poorest 
sections of society (Sharma 20I4). Doordarshan, the national television network, comes with 22 channels, albeit managed by private companies. Given the diversity of language and regions ( 22 official languages) and a plethora of private media actors at play today, the media industry in India is unlikely to follow the pathway of convergence as in the United States or European markets (Chakravartty and Roy 2013).

Furthermore, the networks, in concert with political parties, have launched special channels to propagate particular communal ideologies. For instance, the fundamentalist Hindu party Rashtriya Swayamsevak Sangh (RSS), the Bharatiya Janata Party (BJP), the Marxists of Kerala, the Dravida Munnetra Kazhagam (DMK) of Tamil Nadu, the Congress Party, and even the Catholic Church have their own TV channels. Hence, diversity here is not necessarily conducive to sociopolitical inclusion as would be commonly perceived. Given that all these networks have a growing and competitive online presence, they foster the continuity of political balkanization within the digital media sphere.

While there is no consolidated policy and system of state censorship, sedition laws established during British colonialism have experienced a resurgence in the last two decades (Kalhan et al. 2006). The British criminalized citizens for speech and public collective organization aimed at disrupting and resisting the established order, which were seen as subversive acts as early as 1870 . This colonial machinery continues to pervade the current Indian constitution and has been used to target individuals who have expressed themselves against communal interests, including on social media. In particular, "fundamentalist groups (Hindu, Muslim and Christian) across the country enforce their beliefs and cultural values through sheer muscle power. Such groups threaten to disrupt law and order if their demands are not met" (Chakravartty and Roy 2013, 82).

In just the first three months of 2016 , there were 17 cases of censorship in the "old" media system and eight cases of digital censorship on Google, Facebook, Instagram and YouTube (Kractivism 2016). For instance, a "Pakistan Ki Jai" WhatsApp message expressing sympathy toward Pakistan resulted in the jailing of two Mangalore-based students. An Instagram picture with the caption "Kashmir hearts beats only for Pakistan" was removed instantly from the site. Another incident involved the blocking of Internet services and social media sites in the state of Haryana to deter the spread of the Jat community's protest marches demanding special reservations within state institutions. Hence, this crafting of media politics along 
communal, caste, and religious lines gains legitimacy through the revival of colonial laws and demonstrates its reach in the digital realm. In other words, with social media, communal politics extends to data politics.

Additionally, not all political actors and groups are digital aficionados. Certain leading political parties such as the BJP and its politicians, such as the current prime minister of India, Narendra Modi, have done better than many others in leveraging these digital tools. For instance, Modi, with his "Obama style" social media campaigns, broke new ground in the way politics in India play out, successfully reaching India's remote and vast political audiences. On Twitter, Modi has the largest following among political actors, even more than any mainstream news media channel or journalist in India. With a combination of accessible language, humorous and sarcastic jibes at his opponents such as calling Sonia Gandhi "madam" and her son "shahzada" (prince) or "Rahul babu" (boy) (Pal 2015,I7), and his casual selfies with celebrities, he has managed to capture the attention of a vast political public.

Moreover, Modi's humble beginnings as a son of a tea seller gives hope to the majority of the Indian citizens who fall within the low-income bracket. That being said, it is worth noting that Modi's first political footing was in the right-wing Hindu social organization Rashtriya Swayamsevak Sangh, a fundamentalist wing of the Bharatiya Janata Party. Furthermore, Modi comes with a tainted history of being the sitting chief minister during the bloody communal violence in Gujarat in 2002. These recent histories take a backseat as Modi reinvents himself as the people's man through these new data politics.

While undoubtedly Modi is ingenious in extending his charisma online through such communication strategies, he does not leave much to chance. He has harnessed an army of bots to connect with his constituency and simulate vibrant political communication and participation. For instance, there is a legitimate concern that more than half of his Twitter followers are fake ("60 Per Cent" 20I8). Almost half of them do not have a profile picture, many of them have never tweeted and their Twitter IDs carry five or so numerals, all indicators that they are spam bots to create the illusion of political popularity. This has serious consequences today in the field of journalism. Conventional mass media industries are shaping their political news by what is trending on Twitter. Twitter trends are seen as proxies for public interest. The practice known as astroturfing, the creation of fake grassroots support, is now a growing problem as politicians compete with one another in this new information battlefield. This blurs the genuine 
with the fake political audiences, and puts the power more in the hands of those who are best able to control bot armies.

In fact, today's political communication is a new kind of branding with a novel kind of public relations rising up to meet these needs. The focus today is on the channels of delivery more than the substance of the content. Modi is a brand and citizens are a prospective fandom community. Take Net Solutions, an application development agency in India. They have launched the NaMo ChatBot, a bot on Facebook messenger, one of the most popular and most frequented platforms in India. This bot enables Modi fans to search for all information relating to him including his speeches, podcasts, meeting points, videos, and blogs. This is fast becoming a new political dream for leaders in the United States to Mexico (Woollacott 20I4) - to be seen and heard and be marked as a political celebrity of today with a little help from our bot friends.

To conclude, the datafication of political communication in India should take heed of both the old and new media to gain a more comprehensive picture of the influence of mass media on emerging political audiences. Media diversity does not necessarily result in political inclusion. Colonial legacies such as sedition laws have made a comeback, spurred by social media affordances and reinforced by the savvy bots that have the ability to track and trace citizen identities online as well as fake collective grassroots participation. The trend of communal politics seeping into old and new media channels further fragments political audiences. This is alarming and should be investigated through research that is more empirically grounded.

\section{Exceptionalism in Digital Political Cultures?}

In shifting our attention away from the West, there is a tendency to read this as the building of exceptionalism and maybe even self-exoticism. The label of the "South Asian" scholar can at times be a barrier to one's scholarship as it becomes encased under "area studies," pushing its influence away from mainstream academic theories it seeks to influence and reshape. The "other" is often intended to be on the periphery or to serve as fodder for the reflexivity of the core.

This kind of knowledge-making unsurprisingly has its roots in colonialism as the Western anthropologist would go to study the natives, so as to "translate" their "exoticness" to the so-called civilized cultures of the West (Cohn 1996). It was a novel form of narcissism of the time as it created "reflexive opportunities to expand, even challenge by the contrast, the 
outsider's understanding of his or her own society and culture" (Szanton 2004, 3).

In spite of the tainted trajectory of such scholarship, we scholars seeking to broaden the normative understandings that continue to be dominated by Western ideas and ideologies take this risk. The focus on the "Indian" case is meaningful by itself as it reveals the granularity of a vast and for the most part understudied arena and aspects of the everyday lives of its people. This corpus of knowledge is intended to be juxtaposed against pervasive understandings on datafication, digitization, and social justice, to create a much-needed academic humility, as, in this case, on digital political culture.

Take for instance the idea of digital privacy. Rigorous debate surrounds this important topic, with disproportionate attention on data ownership (Taylor 20I7). The EU with their well-meaning goals of spreading their "gold standard" on privacy rules worldwide, fails to acknowledge the fact that the term "privacy" has no direct translation in most of the world's languages and that there are few studies on what this essentially means to the world's global public as they come online, share passwords, become visible, and at times stay anonymous (Miller et al. 2016).

There is another exceptionalism this chapter may evoke: the argument that classifications of persons - as sources of state-based data sets-are politicized because they are linked to the control of resources is not a new one. Thereby, as this chapter unpacks the problematics of caste classification and big data, it may be seen as the age-old conversation being "rebottled" on governance and surveillance through the lens of the digital. However, this criticism is not novel either. With every new technology intervention into society, there is the demand to not get carried away with deterministic utopias/dystopias driven by novelty. While this voice creates a balance to the other side of the pendulum, it can be just as obstructive in the pursuit of the new forms of social life that emerge through the dialectic of the historical and the future, the old and the new. With that approach, this chapter underlines that indeed caste categorizations as an instrument of control have been deeply investigated but few works so far have brought this into dialogue with the spectrum of intersectionality that big data affords and the often unintended outcomes that emerge, in this case, in Indian politics.

\section{Conclusion}

Datafication of India's citizens promise visibility, representation, and overdue justice to the majority of its undocumented and marginalized publics. 
Anonymity gives way to sociopolitical identity, intended to pave the way for a more inclusive polity. Given the deep inequality, the long-standing communal divisiveness, and the pervasive bias toward the Indian elite, trust is at the heart of how these digitization projects unfold in the making of a vibrant political sphere. Strong and fair legal infrastructures enable the overcoming of distrust. Unfortunately, the dearth of strong privacy laws in India to protect individuals from data harms stand as a serious obstacle to the materialization of these political ideals (Arora and Scheiber 2017).

In many ways, India has made tremendous strides in the last few decades. Much like other countries in the Global South that emerged from colonialism, there is less interest in dwelling on their subjugated past and more motivation in fostering ideas of national reinvention particularly through new technologies. However, it would be a mistake to dismiss the colonial apparatus still in place and its extension to the digital sphere. After all, only through recognition of these structures can we start to dismantle them. Revealing the inherent and systemic divisiveness of communal and caste politics, which were strategically utilized as a means of control in the days of the British Raj, is essential if we are to break away from the past. We need to become more cognizant of the reproduction of power inequalities through the digitization of traditional communal categories and groupings. Otherwise, this will constitute a freezing of progress through the permanence of communal data politics.

The sedition law has proven to create a neocolonialism of the Indian digital sphere, criminalizing freedom of expression, especially along lines of caste and religion. In the growing field of values in design, the Global South needs to become more visible and active if we are to contest whose values get programmed into algorithms and transmitted by transnational global companies like Facebook, Amazon, Twitter, and Google or global policy directives such as the EU General Data Protection Regulation that intends to export its "gold standard" on privacy rules worldwide.

The Indian mass media empire appears to not just stand but also to expand and diversify, more as an archipelago of communal interests. The old and new media systems work in concert to fragment the political sphere, online and off-line. It appears that the information or filter bubble comes to fruition not just within the social media sphere but also within the traditional channels of mass media such as television. This is so particularly along lines of communal interests and political capital. Modi is the new political hero, shedding his tainted history, proving that politicians can reclaim their brand through social media. The political conversation can be controlled through a potent mix of social tools such as compelling digital 
narratives, humor, and personalization as well as technical tools such as the employment of Twitter bots. The political sphere is a public relations sphere. When we speak about visibility, people and bots compete in this expanding realm. In other words, political audiences encompass not just the social but also the technical. While the BJP appears to have gained a head start in data politics, we can only hope that nonprofit agencies and activists step up their game to contest the dominant political narrative.

\section{Acknowledgment}

I would like to thank Philip N. Howard and his team for the invitation to present a draft of this paper at the Algorithms, Automation and Politics workshop funded by the European Research Council and the Oxford Internet Institute, held as a preconference to the International Communication Association meeting in Fukuoka, Japan, held in June 20I6. Further, I would like to thank Sahana Udupa for the invitation to present a draft of this paper at the Digital Politics in Millennial India, funded by the European Research Council, and organized by Ludwig Maximilian University (LMU) Munich and Indraprastha Institute of Information Technology, New Delhi (IIIT-Delhi), held in March 20I8.The feedback from the participants at both these workshops was useful in shaping this paper. All ideas expressed here, however, are my own.

\section{References}

Abraham, Itty, and Ashish Rajadhyaksha. 2015. "State Power and Technological Citizenship in India: From the Postcolonial to the Digital Age." East Asian Science, Tecbnology and Society 9 (I): 65-85.

Arora, Payal. 2or6a. Dot Com Mantra: Social Computing in the Central Himalayas. London: Routledge.

Arora, Payal. 20I6b. "The Bottom of the Data Pyramid: Big Data and the Global South." International Fournal of Communication io (January): I68 I-99. https:// doi.org

Arora, Payal, and Laura Scheiber. 2017. "Slumdog Romance: Facebook Love and Digital Privacy at the Margins." Media, Culture \& Society 39 (3): 408-22.

Axford, Barrie, and Richard Huggins. 200 I. New Media and Politics. London: Sage. Beniger,James. 2009. The Control Revolution: Technological and Economic Origins of the Information Society. Cambridge: Harvard University Press.

Burns, Ryan. 2015. "Rethinking Big Data in Digital Humanitarianism: Practices, Epistemologies, and Social Relations." Geofournal 80 (4): 477-9o.

Chakravartty, Paula, and Srirupa Roy. 2013. "Media Pluralism Redux: Towards 
New Frameworks of Comparative Media Studies 'beyond the West." Political Communication 30 (3): 349-70.

Cohn, Bernard S. 1996. Colonialism and Its Forms of Knowledge: The British in India. Princeton: Princeton University Press.

Datta, Ayona. 2015. "New Urban Utopias of Postcolonial India: 'Entrepreneurial Urbanization' in Dholera Smart City, Gujarat.” Dialogues in Human Geography $5(\mathrm{I}): 3^{-22}$.

De Mul, Jos. 20 5. "Database Identity: Personal and Cultural Identity in the Age of Global Datafication." In Crossroads in New Media, Identity and Law, 97-I I 8. London: Springer.

Endong, F. P. C., ed. 2018. Exploring the Role of Social Media in Transnational Advocacy. Hershey, PA: IGI Global.

Johnson, Jeffrey Alan. 20I4. "From Open Data to Information Justice." Ethics and Information Technology I6 (4): 263-74.

Kalhan, A., G. P. Conroy, M. Kaushal, and S. S. Miller. 2006. "Colonial Continuities: Human Rights, Terrorism, and Security Laws in India." Columbia Fournal of Asian Law 20: 93-234.

Maireder, Axel, Brian E. Weeks, Homero Gil de Zúñiga, and Stephan Schlögl. 20 I 7. "Big Data and Political Social Networks: Introducing Audience Diversity and Communication Connector Bridging Measures in Social Network Theory." Social Science Computer Review 35 (I): I 26-4I.

Mayer-Schönberger, V., and Kenneth Cukier. 20 I3. Big Data-a Revolution That Will Transform How We Live, Think and Work. London: John Murray.

Miller, Daniel, Elisabetta Costa, Nell Haynes, Tom McDonald, Razvan Nicolescu, Jolynna Sinanan, Juliano Spyer, Shriram Venkatraman, and Xinyuan Wang. 2016. How the World Changed Social Media. London: UCL Press.

Mitra, Debashish. 201 5. "Caste Politics and Identity Formation in India: A Comparative Case Study." Journal of South Asian Studies 3 (2): I 55-66.

Morris, David Z. 20i6. Netflix Says Geography, Age, and Gender Are "Garbage" for Predicting Taste. New York: Fortune.

Pal, Joyojeet. 2015. "Banalities Turned Viral: Narendra Modi and the Political Tweet." Television \& New Media I6 (4): 378-87.

Pariser, Eli. 20 I I. The Filter Bubble: What the Internet Is Hiding from You. Harmondsworth, UK: Penguin UK.

Rai, Saritha. 20I 2. "Why India's Identity Scheme Is Groundbreaking." BBC News. June 6, sec. India. http://www.bbc.com

Raman, Bhuvaneswari. 20I2. "The Rhetoric of Transparency and Its Reality: Transparent Territories, Opaque Power and Empowerment." Fournal of Community Informatics 8 (2). http://ci-journal.org/index.php/ciej/article/view/866

Samarajiva, Rohan, and Sriganesh Lokanathan. 2016. Using Behavioral Big Data for Public Purposes: Exploring Frontier Issues of an Emerging Policy Arena. LirneAsia report. http://lirneasia. net/wp-content/uploads/2013/09/NVF-LIRNEasiareport-v8-160201

Sarkar, Swagato. 20I4. "The Unique Identity (UID) Project, Biometrics and ReImagining Governance in India." Oxford Development Studies 44 (4): 5 I 6-33. 
Sharma, Neeta. 20 14. "Public Policy Making: Media Trends in India." SCMS fournal of Indian Management I I (4): 79.

"6o Per Ccent of PM Narendra Modi's Twitter Followers Are Fake: Twiplomacy." March I4, 20I8. Indian Express. http://www.newindianexpress.com/ nation/2018/mar/14/60-per-cent-of-pm-narendra-modis-twitter-followersare-fake-twiplomacy-1786939.html

"Status of Free Speech in India-20r6-A Dire Three Months." April 7, 2016. Kractivism. http://www.kractivist.org/status-of-free-speech-in-india-2016-adire-three-months/

Szanton, David L. 2004. The Politics of Knowledge: Area Studies and the Disciplines. Berkeley: University of California Press.

Taylor, Linnet. 20 I 7. "What Is Data Justice? The Case for Connecting Digital Rights and Freedoms Globally." Big Data \& Society 4 (2). doi: 205395 I 7 I 7736335.

Thomas, Owen D. 20I4. "Foucaultian Dispositifs as Methodology: The Case of Anonymous Exclusions by Unique Identification in India." International Political Sociology 8 (2): I64-8I.

Toness, Bianca Vázquez. 2014. "India Building Database to Unite Records for I.2 Billion.” Bloomberg Technology, December Io. https://www.bloomberg.com

Verba, Sidney, Kay Lehman Schlozman, and Henry E. Brady. I995. Voice and Equality: Civic Voluntarism in American Politics. Cambridge: Harvard University Press.

Woollacott, Emma. 20I4. "Why Fake Twitter Accounts Are a Political Problem." May 28. New Statesman. https://www.newstatesman.com/sci-tech/2014/05/ why-fake-twitter-accounts-are-political-problem

Woolley, S., and P. N. Howard. 2016. "Social Media, Revolution, and the Rise of the Political Bot.” In P. Robinson, P. Seib, and R. Frohlich, eds., 282-92. Routledge Handbook of Media, Conflict, and Security. New York: Routledge. 


\title{
Digital Television in Digital India
}

\author{
Shanti Kumar
}

Television in India is on the threshold of a major transformation as the nation has embarked upon a massive project to completely replace all ana$\log$ systems of broadcasting and cable television with a digital addressable system (DAS). DAS comprises a set of digital hardware and software tools used in broadcasting, satellite, and cable industries for the transmission of television channels in encrypted form to their subscribers. All subscribers get a digital set top box with authorization to access free broadcasting, paid, or on-demand content through encrypted channels on a broadcasting, satellite, or cable network. ${ }^{1}$

As per the deadlines mandated by International Telecommunications Union (ITU), all member countries are required to completely shut off their analog transmissions and shift to DAS systems by no later than 2020 . Many countries have already completed the digital switchover, others like India are in the process of completing the conversion, and a few countries have missed deadlines, or have not started moving from analog to DAS. ${ }^{2}$ In India, the Cable Television Networks (Regulation) Amendment Act of 20 I made it mandatory for all analog cable television systems to switch over to a new Digital Addressable System by December 20I4. As per the consultation paper issued by the Telecommunications Regulatory Authority of India (TRAI) in $20 \mathrm{I}$, the shift to DAS was scheduled to take place in a phased manner across the country. The four metro areas of Delhi, Mumbai, Kolkata, and Chennai were expected to switch over by June 30, 2012. The second phase covered cable TV households in 38 major cities with 
population over I million. The third phase focused on implementation in smaller towns and urban areas with municipal corporations. In the fourth phase, all villages in rural areas were to be digitized by $2014 .^{3}$

However, due to several delays in implementation and over 6o legal challenges to the policy in different parts of the country during the various phases of DAS, the sunset date for digitization in Phase IV was moved to March 3I, 20I7 by the Ministry of Information and Broadcasting in a notice released on December $23,2016 .{ }^{4}$ While analog signals were officially switched off by all broadcasters and cable companies in India on March 3 I, 20I 7, there are still many rural areas where digitization has not been completed as scheduled in Phase IV. The overwhelming challenge of switching over from analog to digital in thousands of small towns and villages dispersed across several states is a major priority not only for the government of India but also for many big and small players in the Indian media industries who see vast potential for growth and profit in rural areas. Therefore, governments at the central and state levels along with corporate media industries are devoting considerable resources to digitize the nation's aging media infrastructure through a flagship program called "Digital India." Launched with great fanfare by Prime Minister Narendra Modi on July I, 20I5, the primary objective of Digital India, as stated on the program's website, is to "transform India into a digitally empowered society and knowledge economy." 5

With a catchy slogan — "the power to empower"-the Digital India program focuses on three key vision areas: (I) the development of digital infrastructure as a public utility, (2) the electronic delivery of services and software on demand, and (3) the digital empowerment of citizens in all walks of life. Reflecting on the achievements of Digital India at the inaugural forum of the Digital India Foundation titled "Create4India" held in August 20I7, R. S. Sharma, the chairman of TRAI, claimed that the program has advanced rapidly in the vision area of creating software applications and services. However, he felt that the program badly lags behind in the area of hardware and infrastructure. ${ }^{6}$ Sharma lamented that while Indians get 93 percent of their data from mobile and only 7 percent from fixed lines, the world on an average gets 46 percent data from fixed lines and 54 percent from mobile. Since it would be impossible to immediately build the new fixed lines necessary to bring India closer to the global averages, Sharma has for long advocated for the use of already built up infrastructure in cable television and broadband networks to enhance fixed line connectivity. ${ }^{7}$ 
Sharma predicts that DAS in the television industry, in conjunction with BharatNet—a high-speed fiber optic broadband national networkwill enable a high level of digital connectivity in both urban and rural areas. While the implementation of DAS in the television industry is nearing completion, the government of India's ambitious project to connect all 25,000 gram panchayats (village councils) through BharatNet has been plagued by several delays. However, BharatNet—also known as Bharat Broadband Network Limited-when complete will be fully interoperable with DAS in the television industry, and with other digitally addressable satellite and mobile networks in Digital India. As the primary fixed line infrastructure of Digital India, DAS and BharatNet, Sharma argues, are crucial for achieving the government's goal of delivering digital services in three key areas in every citizen's life: What I know (my fingerprint or Iris), What I have (credit or debit cards), and What I am (Biometrics). Thus, contrary to the popular belief that the rise of digital, mobile technologies signals the end of television technologies, the chairman of TRAI proclaims that the already built up infrastructure of DAS is the aadhaar (foundation) of Digital India. ${ }^{8}$

In this chapter, I critically evaluate how the switchover from analog to digitally addressable systems in television is taking place under the aegis of the Digital India program. In the first section, I analyze media industry debates, government policy reports, and popular cultural discourses in terms of a growing consensus in favor of the digital switchover in Indian television. In the second section, I discuss how the digital switchover in India is taking place in relation to the International Telecommunications Union's policies of harmonization being promoted on a worldwide scale to maximize the benefits of digitization for all member countries. In the third section, I critically evaluate how the implementation of the switchover from analog to digital television is occurring in conjunction with similar transformations in other media and allied industries through the rapid harmonization of state agendas, market forces, and civil society interests. In conclusion, I outline the political, economic, and cultural implications of harmonization in public and private arenas of life in Digital India.

\section{Television and Digital Addressable Systems in India}

According to a study conducted by Chrome Data Analytics, the number to TV households in India was estimated to be around I80 million in 2017. The study claims that about 89.5 million TV households were successfully 
switched over to digital in the first three phases of DAS switchover. However, more than 40 percent of the remaining 90 million or so TV households in rural India had not been digitized by the sunset date of March 31, 201 7. ${ }^{9}$ The installation of mandatory digital set top boxes in all cable television households in India thus poses an enormous set of challenges for cable operators, broadcasters, advertisers, consumers, and TRAI and other associated governmental agencies. Among the major challenges are concerns about the timely installation of digital set top boxes in all television households; questions about the availability of necessary funds for the procurement of new digital cable boxes, particularly by local cable operators in smaller towns and villages; lack of proper communication with viewers about the implications of the shift to digital television; confusion about the new regime of revenue sharing agreements among television programmers, advertisers, cable operators, and so on. ${ }^{10}$ There still remains a great amount of confusion and uncertainty about Phase IV of the digital switchover in rural India, and critics have wondered whether the digitization schedule has been created in haste without adequate preparation both in the industry and among consumers. ${ }^{11}$

However, advocates of digitization see it as revolutionary change that is long overdue in Indian television. ${ }^{12}$ They argue that the shift to DAShowever expensive, confusing, and cumbersome-is not only essential but inevitable because what constitutes "television" today is very different from what it was when Doordarshan, the government-sponsored network, was the only broadcasting service in India till the r99os. Although Doordarshan is still the only terrestrial broadcaster in the country, since the earlyı 99 os several commercial television channels like CNN, MTV, and the BBC - and later Indian language channels such as ZEE TV, SUN TV, and ETV-became available on local cable networks in India. Television viewers in many cities, towns, and villages were willing to pay a local cable operator-known as the cablewallab—anything from 40 to roo rupees per month for a variety of programming in English, Hindi, and other Indian languages. For much of the paying audiences in India, cable television and not broadcasting soon became the dominant mode for the delivery of programming content. The local cablewallab not only controlled the supply of television content into the viewers' homes but also dictated which channels were part of the "bundle" and where each channel would be located in the programming lineup. During the late I990s and the early 2000 s, as satellite and cable television began to spread rapidly across India, the business of cable distribution rapidly shifted from the early disorganized, 
entrepreneurial phase of the cablewallabs toward a more corporate structure that emphasized rationalization of business practices, efficiency of scale, professionalization of management and technical expertise, transparency in billing systems, and standardization of choice and customizability of services across local operations. ${ }^{13}$

According a report released by TRAI on the status of the cable television industry in 2010 , the number of cable television subscribers in India grew from 410,000 in 1992 to more than 9I million by the end of 2009. The number of satellite television channels grew from literally a handful in 1992 to around 550 channels in 2010 . The cable distribution industry, which began as an entrepreneurial venture of enterprising cablewallabs in the early I990s, rapidly grew to 6,000 multi system operators (MSOs), and 60,000 local cable operators (LCOs). Now competing with the cable operators for distribution of television channels are direct to home (DTH) satellite TV operators and several Internet Protocol television (IPTV) service providers. ${ }^{14}$

DTH and IPTV services in India are already compliant with the new regulations for digitization because they are distributed through encrypted signals that can only be received through a digital addressable box at the consumer end. In addition to transmitting a digital signal, DTH and IPTV also provide a variety of $\mathrm{HD}$ (high definition) channels and ${ }_{3} \mathrm{D}$ features that many MSOs and LCOs in the cable industry did not, particularly in smaller towns and villages. During the switchover from analog to digital cable, DTH providers like Videocon, Reliance Digital TV, TataSky, and Dish TV launched advertising campaigns to highlight that cable signals were not really HD, whereas the DTH HD signal is the "asli" (real) deal. For example, in an ad campaign launched in July 2013, Videocon promoted its $\mathrm{d}_{2} \mathrm{H}$ platform with the tagline "Demand 2 have the Asli Picture" in an effort to position itself as "the" provider for high quality digital television in India. The campaign also highlighted options like recording, rewindingforwarding, pausing live TV, and providing a ${ }_{3} \mathrm{D}$ viewing experience for the viewer that were not offered by competitors in the cable industry. ${ }^{15}$

Other DTH providers like Reliance Digital, Dish TV, and Tata Sky were also quick to capitalize on the seemingly chaotic transformation to digital in the cable industry, and have been running ads in newspapers inviting cable subscribers to switch to DTH, and providing incentives to owners of LCO in the cable industry to switch their allegiance to a more stable DTH industry. IPTV has been a success in some of the major metros and cities but it is currently seen more as a delivery system with great 
potential as broadband connections become available in other parts of the country. More importantly, the success of DTH and IPTV forced MSO and LCO cable operators to hasten the transformation of the cable industry from the old analog system to the new digital system.

While cable, DTH, and IPTV providers are competing with the cable industry for primacy in the digital television marketplace, India's only terrestrial television network, Doordarshan, has also taken rapid strides in its quest to offer digital terrestrial television (DTT) in the country. Doordarshan's analog broadcasting services cover almost 90 percent of the country, but constraints of bandwidth and poor signal quality have forced the Prasar Bharati Corporation, which oversees Doordarshan and All India Radio, to invest heavily in the digitization of the nation's public service broadcasting infrastructure and programming services. As of 2017 , Doordarshan offers DTT services in 16 cities and plans to expand its digital network to more than 60 cities by 2019. Unlike digital cable and commercial DTH providers who require viewers to pay a subscription fee to access their services, Doordarshan's DTT services are over the air and free of charge. Therefore, the Prasar Bharati Corporation is also experimenting with offering radio, television, and other digital services on its DTT network that can be accessed for free on mobile phones and other electronic devices, especially in rural areas that do not have access to cable television, commercial DTH services, or IPTV. ${ }^{16}$

As the many limitations in the cable industry have led policymakers, industry leaders, and media consumers to look for alternative television delivery systems, DTH and DTT have emerged as viable alternatives in many rural and urban areas in India. Much of the debate in the industry and policy circles has focused on whether the digital switchover will be a revolutionary transformation in the delivery of programming services, as its proponents claim, or a mirage the Indian television industry will be chasing in futility for years to come, as critics argue. The advocates of digitization view DAS as the key to overcome the problems posed by the antiquated analog systems in Digital India, and to allow content providers in the television industry and their audiences the ability to directly interact and communicate with each other. It doesn't matter whether you get your TV through broadcasting, cable, direct-to-home satellite systems, or the Internet, DAS seems to be the fix-it-all solution to problems of analog television like limitations of bandwidth, delivery of digital $\mathrm{HD},{ }_{3} \mathrm{D}$, interactive services, targeted advertising, standardization of TV rates, reliable billing practices and so on. ${ }^{17}$ 
For the critics of DAS, the elevation of digital addressable system as a technical fix to all the problems in Indian television is rather problematic. Their criticism of the DAS policy has at least four dimensions to it. The first is an argument about the inherent difficulties in uniformly implementing DAS as a new technology in a politically, economically, culturally, and linguistically diverse country like India. The second strand of criticism comes from those who question the assumption that giving the television industry greater access to television households through DAS will automatically improve the quality of services for the viewers. The third strand of criticism comes from those who argue that the kind of "choice" proposed by the advocates of DAS is a menu-driven format of click-and-choose options that does not fully exploit the interactive potential of digital addressability. The final strand of criticism is that the menu-driven format of choice does not promote the interests of the television viewer at home, but instead serves the commercial interests of the powerful media industries and the statist interests of political leaders in the government. ${ }^{18}$

Although advocates and critics in the media industries differ in their assessments of the ways in which the new DAS regime is being implemented in India, there seems to be little disagreement in these circles about the potential of new digital technologies to overcome the many problems posed by the old analog mode of delivering broadcasting and cable television services. Therefore, not surprisingly, much of the debate on the shift to DAS in India has been framed in terms of the relative advantages and disadvantages of digital set-top boxes over the current analog cable technologies. Underlying this consensus about the ills of the analog world is a common view that the attempt to realize the full potential of the broadcasting revolution of the $1970-1980$ and the satellite television revolution of the r 990 is being hindered by the inability of media content providers to directly address the audiences at home.

In the overall context of the growing consensus about the need for an overall switchover toward digitization in India, I argue that the "digital" in digital television must be analyzed not merely in terms of the technological advantages and disadvantages of the switchover from analog systems. Instead, digitization must be understood in relation to the international politics and policies of "harmonization" being promoted by supranational organizations like the ITU and being aggressively implemented in television and other allied industries by member countries like India. As defined in the policy reports of the International Telecommunications Union, harmonization refers to an internationally coordinated process of digitizing a 
range of public and private infrastructures of life in order to maximize the benefits of broadcasting and new media technologies around the world. In the next section, I move the debate on digitization away from the focus on the pros and cons of the digital switchover as a technical fix-it-all solution for the problems of the outdated analog cable systems. Instead, I seek to pay closer attention to the global discourse of harmonization in digital addressable systems, and critically analyze the political, economic, and cultural implications of the wholesale shift toward digitization in all walks of life.

\section{Television, Harmonization, and Digital Dividends}

According to the ITU, television is at the heart of a new global experiment of harmonization that is now under way to reap the benefits of a "digital dividend" around the world. ITU defines the concept of digital dividend "as the amount of spectrum made available by the transition of terrestrial television broadcasting from analogue to digital." The ITU report states:

The digital dividend may be used by broadcasting services (e.g. provision of more programmes, high definition, ${ }_{3} \mathrm{D}$ or mobile television). It may also be used by other services, such as the mobile service, in a frequency band which could be shared with broadcasting (e.g. for short range mobile devices, such as wireless microphones used in theatres or during public events). It may also be used in a distinct, harmonized frequency band to enable ubiquitous service provision, universally compatible equipment and international roaming (e.g. for International Mobile Telecommunications, IMT). ${ }^{19}$

The ITU Report (released in August 2012) is a 72-page document that details a whole range of technological issues involved in the switchover from analog, and calls for an international consensus on the use and management of the digital dividend through harmonization. In India, as in many other countries around the world, the switchover from analog to terrestrial broadcasting has freed up valuable spectrum space for other uses like wireless and mobile communications in ultra-high frequencies in the range of 698-862 MHz (megahertz, bandwidth that was formerly used for analog broadcasting). The opening up of the $698-862 \mathrm{MHz}$ bandwidth is considered particularly significant in India. The GSM Association, a trade group representing the global mobile industry, has recommended that the 
698-862 MHz bandwidth should be allocated for mobile services. While the mobile communications industries can use higher frequencies ranging from 900 to $3600 \mathrm{MHz}$ to provide high-speed cell phone services in India, the lower frequencies are considered critical for expanding the telecommunications infrastructure into rural areas and other underserved regions of the country. The GSM Association estimates that it is almost 70 percent cheaper to provide mobile broadband coverage at around $800 \mathrm{MHZ}$ than at over 2 rooMHz. Therefore, the GSM Association predicts that mobile and broadband services could be offered at much cheaper rates to consumers at around the $800 \mathrm{MHz}$ range, particularly in rural areas where the major players in the telecommunications industry have been rather unwilling to enter. ${ }^{20}$

Given the crucial role of the telecommunications infrastructure in the Indian government's developmental agenda in the 2 Ist century, major political parties, policymakers, and industry professionals all agree that the digital switchover is a once-in-a-lifetime opportunity to reorganize the newly freed up UHF frequencies in more economical, efficient, and profitable ways, particularly for offering new wireless and mobile services in rural areas. There have been innumerable policy documents, industry reports, and recommendations by consulting firms and think thanks allied with specific media and telecommunication industries advocating for what they see as the best practices for the use of the "digital dividend" and other frequencies in the spectrum space. ${ }^{21}$

The Telecommunications Regulatory Authority of India (TRAI) has also developed many policy proposals to auction off the spectrum space to commercial media and telecommunications companies. One of the biggest challenges in the auction process has been the need to balance the public service mission of the government's broadcasting and telecommunications agencies with the commercial interests and profit motives of the private media companies bidding for the newly released frequencies. The bidding process has also been mired in controversy as TRAI has been accused by some of corruption, and others have complained that the government has set the auction rates too high in its attempts to raise massive revenues to fill its coffers. The quality of the spectrum space released in the auction process has also been a point of contention between the Indian government and industry advocates. While government has set aside large parts of the spectrum-particularly in the high-quality ranges-for military and national security uses, some business leaders in the telecommunications industry claim that the high-quality frequencies reserved for defense pur- 
poses are underutilized, and could be put to better use by the private sector to provide ${ }_{3} \mathrm{G}$ (third generation) and $4 \mathrm{G}$ (fourth generation) cell phone and broadband services to rapidly growing numbers of fixed broadband mobile users in the country. ${ }^{22}$

Since the spectrum space is a limited resource, the debate on the allocation of spectrum frequencies for use by various telecommunications industries has historically been a very contentious one both at national and international levels. All ITU member states have the legal right to exercise their sovereignty on how the spectrum is allocated within their borders. However, since airwaves naturally transcend national borders, it has always been necessary for nation-states to coordinate through the ITU how various frequencies are allocated regionally and internationally in order to avoid interference in signal transmissions. Thus, international and regional harmonization of the spectrum space has once again emerged as a crucial policy issue in debates on the best use and management of the digital dividend within and beyond national borders. ${ }^{23}$

The discourse of harmonization is, of course, not completely new in international affairs. Nor is it entirely restricted to the debate over digital dividends that is shaping national policies for harmonization on global scale under the aegis of the ITU. As the noted German social scientist Franz Rothenbacher points out, the creation of supranational organizations like the United Nations after World War II necessitated the international standardization of concepts, definitions, and methods for collecting data, and for coordinating social research and policy making within and beyond nation-states in the new global order. Rothenbacher argues that the globalization of standards at the United Nations worked through two interrelated aspects: harmonization and synchronization. Harmonization, he argues, refers to the ability to compare standards while synchronization refers to the need to compile the standards simultaneously. Further, Rothenbacher distinguishes between two types of harmonization: ex-ante harmonization and ex-post harmonization. The first refers to making standards comparable from the inception, and the second refers to making standards that are different in many respects comparable as much as possible. Rothenbacher refers to several cases where these two types of harmonization are used in social science research, and examine how data is gathered and standardized using statistical methods in the analysis of population census, labor force surveys, and household budget surveys in Western Europe. ${ }^{24}$

In the digital context, however, the harmonization of national policies 
has some important differences from earlier approaches devised in the social sciences and policy research in the post-World War II era. For example, while Rothenbacher's analysis defines harmonization and synchronization as two different aspects of standardization, in the digital context of the switchover from analog, harmonization and synchronization are two sides of the same coin. In the aforementioned ITU Report on digital television, harmonization is promoted as an essential part of a global strategy for member nation-states, transnational corporations, and consumers alike to harvest the benefits of digitization. Similarly, while the ITU Report makes it amply clear that without synchronization, the potential for reaping the digital dividend would be minimized for all nation-states, it grants considerable autonomy to each member nation-state to set its own standards for the implementation the digital switchover, and for managing the benefits of the digital dividends. In other words, the policy of digital harmonization is as much based on ideals of ex-ante harmonization (establishing international standards for digital switchover from the beginning) as it is on expost harmonization (making very diverse national and regional standards for digitization as comparable as possible). Therefore, in the case of digital switchover from analog, harmonization cannot be easily equated with or subsumed under the category of standardization due to the synchronicity and simultaneity of digitization in a range of applications within and across national and international contexts. Instead, I argue in favor of a much broader definition of harmonization as a way to critically analyze a more generalized process that is currently under way on a global scale for building new digital infrastructures through highly differentiated yet extremely coordinated actions by governments, businesses, and civil society organizations to promote digitization in all walks of life. In the next section, I will examine how the digital harmonization of broadcasting, cable, satellite television, and mobile communications is taking place in conjunction with similar transformations in other allied industries under the banner of Digital India promoted by the Indian government.

\section{Harmonizing the Digital India Project}

The primary objective of the Digital India project is to "transform India into a digitally empowered society and knowledge economy." On the government of India's website for Digital India, the program's goal of harmonization is encapsulated through slogans such as "IT (Indian Talent) + IT (Information Technology) = IT (India Tomorrow)." Capturing the 
postcolonial desire to rewrite the orthographies of harmonization through the futuristic vision of Digital India, Prime Minister Narendra Modi is quoted on the website saying, "Our ancestors used to play with snakes, we play with mouse."25

While the tech-savvy Modi is being hailed by his supporters as a visionary for championing the cause of Digital India, the reality is that governmental agenda for digitization in India has a long history. It emerged in the I99os through the discourse of e-governance on the Internet, and through the establishment of the National e-governance plan in 2006. There were 3 I mission projects in the e-governance plan in areas ranging from agriculture, land records, health, education, passports, police, courts, municipal records, taxes, and so on. Many of these projects have been implemented in full or in part in the past decade, and others-such as e-Kranti 2.0-are being modified and translated to reflect the Modi government's current priorities for Digital India. There are many versions of the priority areas of Digital India in the many different departments and ministries in the Indian government. One version promotes the vision in terms of the nine pillars of digital India: (I) broadband highways, (2) universal access to mobile connectivity, (3) public Internet access program, (4) e-governancereforming government through technology, (5) e-Kranti-electronic delivery of services, (6) information for all, (7) electronics manufacturing, (8) IT for jobs, and (9) early harvest programs. The various aspects of Digital India are coordinated through the Ministry of Electronics, Information and Technology or MeitY. Formed in July 20I6, MeitY's main objective is to provide common branding and to harmonize diverse aspects of governance through the extensive use of digital technologies in public and private realms of social relations. ${ }^{26}$

The goals of harmonization in Digital India are most prominently visible in the very ambitious and rather controversial government-sponsored project called "IndiaStack." With an impressive tagline of "Technology for I.2 Billion Indians," the website indiastack.org describes IndiaStack as a set of application programming interfaces (APIs) "that allows governments, businesses, start-ups and developers to utilize a unique digital Infrastructure to solve India's hard problems towards presence-less, paperless, and cashless service delivery." ${ }^{27}$ IndiaStack was created in 2013 by a group of digital evangelists, software entrepreneurs, and executives of Indian IT companies under the banner of iSpirt- the Indian Software Product Industry Roundtable-to help facilitate the growth of software companies, products, and applications in Digital India. Since then, the iSpirt group has 
been aggressively positioning itself as an indispensable interface between software companies and governmental agencies involved in the various programs of the Digital India project. Advocating for policy changes to support software start-ups, holding boot camps and hackathons to across the country to help product developers create new apps and interfaces, and connecting software buyers, sellers, and entrepreneurs through its online portal "Product Nation" are some of the stated goals of iSpirt. Additionally, iSpirt is responsible for hosting the website for IndiaStack.

Sometimes described as Aadhaar 2.0, IndiaStack builds on the unique identification number system called Aadhaar being implemented across the nation by the government of India. Aadhaar (meaning support in Hindi) is a I 2-digit unique identification number (UID) issued to all residents in India on a voluntary basis by the Unique Identification Authority of India. The agency was established by the government of India in 2009, and began assigning UID numbers in September 20 Io. The Aadhaar numbers are stored in a centralized database and linked to demographic and biometric information such as photographs, ten fingerprints, and iris scans of every individual with a UID number. ${ }^{28}$

IndiaStack adds new layers onto Aadhaar, and uses the UID as the backbone for managing and integrating next generation of application processing interfaces, which can be programmed by various third-party providers. In 20II, an Aadhaar "payments bridge" service was introduced to enable government agencies to make electronic financial transfers to beneficiaries of government programs who had been assigned UID numbers. In 2012 , a paperless e-KYC (Know Your Customer) service was launched that would enable a bank or telecommunication company to authenticate a consumer's identity using Aadhaar. In 20 I6, Aadhaar reached a major milestone when the number of Indians enrolled in the program crossed the one billion mark. In that year, three new services were introduced into the Aadhaarbased system: the first was an online electronic signature service called e-sign that allowed an Aadhaar cardholder to digitally sign a document by utilizing the Aadhaar biometrics for verification. The second was a digilocker service that was made available to Aadhaar cardholders to store, access, and share their documents online. The third service introduced in 2016 was the Unified Payment Interface (UPI) that enables an Aadhaar cardholder to send and receive money from and to a virtual address using a two-factor authentication process based on Aadhaar biometrics on any networked device like a smartphone. ${ }^{29}$

The UPI services are also being integrated with the "Know Your Cus- 
tomer" (KYC) system currently being used by banks and other financial institutions to digitally distribute services and collect payments from consumers. The resulting e-KYC system is used in conjunction with Aadhaar to individually identify each customer and verify his or her identity by using uniquely identifiable data such as a photograph, residential address, marital status, and so on. Introduced in 2002 by the Reserve Bank of India, the KYC system is now used by all banks to ensure that they are fully compliant with the government of India's regulations aimed at preventing money laundering, terrorism financing, and identity theft schemes. ${ }^{30}$

More recently, under IndiaStack, e-KYC has also been expanded to incorporate electronic payment services to individual consumers with Aadhaar cards. One of the main goals of harmonizing e-KYC and Aadhaar through IndiaStack is to move the entire country toward a "cashless" economy. When Prime Minister Modi suddenly announced on November 8,2017 that the 500-rupee and I, ooo-rupee currency notes would no longer be accepted after midnight on November 8, 20I 7, political pundits attributed several noble intentions and ignoble motives to the decision. While some hailed the government's move as a step toward the eradication of black money, others attributed political motives of corruption for the abrupt and precipitous decision. ${ }^{31}$ While the political implications and the economic consequences of the demonetization policy are still being debated and felt around the nation, it is undeniable that the various layers of IndiaStack—such as the Aadhaar-KYC-UPI interfaces-have quickly become the bedrock of the emerging financial-technological infrastructure (fintech) of Digital India. ${ }^{32}$

Nandan Nilekani, one of the key architects of both Aadhaar and the IndiaStack, firmly believes that the emerging fintech infrastructure of IndiaStack has the potential to transform the nation into world's first data democracy. At the heart of Nilekani's dream of data democracy is the process of what he calls data inversion. For Nilekani inverting the data means giving users ownership of their data and empowering them to decide how much of their personal data will be shared with whom, when, and where. Nilekani argues that after the nationwide implementation of the various layers of IndiaStack such as digisign and digilocker, the country will be uniquely positioned to implement data inversion. With his trademark flair for digital utopianism, Nilekani writes, "We have a billion users on the JAM [Jan Dhan, Aadhaar, Mobile] trinity for individuals and strong nationallevel platforms GSTN [Goods and Services Tax Network], BBPS [Bharat Bill Payment System] and UPI [Unified Payment Interface] for businesses. 
We are doing close to 40 million Aadhaar Authentications every day. The government has also developed the India Stack, a set of Open APIs that enable paperless, presenceless and cashless transactions dramatically driving down the cost of transactions. System designers can mix and match between OTP, Aadhaar Authentication and UPI PIN to create robust and secure authentication." ${ }^{33}$

Jan Dhan Yojana-which Nilekani glowingly refers to in the abovementioned quote- has been billed by the government of India as the largest financial inclusion program in history. The program seeks to provide every Indian household digital access to banking services by giving them zero balance accounts in all commercial banks in the country. To celebrate the third anniversary of Jan Dhan Yojana, Prime Minister Modi tweeted on August 27, 2017 that the program had provided near universal access with a 99.99 percent success rate. Critics of the program peg the success rate to lower numbers ranging from 70 to 90 percent, and claim that the government's inflated numbers include many Indians who already have bank accounts. But advocates of JAM claim that the nationwide implementation of these programs can provide the necessary fintech infrastructure for every Indian to participate in the cashless economy of Digital India. ${ }^{34}$

According to R. S. Sharma, the chairman of the Telecom Regulatory Authority of India, a cashless economy can be achieved by gradually making all payment systems in Digital India compatible with the Aadhaar card. For example, in the television industry, the new digital addressable system is being promoted as a mechanism to uniquely identify each subscriber in coordination with the Aadhaar and KYC systems. According to a study released by the Unique Identification Authority of India in April 2012, telecommunications companies were projected to save over Rs. I, ooo crore $^{35}$ every year if they used Aadhaar to verify the identity and address of new subscribers. The report claims that the telecom industry can save this money by going paperless and cashless in backend processes, and by avoiding the fines that the Telecom Enforcement Resource and Monitoring cell imposes on companies for failing to verify subscriber identity in a proper and timely manner. ${ }^{36}$

Dish TV—one of the leading providers of DTH services in India—was among the first in the television industry to embrace the Aadhaar system for uniquely identifying its customers with minimal delays and confusion, and for rapidly expanding its subscriber base across the country. "Dish TV is proud to align with UIDAI to recognise and support the country's largest movement to provide unique ID numbers to its residents. Aadhaar will also 
serve an additional payment option as the UID has a direct connect to the banks and financial institutions," said Dish TV chief operating officer Salil Kapoor in statement released to announce the implementation of the new policy in February $201 \mathrm{I} .{ }^{37}$

But the poster child for the successful integration of the cashless, paperless interface of IndiaStack into media business practices is, without any doubt, the Reliance Jio mobile phone. In September 20I6, Reliance Industries launched its mobile phone services called Reliance Jio in an already crowded market dominated by corporate giants like Bharti Airtel, Vodafone India, Idea Cellular and the state-run Bharat Sanchar Nigam Limited. Describing how Reliance capitalized on the IndiaStack infrastructure to propel its mobile phone business to the top of a crowded and competitive industry, Arvind Gupta and Philip Auerswald write that Jio "succeeded in using the India Stack to enroll Io8 million consumers in I70 days with a totally paperless, mobile-centric manner-in the process achieving customer acquisition costs of less than \$ (USD) per customer, compared with the prior industry standard of $\$ 25$." Gupta - a founding member of iSpirt, who currently heads the Digital India Foundation and also leads the ruling Bharatiya Janata Party's IT team-and Auerswald-a self-proclaimed advocate for digital disruption-believe that the use of IndiaStack by media and technology companies like Reliance Industries to launch an ecosystem of Aadhaar-compliant devices with built-in biometric authentication will soon transform India into a digital-first economy. ${ }^{38}$

While the current interactions and intersections between IndiaStack and Aadhaar-enabled devices in the broadcasting, cable, satellite television, and mobile industries are currently limited to issues such as billing, payments through UPI, and subscriber identification using e-KYC systems, the future potential is immense. At the same time, critics of Aadhaar and IndiaStack point to the equally immense concerns in the areas of privacy and surveillance due to the encroachment of digital technologies into every aspect of life in India. The issues of privacy and digital surveillance took center stage on February 3, 2017 when IndiaStack's Twitter account posted an image of a group of people on a crowded street but individually identified with their Aadhaar ID numbers. IndiaStack had posted the image from the website of OnGrid as a way to welcome the background verification company into the community of developers that had adopted its APIs to advance their business practices. However, the tweet engendered a big debate on and off Twitter and was soon taken down; IndiaStack issued a detailed clarification on its Twitter account about how sandbox develop- 
ers like OnGrid can use the biometric data from Aadhaar only with users' consent. ${ }^{39}$ But the episode served as a cautionary reminder to the critics of Digital India about how Aadhaar and IndiaStack could very easily and very quickly turn India into an Orwellian Big Brother nation. ${ }^{40}$ At the same time, the systemic inefficiencies and corruption in the Aadhaar ID system have made many people skeptical of the government's ability to safely and ethically monitor and control the massive amounts of personal data that are constantly being generated and transacted on a daily basis by more than a billion Indians. For example, there are many stories in newspapers about how dogs, cats, and cows or even Hindu deities like Hanuman have managed to get their own Aadhaar cards. ${ }^{41}$

Leading critics of Aadhaar, like the Member of Parliament Rajeev Chandrasekhar and privacy advocate Usha Ramanathan, have for years cautioned that consolidation of all biometric data such as iris scans and fingerprints into a single government-sponsored hybrid public-private system like IndiaStack could be easily manipulated by corporate interests for commercial gain, or potentially be hacked by third parties and thus compromise the privacy and security of individual users. ${ }^{42}$ Moreover, biometric data such as fingerprints and iris scans may not always be completely reliable indicators of one's gender, sexuality, class, caste, or religious identity, particularly when such identities are culturally fluid in a country like India where the interoperability of digital technologies has not been-and may never be-fully completed. In such a scenario, consumers and citizens in culturally marginalized and digitally underserved areas could potentially be denied vital services. Or worse, in the event of a major catastrophe, critics fear that Digital India may come to a grinding halt as millions will be unable to conduct basic transactions of everyday life in the presence-less, paperless, and cashless society being promoted through programs like Aadhaar and IndiaStack. ${ }^{43}$

\section{Conclusion}

The growth of digital addressable systems in television and allied industries provides illuminating insights into the emerging consensus about how the benefits of digitization can be reaped through the harmonization of telecommunications policies at supranational organizations like ITU and among its member states like India. I posit harmonization as a new mode of digital interoperability that cannot be reduced to earlier debates about standardization versus diversification, or homogenization versus hetero- 
genization, or globalization and localization in global media studies. Instead, I argue that the development of new digital technologies through nationally and internationally harmonized systems such as DAS, Aadhaar, and IndiaStack in Digital India requires a new understanding of the emerging modes of digital address in our world today. The debate over digital addressable systems cannot be simply reduced to the positive versus negative effects of new technologies like digital television at home or more generally in media culture and industries. Media consumers are increasingly ambivalent about the potential threats of digitization to their privacy and growing more aware of the possibilities of greater surveillance by the media industries in the digital world. But, at the same time, consumers recognize that many everyday conveniences of better programming services, efficiency of delivery mechanisms, and greater security and mobility both inside and outside the home depend greatly on the harmonization of their digital addressable systems like television, mobile phones, computers, and other personal devices. As is evident from the recent attempts of major players in the media industry like Dish TV and Reliance Industries to integrate the DAS platform with the IndiaStack and Aadhaar systems, the rise of digital addressable systems and their ability to uniquely address viewers as consumers and citizens raises new questions about the changing relationships between public and private spaces, privacy and surveillance, and the state and its subjects. These are questions that Indian media scholars need to address by extending our critiques of television industries and cultures to a more sustained analysis of the growing harmonization of digital infrastructures like DAS, BharatNet, and Aadhaar with a range of open application processing interfaces being generated through programs like IndiaStack in Digital India.

\section{Notes}

I. India Telecom Online, "Digital Addressable Cable TV Systems (DAS)," September 22, 20I2, http://www.indiatelecomonline.com

2. The ITU provides a good summary of the current status of the switchover in all its member countries on its website that is frequently updated to provide a current snapshot of the schedule: http://www.itu.int/en/ITU-D/Spectrum-Broadcasting/Pages/DSO/Summary.aspx

3. Telecommunications Regulation Authority of India, Consultation Paper, http://www.trai.gov.in/ConsultationDescription.aspx. For a brief overview of the main elements of the TRAI consultation paper, and its discussion of the key challenges facing the industry in the shift to digital cable, see http://www.broadbandindiamagazine.com 
4. "Delhi HC Removes Hurdles for Implementation of DAS," Indiantelevision.com, January I, 2017 , http://www.indiantelevision.com

5. See About the Program section of the website at http://digitalindia.gov.in

6. IANS, "India's Digital Economy Not Doing Well in Creating Infrastructure: TRAI Chairman," Business Standard, August 8, 201 7, http://www.businessstandard.com

7. R. S. Sharma, "ICT-Enabling Empowerment of Citizens Crucial for Success of Digital India Programme," Economic Times, July I, 2015 , https://blogs.economictimes.indiatimes.com

8. "TRAI: DAS-BharatNet Digital India's 'Aadhaar," Indiantelevision.com, December 20, 2016, http://www.indiantelevision.com

9. "Work in Progress," Broadcast and CableSat, May 201 7, http://broadcastandcablesat.co.in/index.php

ı. "Background Paper on Digitizing Indian Broadcasting," May 20 I 2, Associated Chambers of Commerce and Industry in India, www.assocham.org/arb/general/CMS-Final-Background-paper.pdf

I I. B. B. Nagpal, "Even Official Figures Show Cable TV Digitisation in Incomplete," Indiantelevision.com, April I 2, 20 I 7, http://www.indiantelevision.com

I2. Investec, "India C\&S TV Distribution," Broadcast \& Cable Sat, January 7, 20I6, http://www.broadcastandcablesat.co.in/images/reports/20170113-digitalization-in-the-slow-lane-report.pdf

I3. Shailaja Bajpai, "The World Came Home: The History of Television in India," Indian Express, July 24, 2016, http://indianexpress.com

I4. Telecommunications Regulation Authority of India, "Recommendations Related to Digital Terrestrial Broadcasting in India," January 3 I, 20 I 7, http://www. trai.gov.in

I 5. Videocond2h, "What Is Asli HD?," https://www.videocond2h.com/what-isasli-hd.php

I6. Harveen Ahuluwalia, "Trai Proposes Road map for Digital Terrestrial Transmission," Live Mint, January 3 I, 20 I 7, http://www.livemint.com/Consumer/ vZOHMlgdmiCbshVmUOiEfK/Trai-proposes-road-map-for-digital-terrestrialtransmission.html

I 7. T. V. Ramachandran, "Does the Key to Digital India Lie with Your Local Cable Operator?," Rediff.com., April I 9, 20 I 7, http://www.rediff.com/business/column/does-the-key-to-digital-india-lie-with-your-local-cable-operator/20170419. htm

I 8. Vidya S. Nath, "The Digitization Mirage for Cable in India," Frost and Sullivan Marketing Insight, August 4, 20 I I, http://www.frost.com/prod/servlet/ market-insight-print.pag

I 9. International Telecommunications Union (ITU), "Digital Dividend: Insights for Spectrum Decisions," August 201 2, http://www.itu.int

20. Robindra Mangtani, "The Importance of the $700 \mathrm{MHz}$ Band for India," GSM Association, 2009, http://www.cmai.asia

2 I. See, for instance, World Development Report, World Development Report 2016: Digital Dividend," World Bank, May I 7, 2016, http://www.worldbank.org; Paul Taylor, "Claiming India's Digital Dividend," SAP, March 25, 20 I6, https:// 
news.sap.com; and Ananth Padmanabhan, "Digital Dividend: Framing the Problem," Carnegie India, November I, 20 16, https://carnegieindia.org

22. Shamika Ravi and Darrel M. West, "Spectrum Policy in India," Center for Technology Innovations at Brookings, August 201 5, https://www.brookings.edu/ wp-content/uploads/2016/06/Spectrum-Policy-in-India8515.pdf

23. Jennifer A. Manner, Spectrum Wars: The Policy and Technology Debate (Norwood, MA: Artech House, 2003).

24. Franz Rothenbacher, Statistical Sources for Social Research on Western Europe 1945-1995: A Guide to Social Statistics (New York: Springer Fachmedien Wiesbaden GmBh, I998), 36.

25. See the website for Digital India, http://digitalindia.gov.in

26. Aman Sharma, "DeITY Becomes a New Ministry, Leg-Up for Ravi Shankar Prasad," Economic Times, July I9, 2016, https://economictimes.indiatimes.com/ news/economy/policy/deity-becomes-a-new-ministry-leg-up-for-ravi-shankarprasad/articleshow/53285683.cms

27. "What Is India Stack?" India Stack, http://indiastack.org

28. N. S. Ramnath, "Aadhaar: A Quiet Disruption," Founding Fuel, June 25, 20I6, https://www.foundingfuel.com

29. N. S. Ramnath, "Aadhaar 2.0: Creating India's Digital Infrastructure," Livemint, June 28, 20I6, http://www.livemint.com/Politics/afjuy0dHgS4beFggSTVddP/Aadhaar-20-Creating-Indias-digital-infrastructure.html

30. Reserve Bank of India, "Notifications: Know Your Customer (KYC) Guidelines-Anti Money Laundering Standards," November 29, 2004, http:// www.rbi.org.in/scripts/NotificationUser.aspx

3. "The Ropy Rupee Recall: Modi's Attempt to Crush the Black Economy Is Hurting the Poor. Without Cash, Indians Are Struggling-Readers' Comments," Economist, December 3, 2016, https://www.economist.com

32. Sasi Desai and Nipun Jasuja, "India Stack: The Bedrock of a Digital India—a Guide to the India Stack and Its Disruptive Potential," Medium.com, October 27 , 2016, https://medium.com

33. Nandan Nilekani, "India Must Become the World's First Data Democracy," The Week, September Iо, 20I7, https://www.theweek.in/theweek/specials/indiamust-become-the-worlds-first-data-democr-acy.html

34. Mayank Jain, "Government Claims Jan Dhan Yojana Was a Big Success. Here's a Reality Check-Independent Research Suggests That the Financial Inclusion Scheme May Not Have Had as Big an Impact," Scroll.in, September 6, 20I 7, https://scroll.in

35. $\mathrm{I}$ crore $=$ Io million.

36. Press Trust of India, "Using Aadhaar as KYC Norm Can Save Telecos Rs I, ooo cr, Says Study," Business Standard, April I 2, 2012 , http://www.business-standard.com

37. Press Trust of India, "Dish TV Aligns with Aadhaar, to Accept UID Number as ID Proof," Business Standard, January 25, 2013 , http://www.business-standard. com

38. Arvind Gupta and Philip Auerswald, "How India Is Moving toward a DigitalFirst Economy," Harvard Business Review, November 8, 201 7, https://hbr.org 
39. IndiaStack, "Dear All-A Clarification on Aadhaar API and the Use of It. You Can Post Your Queries around the APIs All Here: http://indiastack.org," Twitter, February 3, 20I 7, https://twitter.com

40. Vindu Goel, “'Big Brother' in India Requires Fingerprint Scans for Food, Phones, and Finances," New York Times, April 7, 20I8, https://www.nytimes. com/2018/04/07/technology/india-id-aadhaar.html

4I. Manish Singh, "Is India's Central Database with Biometric Details of its Billion Citizens a Privacy Nightmare?," Mashable, February I3, 20I 7, https://mashable.com

42. Usha Ramanathan, "Aadhaar Project: Blundering along, Dangerously," Frontline, April 28, 2017, http://www.frontline.in/cover-story/blundering-alongdangerously/article9629188.ece. Also see Nikhil Pahwa, "Rajya Sabha MP Rajeev Chandrasekhar on Privacy, Data Localisation, Consent and More," Medianama, October I 2, 20I 7, https://www.medianama.com

43. David Medine, "India Stack: Major Potential, but Mind the Risks," CGAP, April Iо, 20I 7, http://www.cgap.org

\section{References}

Ahuluwalia, Harveen. 20I7. "Trai Proposes Road Map for Digital Terrestrial Transmission." Live Mint. January 3I. http://www.livemint.com/Consumer/ vZOHMlgdmiCbshVmUOiEfK/Trai-proposes-road-map-for-digital-terrestrial-transmission.html

"Background Paper on Digitizing Indian Broadcasting." May. Associated Chambers of Commerce and Industry in India. May. www.assocham.org/arb/general/ CMS-Final-Background-paper.pdf

Bajpai, Shailaja. 20ı6. "The World Came Home: The History of Television in India." Indian Express, July 24. http://indianexpress.com

"Delhi HC Removes Hurdles for Implementation of DAS." 20 I 7. Indiantelevision. com. January I. http://www.indiantelevision.com

Desai, Sasi and Nipun Jasuja. 20 16. "India Stack: The Bedrock of a Digital India-a Guide to the India Stack and Its Disruptive Potential." Medium.com. October 27, https://medium.com

Goel, Vindu. 2018. “'Big Brother' in India Requires Fingerprint Scans for Food, Phones and Finances." New York Times, April 7, https://www.nytimes. com/2018/04/07/technology/india-id-aadhaar.html

Gupta, Arvind, and Philip Auerswald. 2017. "How India Is Moving Toward a Digital-First Economy." Harvard Business Review. November 8. https://hbr.org

IndiaStack. 20I 7. "Dear All-A Clarification on Aadhaar API and the Use of It. You Can Post Your Queries around the APIs All Here: http://indiastack.org." Twitter, February 3. https://twitter.com

India Telecom Online. 20 г 2. "Digital Addressable Cable TV Systems (DAS)." September 22. http://www.indiatelecomonline.com

Indo Asian News Service. 20 I 7. "India's Digital Economy Not Doing Well in Creating Infrastructure: TRAI Chairman." Business Standard, August 8. http://www. business-standard.com 
International Telecommunications Union (ITU). 20 2 2. "Digital Dividend: Insights for Spectrum Decisions.” August, http://www.itu.int

Investec. "India C\&S TV Distribution." 2016. Broadcast \& Cable, January 7. http:// www.broadcastandcablesat.co.in/images/reports/20170113-digitalization-inthe-slow-lane-report.pdf

Jain, Mayank. 20I 7. "Government Claims Jan Dhan Yojana Was a Big Success. Here's a Reality Check-Independent Research Suggests that the Financial Inclusion Scheme May Not Have Had as Big an Impact." Scroll.in, September 6. https://scroll.in

Mangtani, Robindra. 2009. "The Importance of the $700 \mathrm{MHz}$ Band for India." GSM Association. http://www.cmai.asia

Manner, Jennifer A. 2003. Spectrum Wars: The Policy and Technology Debate. Norwood, MA: Artech House.

Medine, David. 201 7. "India Stack: Major Potential, but Mind the Risks." CGAP, April ro, http://www.cgap.org

Nagpal, B. B. 20 1 7. "Even Official Figures Show Cable TV Digitisation in Incomplete." Indiantelevision.com. April I 2. http://www.indiantelevision.com

Nath, Vidya S. 20 I r. "The Digitization Mirage for Cable in India." Frost and Sullivan Marketing Insight, August 4. http://www.frost.com/prod/servlet/marketinsight-print.pag

Nilekani, Nandan. 20 I 7. "India Must Become the World's First Data Democracy." The Week, September Io. https://www.theweek.in/theweek/specials/indiamust-become-the-worlds-first-data-democr-acy.html

Padmanabhan, Ananth. 20r6. "Digital Dividend: Framing the Problem." Carnegie India, November I. https://carnegieindia.org

Pahwa, Nikhil. 2017. "Rajya Sabha MP Rajeev Chandrasekhar on Privacy, Data Localisation, Consent and More." Medianama, October I2. https://www.medianama.com

Press Trust of India. 20I2. "Using Aadhaar as KYC norm Can Save Telecos Rs I,, 00 cr, Says Study.” Business Standard, April I 2. http://www.business-standard. com

Press Trust of India. 20I 3. "Dish TV Aligns with Aadhaar, to Accept UID Number as ID Proof." Business Standard, January 25. http://www.business-standard.com

Ramachandran, T. V. 20I6. "Aadhaar 2.o: Creating India's Digital Infrastructure." Livemint, June 28. http://www.livemint.com/Politics/afjuy0dHgS4beFggSTVddP/Aadhaar-20-Creating-Indias-digital-infrastructure.html

Ramachandran, T. V. 20 I 7. "Does the Key to Digital India Lie with Your Local Cable Operator?” Rediff.com, April i 9. http://www.rediff.com/business/column/ does-the-key-to-digital-india-lie-with-your-local-cable-operator/20170419. htm

Ramanathan, Usha. 2017. "Aadhaar Project: Blundering Along, Dangerously." Frontline, April 28. http://www.frontline.in/cover-story/blundering-along-dangerously/article9629188.ece

Ramnath, N. S. 20r6. "Aadhaar: A Quiet Disruption.” Founding Fuel, June 25. https://www.foundingfuel.com

Ramnath, N. S. 20r6. “Aadhaar 2.o: Creating India’s Digital Infrastructure.” Live- 
mint, June 28, 2016. http://www.livemint.com/Politics/afjuy0dHgS4beFggSTVddP/Aadhaar-20-Creating-Indias-digital-infrastructure.html

Ravi, Shamika, and Darrel M. West. 20 I 5. "Spectrum Policy in India." Center for Technology Innovations at Brookings, August. https://www.brookings.edu/wpcontent/uploads/2016/06/Spectrum-Policy-in-India8515.pdf

Reserve Bank of India. 2004. "Notifications: Know Your Customer (KYC) Guidelines-Anti Money Laundering Standards.” November 29. http://www. rbi.org.in/scripts/NotificationUser.aspx

"The Ropy Rupee Recall: Modi's Attempt to Crush the Black Economy Is Hurting the Poor. Without Cash, Indians Are Struggling-Readers' Comments." 20 I6. Economist, December 3. https://www.economist.com

Rothenbacher, Franz. 1998. Statistical Sources for Social Research on Western Europe 1945-1995: A Guide to Social Statistics. New York: Springer Fachmedien Wiesbaden $\mathrm{GmBh}$.

Sharma, Aman. 20 16. "DeITY Becomes a New Ministry, Leg-Up for Ravi Shankar Prasad.” Economic Times, July I9. https://economictimes.indiatimes.com/news/ economy/policy/deity-becomes-a-new-ministry-leg-up-for-ravi-shankarprasad/articleshow/53285683.cms

Sharma, R. S. 201 5. "ICT-Enabling Empowerment of Citizens Crucial for Success of Digital India Programme.” Economic Times, July I. https://blogs.economictimes.indiatimes.com

Singh, Manish. 20 I 7. "Is India's Central Database with Biometric Details of Its Billion Citizens a Privacy Nightmare?” Mashable, February I 3. https://mashable. com

Taylor, Paul. 20 I 7. "Claiming India's Digital Dividend." SAP, March 25. https:// news.sap.com

Telecommunications Regulation Authority of India. 201 7. "Recommendations Related to Digital Terrestrial Broadcasting in India." January 3 I. http://www.trai. gov.in

“TRAI: DAS-BharatNet Digital India's “Aadhaar.” 20r6. Indiantelevision.com, December 20. http://www.indiantelevision.com

Videocond2h. 20I 7. "What Is Asli HD?" https://www.videocond2h.com/what-isasli-hd.php

"What Is India Stack?" 20I 7. IndiaStack. http://indiastack.org

"Work in Progress." 20I 7. Broadcast and CableSat. May. http://broadcastandcablesat.co.in/index.php

World Development Report. 2016. World Development Report 2016: Digital Dividend." World Bank. May i 7, 20г6. http://www.worldbank.org 


\title{
Imagining Cellular India
}

\author{
The Popular, the Infrastructural, and the National \\ Rahul Mukherjee
}

In August 1995, Jyoti Basu, then chief minister of West Bengal, called Union Telecom Minister Sukhram on a Nokia mobile phone, "ringing in" the cell phone revolution in India. From that one cell phone subscriber to I,035.I2 million subscribers at the end of September 2016, the Indian mobile phone market is the second largest in the world, surpassed only by China. ${ }^{1}$ With this exponential growth of mobile phones, the cellular infrastructure to support them (particularly cell towers) has had to also grow at breakneck pace. As of June 30, 2017 , Indus Towers, the biggest tower company operating in I 5 circles in India, manages I 22,920 towers with 297,867 tenancies. ${ }^{2}$ Drawing a fascinating infrastructural analogy, Robin Jeffrey and Assa Doron note that towers are to cell phones what gas stations are to automobiles. ${ }^{3}$ The work of scholars such as Nimmi Rangaswamy suggests that growth of cyber cafés has shown mixed results in different parts of India. ${ }^{4}$ However, mobile phones, being relatively more accessible, affordable, and easy to use than computers, promise the possibility of closing the digital divide through consumerist bottom-up interventions, even as questions regarding restricted computability remain. ${ }^{5}$ New additions to mobile media assemblages in the form of microSD cards and WhatsApp applications afford new possibilities for listening, watching, sharing, and communicating, but they are also disruptive, rerouting erstwhile circulations of CDs and DVDs. 
Communication studies scholars Anandam Kavoori and Kalyani Chaddha emphasize the need to study the cell phone as a cultural technology, exemplifying through their analysis of cell phone advertisements how a technology attains particular meanings within a cultural milieu. ${ }^{6}$ In this chapter, I take the cultural-ness of mobile phone technology seriously through analysis of ads, Bollywood films, and anthropological vignettes and interviews (with mobile media dealers, mobile phone repair workers, and mobile phone users). The cultural meanings of mobile technology are crucial to study. Anthropologist William Mazzarella has carried out such an exercise through an ethnography of Indian advertising workplaces. ${ }^{7}$ Nimmi Rangaswamy and Kabita Chakraborty have undertaken innovative fieldwork to examine local mobile phone cultures in urban slums in Hyderabad and Kolkata, respectively. ${ }^{8}$ While working through Indian cell phone cultures in this chapter, in addition to my own fieldwork in cities and small towns of India, I espouse a multiscalar and multimethod approach so as to connect interviews, texts, and practices to meanings, experiences, and imaginations.

It is important to understand how cellular infrastructures are very much a part of the everyday life of people, and hence a part of their culture. Culture, as defined by Raymond Williams (and Stuart Hall, among many other scholars of the Birmingham school), retains a sense of the everyday and ordinary: as Williams explains, "culture is ordinary" and is manifested in the values and meanings people give to objects and ways of living in their everyday life. ${ }^{9}$ A lot of Indian citizens' everyday practices-whether it is booking a cinema hall (or airline) ticket through apps/platforms or remaining connected with friends and relatives (through calls or WhatsApp messages)—happens through (and is shaped by) the mobile phone. As I will discuss, there are people who cannot stream music and hence develop a workaround by downloading songs on memory cards, and then inserting those cards into mobile phone slots so that they can access them. There is an entanglement, in each of the above-mentioned examples, of social practices and media practices, and cellular infrastructures are constitutive of these practices. The mobile phone is itself a technology/infrastructure that supports-that is, provides a foundation (operating system) forapplications like Skype and Uber to run, and slots for memory cards to function. The mobile phone exchanges signals (radio waves) with cell antennas (and cell towers) that form the extended cellular infrastructure. The strength of these signals determines whether cell phone calls will be completed or whether the amount of bandwidth required to stream a YouTube 
video on the phone will be available. If the cell antenna signal strength becomes too high, it could (potentially) cause cancer. Hence, whether it is about fulfilling a desire for the seamless streaming of YouTube videos (or an uninterrupted video chat) or concerns about the environmental/health impact of cell antenna signals, we can see that cell phone infrastructures become objects of cultural concern. Such cellular technologies become part of people's everyday lives. Indeed, infrastructures in this chapter, as Brian Larkin would say, should not be understood as exclusively conceptual (soft) or exclusively hard material/technical objects ${ }^{10}$; rather, infrastructures, as Abdoumaliq Simone has argued, can emerge in the "complex combinations" and conjunctions of "objects, spaces, persons and practices."11

Imagining cellular India is incomplete without an infrastructural imagination since imagining infrastructures is connected with imagining nations: the values of growth and development aspired by a nation's citizens seem emblematized in particular infrastructures. If in the newly postcolonial India of Jawaharlal Nehru, dams and nuclear reactors stood as modern temples of India, then today cell towers epitomize the new "pillars" of India's development. Cell towers embody the promises made in Prime Minister Narendra Modi’s "Digital India" campaign, which aims to equip I.2 billion citizens of India with a smartphone. The recent, much touted entry of Reliance Jio in India's telecom market wants to achieve precisely that target with its $4 \mathrm{G}$ LTE (fourth generation long-term evolution) cellular technology.

With an aggregation of applications and facilities (camera, audio player, credit card, notebook, design pad) available on the smartphone, "talk" is not the only thing people do with their mobile phones. The mobile phone is connected to various information platforms and infrastructural assemblages, and thus human bodies using such phones are conditioned by a range of human and nonhuman forces including algorithms, electromagnetic signals, and networked friendships. Therefore, it is important to explore, as Amit Rai has influentially argued, the phenomenological encounters of humans with mobile phone assemblages: "how mobile phones affect micro-transformations in perceptual capacities and self-expression." ${ }^{12} \mathrm{We}$ need to see developments in mobile phone technologies alongside developments in other media forms like television and radio. In the new networked/convergence media model, active audiences, as part of "mobile publics," ${ }^{13}$ react to live television chat shows and reality shows by tweeting comments in real-time or voting in/out participants.

The aim of this chapter is not to suggest that Indians have an absolutely 
unique way of engaging with mobile technologies. A hotel receptionist and a cab driver I conversed with in Tulum, Mexico were avid WhatsApp users, explaining to me that they prefer WhatsApp to phone texting because they have a lot to communicate, often all the time, and WhatsApp was a good over-the-top service since it did not consume a lot of Internet data. The reasons for favoring WhatsApp mentioned here are the same ones I heard from my interview participants in Delhi. The popularity of WhatsApp cannot be explained away by technological determinism or economic determinism. The "pointless chit-chat" and the trading of gossip that WhatsApp has unleashed has much to do with emerging socialities in India and Mexico, and that makes WhatsApp a potent application used by politicians to reach out to their publics. WhatsApp's affordances have made it central to India's fake news cycle and viral spreading of rumors that have even instigated communal riots. ${ }^{14}$

I begin with how mobile phone advertisements and Bollywood cinema have engaged with the cell phone. Both Bollywood films and cell phone ads, while often spectacular, are also critical sites to witness the ordinary lives of Indian citizens where the cell phone is a constant companion. Tracking the reconfigurations of cell phone advertisements and the use of cell phones in Bollywood films through the last 20 years is a way of understanding how cell phone use has changed, in what ways public perception about mobile phones has shifted, and how cellular network companies, ad copywriters, film directors, and screenwriters imagine their consumers and audiences as cell phone users. I argue that such an analysis offers a way to gauge the national-popular cellular imagination. Following this section, I examine the informal ways and workaround cultures (fugaad) of using cell phones practiced by socially and economically disadvantaged communities. These subaltern-popular practices help us understand how various communities with differential digital access find ways to express themselves and their aspirations through mobile phones. Finally, in the penultimate section on infrastructures, I reflect on recent controversies related to cell tower radiation and net neutrality in India.

\section{Mobile Phones and a New National-Popular}

The mobile phone's inclusion in Bollywood scripts has altered cinematic notions of space and time, and has particularly amplified representations of people's intimate encounters with terror and love in recent films. In Aamir (Raj Kumar 2008) and $A$ Wednesday (Neeraj Pandey 2008), cell phone calls 
become a way not only for protagonists and antagonists to stay in touch, but also to surveill and manipulate each other. While in Aamir the protagonist feels dragged more and more into the terror network with each new call from the kidnapper, in $A$ Wednesday it is the common man who uses the cell phone to make the purportedly inefficient state/police fight against terrorists. ${ }^{15}$ Shaunak Sen analyzes the film Good Night, Good Morning (Sudhish Kamath 20I2), where two strangers connect with each other via mobile phone while traveling in separate spaces, forming an intimate bond. ${ }^{16}$ Intimacy on the phone involves probing questions, lingering pauses, sweating and stammering, and, by extension, these momentary hesitations, anxieties, and pleasures are also part of today's WhatsApp conversations.

Sometimes, the cell phone might seek to reassign particular spaces to specific genders. Airtel's ad (released in 2015) featuring a youthful couple became controversial, stirring quite a buzz on television and social media for its portrayal of gendered subjectivities. The ad opens with two working professionals in a meeting at a swanky office. The female boss assigns work to her male colleague, and is shown to be sympathetic but firm in stating that the assignment needs to be completed. ${ }^{17}$ Soon after, we see the boss cooking in her home, and then video calling her male colleague, who we now know is her husband. Using Airtel's smartphone network, the bossnow-wife sends her husband videos of the food she has prepared and on a video-chat asks him to come home (see figure 3.I), saying "Boss ko bolo wife bula rahi hain"/"Tell the boss your wife is calling." The ad was alleged to have been progressive and regressive at the same time. On the one hand, it was breaking stereotypes by having a wife as her husband's boss and, on the other hand, reaffirming the stereotype of a wife cooking for her husband in the domestic space.

The Airtel ad also showcases new affordances of video calls available through upgrades to Airtel $3 \mathrm{G}$ and Airtel $2 \mathrm{G}$. The mobile phone screen's ability to vividly capture the sumptuous meal being cooked is shown in conjunction with the Airtel ${ }_{3} \mathrm{G}$ label, which is conspicuously prominent (see figure 3.I). Mobile phone companies and ad agencies claim that each new service offered or each new application supported by the mobile phone or the network provider is an "enhancement," or, still better, an "enrichment" to the lives of their consumers, and hence requires a new advertisement. For instance, if Idea Cellular offers ${ }_{3} \mathrm{G}$ services or Airtel supports Facebook for the first time, this enrichment needs a new ad. In 20 IO and $20 \mathrm{II}$, when these ads first appeared, the ad world was trying to crack the code for how to showcase mobile phones that had "data" and not just "voice." 


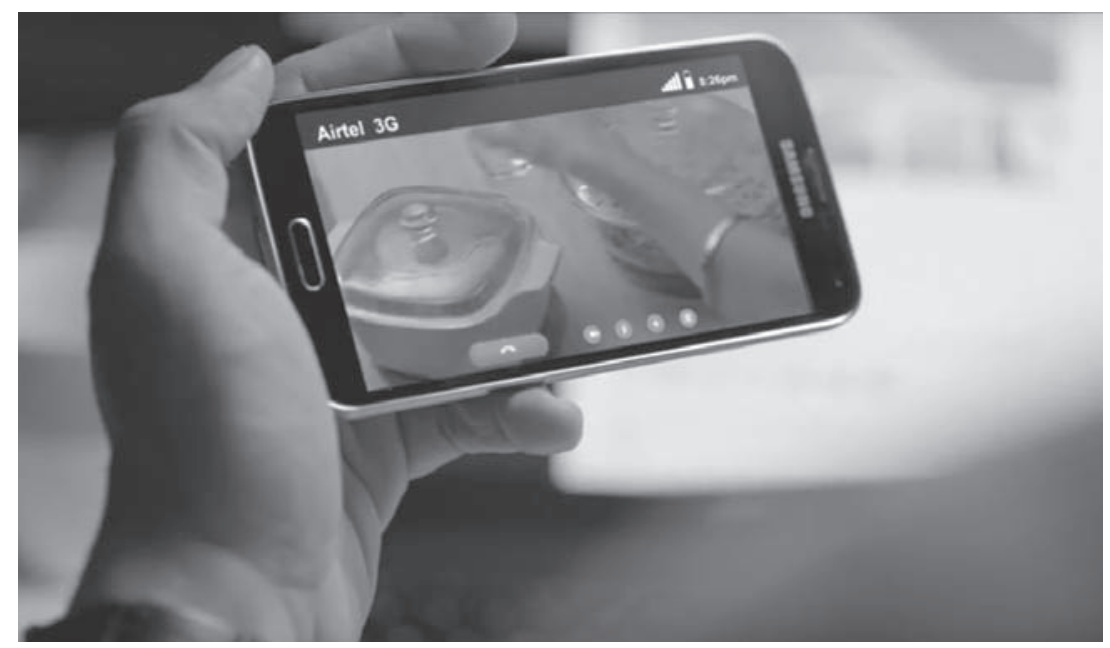

Figure 3.I. Boss (wife at home) calling husband at work. (Snapshot from Airtel Boss ad, 2015.)

Gendered subjectivities and values assigned to particular practices are not only a field of contention in urban environments but are also key in small towns and rural areas. The use of cell phones by women in lowincome households in small towns was considered transgressive, a challenge to traditional gender norms. While mobile phone ads celebrated the new liberated mobile wali (a woman in possession of a mobile phone), this mobile-fueled empowerment of women was also met with anxiety by the prevalent patriarchal system. Manoj Tiwari's "Mobile Wali" song (rendered in Bhojpuri with innuendos and suggestive lyrics) satirized the condition of men and women coping with the new norms of social relations brought on by the introduction of mobile phones. ${ }^{18}$ By 2010 , the mobile phone had become an object of desire and dismay, and its entanglement with discourses of sexuality seemed inevitable. The Lava brand of mobile phones marketed its Lava Io mobile handset with an ad campaign having the following tagline- "The Lava ro with the gun metal finish and masculine edges separates the men from the boys." ${ }^{19}$ The ad features a female supermarket cashier who, instead of offering teabags as a form of change (due to a shortage of coins), ends up offering condoms to a male customer who has just bought a new Lava io phone.

More broadly, advertising and marketing industry lore about Indians 
being known for their garrulity, argumentativeness, and make-do culture remains powerful. Not surprisingly, cell phone ads exploit these tendencies when they suggest a "chota recharge" (small recharge). In a Vodafone/ Hutch ad, Bollywood actor Irfan Khan posits a situation where all the talktime has been exhausted by the 2oth day of the month, and the monthly salary has also been expended by then. In such circumstances, he suggests it is best to go for a "chota recharge" of only 50 rupees..$^{20} \mathrm{In}$ another ad Khan conjures a scenario where it is imminent that a lover needs to patch things up with his girlfriend on the phone, but has no talk-time left. Hoping that a simple "I love you" will suffice he can opt for a Io rupee "chota recharge." Mobile phone conversations involve intimacies and expressions, but these intimacies and expressions have to be budgeted, rationed, and calculated. Capitalism modulates affections. ${ }^{21}$ Here, it needs to be noted that what Khan/Vodafone are prescribing in terms of budgeting time or what Lava phone (in the earlier example) is suggesting as connoting masculinity may not necessarily be the way Indians use and perceive their mobile phones. That said, in the ad's prescription/suggestion, there begins a process of attaching meanings and values on particular practices and perceptions.

The above-mentioned Vodafone ads emphasized economizing talk times and budgeting streaming videos, but this discourse was completely transformed by the arrival of Reliance Jio in December 2015. Jio promised free talk time and boundless data connectivity at affordable prices, thus unburdening its customers from worrying about talking or streaming too much. Jio's icon had many balloons and its ads depicted Jio customers flying in the air supported by colorful balloons while chatting or surfing the Net on smartphones and devices connoting the unburdened freedom they felt. ${ }^{22}$ Jio customers simply did not have to count how many times they were downloading or streaming a video, something that legendary Bollywood actor Amitabh Bachchan conveys in his inimitable baritone voiceover for a Jio ad: "Cricket, movies, downloads—bhala yeh bhi koi ginta hain?" ("Cricket, movies, downloads—-does anybody count these things?"). The ad ends by showing a woman with outstretched hands in a lush field with the sun's radiant light on her as Bachchan's voice offers the coda: "Ab Ginh ke nahi, khul ke jio" ("Now, do not count and live, just live openly"). ${ }^{23}$

India's conjugated narrative with the cell phone needs to be told keeping in mind the nation's cultural specificities, and yet it might be too much to say that such a narrative is "unique" to the nation. India's regional disparities, caste asymmetries, political carnivals, and gendered subjectivities provide opportunities to see varied perceptions, imaginations, and uses of cell phones. At times, mobile phones act as great equalizers, removing 
some of the above-mentioned disparities, but during other times they create new inequalities. Disparities within the population mean different audience segments have to be targeted. An Airtel executive once told me that when Airtel makes ads for rural consumers, they are more functional in nature, focusing on how the cell phone can help the villager's livelihood. In contrast, when Airtel targets its urban users, the ads are thematic. The Airtel "Tarraki" ads featuring Rajpal Yadav and Shreyas Talpade set in rural or suburban India indeed follow the trajectory of how their lives have changed after acquiring a cell phone: through the use of cell phones, these villagers, who make their living playing instruments at weddings, start contacting their clients directly (and thus cut their earlier reliance on middlemen), thereby taking control of their own business. ${ }^{24}$ Airtel's ads for urban youth, such as the very popular "Har Ek Dost Zaroori Hota Hain," take place in a college classroom and concern themselves with cell phones being used for building and maintaining expanded socialities. ${ }^{25}$ Along similar lines, the ad for Samsung's Guru brand of low-end mobile phones features Aamir Khan as a village youth who moves to the city, but is nonetheless able to maintain his village friendships through the Samsung phone. It is quite semiotically telling that Khan is shown getting down from an Uttar Pradesh State Transport bus, a key identification object for a lot of youths traveling from small towns to big cities in search of work. ${ }^{26}$ Samsung Omnia has the same Aamir Khan as the brand ambassador, but this time Khan plays somebody who glides through the endless apps and services that Omnia, a higher end mobile handset, provides. ${ }^{27}$

That livelihood is the chief reason for people in rural India to buy phones might be somewhat untenable. In 20 I I, I was discussing with an Indian Institute of Technology Bombay computer science professor about an agriculture-informatics application he had installed in the mobile phones of several farmers in several villages of Maharashtra. This app was supposed to help the farmers share seed and crop price updates. The professor clarified that farmers in rural Maharashtra do not spend their time on such apps, but use their phones mostly to listen to the weekly top I 5 Bollywood songs. Thus, the cell phone is not merely a functional tool for rural Indians, but is an object associated with pleasure and entertainment.

\section{Mobile phones and the Subaltern-Popular}

The nation could be a hegemonic construct (and hermeneutic) if seen as a reconciliation of heterogeneities. Thus, alongside the national-popular, I am interested in briefly sketching the ways mobile media assemblages 
operate in informal and piratical markets, and enable consumption and circulation of locally produced music videos (Bhojpuri, Mewati) and films in India's hinterlands.

In Mewat ("land of Meos"), a region southwest of Delhi, Maulavis (religious preachers) strictly object to the consumption of visual images, and yet supposedly notorious "Mewati Videos" with "lurid" lyrics are popular there. Such music videos circulate amid the community's tight censorship regime because producers deploy innovative publicity strategies. Mobile phone shop owners are key "mediators" in the music sharing network; the most prevalent way of circulating these videos within the villages is through microSD (micro Secure Digital memory) cards that are procured from phone vendors, which then make the videos compatible to be watched on mobile phones by performing the necessary format changes. The small and inconspicuous size of mobile phone screens and microSD cards (often carried in polythene covers kept in shirt pockets) ensure portability and aid youth in privately consuming (and circulating) such videos, thereby sidestepping the risks of getting caught by village elders and religious men. ${ }^{28}$ There is an entire informal economy of music video circulation that is enabled by microSD cards, Bluetooth, and mobile phones.

The memory card or the microSD card is a key flash memory technology that supports download cultures in India, particularly in places where the bandwidth required for Internet streaming is unavailable. Music enthusiasts go to download vendors who put songs and music videos onto these memory cards, which are then plugged into mobile phones or $\$ 3$ iPod knock-offs or audio players. These audio platforms themselves also generate affective associations with other popular consumer products: new Chinesemanufactured audio players (speakers) being sold in rural Gaya (in India where Bhojpuri music is popular) are made out of Gillette shaving cream or Coke bottle casings equipped to play music through USB and microSD cards (but not CDs or cassettes) (see figure 3.2). Some of these plastic cans also have images of Bollywood actors from a scene of their last films.

Operating between the stable and the ephemeral, between the celebrated and the censored, this subaltern-popular usage of mobile phones, which fashions vernacular lifeworlds in informal economies, remains understudied because of the selective conceptual frameworks of contemporary scholarship. Such mobile media practices then remain "infra" in the sense of infrastructures, that is, invisible and illegible. Digitization has led to the micromaterialization of music: the mp3 phenomena plays out in different ways in different parts of the world. While mapping digital music in the 


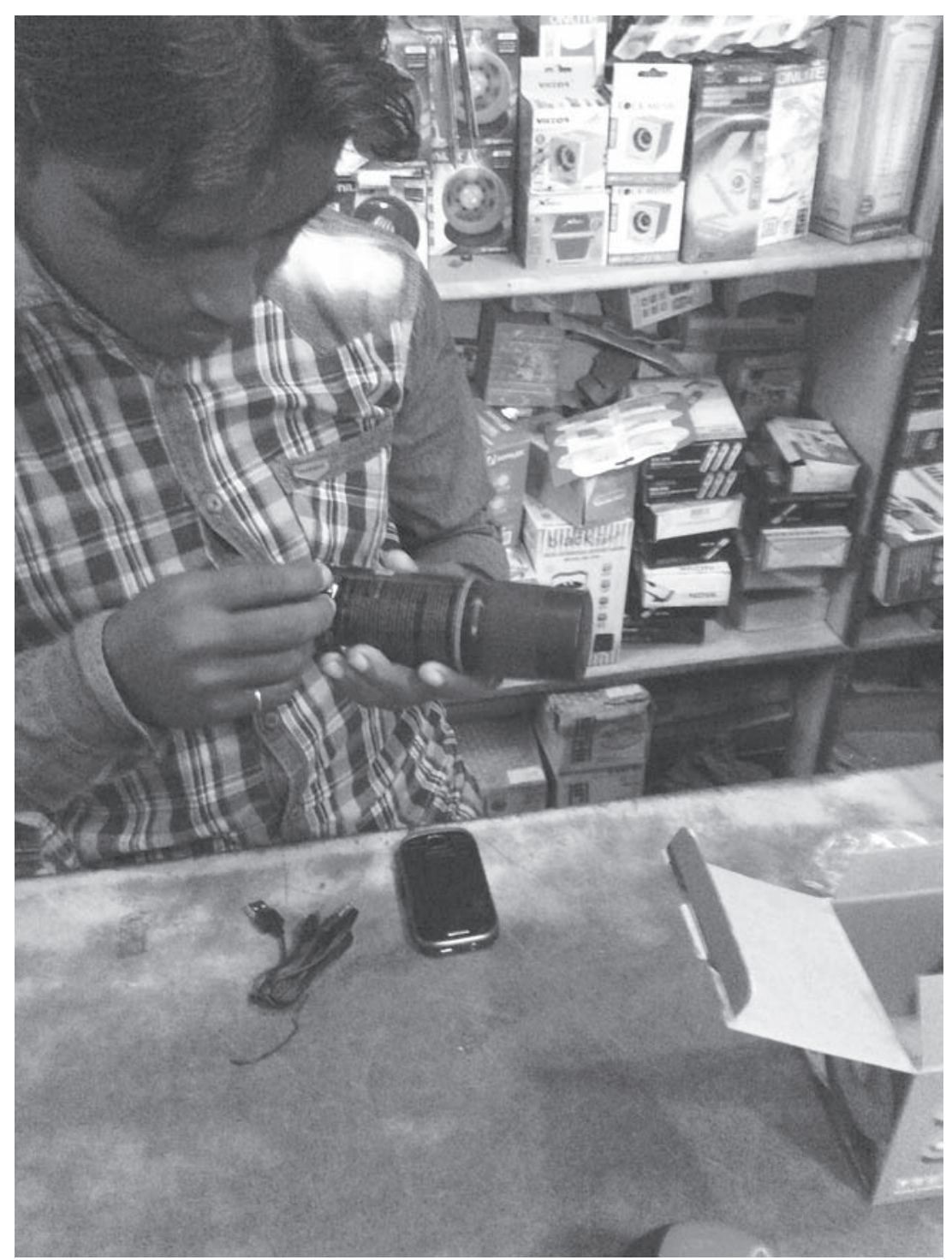

Figure 3.2. Memory card being put inside an Axe audio player in Gaya mobile phone shop 
United States makes us think of platforms like Tidal and Spotify (and then by extension cloud computing and server farms), the narrative of microSD cards in the rural hinterlands of India points toward a different trajectory of informal circulation. ${ }^{29}$ From 2010 to 2015 (before WhatsApp and then Jio connections) became popular, memory cards were being used extensively by migrant workers in informal settlements (slums) in urban and peri-urban areas. Mobile recharge shops for cheap feature phones were a place where these memory cards were sold and loaded with music, and Swati Janu has noted how such recharge shops (along with cyber cafés and underground gaming parlors) have acted as an "informal digital substructure" for settlement dwellers in cities like Delhi and Mumbai. ${ }^{30}$

Alongside memory cards, Bluetooth technology is an integral part of the Indian cellular imagination. Bluetooth is a key technology of audio and video transfer among villagers in rural India. The mobile phone not only enables conversations but also allows for listening to music, thus functioning as a radio. The process of sharing music across phones through Bluetooth is termed "Bultoo" by particular tribal communities. ${ }^{31}$ The number of radio programs in tribal languages is very limited. Many indigenous tribes living in dense forests in India have used the potential of Bluetooth to get their voices heard on radio programs made in their own languages of Kurukh (Oraon tribe) and Mundari (Munda tribe) among others. They record the music and news from their locality and transfer them through Bluetooth. This content then moves across several villages to finally reach a panchayat town where it can be uploaded to the Internet portal CGNet Swara for wider dissemination. Radio programs featuring music and news can be heard over mobile phones through Bluetooth sharing, a phenomenon labeled "bultoo radio." Mobile phone technologies have brought about an oral and vernacular resurgence in India, and in doing so have redefined media citizenship.

In a recent article, Jackie O'Neill and others argue that while, in 2009, microSD cards and Bluetooth were key file sharing technologies, by 2015 , with the easy availability of low-cost smartphones, WhatsApp has become the primary sharing app among even lower middle-class population groups in Indian urban centers such as Bangalore. ${ }^{32}$ Much of my study on memory cards in Mewat was done in 2013 and things are changing there as well, with many of my interview participants chatting with me on WhatsApp nowadays. That said, during my January 2016 fieldwork in the peri-urban regions of Gaya, I still observed wide use of memory cards on feature phones for music sharing/listening among working-class populations. The 
entry of Jio has more recently further led to decreased use of memory cards because streaming has become both more available and more affordable.

\section{Cellular and mobile infrastructures}

Cell phones require two key infrastructures to operate: the wireless spectrum and cell towers. The scarcity of spectrum as a resource has often led to desperate battles between competing cellular operators, sometimes exposing the connivance of governmental officials who are supposed to be acting as regulators (of the telecom sector) but have thoroughly compromised their positions by favoring one telecom service provider over another. In 2008 , the former telecom minister A. Raja was found to be involved in illegally undercharging cellular companies during the distribution of spectrum licenses. This became the infamous $2 \mathrm{G}$ scandal, which led to a severe loss of credibility for Raja's party (DMK, or the Dravida Munnetra Kazhagam) and the Congress-led United Progressive Alliance government. ${ }^{33}$ On December 22, 20I 7, a special court judge acquitted A. Raja who, along with the Congress Party, then said that they were clean all along and that the $2 \mathrm{G}$ scandal was all about perception of corruption and not actual corruption. ${ }^{34}$ The public interest in the $2 \mathrm{G}$ spectrum allocation scandal was not only because of the huge sums of money involved but also because corruption in the rapidly growing telecom sector is viewed as a retrenchment of the government's commitment to technological development.

More recently, with the entry of Reliance Jio, the spectrum wars are heating up again. In 2016 , Jio acquired spectrum in the $800 \mathrm{MHz}$, I $800 \mathrm{MHz}$, and $2300 \mathrm{MHz}$ bands. This led Jio's competitor and India's largest telecom provider, Bharti Airtel, to acquire the Norwegian telecom firm Telenor's India operations so as to use the company's $43.4 \mathrm{MHz}$ spectrum in the $1800 \mathrm{MHz}$ band. Such spectrum consolidation is crucial for Airtel to expand its customer base and match Jio's network capacity in delivering $4 \mathrm{G}$ data services. In order to withstand competition from Jio and Airtel, two other cellular operators, Idea and Vodafone, also decided to merge to increase their net spectrum footprint. ${ }^{35}$ Thus, spectrum as a key resource and infrastructure is very much a part of the Indian cellular imagination.

Cell towers are ubiquitous in the Indian skyscape but they were also inconspicuous for a long time until their disruptive effects came to the forefront. Cell towers acquired visibility in 2010 when the signals emitted by them were considered potentially carcinogenic. This, however, is only one kind of image/imagination of cell towers. After dams and nuclear reac- 
tors, cellular infrastructures, which enable omniscience and connectivity, are touted as the new temples (and cathedrals) of (modern) India.

Since 2010 , there was growing uncertainty within the expert community including radio-frequency scientists and oncologists about how to measure radiation from cell antennas, how to affix threshold levels, and how to ascertain their effects on different human bodies, including those of women, children, the young, and the elderly. ${ }^{36}$ Regulations set by the Indian Department of Telecommunication and municipal corporations were openly being flouted by tower companies and commercial establishments that offered their rooftops to cellular operators to set up towers. Gaurav Bhatia lives in Clover Apartments in Cuffe Parade area in Mumbai. He fears for the health of his preteen boy and girl because of 29 cell antennas that are located on the rooftop of the Hotel Supreme, a commercial lodge next to his residential apartment. This particular picture (see figure 3.3) taken from Bhatia's balcony of the Hotel Supreme terrace should give some sense of just how blatantly laws regarding cell antenna siting have been flouted.

During the cell tower radiation controversy, people felt helpless and frustrated because they were unable to evict proximate towers. After a while, cancer was not the only potential problem from cell antenna signals. Urban residents living close to towers complained of severe headaches, hair loss, nausea, and sleeplessness, thereby demonstrating a heightened sensitivity to electromagnetic fields, often referred to as "electrosensitivity." Beyond the embodied experiences of using mobile phones, we also need to understand the affective encounters between human bodies and infrastructures (which support mobile phones) that arise because of interactions and interferences between antenna signals (electromagnetic fields) and neural impulses in the body. ${ }^{37}$

Bollywood celebrities like Juhi Chawla and Farhan Akhtar supported concerned citizens (who often were elite urban middle-class people) in campaigning for stricter regulation of cell antennas. This campaign reached its peak in August 2012. Cellular operators complained that the cell tower radiation scare had impeded the growth of cell towers. While mobile towers may not be environmentally sustainable, they help to sustain calls. Beginning in 2015 , mobile phone users who subscribed to a number of different telecom companies had to face incomplete conversations. Other problems related to connectivity, weak mobile signal, patchy mobile Internet data services, and busy networks were also reported..$^{38}$ When asked for an explanation, cellular companies pointed to insufficient spectrum and mobile towers 




Figure 3.3. Cell antenna cluster atop Hotel Supreme (Cuffe Parade, Mumbai)

as the causes. Both these causes are infrastructural and are very much a part of the cellular imagination. Should we still imagine cell towers to be the new temples of neoliberal 2 Ist century India or should we consider them potential radiation machines? Are we fine with tolerating cell towers just because they help us to have smooth mobile phone connectivity?

The same argument about (enhancement of) infrastructures is given by telecom companies when they argue against net neutrality. Suggesting that the Internet cannot be a public commons, when multiple infrastructures, whether they be spectrum or cables or cell towers, are dependent on private investment, the telecom companies (telcos) in India have wanted to create high-bandwidth (hi-speed) lanes for services and sites that pay them more. Advocates of net neutrality have argued that this would lead to prioritizing the already powerful companies and their services, thus compromising the fundamental democratic nature of Internet communication.

In developing nations like India (and countries such as Indonesia, Philippines, Zambia), the net neutrality debate takes another turn. Specific telecom providers (like Airtel) can work with particular companies (such as Flipkart) to provide their (Flipkart's) services a zero-rating (for a fees that Flipkart has paid to Airtel) so that a user of that particular telecom provid- 
er's (Airtel's) connection will not have to buy an additional consumer data pack for that service. For many other services, the consumer of Airtel's connection will have to buy extra data packs. ${ }^{39}$ This is something that the comic collective All India Bakchod (AIB) mentioned in their popular video while campaigning for protecting net neutrality in India. They name-dropped Flipkart in their video and also gestured toward the famous Airtel ad "Har Ek Dost Zaroori Hota Hain/Every Friend Is Necessary," even implying at one point that not all friends are really necessary, and that our telecom operator might not be our friend after all. ${ }^{40} \mathrm{AIB}$ often makes irreverent satire on the political culture of India. That AIB decided to make a video upholding net neutrality suggests that telecom policies are culturally resonant, for such policies in the process of being enacted might have ramifications for prevalent values and practices. AIB, which depends on social media for the promotion and circulation of its videos, suggested that telcos might decide to slow down the loading of AIB videos if net neutrality were eschewed. In urban India, where the start-up culture is gaining momentum, attacks on net neutrality by telecom operators were seen as a threat to newly starting small businesses that could not afford to pay fees to telcos that Facebook and WhatsApp can in exchange for preferential treatment.

\section{Conclusion}

A chapter that explores the Indian cellular imagination must acknowledge the limits of any mapping exercise given the sheer scale, linguistic and regional diversity, and so on. I have flitted from one ad to another event, one app to still another practice in order to understand the dynamism of the Indian mobile media ecology, which has been shaped by historical forces, market competition, technological developments, and cultural messiness. My goal here has been to show how mobile mediation envelops the deeply divided social fabric of India. Mobile mediation has an infrastructural aspect that cannot be ignored as posh residents of Carmichael Road in Mumbai, for instance, discovered when cases of cancer in their neighborhood were attributed to proximate cell towers. Cell towers were viewed as encroachments and yet could not be done away with because people were so used to the convenience of using the always-connected cell phone.

The Indian cellular imagination is partly created by Bollywood and advertisements as they package and market affective desires, intimacies, and vulnerabilities about the mobile phone. However, the national-popular dimensions of Bollywood can be hegemonic and commercial advertisement 
might be presenting controlled contingencies (and not situated precarities), and therefore one has to understand the subaltern practices (workaround cultures) of working with cell phones under limited electricity, bandwidth, talk-time, and so on. Imaginations are after all enacted in lived practices.

Modi's vision of "Digital India" is predicated on a series of apps/platforms such as PayGov and BHIM (Bharat Interface for Money) that ensure demonetization, e-government, online delivery of banking documents, and net banking. Various e-government initiatives that once started with computer kiosks have now become Web 2.0 apps/e-portals like BHIM. With a majority of Indian citizens accessing Internet (only) through their mobile phones, the smartphone is a crucial device to make it possible for ordinary citizens to utilize these services. In such a governmental vision of India, the mobile phone, simply put, is the most crucial tool of governmentality.

Beyond governmentality, "Digital India" is also about the politics of aspiration, and the mobile phone has furthered this production of aspiration, bringing rural Indians in virtual (yet intimate) contact with urban middle-class lifestyles. Due to the mobile media devices they own and operate, even people within low-income groups now are aware of the large variety of consumer choices available if only one had money. Whether it is a network service like Jio or an application like WhatsApp, the additions to mobile media are continuing to breach limits of streaming and communication, and perhaps even more significantly, the capacity to aspire and desire. In contributing to the narrative of aspirational India, mobile media are not just helping Indians imagine an optimistic future, but also furthering anxieties about new vulnerabilities such as hate-filled rumors about (vulnerable) minority communities smuggling cattle or kidnapping children. Even Jio streaming services sometimes do not work due to absence of proximate cell towers and spectrum distribution issues. Furthermore, WhatsApp is unable to find ways of regulating circulation of rumors through its own platform. Infrastructural limits thus have a way of puncturing myths of freedom and aspirational mobilities. In this unpredictable India of aspirational mobilities, young Indians spend their entire day on smartphones, partly because they do not have a stable job, and perhaps also because their temporary job entails forwarding thousands of WhatsApp messages to hundreds of WhatsApp groups for political mobilization.

While conceptualizing the mobile phone (or still better, mobile media) as part of, and embedded in, Indian cultures, this chapter has demonstrated how lived experiences of social space and time have changed with mobile technologies. These shifting considerations of social space-times 
have a bearing on concerns of privacy, decency, gender-religion-and-caste dynamics, public-private boundaries, and perhaps most importantly, on the social fabric of the country.

\section{Notes}

I. NDTV report, "India's Mobile User Base Touches I03.5 crore: Telecom Regulator," September 9, 20 I6: http://www.ndtv.com (accessed August 30, 20 I 7 ).

2. More information can be found in Indus Towers page: http://www.industowers.com (accessed July I, 20 I 5).

3. Robin Jeffrey and Assa Doron, Cell Phone Nation: How Mobile Phones Have Revolutionized Business, Politics, and Ordinary Life in India (Gurgaon: Hachette Book Publishing India, 2013).

4. Nimmi Rangaswamy, "Disruptive IT in South India," in Sarai Reader 3: Shaping Technologies, ed. Ravi Vasudevan, Ravi Sundaram, Jeebesh Bagchi, Monica Narula, and Shuddhabrata Sengupta (Delhi: Centre for the Study of Developing Societies; Amsterdam: Waag Society for Old and New Media, 2003), I 70-76.

5. Rich Ling and Heather Horst, "Mobile Communication in the Global South," New Media \& Society I 3 (3) (201 I): 363-74.

6. Anandam Kavoori and Kalyani Chadha, "The Cellphone as a Cultural Technology: Lessons from the Indian Case," in The Cell Phone Reader: Essays in Social Transformation, ed. Anandam Kavoori and Noah Arceneaux (New York: Peter Lang, 2008).

7. William Mazzarella, Shoveling Smoke: Advertising and Globalization in Contemporary India (Durham, NC: Duke University Press, 2003).

8. Kabita Chakraborty, "Young People's Mobile Phone Cultures in the Urban Slums of Kolkata," in Youth, Media, and Gender in Post-Liberalization India, ed. Nadja-Christina Schneider and Fritzi-Marie Titzmann, (Berlin: Frank \& Timme, 20I 5), I9I-2 I4. Also see Nimmi Rangaswamy and S. Yamsani, "Mental Kartha Hai or It's Blowing My Mind: Evolution of the Mobile Internet in an Indian Slum," paper presented at the "EPIC, Ethnographic Practice in Industry" Conference Boulder, CO, September I 8-2 I, 20 I I.

9. Raymond Williams, "Analysis of Culture," in Cultural Theory and Popular Culture: A Reader, ed. John Storey (Athens: University of Georgia Press, I998), 4856.

Io. Brian Larkin, Signal and Noise: Infrastructure and Urban Culture in Nigeria (Durham, NC: Duke University Press, 2008).

I r. AbdouMaliq Simone, "People as Infrastructure: Intersecting Fragments in Johannesburg," Public Culture I6 (3): 407-29, at 408.

I2. Amit Rai, "On the Fugaad Image: Embodying the Mobile Phone in India," Postmodern Culture 23 ( I) (2012).

I3. Aswin Punathambekar, "Reality Television and the Making of Mobile Publics: The Case of Indian Idol," in Real Worlds: Global Perspectives on the Politics of Reality Television, ed. Marwan Kraidy and Katherine Senders (New York: Routledge, 2OII), I4O-53. 
I4. Sahana Udupa, "Viral Video: Mobile Media, Riot, and Religious Politics," in Media as Politics in South Asia, edited by Sahana Udupa and Stephen McDowell (London: Routledge, 201 7 ).

I 5. Shaunak Sen, "It's Ringing Again': Cellular Ambiguities in Hindi Cinema," Bioscope 4 (2) (2013): I 59-8I.

I6. Ibid.

I 7. Airtel "Boss: Smart Phone Network" ad: https://www.youtube.com (accessed September 2, 2015).

I8. See Robin Jeffrey and Assa Doron, Cell Phone Nation: How Mobile Phones Have Revolutionized Business, Politics, and Ordinary Life in India (Gurgaon: Hachette Book Publishing India, 2013), I 86-89..

I9. Lava ad: http://www.bing.com (accessed September 4, 2015).

20. Vodafone ad: https://www.youtube.com (accessed July 4, 2016).

2I. Another Vodafone ad: https://www.youtube.com (accessed July 4, 2016).

22. Reliance Jio TV ad: https://www.youtube.com (accessed August 30, 2017)

23. Another Reliance Jio ad with Bachchan's voice-over: https://www.youtube. com (accessed August 30, 201 7 ).

24. Airtel "Tarraki" ad: https://www.youtube.com (accessed September 2, 201 5).

25. Airtel "Har Ek Friend Zaroori Hota Hain" ad: https://www.youtube.com (accessed September 2, 2015).

26. Samsung "Guru" ad: https://www.youtube.com (accessed September 2, $2015)$.

27. Samsung "Omnia” ad: https://www.youtube.com (accessed September 2, 2015).

28. For more, see Rahul Mukherjee and Abhigyan Singh, "MicroSD-ing 'Mewati Videos': Circulation and Regulation of a Subaltern-Popular Media Culture," in Asian Video Cultures: In the Penumbral of the Global, ed. Joshua Neves and Bhaskar Sarkar (Durham, NC: Duke University Press, 20I7).

29. Rahul Mukherjee and Abhigyan Singh, "Reconfiguring Mobile Media Assemblages: Download Cultures and Translocal Flows of Affective Platforms," Asiascape: Digital Asia 4 (3): 257-84. The use of memory cards and download cultures that I have discussed are not just happening in rural India; they can be also observed in places like contemporary Cuba where people have their memory sticks every week filled with the latest Internet "packages" (paquetes) containing films, American television series, software, and even ads for local Havana hotels/restaurants. See Anna Pertierra's important fieldwork-based paper, "If They Show Prison Break in the United States on a Wednesday, by Thursday It Is Here: Mobile Media Networks in Twenty-First-Century Cuba," Television \& New Media I3 (5) (2012): 399-4I4.

30. Swati Janu, "On-the-Go Settlements: Understanding Urban Informality through its Digital Substructure," Urbanisation 2 (2) (20 I 7): I I 6-34.

3 I. Shubranshu Chaudhury, "Tech Tonic for the Heart of India," Hindu, January I 5, 2016: http://www.thehindu.com/opinion/op-ed/tech-tonic-for-the-heart-ofindia/article8108144.ece (accessed September 2, 20 I 5).

32. Jackie O’Neill, Kentaro Toyama, Jay Chen, Berthel Tate, and Aysha Siddique, "The Increasing Sophistication of Mobile Media Sharing in Lower-Middle- 
Class Bangalore," ICT4D 2016 Proceedings of the Eighth International Conference on Information and Communication Technologies and Development (New York: ACM), 2016.

33. For an extended discussion of the $2 \mathrm{G}$ scandal, refer to Jeffrey and Doron, Cell Phone Nation.

34. "Scam, or Folklore? In 2 G Case Verdict," Hindu, December 2 2, 20 I 7. http:// www.thehindu.com/opinion/editorial/scam-or-folklore/article22178907.ece

35. "Bharti Airtel Receives CCI Nod for Merger with Telenor India" Economic Times, June 7, 2017, http://economictimes.indiatimes.com/news/company/corporate-trends/bharti-airtel-receives-cci-nod-for-merger-with-telenor-india/articleshow/59013800.cms (accessed August 30, 201 7).

36. The Indian government wanted to demonstrate that it was politically responsive toward public anxiety, and therefore the Indian Department of Telecommunications reduced the EMF emission levels to I/ I oth of the prevailing ICNIRP norms $\left(.45 \mathrm{~W} / \mathrm{m}^{2}\right)$. However, dissident scientists contested that such blanket standardization, highlighting cancer cases close to towers where the recorded powerdensity of electromagnetic radiation was found to be as low as .oor W/sqm. See the Department of Telecommunications advertisement/circular here: http://www.dot. gov.in

37. For more about electromagnetic fields and electrosensitivity, see Rahul Mukherjee, "Wireless Saturation," in Saturation: An Elemental Politics, ed. Melody Jue and Rafico Ruiz, Duke University Press (forthcoming).

38. Prasanto K. Roy, “Why India's Mobile Network Is Broken," BBC News, December 3, 20I4, http://www.bbc.com (accessed July 9, 201 5).

39. Guardian article on net neutrality in India: http://www.theguardian.com (accessed September 4, 201 5).

40. AIB video upholding net neutrality: https://www.youtube.com (accessed September 4, 2015).

\section{References}

Chakraborty, Kabita. 201 5. "Young People's Mobile Phone Cultures in the Urban Slums of Kolkata." In Youth, Media, and Gender in Post-Liberalization India, edited by Nadja-Christina Schneider and Fritzi-Marie Titzmann, I9I-2 I4. Berlin: Frank \& Timme.

Janu, Swati. 2017. "On-the-Go Settlements: Understanding Urban Informality through Its Digital Substructure." Urbanisation 2 (2): I I 6-34.

Kavoori, Anandam, and Kalyani Chadha. 2008. "The Cellphone as a Cultural Technology: Lessons from the Indian Case.” In The Cell Phone Reader: Essays in Social Transformation, edited by Anandam Kavoori and Noah Arceneaux. New York: Peter Lang.

Larkin, Brian. 2008. Signal and Noise: Infrastructure and Urban Culture in Nigeria. Durham, NC: Duke University Press.

Ling, Rich, and Heather Horst. 20ı I. "Mobile Communication in the Global South." New Media \& Society I3 (3): 363-74. 
Mazzarella, William. 2003. Shoveling Smoke: Advertising and Globalization in Contemporary India. Durham, NC: Duke University Press.

Mukherjee, Rahul. Forthcoming. "Wireless Saturation.” In Saturation: An Elemental Politics, ed. Melody Jue and Rafico Ruiz. Durham: Duke University Press.

Mukherjee, Rahul, and Abhigyan Singh. 20r7. "MicroSD-ing 'Mewati Videos': Circulation and Regulation of a Subaltern-Popular Media Culture." In Asian Video Cultures: In the Penumbral of the Global, edited by Joshua Neves and Bhaskar Sarkar. Durham, NC: Duke University Press.

Mukherjee, Rahul, and Abhigyan Singh. 201 7. "Reconfiguring Mobile Media Assemblages: Download Cultures and Translocal Flows of Affective Platforms." Asiascape: Digital Asia 4 (3): 257-84.

O’Neill, Jackie, Kentaro Toyama, Jay Chen, Berthel Tate, and Aysha Siddique. 20 I6. "The Increasing Sophistication of Mobile Media Sharing in Lower-MiddleClass Bangalore." ICT4D 20I6. Proceedings of the Eighth International Conference on Information and Communication Technologies and Development, New York, ACM.

Pertierra, Anna. 2012. "If They Show Prison Break in the United States on a Wednesday, by Thursday It Is Here: Mobile Media Networks in Twenty-FirstCentury Cuba." Television \& New Media I 3 (5): 399-4I4.

Punathambekar, Aswin. 20 I r. "Reality Television and the Making of Mobile Publics: The Case of Indian Idol." In Real Worlds: Global Perspectives on the Politics of Reality Television, edited by Marwan Kraidy and Katherine Senders, I40-53. New York: Routledge.

Rai, Amit. 201 2. "On the Fugaad Image: Embodying the Mobile Phone in India." Postmodern Culture 23 (I): https://muse.jhu.edu

Rangaswamy, Nimmi. 2003. "Disruptive IT in South India." In Sarai Reader 3: Shaping Technologies, edited by Ravi Vasudevan, Ravi Sundaram, Jeebesh Bagchi, Monica Narula and Shuddhabrata Sengupta, I 70-76. Delhi: Centre for the Study of Developing Societies; Amsterdam: Waag Society/for Old and New Media.

Rangaswamy, Nimmi, and S. Yamsani. 20 r . "Mental Kartha Hai or It's Blowing My Mind: Evolution of the Mobile Internet in an Indian Slum." Paper presented at the "EPIC, Ethnographic Praxis in Industry" Conference, Boulder, $\mathrm{CO}$, September I 8-2 I.

Sen, Shaunak. 20 I 3. "It's Ringing Again': Cellular Ambiguities in Hindi Cinema." Bioscope 4 (2): I 59-8I.

Simone, AbdouMaliq. "People as Infrastructure: Intersecting Fragments in Johannesburg." Public Culture I6 (3): 407-29.

Udupa, Sahana. 20 1 7. "Viral Video: Mobile Media, Riot, and Religious Politics." In Media as Politics in South Asia, edited by Sahana Udupa and Stephen McDowell. London: Routledge.

Williams, Raymond. I988. "Analysis of Culture," In Cultural Theory and Popular Culture: A Reader, edited by John Storey, 48-56. Athens: University of Georgia Press. 


\title{
Bridging the Deepest Digital Divides
}

\author{
A History and Survey of Digital Media in Myanmar
}

\section{Daniel Arnaudo}

The digital divide between those inside this online world and those outside is deep and profound. Entering and mastering this space is a steep climb. One of the deepest divides, followed by one of the most rapid ascents, can be found in Myanmar. This is true principally because the country is undergoing a political transition that is just as sudden. After decades forming part of the British Empire, an authoritarian regime led by the military controlled the state in various forms from the I96os until 2010, when the government initiated reforms and allowed more free elections. These reforms included opening up the Internet, removing censorship controls, restricting surveillance, allowing the sale of computers, modems, and cell phones, and granting citizens access to the global network.

An examination of the history of the country, formerly known as Burma, shows how media has played a key role in defining its political system. This began with a colonial press when Burma was part of the British Empire and India, continued with a briefly democratic media after independence, followed by increasing consolidation and government control under the military dictatorship. At the same time, an international network of exiles shaped global opinion about the country and linked it to the newly commercialized Internet. This network played a role in encouraging democratic reforms, starting with changes in policies by the dictatorship in $20 \mathrm{IO}$, followed by local elections, the freeing of political prisoners, and culmi- 
nating in the election of the opposition National League for Democracy (NLD) party to a large majority in parliament in 2015 and control of the presidency and legislature in 2016.

In the past five years, the Internet has become available to anyone in Myanmar with a cell phone. As late as 20 I I less than I percent of the population had used the Internet, making it one of the least virtually accessible points on earth, after North Korea, East Timor, and Eritrea. ${ }^{1}$ Simultaneously, a media system that had been completely controlled by the military became relatively independent. This combination of factors has created a relatively unique situation of a country moving from a completely closed authoritarian system to an open, democratic one while adopting a modern, largely mobile Internet.

The development of the Internet in Myanmar, with its rapidly transitioning democratic political system, has created a networked public sphere ${ }^{2}$ that has been shaped by the dictatorship but is no longer completely beholden to it. Foreign companies have been invited to invest in the country, and the nature of a borderless network has given multinationals an entry into a newly digitized population without any invitation by a state that once sought omnipotence and omnipresence. This chapter will examine this media history intertwined with the development of Myanmar's Internet, the transition toward democracy, and how the country's digital media has come to reflect the fractured, recovering polity and rapidly developing society that Myanmar has become.

\section{Burma's Painful Birth and Unresolved Ethnic Conflicts}

Myanmar is undergoing a revolution in media across platforms with a population that has very little experience with any form of a free press, either print or digital. However, the country is also in the midst of an ongoing transition to democracy as this media landscape shifts rapidly. Since World War II and independence, what was then Burma struggled with the formation of a national identity. Burmese are the dominant ethnic group, making up roughly 68 percent of the population, but a number of other groups including Shan, Kachin, and Chin make up a significant proportions of the national census, ${ }^{3}$ and declared war after their claims to power were ignored. The Pangalong Agreement signed in 1947 formed the Union of Burma in 1948 through independence from Great Britain, and guaranteed various rights to autonomy for other ethnic peoples, particularly the Chin, Kachin, and Shan, who were signatories. ${ }^{4}$ However, negotiations to 
construct the shape of the Union collapsed after the assassination of Aung San, the principal leader of Burma's independence and the nascent government's signatory of the Agreement. The lack of any accord to formally organize the country in a federal political system respecting ethnic autonomy over local affairs crippled the Union of Burma and led to growing insurgencies. With the fall of the Union to a group of senior military officers led by Army Chief of Staff General Ne Win, these conflicts deepened as the new leadership eliminated opposition and promoted a "Burmese path to socialism." Following years of varying forms of dictatorship from I96 I until 20 Io, these conflicts continued and created independent zones where rebel groups controlled territory, sometimes with the support of China, with which Myanmar shares a border, along with Thailand, Laos, Bangladesh, and India.

These conflicts remain a central issue for the new democratically elected government of Aung Sung Su Kyi (daughter of Aung San) and her National League for Democracy party, which continues to primarily represent Burmese. Ethnic groups outside of the central, developed areas and on the fringes of political movements continue to struggle for access to power and economic resources in this context.

\section{Burmese Media under the Dictatorship}

By the time the Internet became commercialized and entered into common global usage in the I99os, Myanmar's media and information landscape had been locked tight 8 in an authoritarian political system for decades. After a brief flowering in the interwar years under the British, independent Burmese media had diminished by the Second World War and the growing conflicts throughout the country in the turbulent period that created the independent Union of Burma. ${ }^{5}$ The same gunmen who assassinated Aung San and ended hopes for a federal state also killed many in his government simultaneously, including the first minister of information and the publisher of the influential journal Deedok, Ba Cho. Others were targeted in the aftermath including U Saw, the editor and founder of the influential Thuriya newspaper, who was arrested for his role in the murder of U Saw and hung by the British in I948. ${ }^{6}$ By the time an independent Burmese state formed, the press had been sufficiently cowed by threats of assassination, exile, or economic hardship to self-censor or go out of business.

The military dictatorship tightened its grip on power from the formation of a Union Revolutionary Council in 1962 until it banned all politi- 
cal parties other than the military's Burmese Socialist Programme Party in I964. Afterwards, the government increasingly consolidated the media and instituted new laws restricting the remaining independent press. Particularly through the Law for the Registration of Printers and Publishers of 1962 , the government moved to tighten dissent within the media and opposition parties. This included restrictions on what the press could say, political objectives and party platforms, and a requirement that censors vet all publications before approval. ${ }^{7}$ This law would be cited repeatedly by successive military governments in justifying crackdowns on dissidents, media, and nascent opposition parties. A Press Scrutiny Board censored content and kept track of all that was written or broadcast.

The regime slowly nationalized or closed the remaining independent newspapers, and by the end of the I96os only six government-run publications remained. The import of foreign papers were also heavily restricted, and local bureaus of international organizations such as Reuters were forced to use correspondents that had been approved by the government, creating unique hybrid bureaus controlled by foreign groups but reporting the dictatorship's perspective. ${ }^{8}$ Myanmar's radio became completely government operated in this period, television did not come to the country until very late, June 3, I980, and only in Rangoon until a few years later. ${ }^{9}$ In 1985 , the Ministry of Communications, Posts, and Telegraphs enacted a special Television and Video Law, later updated in 1996 . The law required a government license for anyone to acquire television or video equipment such as a satellite dish or broadcasting equipment, effectively placing any video technology under government control, and limiting the means of citizens for receiving foreign broadcasts. ${ }^{10}$

Myanmar's people could receive foreign radio broadcasts such as the BBC and Voice of America, or the Democratic Voice of Burma, operating a long-range signal out of Norway. ${ }^{11}$ The BBC's Burmese service in particular became one of the most popular regional languages, but the government also became very effective at jamming these foreign signals. In general, the media environment had entered completely under the control of the military.

Local radio systems operated sporadically in rebel areas, in particular the People's Voice of Burma, controlled by the Chinese-sponsored Communist Party of Burma, which operated from the late '6os in China and in the Wa hills in the northeastern part of the country. Local peoples did operate independent samizdat operations within these ethnic areas, particularly the "Karens, Shans, Kachins, Palaungs, Pa-Os, Karennis and 
Rohingya Muslims from Arakan State" but these did not circulate widely because of the heavy government control and the limited reach of these groups. ${ }^{12}$

In this heavily restricted and almost completely closed environment, cracks began to appear in the late I980s, as the economy entered into crisis and people pressed for a change in government. Stressed by growing changes, the government moved to stop the riots and protests, particularly those organized around universities, which came to a head in the "8888 Revolution" starting around the August 8, I988. The government repressed the protests by declaring martial law and firing into crowds, murdering and imprisoning thousands in the process. ${ }^{13}$

After suspending the constitution, they instituted the State Law and Order Restoration Council (SLORC), headed by the military chief, Saw Maung. SLORC said it had been called to maintain law and order, improve transportation as well as the humanitarian situation, and hold elections. ${ }^{14}$ In I989, SLORC renamed the country Myanmar, partly to recognize the different ethnic groups in the country apart from the ethnic Burmans and to undo the colonial legacy, among other factors. ${ }^{15}$

In the aftermath of this uprising, various members of the opposition formed a new party, the National League for Democracy, to contest national elections in 1990, which SLORC declared would be open and fair. Suu Kyi took on the leadership of the party. After winning 392 seats in the National Assembly and nearly 59 percent of the popular vote, it appeared the NLD would take power, but the SLORC annulled the results, refused to allow the legislature to convene, and cracked down on opposition anew. It placed Suu Kyi under a house arrest that would continue off and on for the next two decades. ${ }^{16}$

\section{The Burmese Internet Forms in Exile}

However, in this period a key factor changed the political equilibrium: the global adoption of the commercial Internet, including by Myanmar's people. As early as 1988 , exiles from groups such as the Committee for the Restoration of Democracy in Burma and the All Burma Students Democratic Front were operating Usenet groups to spread information about the country and organize. ${ }^{17}$ In 1994, the Open Society Institute funded the creation of BurmaNet, an e-mail listserv that morphed into a website later in the I99os. Universities in the developed world particularly connected to the web and served as organizing centers for Burmese exiles such as Muang 
Zarni at the University of Wisconsin, who organized the Free Burma Coalition in 1995 . This online coalition grew to connect "[r]oughly I 50 colleges and universities, thirty high schools, over one hundred communitybased Burma support groups, and individual supporters in twenty-eight countries scattered in Asia, Australia, North America, and Europe." This had the goal of ending investment by multinationals in Burma and building an "international Free Burma movement in support of Burma's freedom struggle." 18

Conversely, the government established several international websites to promote its image abroad, including registering Myanmar.com, the International Telecommunications Union's (ITU) Myanmar website, and the Myanmar Information Committee. ${ }^{19}$ These generally promoted the regime's views to the international community and were not for domestic consumption. Written in English, they distributed government-controlled news sources such as the New Light of Myanmar, or offered propaganda on ethnic conflicts, drug trafficking, the regime's position on political issues, and tourism information.

Domestically, the country's nascent networks remained under the control of the military, which restricted online technology in much the same way they had controlled video technology under the 1985 Television and Video Law, which they updated in 1996. They bolstered it with a new Computer Science and Development Law mandating similar controls on ICTs such as modems, fax machines, computers, and software. ${ }^{20}$ Possession of almost any ICTs without a permit would result in imprisonment. Internet access itself required approval of the government, which operated the domestic networks and kept them heavily monitored. For example, cyber cafes were required to record user browsing every five minutes. ${ }^{21}$ The Ministry of Defense controlled the country's only Internet server, and any e-mail correspondence was monitored and redacted. ${ }^{22}$

Simultaneously, its surveillance infrastructure grew to manage the new threat, particularly with a new electronic center in Rangoon ${ }^{23}$ and various listening posts in place throughout the country to monitor activity in the new virtual space. ${ }^{24}$ As a result of these laws, a strong censorship system became largely self-policing through fear of an omnipresent surveillance infrastructure, and a severely restricted media and political system. A society had formed by the beginning of the twenty-first century with few links to the outside world, no independent media, and a complete lack of experience with ICTs.

However, information persisted on entering this closed world, partly 
through the growing online networks created in the I990s. Early Usenet groups and e-mail listservs transformed into websites such as BurmaNet, Radio Free Burma, the Free Burma Project, and others, which began to publish and share longer articles. ${ }^{25}$ The NLD continued to organize and advocate for free and fair elections despite the fact that its leadership had been imprisoned, killed, or forced into exile, and its leader Suu Kyi was in a near continual state of house arrest. ${ }^{26}$ In I999, the country connected to the SEA-WE-ME 3 cable, the first truly transoceanic, higher bandwidth Internet connection for a country that previously had had to use satellite or dial-up connections to get online. ${ }^{27}$ New stronger means of access developed as national and global events altered people's perceptions of the regime, and the creation of a Burmese language Internet helped accelerate these transformations, improving organization for opposition groups and providing a means for Myanmar's people to connect online and confront the regime.

\section{The Struggle to Code the Burmese Language}

One of the key tools to develop a national cyberspace is a font for native language encoding, certified as Unicode by the World Wide Web Consortium. As the regime had no interest in developing this standard and no real expertise at the time, a group of Burmese expatriates designed their own system known as Zawgyi so that they could communicate in their own language and allow for the propagation of Burmese media online. Unfortunately, this standard did not hew to the Unicode system rules, and was rather hard coded in such a way that it is difficult to translate the characters into other systems. ${ }^{28}$

The Burmese language is much different from Latin languages. The writing process comprises a base character modified by selected components to create different meanings. Before new intelligent rendering systems came into common usage, typing any Myanmar language on a computer was difficult. Early operating systems and particularly Windows up to XP Service Pack 2 did not support systems that could render Myanmar text properly. The solution was to hard code variations of the same character, rather than changing elements within the character. ${ }^{29}$ The Myazedi character set, first released out of beta in 2003, represented one of the first versions of this. ${ }^{30}$ However, it was expensive to use, costing \$ Ioo for a user and $\$ \mathrm{I}, 000$ for a developer. ${ }^{31}$ 
In 2006, a group of developers based in Mandalay released a similar font named Zawgyi that contained many elements of Myazedi and could be used for free. Much of the code base appears to have been copied and then modified from Myazedi, but because it did not cost anything to use, early Internet citizens rapidly adopted it. The Zawgyi script maintained the hard coded nature of Myazedi, and as a result a single word could be written in various ways, and it did not conform to Unicode standards that ensure compliance with rendering across languages and countries.

By the early 200os, the Internet had entered pockets of the country, principally Yangon and Mandalay, and the government instituted new web regulations, in addition to existing censorship laws such as the 1962 Printers and Publishers Act and restrictions on owning ICTs. These decreed:

- Any writings detrimental to the interests of the Union of Myanmar [Burma] are not to be posted.

- Any writings directly or indirectly detrimental to the current policies and secret security affairs of the government of the Union of Myanmar are not to be posted.

- Writings related to politics are not to be posted.

- Internet users are to inform MPT [Ministry of Communications, Post and Telegraph] of any threat on the Internet.

- Internet users are to obtain prior permission from the organization designated by the state to create Web pages. ${ }^{32}$

The government also approved the Electronic Transactions Act, which criminalized electronic transactions "detrimental to the security of the state or prevalence of law and order or community peace and tranquility or national solidarity, or national culture." ${ }^{33}$ These laws, along with the ICT ownership restrictions in the Computer Science and Development Law of I996, prior censorship laws, and pervasive security and surveillance continued to severely restrict domestic users' online access.

However, despite these challenges, Myanmar's blogosphere exploded with the help of new language encoding that allowed Burmese and other ethnic speakers to begin to converse in their own words. Disruptive events such as the Saffron Revolution in 2007 , a political protest sparked by monks denouncing rising fuel prices, ${ }^{34}$ and Cyclone Nargis, disrupted traditional communications across the country and led to calls for better emergency response, coordination, and information resources for ordinary citizens. ${ }^{35}$ 
The revolts during the Saffron Revolution caused the government to shut down the national Internet by disconnecting its international connections, blocking websites, and prohibiting foreign press access. ${ }^{36}$ The blockages didn't stop the spread of information and the network effects from those with connections to the Internet. In 2005 there were less than Io blogs dedicated to Myanmar's news and politics, while by August 2009 there were over $140 .{ }^{37}$

While the Internet remained out of the reach of most of Myanmar's people due to the dictatorship's continued control of ICTs and a lack of development, communities outside Myanmar and the small domestic user base allowed to use computers began to create content and propagate it primary in the free Zawgyi script. As in all countries around the world, this increasingly came in the form of cell phones and other mobile ICTs such as tablets. In 2005, a Unicode compliant script known as Myanmari created an alternative that rendered the Burmese language properly, but continued to struggle because of the difficulties involved in configuring it to work with Windows. Zawgyi also gained popularity among Burmese bloggers and particularly through the popular planet.com.mm website. ${ }^{38}$

Partly because many users began their experience using ICTs with $\mathrm{Za}$ wgyi and also because it is designed to be built into software such as Microsoft Word or Explorer without an easy uninstall option, migration became a challenge. Minority ethnic groups remained severely underrepresented in terms of online media, as they had in other forms, partly because of the rigid nature of the coding schema, focused on Burmese. As with many unique languages, including Burmese itself, the languages of Myanmar's diverse ethnic groups require a unique coding and an online community, which was often weak or nonexistent, to support it. The struggles to encode and standardize the Burmese language online represent a major legacy of the dictatorship in a unique way that hinders translation, adoption by major online media or Internet companies, search, and a host of other online functions.

The use of the Zawgyi font has created a cascade of issues, present and future. Search, filtering, or indeed any type of activity that requires a machine to recognize the script becomes problematic. As more applications use modern programming techniques, machine learning, and voice recognition, these problems stemming from Zawgyi's hard coded nature will become more apparent. It also leaves little room for expansion and use by other ethnic languages, which are continually underrepresented in the online space. ${ }^{39}$ 


\section{Transitions in Democratic and Virtual Space}

Now the country had its language and nascent connections to a growing international activist network, but an entrenched regime that refused to move forward. This changed drastically in 20ro, when the military ceded power to a nominally civilian government. The NLD did not participate in the election, ${ }^{40}$ calling the system unfair and the results fraudulent. ${ }^{41}$ Nonetheless, the new, nominally civilian administration still controlled by the military began allowing serious reforms.

The military released Aung San Suu Kyi from house arrest, allowed her to travel the country, released political prisoners, and allowed them to contest future elections that they said would be free and fair. The regime also promised to open up the economy, legalized unions, and guaranteed freedom of information. ${ }^{42}$ In an interview published in 201 2 , the minister of information described three stages the government would follow to achieve media independence:

"We have been relaxing restrictions on the press phase by phase. In this [first] step, we are paving the way for domestic periodicals to practice press freedom with responsibility and accountability . . . a learning period in order to work in harmony with the future print media law . . . Because of these reforms today, I 73 journals and I 24 magazines can now publish without prior approval from the Press Scrutiny and Registration Department ... In the second step, we are dealing with a new print media law that ensures press freedom in accord with the Constitution and replacing the existing Registration of Printers and Publishers Law (1962). In this process, the Myanmar government has been cooperating with regional media organizations since 2008 . We are currently in the process of drafting the new media law, and [will] include the outcome from this conference in the second draft." In the third stage, he said, the Ministry of Information will support the private media sector "for [the] harmonious exercise [of] freedom and accountability under the new print media law."43

This process quickly accelerated, as domestic press outlets proliferated rapidly. On March 4, 20I4, the government passed a new Media Law, allowing for newspapers and television and radio stations to report the news more independently. The law superseded the censorious 1962 Printing and 
Publishers Registration Act to allow publications about politics and indeed any subject with far fewer controls, but others laws still remain to threaten imprisonment, encouraging self-censorship. ${ }^{44}$ In August 201 5, the parliament approved a law to allow private control of television stations. ${ }^{45}$ Foreign broadcasts of both television and radio channels are allowed through satellite connections, which have proliferated rapidly, especially in urban areas such as Yangon. ${ }^{46}$ Restrictions on the import and use of ICT and audio-video technologies such as the 1985 Television and Video or the Computer Science and Development laws have been superseded or suspended but not repealed since the return of partial democracy. ${ }^{47}$

In addition to completely new mass media, Myanmar faced a challenge in that cell phones quickly became ubiquitous, but hardly anyone has experience with computers or other ICTs, nor understanding of informational concepts such as searching, sharing, or verifying. Myanmar's cellular system started under the control of the dictator in control of the country in the r 990 s, Ne Win, which the government later transferred to the control of the Ministry of Communications, Post and Telegraph (MPT) after his arrest during an alleged coup attempt in 2002. Under Ne Win's control in the late ' 90 , SIM cards were a restricted ICT and required a military connection or approval to purchase for as much as $\$ 3,300 .{ }^{48}$ These remained highly priced at around $\$ 500$ and thoroughly restricted until 2012, when the government cut the price in half and then to less than $\$_{2},{ }^{49}$ allowed the public to purchase them without approval, and began the process of allowing competition to enter the market. In 20I4, MPT granted two foreign telecoms, the United Arab Emirates' Ooredoo and Norway's Telenor, I 5-year licenses to build out networks covering around 90 percent of the country within two to three years, starting in the major cities. ${ }^{50}$

The Internet is conceptualized much differently in the mobile context, especially in developing countries with fewer resources, low broadband penetration, and a weak educational system. ${ }^{51}$ These competencies are poorly understood by the vast majority of the population. While literacy is high at roughly 93 percent, ${ }^{52}$ there is a low level of development, and a weak educational system with universities and schools plagued by years of shutdowns, underfunding, authoritarian administrative control, and censorship. Simultaneously, few users have prior experience with independent media, the Internet, or ICTs outside of members of academia, the government, and the military.

With no restrictions in place and cheaper technology available, Myan- 
mar's people rapidly adopted cell phones and other ICTs. However, while they are able to communicate using the new devices, they are often spreading information without understanding the underlying context. While literacy is high, media and information literacy is lower, as people have little experience with either the new devices, the Internet, or independent media. According to the International Telecommunications Union, there were fewer than 600,000 mobile phones in 2010 , but by 2015 reported over 40 million subscriptions. ${ }^{53}$ However, rapid adoption of cell phone technology came alongside a low adoption of traditional computing and broadband technology—a situation common across the developing world. The ITU measured Myanmar's broadband penetration rate at less than 2 percent in $2014,{ }^{54}$ while the cost of access remains high, at least $\$ \mathrm{I} 7$ a month for basic broadband, and anywhere from $\$ 200$ to $\$$ I, ooo for a fiber-optic high-speed connection..$^{55}$ All of these costs remain exceedingly high for individuals in a country with GDP of just over $\$ 980$ per capita in 20I4. Broadband access outside of the major metropolitan areas is negligible to nonexistent. ${ }^{56} \mathrm{In}$ 20I4, Myanmar's neighbor, Thailand, had a similarly low level of Internet penetration at around 8 percent, but still a much higher level of cell phone adoption, with I44 subscriptions per roo inhabitants. ${ }^{57}$

New international connections are coming, both overland to Thailand and China, as well as over the sea, particularly the new SEA ME WE 5 cable that will connect Myanmar to an international consortium of countries from Singapore to Marseille, France. The 20,000 kilometer cable system launched in 2016 has a $23 \mathrm{~Tb} / \mathrm{s}$ capacity, ${ }^{58}$ a major upgrade from the existing SEA ME WE 3's $4.6 \mathrm{~Tb} / \mathrm{s}$ capacity, which will also provide greater redundancy in international links than has been the case in the past. ${ }^{59}$ The Myanmar link, projected to be completed by the end of 2018 , and further international and regional connections are coming through the overland Myanmar-Malaysia-Thailand Interconnect (MYTHIC) and transoceanic Asia Africa Europe-I (AAE-I) cables. ${ }^{60}$ As discussed, access remains relatively slow and expensive for the population, and will remain so at least until these initiatives are completed.

Domestically, in January 2017 the government granted a fourth license to the Vietnamese owned Viettel and a consortium of Myanmar companies (Myanmar Economic Corporation or MECTel) controlled by the military. The group will operate under the name MyTel and use existing infrastructure controlled by the local MECTel group with a focus on bringing low cost $2 \mathrm{G}$ and ${ }_{3} \mathrm{G}$ services, particularly to rural areas. ${ }^{61}$ 


\section{Modern Myanmar's Online Ecosystem}

Major cell phone and device manufacturers such as Huawei and Samsung preload Zawgyi in Android operating systems so that new users continue to come online using the flawed font. Facebook, the network they are most likely to begin using first, supports the Unicode and Zawgyi standards, but because so much content is in the latter, and new adopters gain experience with it first, it continues to be the default. ${ }^{62}$

Companies besides Facebook have been slow or unwilling to adopt the Zawgyi standard. Microsoft has not developed Myanmar language software or documentation for most of its applications, and Internet companies such as Google have been slow to adopt a consistent framework for its products entering Myanmar. As the first mover and an ecosystem that allows Zawgyi without conflict, Facebook has become the dominant platform. A survey in 2014 by the Sri Lankan NGO LIRNEasia found that many people, not only in Myanmar but across Asia, were not even aware that they were using the Internet. One out of roo Myanmar people responded that they used the Internet, but four out of 100 said they used Facebook in $2014 .{ }^{63}$

This domination of the market has been bolstered by zero rating programs such as Facebook Zero, offered by Telenor starting in 20I4, which allows individuals to use Facebook without using their data, which is "rated zero.” Another Facebook-funded initiative known as Free Basics entered the market through MPT in $2016 .{ }^{64}$ Free Basics offers similar zero rated access to an array of apps including the social network, and has become a point of contention in countries such as India, which barred it from the country in 2015 , arguing that besides funneling users into closed corporate ecosystems, the program abrogated network neutrality laws. ${ }^{65}$

Other popular apps include Viber, WeChat, WhatsApp, and Skype, used for calling and messaging. Locals have developed a limited amount of applications; interesting examples such as Yik Yak ${ }^{66}$ and Hush ${ }^{67}$ provide anonymized instant messaging systems. Piracy is rampant and margins are low, so it is challenging to find a money-making business model for both local and multinational businesses. ${ }^{68}$ For years, the Google Play store didn't include Myanmar-specific apps, and did not offer support for Burmese, so users came up with alternatives through circulating USB sticks or privately posted applications. ${ }^{69}$

Gmail has also become incredibly popular, especially after Google introduced Burmese language support for both the Zawgyi and Unicode standard keyboards in February 2015, as well as Google Search in $2013^{70}$ 
and Google Translate in 2014, which takes text in both forms, but only outputs unicode. ${ }^{71}$ Android remains far and away the most popular operating system, with over 90 percent of the market captured. ${ }^{72}$

As mentioned, new users in developing countries that lack a strong educational system, low ICT use, and an authoritarian history often have no knowledge of the risks involved online and how to protect their security. There are no precise words in Burmese for privacy, in addition to anglicized ones for things such as computer, website, and other technical terms. ${ }^{73}$ A history of royalism, colonialism, and military authoritarianism may have precluded privacy concepts linguistically, and created serious barriers to developing a culture that values it, either in government regulations, within the private sector, or for ordinary citizens. ${ }^{74}$ This predilection to ignore the value of privacy is itself very valuable to Internet multinationals such as Google, Facebook, Apple, and others that profit from user data at the center of their business models. The country's population lacks digital literacy after years offline. When they do connect, it is primarily through mobiles, using Android and Facebook, and they often do not know about alternative apps or why they would want to use them.

The government has encouraged this movement by posting almost all press releases and other official information on Facebook. The Minister of Information from 2010 until 2015 was known as the "Minister of Facebook" and became known for his interactions on the social network. ${ }^{75}$ The result of all these factors is that Facebook reportedly had over nine million monthly active users in Myanmar in 2016 $6{ }^{76}$ and through code, government help, and exponential proliferation, the social network has become the key method of digital access for businesses, the public sector, and ordinary citizens. The primary mode of advertising, community organizing, search, communication, news, and a host of other functions is now delegated to a single social network, more so than almost any country on earth. This development has shaded every aspect of Myanmar's digital media landscape in its transition to democracy.

\section{Conclusion: Future Challenges on Democratic and Digital Frontiers}

Suu Kyi's NLD party fulfilled the promise of the annulled I990 parliamentary election in December 2015 when it clinched more than two-thirds of the seats in Myanmar's legislature. ${ }^{77}$ A year later, in 20r6, Suu Kyi clinched the presidency. While Suu Kyi had been unable to run because the consti- 
tution bars citizens who have foreign spouses from holding political office (she had a British husband, now deceased), she effectively retains control of the government as the leader of the party and the democracy movement. Indeed, as state counsellor, Suu Kyi is officially in control of the government. ${ }^{78}$ Additionally, the military retains control of key aspects of the government including key ministries (defense, home, and border affairs), 25 percent of the parliament, leadership in key states, and much of the economy. ${ }^{79}$ This arrangement has created a hybrid system and an effective veto for any changes to the constitution, which has contributed to the persistence of dictatorship era regulations such as the Computer Science and Development or the Electronic Transactions laws. Just before the changeover, in 2013 , the government instituted a new Telecommunications Law, which allowed for outside investment but has also provided the means for the government to sue users for posting "defamatory" information about officials online. Civil society groups have argued that this has been used to shape public opinion and muzzle opposition. ${ }^{80}$ The fact that these laws remain in place has created the potential for continued censorship in various forms.

Another central historical political issue that has transitioned to the online landscape is the problem of ethnic representation, particularly of minority communities that have been persecuted for their opposition to the dictatorship, their religion, or other differences. Ethnic conflicts that have raged since independence remain unresolved, still technically in a state of war and unconnected to the central government. This has resulted in large parts of the country remaining underserved by telecom services and often unable to access the Internet. Many of the smaller parties, often made up of ethnic groups, are not represented online. For example, only one-third of the 9I registered parties in 2015 had an active Facebook presence. ${ }^{81}$ The continuing plight of the Rohingya illustrate another kind of conflict.

In 2013, Anonymous publicized the plight of the Rohingya people, a persecuted ethnic group residing mostly in western Myanmar near the border with Bangladesh. As Muslims, they are a minority in a Buddhist society and have been subject to attacks, often organized online through social networks, particularly Facebook. Flashmobs in this context can be a very dangerous thing, and groups have organized riots, murders, and even massacres of Rohingya people based on faulty online information. For instance, on June 3, 20I 2, rioters killed I I people traveling to Yangon in the western Arkan state that borders Bangladesh, mistaking them for Rohingya. ${ }^{82}$ 
Seeking to draw attention to these attacks, members of Anonymous began attacking government websites and called on their membership to tweet the hashtag \#rohingyaNOW or \#OpRohingya, resulting in over 24,000 tweets an hour at $5 \mathrm{p}$.m. on March 24, 20I4. ${ }^{83}$ Twitter is not used very much in the country in comparison to Facebook, but it is an important tool for international users to spread online political awareness campaigns. ${ }^{84}$ Online attacks have continued and spread in different forms. In 2015 , reports indicated that the Blink Hacker Group had targeted the Democratic Voice of Burma for its coverage of attacks on Rohingya ${ }^{85}$

Beginning in August 2017, the Rohingya crisis deepened, as riots sparked by videos circulating on Facebook of alleged crimes by Muslims helped inflame populations living near their communities to attacks on them, driving them to serious protests, to attack villages, burn houses, rape women, and push hundreds of thousands to flee, mostly into exile in Bangladesh. Principally in the Rakhine state, these actions were often driven by religious leaders pushing propaganda against Rohingya and calling for their expulsion from the country, often with the support of the military and local police, citing disinformation or misinformation about these groups ${ }^{86}$

These actions, which the UN Human Rights Commission assessed as credible allegations of human rights violations, with the lead author of the report noting that "[r]egarding the Myanmar military, we are receiving credible reports of indiscriminate or disproportionate attacks, extrajudicial killings, arbitrary deprivation of liberty, enforced disappearances, destruction of property and pillage, torture and inhuman treatment, rape and other forms of sexual violence, forced labour, and the recruitment of children into armed forces," and highlighted the catastrophe occurring, with over $67 \mathrm{I}, 000$ people fleeing into exile. ${ }^{87}$ The challenges of creating a democratic, pluralistic state are being increasingly threatened, particularly as the Suu Kyi government tries to thread the needle and continue making progress toward democracy while satisfying the Burman majority, now interconnected and often inflamed by social media. A new coalition of civil society groups has formed under the name "Dear Mark" after they penned a letter to Mark Zuckerberg asking him to respond to issues in Facebook's content moderation and other policies ${ }^{88}$ Facebook has struggled to respond to threats, hate speech, misinformation, and disinformation online, and now it is facing a mounting debate over its role in Myanmar's society.

The press has also come under attack, as two Reuters journalists investigating the attacks have been imprisoned, and continue to be confined throughout their trial, as Reuters has published their articles and pressed 
for their release, but they are being threatened with being charged under the Official Secrets Act. ${ }^{89}$ These threats demonstrate how these communities, technical and media, are connected. There are new delivery mechanisms that the regime will have to contend with in the form of the Web and social networks, while traditional media is now increasingly international and interconnected. ${ }^{90}$ Both groups play a symbiotic, critical role in the function of civil society.

The gender divide remains wide in what is still a very paternalistic society. According to research by LIRNEasia, women were 28 percent less likely to own a phone than men, with $72 \%$ of men saying they owned a phone to 52 percent of women, up from 43 percent and 26 percent, respectively, in $2015 .{ }^{91}$ Unlike in many other Asian countries, women do hold a significant amount of power as the head of the household, for instance over purchasing decisions such as a phone. However, as they traditionally stay at home while the men of the family go out to work, they have often delegated the phone to them, and this has encouraged the disparity. However, as more families are able to afford multiple devices, the disparity is likely to shrinkfurther. ${ }^{22}$

Censorship and surveillance are making a return in 2017 , as the military continues to control a significant portion of the government administration and holds veto powers over proposed legislation or repeal. Freedom House declared the country's Internet and media "Not Free" in 20I6, citing attacks on the press by the government, self-censorship, possible government-sponsored hacking campaigns, and the preservation of dictatorship-era legislation. ${ }^{93}$ Users have been jailed for posting offensive material against both members of the military ${ }^{94}$ and against Suu Kyi ${ }^{95}$ under the 2013 Telecommunications Law.

Continued progress toward a strong, independent media system will depend not only on new infrastructure, but also a deep commitment to the democratic process, which is being tested, particularly with the ongoing crisis in the west of the country in Rohingya areas near Bangladesh, but also in the other areas that continue under rebel control and with continuing clashes between the military and local groups. Citizens, businesses, and government officials lack these skills, and will need continued training to reach higher levels of information literacy. This includes both ICT skills and conceptual knowledge to work in the online environment and implement large-scale informational goals, from the national census, election monitoring, local language applications, and a host of other projects, but also the understanding of how to assess content as true or false, and to avoid being provoked by fake but emotionally compelling narratives. 
The government led by Suu Kyi's NLD walks a fine line, grappling with this new digital world, pondering how to fight online hate speech against Muslims without antagonizing the Buddhist majority, organize electronic services, and police the cyberspace democratically. In this new, more open era for Myanmar, regression is just as possible as progress while old laws remain and the military retains significant control of the legislature, the executive, and key economic sectors. With the new digital media deeply embedded in Myanmar's culture and society, there will never be a way to completely return to an older system, but media suppression in various forms remains deeply entrenched after a history of censorship, surveillance, and suspicion. Progress on these fronts will take longer, but will undoubtedly depend on the Internet, strong independent media, and an interconnected, educated online society to truly move beyond this authoritarian historical legacy.

\section{Notes}

I. ITU, "Percentage of Individuals Using the Internet," International Telecommunications Union, December 20I6. http://www.itu.int

2. Yochai Benkler, The Wealth of Networks: How Social Production Transforms Markets and Freedom (New Haven: Yale University Press, 2006).

3. "The World Factbook-Burma," Central Intelligence Agency, Accessed January 3I, 20I7. https://www.cia.gov/library/publications/the-world-factbook/geos/ bm.html

4. Hugh Tinker, Burma: The Struggle for Independence 1944-1948, Vol II (London: H.M. Stationery Office, I983), 404-5.

5. Bertil Lintner, "Access to Information: The Case of Burma," (Manila: Philippine Center for Investigative Journalism, 200I), http://www.asiapacificms.com

6. Mridul Chowdhury, "The Role of the Internet in Burma's Saffron Revolution," Berkman Center Research Publication, no. 2008-08 (September 2008). doi:http://dx.doi.org

7. Ibid.

8. Ibid.

9. Lintner, "Access to Information."

Io. Television and Video Law, Pub. L. No. 8/96 (I996). http://www.burmalibrary.org

I I. "In Pursuit of Truth: Undercover Journalism and the Democratic Voice of Burma," Tavaana. Accessed February i 7, 201 7. https://tavaana.org

I 2. Lintner, "Access to Information," 5 http://www.asiapacificms.com

13. Martin Smith, Ethnic Groups in Burma: Development, Democracy and Human Rights, ed. Annie Allsebrook and Anne-Marie Sharman (London: Anti-Slavery International, I994), 70.

I4. James F. Guyot, "Myanmar in I990: The Unconsummated Election., Asian Survey 3I (2) (February I, I99I): 205-I I. DOI: 10.2307/2644932. 
I 5. Gustaaf Houtman, Mental Culture in Burmese Crisis Politics: Aung San Suu Kyi and the National League for Democracy (Tokyo: Tokyo University of Foreign Studies, Institute for the Study of Languages and Cultures of Asia and Africa, I999), 43-47.

I6. James F. Guyot, "Myanmar in I990: The Unconsummated Election," Asian Survey 3I (2) (February I, I99I): 205-I I. DOI: I0.2307/2644932.

I 7. Zarni, "Chapter Three: Resistance and Cybercommunities: The Internet and the Free Burma Movement," Counterpoints 59 (2000): 7I-88.

I8. Ibid, 79 .

I9. For more sources on Myanmar's early Internet, see Viola Krebs, "The Impact of the Internet on Myanmar," First Monday, no. 8 (April 20, 200I), http:// journals.uic.edu/ojs/index.php

20. Computer Science and Development Law, Pub. L. No. io/96. Accessed February I 5, 20I 7. http://www.burmalibrary.org

$2 \mathrm{I}$. "Internet Filtering in Burma in 2005: A Country Study," OpenNet Initiative, 2005, https://opennet.net

22. "Burma Country Report," Human Rights Reports for i999, U.S. Department of State, February 25, 2000, https://www.state.gov

23. Monique Skidmore, Karaoke Fascism: Burma and the Politics of Fear, Ethnography of Political Violence (Philadelphia: University of Pennsylvania Press, 2004), 70. http://public.eblib.com/choice/publicfullrecord.aspx

24. Andrew Selth, "Burma's Intelligence Apparatus," Intelligence and National Security I3 (4) (December I, I998): 33-70. DOI: I0. I080/02684529808432504.

25. For early websites, see Krebs's bibliography. The Burmese blogosphere is described in Amara Thiha, "Revolution through Cyberspace: Burmese Blogosphere and Saffron Revolution,"in Proceedings of the 4 th ACM/IEEE International Conference on Information and Communication Technologies and Development, 48:I-48:7. ICTD 'ı. New York: ACM, 20 Iо. doi:Io. I I 45/2369220.2369266.

26. Justin McCurry, "Burma's Leader Announces First Elections since I990," Guardian, January 4, $20 \mathrm{I}$ o, sec. World news. https://www.theguardian.com

27. Jeremy Mullins, "French Firm to Assist MPT in Expansion of International Telephone Services," Myanmar Times, September 22, 2014. http://www.mmtimes. com/index.php/business/technology/11743-french-firm-to-assist-mpt-in-expansion-of-international-telephone-services.html

28. Martin Hoskin, "Representing Myanmar in Unicode," Unicode Technical Note, December I3, 201 2. http://unicode.org

29. Griffin Hotchkiss, "Battle of the Fonts," Frontier Myanmar. Accessed March 30, 2016. http://frontiermyanmar.net

30. http://www.myazedi.com

3 I. Hotchkiss, "Battle of the Fonts."

32. "Internet Filtering in Burma in 2005: A Country Study," OpenNet Initiative, 2005. https://opennet.net

33. Electronic Transactions Law, Pub. L. No. 5/2004 (2004). http://www.wipo. int/wipolex/en/text.jsp

34. Thiha, "Revolution through Cyberspace."

35. Daniel Gawthrop, "Circumventing the Junta: How Burmese Exiles Use Independent Media to Foster Civic Culture and Promote Democracy" (ProQuest Dissertations, 2009), http://search.proquest.com 
36. "Pulling the Plug: A Technical Review of the Internet Shutdown in Burma," OpenNet Initiative, 2007. https://opennet.net

37. Thiha, "Revolution through Cyberspace."

38. Hotchkiss, "Battle of the Fonts."

39. Ibid.

40. "Suu Kyi's NLD Party to Boycott Burma Election," BBC News, March 29, 2010. http://news.bbc.co.uk/2/hi/asia-pacific/8592365.stm

41. "Suu Kyi Defends Election Boycott," Al fazeera English, November i 8, 20 го. http://www.aljazeera.com/news/asia-pacific/2010/11/20101118101724623904. html

42. Marie Lall, "Viewpoint: Has a Year of Civilian Rule Changed Burma?," BBC News, November 7, 201 I, sec. Asia. http://www.bbc.com

43. "Burma Undergoing 'Three-Step' Media Reform: Information Minister," Mizzima News, March I9, 2012. https://web.archive.org/web/20130322051441/ http://mizzima.com/news/inside-burma/6780-burma-undergoing-three-step-media-reform-information-minister.html

44. "'They Can Arrest You at Any Time," Human Rights Watch, June 29, 20 I 6. https://www.hrw.org.

45. "Myanmar Country Report," Freedom of the Press 2016 (New York: Freedom House, 2016). https://freedomhouse.org

46. Phyo Wai Kyaw, "Hot Demand for Satellite Dishes," Myanmar Times, September I2, 20I6. http://www.mmtimes.com/index.php/special-features/227-ittelecommunications-2016/22465-hot-demand-for-satellite-dishes.html

47. "'They Can Arrest You at Any Time," Human Rights Watch, June 29, 20 I6. https://www.hrw.org

48. Hpyo Wai Tha, "Burmese SIM Card Price Slashed by Half," Irrawaddy, March 6, 20I 2. http://www2.irrawaddy.com/article.php

49. Sam Petulla, "Myanmar Cuts the Price of a SIM Card by $99 \%$," Quartz. Accessed February I6, 201 7. https://qz.com

50. "Telecoms Take-Off," Economist Intelligence Unit, February I I, 20 I4. http:// country.eiu.com/article.aspx

5I. Christoph Pimmer, Sebastian Linxen, Urs Gröhbiel, Anil Kumar Jha, and Günter Burg, "Mobile Learning in Resource-Constrained Environments: A Case Study of Medical Education," Medical Teacher 35 (5) (2013): e I I 57-65. doi: I0.3 Io9 /OI42 I 59 X.2012.733454.

52. "The World Factbook-Burma," Central Intelligence Agency. Accessed January 3I, 20I 7. https://www.cia.gov/library/publications/the-world-factbook/geos/ bm.html

53. "ITU Mobile Cellular Subscriptions by Country," International Telecommunications Union, 2016. http://www.itu.int

54. ITU, "Percentage of Individuals Using the Internet," International Telecommunications Union, December 20I6. http://www.itu.int

55. . "Myanmar Country Report," Freedom on the Net (New York: Freedom House, 2016). https://freedomhouse.org

56. Ibid.

57. See ITU Mobile Cellular Subscriptions by Country.

58. "Cable Compendium: A Guide to the Week's Submarine and Terrestrial De- 
velopments," TeleGeography Comms Update, December i6, 20 16. https://www.telegeography.com/products/commsupdate/articles/2016/12/16/cable-compendiuma-guide-to-the-weeks-submarine-and-terrestrial-developments/index.html

59. "SEA-ME-WE 3 Cable Cut Disrupted Myanmar Internet-Submarine Cable Networks," Submarine Cable Networks. Accessed February i6, 20 I 7. http:// www.submarinenetworks.com

6o. Naomi Gingold, "Myanmar's Connectivity Catch-Up," Frontier Myanmar. Accessed January 30, 201 7. http://frontiermyanmar.net

6r. "New Licensee to Operate under Mytel Brand, Use MECTel Infrastructure," TeleGeography Comms Update, January I 7, 201 7. https://www.telegeography. com/products/commsupdate/articles/2017/01/17/new-licensee-to-operate-undermytel-brand-use-mectel-infrastructure/index.html

62. Hotchkiss, "Battle of the Fonts."

63. Rohan Samarajiva, "More Facebook Users than Internet Users in South East Asia?," August 30, 20I4. http://lirneasia.net

64. Catherine Trautwein, "Facebook Free Basics Lands in Myanmar," Myanmar Times, June 6, 20г6. http://www.mmtimes.com/index.php/business/ technology/20685-facebook-free-basics-lands-in-myanmar.html

65. Cory Doctorow, “'Poor Internet for Poor People': India's Activists Fight Facebook Connection Plan,” Guardian, January I 5, 20I6, sec. Technology. http:// www.theguardian.com

66. Poppy McPherson, “There's an App for That (in Myanmar)," Diplomat, June 2, 20I 5. http://thediplomat.com

67. Aung Kham, "Rival of Social Apps in Myanmar?," Myanmar Entrepreneur, June 8, 2015. http://myanmar-entrepreneur.com

68. Indi Davis, "Monetising Music to Overcome Piracy," Frontier Myanmar, September 5, 20I6. http://frontiermyanmar.net

69. McPherson, "There's an App for That (in Myanmar)."

70. Sami Khan, "Gmail Arrives in Myanmar with Local Language Support; How to Change Your Language," International Business Times, February 26, 2015. http://www.ibtimes.co.in

7r. "Say Hello with Google Translate in Malayalam, Myanmar, Sinhala and Sundanese," Google Asia Pacific Blog. Accessed February I6, 2017. https://asia. googleblog.com/2014/12/say-hello-with-google-translate-in.html

72. "Mobile OS Share in Myanmar 2014-20 I6," Statista. Accessed February I6, 20I 7. https://www.statista.com

73. Thomas Fuller, "Those Who Would Remake Myanmar Find That Words Fail Them," New York Times, July I 9, 20 I 5. https://www.nytimes.com/2015/07/20/ world/asia/those-who-would-remake-myanmar-find-that-words-fail-them.html

74. Alexandrine Pirlot de Corbion, "The Right to Privacy in Myanmar," Privacy International, May I 2, 2015 . https://www.privacyinternational.org.

75. Thu Thu Aung and Ye Mon. "Minister for Facebook Gets Ready to Sign Off," Myanmar Times, December I I, 20 I 5. http://www.mmtimes.com/index.php/ national-news/yangon/18094-minister-for-facebook-gets-ready-to-sign-off.html 76. Trautwein, "Facebook Free Basics Lands in Myanmar," June 6, 2 о 6. 
77. "Myanmar Election: Suu Kyi's NLD Wins Landslide Victory," BBC News, November I 3, 20 I $_{5}$, sec. Asia. http://www.bbc.com

78. Liam Cochrane, "Aung San Suu Kyi to Become 'State Counsellor' of Myanmar," ABC News, April 5, 20I6. http://www.abc.net.au

79. Ibid.

80. Mong Palatino, "Myanmar Activists Say Junta-Era Defamation Law Must Go," Global Voices, January 30, 201 7. https://globalvoices.org

8I. Catherine Trautwein and Wa Lone, "The Facebook Election? Not Quite Yet," Myanmar Times, October 7, 201 5. http://www.mmtimes.com/index.php/business/technology/16877-the-facebook-election-not-quite-yet.html

82. Sai Latt, "Intolerance, Islam, and the Internet in Burma," New Mandala, June Iо, 20I 2. http://www.newmandala.org

83. Dell Cameron, "Anonymous Taught Twitter about the Rohingya Genocide," Vice, March 25, 20I3. http://www.vice.com

84. See https://www.socialbakers.com for rates of followers for Myanmar related Twitter accounts. The largest Myanmar related accounts have less than 400,000 followers as of the time of this writing in June 2018.

85. "Fighting Cyber Attacks during the Burmese Elections," Unleashed Research Labs, November 20 5. http://unleashed.blinkhackergroup.org

86. John Reed, "Hate Speech, Atrocities and Fake News: The Crisis in Myanmar," Financial Times, February 22, 2018. https://www.ft.com

87. "Fact-Finding Mission on Myanmar: Concrete and Overwhelming Information Points to International Crimes," UN Human Rights Council, March I 2, 2018. http://www.ohchr.org/EN/HRBodies/HRC/Pages/NewsDetail.aspx

88. Kevin Roose and Paul Mozur, "Zuckerberg Was Called Out over Myanmar Violence. Here's His Apology," New York Times, April 9, 2ог 8, sec. Business Day. https://www.nytimes.com/2018/04/09/business/facebook-myanmar-zuckerberg. html

89. https://www.reuters.com

90. For more details of the case, see "Myanmar Reporters," Reuters. Accessed June 6, 2018. https://www.reuters.com

91. "Mobile Phones, Internet, Information, Knowledge: Myanmar 2016," LiRNE Asia, December 20I6. http://lirneasia.net

92. Helani Galpaya, "Myanmar's Digital Gender Divide," Communications of the ACM 59 (IO) (October 2016): 22. DOI: IO. I I45/2988443.

93. See "Myanmar Country Report," Freedom of the Press 2016 (New York: Freedom House, 2016), https://freedomhouse.org. "Myanmar Country Report," Freedom on the Net (New York: Freedom House, 2016). https://freedomhouse.org

94. Zaw Zaw Htwe, "Kachin Activist Released after Imprisonment for Facebook Post," Myanmar Times, April I, 20I6. http://www.mmtimes.com/index.php/ national-news/19805-kachin-activist-released-after-imprisonment-for-facebookpost.html

95. Salat Thant Zin, "USDP Official Sued over Fake Suu Kyi Nude Shared on Facebook," Irrawaddy, October I 9, 20 I 5. https://www.irrawaddy.com 


\section{References}

Aung, Thu Thu, and Ye Mon. 2015. "Minister for Facebook Gets Ready to Sign off." Myanmar Times, December I I. http://www.mmtimes.com/index.php/national-news/yangon/18094-minister-for-facebook-gets-ready-to-sign-off.html

Benkler, Yochai. 2006. The Wealth of Networks: How Social Production Transforms Markets and Freedom. New Haven: Yale University Press.

Best, Michael L. 20I6. "Mobile Computing and Political Transformation." Communications of the ACM 59 (Iо) (October): 2 I-23. https://doi.org

Brough, Melissa, and Zhan Li. 20I3. "Media Systems Dependency and Human Rights Online Video: The 'Saffron Revolution' and WITNESS's Hub.” International fournal of Communication 7 (January 30): 24.

Chowdhury, Mridul. 2008. "The Role of the Internet in Burma's Saffron Revolution.” Berkman Center Research Publication, no. 2008-o8 (September). https:// doi.org/http://dx.doi.org

Cochrane, Liam. 20r6. "Aung San Suu Kyi to Become 'State Counsellor' of Myanmar." ABC News, April 5. http://www.abc.net.au

Corbion, Alexandrine Pirlot de. 201 5. "The Right to Privacy in Myanmar." Privacy International, May I 2. https://www.privacyinternational.org

Crampton, Thomas. 2000. "Burma Draws an Internet Weapon in Its Fight against Dissident." International Herald Tribune, August 3 I.

Danitz, Tiffany, and Warren P. Strobel. I 999. "The Internet's Impact on Activism: The Case of Burma." Studies in Conflict \& Terrorism 22 (3) (August I): 257-69. https://doi.org

Davis, Indi. 2016. "Monetising Music to Overcome Piracy." Frontier Myanmar, September 5. http://frontiermyanmar.net

Ekeh, Chizom, and Martin Smith. 2007. "Minorities in Burma." Minority Rights Group (blog), October. http://minorityrights.org

Fisher, Jonah. 20r6. "Aung San Suu Kyi: Power Not Presidency in Myanmar.” BBC News, March I 5, sec. Asia. http://www.bbc.com

Frontier Myanmar. 20 I 7. "World Bank's MIGA Backs \$ Ioom 4,50okm Fibre Optic Rollout." Frontier Myanmar. Accessed February 7, 201 7. http://frontiermyanmar.net

Fuller, Thomas. 2015. "Those Who Would Remake Myanmar Find That Words Fail Them." New York Times, July i 9. https://www.nytimes.com/2015/07/20/ world/asia/those-who-would-remake-myanmar-find-that-words-fail-them. html

Galpaya, Helani. 20r6. "Myanmar's Digital Gender Divide." Communications of the $A C M 59$ (Io) (October): 22. https://doi.org

Gawthrop, Daniel. 2009. "Circumventing the Junta: How Burmese Exiles Use Independent Media to Foster Civic Culture and Promote Democracy." ProQuest Dissertations. http://search.proquest.com

Ghoshal, Abhimanyu. 201 5. "Gmail Adds Burmese Language Support." The Next Web, February 26. https://thenextweb.com

Gilbert, Dave, and Violet Cho. "Voices of Moderation on Burmese Facebook." New Mandala (blog), June I 5, 201 2. http://www.newmandala.org 
Gingold, Naomi. 20I 7. "Myanmar's Connectivity Catch-Up." Frontier Myanmar. Accessed January 30, 20I 7. http://frontiermyanmar.net

Gleeson, Sean. 20 I 7. "The Muzzling of the Myanmar Times." Frontier Myanmar. Accessed April I I, 20I 7. http://frontiermyanmar.net

Guyot, James F. I991. "Myanmar in I990: The Unconsummated Election." Asian Survey 3 I (2) (February I): 205-I I. https://doi.org

Havely, Joe. 2000. "When States Go to Cyber-War." BBC News, February i6. http://news.bbc.co.uk/2/hi/science/nature/642867.stm

Hoskin, Martin. 2012. "Representing Myanmar in Unicode." Unicode Technical Note, December I3. http://unicode.org

Hotchkiss, Griffin. 2016. "Battle of the Fonts." Frontier Myanmar. Accessed March 30, 20I6. http://frontiermyanmar.net

Houtman, Gustaaf. 1999. Mental Culture in Burmese Crisis Politics: Aung San Suu Kyi and the National League for Democracy. Tokyo: Tokyo University of Foreign Studies, Institute for the Study of Languages and Cultures of Asia and Africa.

Hpyo Wai Tha. 20r 2. "Burmese SIM Card Price Slashed by Half." Irrawaddy, March 6. http://www2.irrawaddy.com/article.php

Htwe, Zaw Zaw. 20 16. "Kachin Activist Released after Imprisonment for Facebook Post.” Myanmar Times, April I. http://www.mmtimes.com/index.php/nationalnews/19805-kachin-activist-released-after-imprisonment-for-facebook-post. html

Kham, Aung. 2015. "Rival of Social Apps in Myanmar?" Myanmar Entrepreneur (blog), June 8. http://myanmar-entrepreneur.com

Khan, Abu Saeed. 20 1 7. "Campana Takes Giant Leap to Plug Myanmar Fail-Safe; LIRNEasia—a Regional ICT Policy and Regulation Think Tank Active across the Asia Pacific." Accessed February 7, 201 7. http://lirneasia.net

Khan, Sami. 2015. "Gmail Arrives in Myanmar with Local Language Support; How to Change Your Language." International Business Times, February 26. http://www.ibtimes.co.in

Krebs, Viola. 200 I. "The Impact of the Internet on Myanmar." First Monday, no. 8 (April 20). http://journals.uic.edu/ojs/index.php

Kyaw, Phyo Wai. 20r6. "Hot Demand for Satellite Dishes." Myanmar Times, September I 2. http://www.mmtimes.com/index.php/special-features/227-it-telecommunications-2016/22465-hot-demand-for-satellite-dishes.html

Lall, Marie. 20 I I. "Viewpoint: Has a Year of Civilian Rule Changed Burma?" BBC News, November 7, sec. Asia. http://www.bbc.com

Latt, Sai. 201 2. "Intolerance, Islam, and the Internet in Burma." New Mandala (blog), June Io. http://www.newmandala.org

Lintner, Bertil. 200 I. "Access to Information: The Case of Burma." Manila: Philippine Center for Investigative Journalism. http://www.asiapacificms.com

Macfarquhar, Neil. 2010. "U.N. Doubts Fairness of Election in Myanmar." New York Times, October 2 I. http://www.nytimes.com/2010/10/22/world/ asia/22nations.html

McCurry, Justin. 2010. "Burma's Leader Announces First Elections since i99o." Guardian, January 4, sec. World news. https://www.theguardian.com 
McPherson, Poppy. 201 5. "There's an App for That (in Myanmar).” Diplomat, June 2. http://thediplomat.com

MEF. 20 16. "Essential Mobile Snapshot: Myanmar." MEF (blog), August 24. http:// mobileecosystemforum.com

Mullins, Jeremy. 20I4. "French Firm to Assist MPT in Expansion of International Telephone Services." Myanmar Times, September 22. http://www.mmtimes. com/index.php/business/technology/11743-french-firm-to-assist-mpt-in-expansion-of-international-telephone-services.html

"Myanmar Election: Suu Kyi's NLD Wins Landslide Victory." 201 5. BBC News, November I3, sec. Asia. http://www.bbc.com

“Myanmar Reporters." 20I8. Reuters. Accessed June 6, 2018. https://www.reuters. com

Nizza, Mike. 2007. "Burmese Government Clamps Down on Internet." The Lede, I I 90985575 . https://thelede.blogs.nytimes.com/2007/09/28/burmese-government-clamps-down-on-internet

Palatino, Mong. 201 7. "Myanmar Activists Say Junta-Era Defamation Law Must Go." Global Voices (blog), January 30. https://globalvoices.org

Paul Budde Communication Pty Ltd. 20r6. "Myanmar (Burma)—Telecoms, Mobile, Broadband and Digital Media-Statistics and Analyses." Research and Markets, August. http://www.researchandmarkets.com

Petulla, Sam. 20I 7. "Myanmar Cuts the Price of a SIM Card by 99\%." Quartz (blog). Accessed February i 6, 20 I 7. https://qz.com

Pimmer, Christoph, Sebastian Linxen, Urs Gröhbiel, Anil Kumar Jha, and Günter Burg. 20I 3. "Mobile Learning in Resource-Constrained Environments: A Case Study of Medical Education.” Medical Teacher 35 (5): e I I 57-65. https://doi.org

Reed, John. 2018. "Hate Speech, Atrocities and Fake News: The Crisis in Myanmar." Financial Times, February 2 2. https://www.ft.com

"Reuters Reporters Arrested under Myanmar Secrets Act Denied Bail." 2018. Reuters, February I. https://www.reuters.com

Roose, Kevin, and Paul Mozur. 20r 8. "Zuckerberg Was Called Out over Myanmar Violence: Here's His Apology.” New York Times, April 9, sec. Business Day. https://www.nytimes.com/2018/04/09/business/facebook-myanmar-zuckerberg.html

Salat Thant Zin. 20 I 5. "USDP Official Sued over Fake Suu Kyi Nude Shared on Facebook.” Irrawaddy, October i9. https://www.irrawaddy.com

Samarajiva, Rohan. 20I4. "More Facebook Users Than Internet Users in South East Asia?," August 30. http://lirneasia.net

Selth, Andrew. I998. "Burma's Intelligence Apparatus." Intelligence and National Security I3 (4) (December I): 33-70. https://doi.org

Skidmore, Monique. 2003. "Darker Than Midnight: Fear, Vulnerability, and Terror Making in Urban Burma (Myanmar).” American Ethnologist 30 (I) (February I): 5-2 I. https://doi.org

Skidmore, Monique. 2004. Karaoke Fascism: Burma and the Politics of Fear. Ethnography of Political Violence. Philadelphia: University of Pennsylvania Press. http://public.eblib.com/choice/publicfullrecord.aspx

Smith, Martin. 1994. Ethnic Groups in Burma: Development, Democracy and Human 
Rights. Edited by Annie Allsebrook and Anne-Marie Sharman. London: AntiSlavery International.

Smith, Martin. I999. Burma: Insurgency and the Politics of Ethnic Conflict. 2nd ed. Dhaka: Zed Books.

"Snapshot." 2018. Accessed June 4, 2018. https://www.ft.com

Thiha, Amara. 2010. "Revolution through Cyberspace: Burmese Blogosphere and Saffron Revolution." In Proceedings of the $4^{\text {th }}$ ACM/IEEE International Conference on Information and Communication Technologies and Development, 48: I-48:7. ICTD 'ı. New York: ACM. https://doi.org

Trautwein, Catherine. 2016a. "Facebook Free Basics Lands in Myanmar." Myanmar Times, June 6. http://www.mmtimes.com/index.php/business/ technology/20685-facebook-free-basics-lands-in-myanmar.html

Trautwein, Catherine. 20r6b. "Mobile Operators Comply with One in Four Data Requests." Myanmar Times, March 30. http://www.mmtimes.com/index.php/ business/technology/19721-mobile-operators-comply-with-one-in-fourdata-requests.html

Trautwein, Catherine, and Wa Lone. 201 5. "The Facebook Election? Not Quite Yet." Myanmar Times, October 7. http://www.mmtimes.com/index.php/business/technology/16877-the-facebook-election-not-quite-yet.html

Zainudeen, Ayesha. 2014. "Telenor Brings Zero-Rated Wikipedia and Facebook Access to Myanmar." LIRNEasia (blog), November 3. http://lirneasia.net

Zarni. 2000. "Chapter Three: Resistance and Cybercommunities: The Internet and the Free Burma Movement." Counterpoints 59: 7 I-88.

Zuckerman, Ethan. 20I4. "Myanmar, No Longer Closed, Still Complicated." My Heart's in Accra (blog), March I 2. http://www.ethanzuckerman.com 
PART 2

\section{Platforms}




\title{
Dating Applications, Intimacy, and Cosmopolitan Desire in India
}

\author{
Vishnupriya Das
}

On October 8, 20I5, TrulyMadly Matchmakers Private Ltd. cemented its presence as a key player in India's mobile-phone-based dating app market by releasing a digital advertisement that went viral. The video, titled "Creep Qawwali", opened with two troupes of female qawwali ${ }^{1}$ singers sitting on the floor, facing each other, in an ornate room replete with chandeliers, candelabras, fairy lights, and flower arrangements. The title briefly superimposed on this scene included cartoon hearts, a tabla, ${ }^{2}$ and a bearded caricature of what I was told was a "stereotypically creepy" man with wide leering eyes and a curly beard. ${ }^{3}$ In the advertisement, the female singers were locked in a tongue-in-cheek lyrical battle in Hindi (with a smattering of English words) debating which one of them suffered the "creepier" man hitting on them. To prove their points, each expound on their trysts with such men in physical and digital spaces:

Woman I: My creep has sent me his picture via WhatsApp

Woman 2: My creep has sent me his dick picture via WhatsApp

Woman r: He has distributed our wedding cards already

Woman 2: He has already named my baby. ${ }^{4}$

After four minutes and 56 seconds of back and forth, the video ended with the two women realizing that the same man had been creeping on 
them all along. Their relief at this discovery was marked by laughter, an onscreen embrace, and the tagline- "Don't let boy browsing turn into creep browsing. Date wisely. Verified profiles only on TrulyMadly." 5

The year the advertisement released, there were over 35 mobilephone-based dating applications accessible through iOS and Android operating systems in India, all claiming to provide services that would allow their users the possibility of romantic connection without marriage as an explicitly articulated end. ${ }^{6}$ Unlike international companies targeting a "global" audience, TrulyMadly was a "local" heterosexual dating application produced and developed in India targeting users within the country. In 2015, having just landed 5.7 million dollars from angel investors in its first round of funding (the largest amount of Series A by any Indian dating app company), TrulyMadly was considered a "leader" among local dating apps. ${ }^{7}$ During an interview with popular technology magazine TechCrunch, Sachin Bhatia, one of the cofounders of the app, remarked on their unique position within the country's dating app ecosystem, saying "Facebook is India's Facebook and Twitter is India's Twitter, but Tinder won't be India's Tinder." 8

Analyzing the ways in which dating is framed by a key player in an evolving digital industrial ecosystem provides an avenue to explore broader questions regarding the place of female sexuality in emerging technology companies, which, going by historical precedent, have a significant influence on national imaginaries of desire and modernity. In this chapter I trace how historical tensions between piety and promiscuity in the figure of the Indian young, middle-class woman are played out in today's information-rich digital age. I begin by examining the specific affordances of smartphone technologies that these platforms depend on. Then, I examine academic discussion surrounding (nondigital) new media technologies and the erotic in India, drawing links between these historical antecedents and questions surrounding the current digital dating app ecosystem in the country. Finally, focusing on TrulyMadly, I delve into the production strategies through which a local Indian dating app company constructs what "appropriate" male and female behavior should look like on their platform. Exploring how companies like TrulyMadly are grappling with how to best depict the possibilities of Internet-enabled intimacy and "Indianness" in mobile dating platforms, I argue that understanding the intersections of Internet-enabled mobile media technologies and sexuality in India today mandates a deeper examination of how "dating" is imagined by digital industries claiming the term. 


\section{Dating Apps: A Brief History}

The origins of mobile-phone-based dating can be traced to the launch of Grindr, a gay male geo-social app in March 2009. The defining feature of Grindr's design was its ability to match users based on their geographic proximity to each other. ${ }^{9}$ By 20 I I Grindr's user base had expanded to India where it faced competition from Scruff (another international gay male geo-social dating app) and Planet Romeo (a web-based gay men's dating website popular since the early 2000 s that had just launched its mobile avatar). ${ }^{10}$ As of 2016 in India only international corporations marketed themselves as dating apps for the queer community. On the other hand, as noted earlier, there were multiple heterosexual dating apps marketing themselves as catering to uniquely "Indian" erotic desires during the same period. This difference in the concentration of international versus national companies explicitly catering to gay male users is striking, though not entirely surprising considering the illegality of homosexuality in the country.

It should also be noted that in the years preceding Grindr's launch, between 2005 and 2010 the web-based heterosexual dating market was exploding across the Western world. ${ }^{11}$ However, in India, dating websites had little presence. Instead, it was chatrooms (Yahoo, MSN) and messaging services on social networking platforms (Orkut, Hi 5 , Facebook) that were the places where intimate connections (not explicitly aimed at marriage) were being imagined and forged. Writing about these digital spaces Kabita Chakraborty observes that "through theme-based rooms, like love and friendship rooms, chat services participants interested in developing romantic and other relationships could meet, communicate and share various multimedia information, including photos and videos of themselves."12

Tinder, a primarily heterosexual dating app, launched in 2012 (five years after Grindr was founded). Tinder adopted an interface similar to Grindr (matches based on geographic proximity, touch screen based swipe features) and like Grindr its user base quickly spread across the globe. In 2014 , the Indian edition of the Wall Street fournal published a commentary section observing how Indians were "ditching" their blackberries to get on iPhones that supported the app..$^{13}$ At the same period as Tinder's global expansion (2013 to 2014) numerous India-focused dating appsTrulyMadly, DesiCrush, Woo, icrushiflush-were launched by nonresident Indian entrepreneurs targeting the Indian market, each claiming that they held the key to answer the question of what Indians were looking for in non-marriage-based intimacy. 
By 2016 , there were a slew of both global heterosexual dating app companies extending their reach into the Indian market and local companies aimed specifically at users located in India. Smartphone technologies allowed for features such as swiping (right or left) through profiles and setting radii to find new matches. ${ }^{14}$ While feature phones still make up the majority of the Indian handheld market, smartphone penetration estimates in India for 2016 were 28.3 percent (as a percentage of all handset users), nearly double the 14.8 percent penetration estimates in $2013 .{ }^{15}$ The word "dating" was used by PR managers, user interface designers, journalists, and company founders of both types of organizations as a catch-all to describe everything from no-strings-attached casual sex to platonic friendship to matrimony. Interestingly, most dating applications (even those that had website avatars) were accessed through smartphones, allowing users to simultaneously move across geographic locations and multiple digital platforms when searching for and communicating with matches. Adrianna de Souza de Silva and Jordan Frith describe this sense of being in perpetual motion using location-aware apps to constantly coordinate and communicate one's spatial orientation as a new form of spatiality- "hybrid space."16 While theorizations of hybrid space are not unique to India, it is nonetheless worth noting, as the corporate imaginary of mobile-phone-based dating becomes inextricably intertwined with industry attempts to capitalize on experiences of digital hybridity.

One way to study dating apps in India without treating technologies that govern them as all powerful or merely instrumental in structuring imaginaries of intimacy ${ }^{17}$ is to situate these applications within a longer history of media and communication technologies associated with the erotic. ${ }^{18}$ In an edited collection on Media Erotics and Transnational Asia Purnima Mankekar and Louisa Schein write about the difficulties of studying "the erotic" as a conceptual category because of its fuzzy boundaries and tendency to be framed in terms of oppositional logics of similarity or difference. ${ }^{19}$ In an effort to engage with these concerns, I focus on institutional developments that provide the infrastructure required for the proliferation of dating apps and go on to map the particular assemblage of global flows of information, labor, and ideas that shape the potentials and pitfalls of dating apps that target Indian consumers.

The institutional, physical, and financial infrastructure required to sustain wireless phone growth in India can be traced back to policy decisions made during the late I990s and early 200os. During this period, the Department of Telecommunication Services (soon to become Bharat 
Sanchar Nigam Limited) began to put into action a series of policies aimed at ensuring the success of India's nascent cellphone industry. ${ }^{20}$ Assa Doron and Robin Jefferies trace these changes, noting that in October 1999 a New Telecom Policy (NTP-99) was formed under a coalition government. NTP-99 put forth longer mobile license periods, expanded the scope of services private telecom companies could provide, and reformed the structure of the country's regulatory authority (TRAI) to allow it have the final say in mobile phone charges. As a result of these changes the number of cellphone users in the country grew fourfold between I 999 and 2005, with the majority of users becoming subscribers of private company networks. ${ }^{21}$ While these regulatory changes are not directly linked to the rise of dating app use in the country, they provide a foundation to begin examining the link between digital platforms (such as dating apps) and medium specific technologies they are intertwined with (here, mobile phones).

Along with the proliferation of cellphones were a series of moral panics about the disintegration of Indian cultural values as a result of mobile phone use. ${ }^{22}$ In 2004 a video clip of two underage students engaging in sexual activity was recorded over a cellphone and passed as a MMS (multimedia messaging service) clip from one mobile phone user to another. In the aftermath of this event, several educational institutions banned the use of mobile phones within the premises of their buildings. ${ }^{23}$ The 2004 "DPS MMS Scandal," as it came to be colloquially known, marked the beginning of a series of well-publicized news stories where mobile phones were placed at the center of national debates regarding issues of female sexuality and individual privacy. ${ }^{24} \mathrm{~A}$ big part of the moral uproar surrounding the clip was that the two individuals involved were underage and came from "well-educated upper-middle class" backgrounds. Through the 2000 s as debates raged over national media regarding the potential consequences of mobile phones on Indian female sexuality and family life, young technology entrepreneurs began appearing in cities like Bangalore, Hyderabad, and Delhi trying to wrangle their claim on the country's expanding market for Internet-enabled applications. ${ }^{25}$ Anna Lee Saxenian examines the rise of these cross-regional flows between Silicon Valley and Indian technology capitals, noting how the globalization of entrepreneur networks in these regions was emblematic of broader labor market changes that blurred the distinction between center and periphery in digital technology production..$^{26}$ Among the growing legion of nonresident entrepreneurs that began to arrive in India during the late 2000 s were the founders of Shaadi.com and Bharat Matrimony, two start-ups that transformed the Indian paper matri- 
monial column into a searchable interactive online database using Western websites such as 'Match.com' as templates to design their interfaces. ${ }^{27}$

The aesthetics of and advertisements for Indian matrimonial websites prominently displayed the figure of a New Indian Woman who Shoma Munshi describes as a person who embodies a global lifestyle but sticks to Indian values. Nearly two decades before Shaadi.com and Bharat Matrimony launched, Munshi traced how burgeoning Indian makeup and fitness industries deployed the figure of this New Indian Woman through images of femininity that were simultaneously shaped by global media flows and laced with local ideals of femininity. ${ }^{28}$ Tracing this figure in the television industry of the ' 80 s and 'gos, Purnima Mankekar argues that popular television melodramas such as Udaan and Rajani sustained the imaginary of this suitably modern female figure by featuring "secular, modern middle class consumers." ${ }^{29}$ Theoretically, conceptualizing advertising as a practice of commodity production that builds public culture, William Mazzarella, in examining a range of Indian advertising campaigns between the I980s and I990s, argues that "Indianness" becomes a commodity in the contemporary advertising industry that is increasingly commercially viable in a globalizing market. ${ }^{30}$ Similarly, observing the first time that the Miss World pageant was held in Bangalore, India in 1996, Radhika Parameswaran writes about how perceptions regarding the benefits of being associated with the event for producers of the local culture industry were tied to categories of gender and nation. ${ }^{31}$

As with many of the consumerist activities surrounding the lifestyle of India's new middle class, socially approved behaviors for women intertwine with broader political and cultural debates regarding acceptable versions of modernity. Here, it is worth remembering that while this chapter is focused on India, this figure of a 'new woman' is associated with a wide variety of non-Western spaces in South and Southeast Asia where gendered ideals of modernity became tied to the feminine figure over the first half of the twenty-first century.

Underlying all these narratives is the centrality of appropriate displays of femininity in the national imagination of modernity. ${ }^{32}$ Because of these reasons, I am in interested in how ideals of both masculinity and femininity negotiated by industry actors within the present moment of erotic proliferation have helped the rise of mobile-phone-based dating in India. Examining these technology cultures involves tracing how ideas surrounding "dating" are used by dating app companies in their production decisions. ${ }^{33}$ In what follows, I examine how ideas about "dating" are imagined and mo- 
bilized by TrulyMadly, one of the leading Indian dating app companies. To be sure, observations about TrulyMadly are not reflective of production and design cultures across dating app companies. But it does provide a rich site to examine how historical tensions between piety and promiscuity in the figure of the Indian young, middle-class woman get worked out in an effort to make "Indianness" commercially viable in mobile mediated dating.

\section{TrulyMadly: Safely Sexual}

On a hot June afternoon, I made my way to TrulyMadly's corporate headquarters to try and understand how its executives mobilized and deployed the term "dating" in their production and design practices. The layout of the south Delhi office exuded a modern minimalist aesthetic. Walking into the ground floor foyer from a dusty street in an up-and-coming neighborhood (filled with small independent art galleries), I was greeted by an all-white décor and an open floor plan. The style of the space was particularly notable considering that all three founders of the app were in their late 30 s/early 4 os and entering the realm of mobile dating from traditional corporate careers in travel and banking. ${ }^{34}$ Shuffling my feet into what appeared to be a waiting area, I perched myself on the edge of an ottoman (again, all white) underneath a neon sign made up entirely of lightbulbs spelling the word "CHAI" in capital letters. I had managed to get one of the cofounders' contact details the evening before. Tracking down busy professionals working in dating app companies operating in India was an exercise in tenacity and persistence that involved gaining access to large "entrepreneur WhatsApp" groups. In these groups emotional support, financial advice, and network contacts were crowd-sourced $24 / 7$ by members of India's start-up software and business development community.

Fifteen minutes after arriving at TrulyMadly's office I found myself inside a meeting room with two glass walls listening to one of the app's founders give me his take on a question that had been on my mind for a while: What did TrulyMadly believe Indians were looking for on the app? The answer according to him was simple: the app allowed people to safely explore their sexual desires. As the interview went on he described how he was initially surprised by survey responses conducted by the company where users repeatedly indicated that one of their favorite parts of the app was "dirty talking" with people they had never met. Asking him why he had found this surprising, I was told, "Well, you don't expect this from Indian girls, do you?" This response captures much of the essence of public dis- 
course regarding behavioral norms for women-namely the idealization of "good" women as innately passive in sexual scenarios. For example, scholars have noted that media representation of female sexuality in Bollywood tends to characterize female leads as stoic bearers of the amorous desires of male heroes, rarely if ever being driven by sexual desire themselves. ${ }^{35}$ Instead, the burden of the erotic is borne by the figure of the vamp who makes a temporary appearance often through a song or dance routine (colloquially known as an item number) and then disappears back into the periphery of the storyline. ${ }^{36}$ What becomes expected from women, or at least from those portrayed as "good," is romantic desire devoid of sexual drive.

What is interesting to note in the case of TrulyMadly is not so much their apparent surprise at sexual activity initiated by females over their platform or attempts to capitalize on it, but rather their efforts to bound possibilities of this erotic desire through discourses of safety both in the digital and physical domains. The spatial and temporal mobility that these apps bring by virtue of their constant connectivity provides an additional layer of complexity to the idea of digitally mediated desire in a country where concerns surrounding women's safety and sexuality found their way into the spotlight of public discourse since the Delhi Gang Rape of 20 I $2 .{ }^{37}$

This centrality of "safety" is reflected in TrulyMadly's app design, marketing material and public statements. For example, in their brief company description on the Google App Store and CrunchBase (an open market company database) TrulyMadly use the analogy of friends setting up other friends on a date, except here the "friend" doing the setting up is their digital platform: "Safe and Discreet-They're like those friends who know how to keep all information you share, private. Your profile can only be viewed by the ones they sort out for you. And you can only be messaged by those you have liked. No casual surfing, no spamming, no peeping tom business."

The term "They" in the excerpt above refers to the app itself (TrulyMadly). The platform is presented as a friend who knows what is best for you. A key concern for the app is keeping romantic and intimate connections over the app both "safe and discreet." What is not permitted in this vision of appropriate intimacy over the platform is "casual surfing," "spamming," and "peeping tom business." The use of the phrase "peeping tom" is particularly interesting not just because of its colloquial, informal tone but also because it brings in dynamics of who should or should not be looking. As highlighted in the discussion on TrulyMadly's "Creep Qawwali" advertisement, the figure of the male creep is the most likely candi- 
date to be the "peeping tom" that women need protection from. Thus, the female users "dirty talking" with strangers on the platform in many ways directly opposes the intended/desired definition of "dating" the platform seeks to facilitate. If the logics of intimacy, as Lauren Berlant and Lisa Lowe suggest, can be conceived of as more than closeness between individuals (romantic or sexual) but rather a bio-politics through which institutional forces administer power, then what versions of modernity does TrulyMadly's engagement with the term dating provide? In an effort to answer this question I delve into the specific practices through which TrulyMadly operationalizes "appropriate dating" through its design, marketing, and financial structure. In particular I explore the ways in which gendered sexuality intersects with what appropriate mobile dating is imagined by the producers and designers of the platform.

Since I was interested in the specific processes through which "security" was guaranteed by "local" dating applications, I asked TrulyMadly's cofounder to elaborate on how they guaranteed safety in their app: "TrulyMadly's most obvious difference is that it uses trust-based scores to verify," he said. "The process, of course, also provides women with greater peaceof-mind about their potential matches." ${ }^{38}$ As part of this process of verification, TrulyMadly users were asked to sign in through Facebook and were given the option to provide their voter card information in return for access to more matches and better matching features on the platform. Using this information TrulyMadly manually compared demographic data provided on the card with criminal databases and Facebook accounts. For example, if a man had a criminal record or his Facebook account did not have a profile photo with a face on it they were automatically removed from the app. Reviewing a combination of national identification documents and online behavior is not an uncommon practice; social media platforms, online marketplaces, and matrimonial columns have long used incentives (such as greater searchability) to encourage users to provide identifying documents (from passports to mobile numbers).

While these efforts are not unique, here are at least two things that are interesting about verification efforts by TrulyMadly. ${ }^{39}$ The first is that "safety" was largely a manually mediated process. This is notable in a digital sphere increasingly dominated by narratives of the centrality of algorithmic cultures and suggests a need for closer scrutiny of common presumptions regarding the digital architecture of Internet-enabled mobile applications (more specifically, dating apps). The second was that the burden of having to prove one's identity was placed almost exclusively on 
older men - specifically men above the age of 27 : "For men above 27 we always access their Facebook accounts. So we have one girl whose job is just to access Facebook accounts. This audit we do for men over 27 who are married."

The monitoring of age on dating applications can occur through explicit methods such as minimum and maximum age restrictions as well as deterrents such as age warnings on Google and Apple Play. Taking the case of Tinder, Stephanie Duguay observes that the app allows individuals between the ages of I 3 to I 7 to be matched only with other users within the same age bracket. ${ }^{40}$ In addition, she notes that the maximum possible age setting over the app is 55 , suggesting a strong focus on a younger demographic. Similar structural features to target younger audiences yet deter "children" from dating platforms can be seen on the popular dating applications, including TrulyMadly. What I was particularly curious about in the case of TrulyMadly was why the age 27 was chosen as the age after which men received additional scrutiny. The reasons I was given were vague but appeared to be partly arbitrary and partly based on the fact that 27 was just above the average age of marriage in the country and the organization wanted to prevent married men from joining it. It is also worth noting that as of 2017 , age 27 generationally splits the Indian population roughly between those born before or after economic liberalization in the I99os. ${ }^{41}$ The centrality of the institution of marriage in determining appropriate relationships as well as who might be possible threats for these relationships alludes to a fuzzy definition of safety as both a protection from everyday acts of physical/emotional violence as well as protection from a range of forces that threaten not the individual, but social institutions.

The processes to ensure safety by TrulyMadly allude to two types of 'danger' that the company believed Indian women needed protection from. The first was the danger of unwanted male attention as humorously advertised in its viral video "Creep Qawwali" (described at the beginning of this chapter). The second was the danger of the breakdown of the institution of "marriage," which is deemed by TrulyMadly to be particularly vulnerable. This is not to say that TrulyMadly explicitly structured its app around protecting the institution of marriage, but rather the figure of the "creep" that women on the app needed protection from was feared to be a man who transgressed the bounds of marriage. In this way, sexual liberation becomes premised on "protection and safety" where what is considered as safe is mobilized through corporate decisions that attempt to structure user 
interactions on the app. ${ }^{42}$ Thus, even as the expansion of the possibilities for females to express and explore their desires becomes a central part of the structure of the app and its advertising, the core of this expansion remains dependent on the guarantee of safety for women.

\section{Desire 101}

Between 2015 and 2016, apart from "Creep Qawwali," TrulyMadly put forward two more ad campaigns. The first, \#boybrowsing, centered around girls checking out and flirting with young attractive men in real life and then browsing through profiles over the app. The second, called Watcbboyz, featured a music video with the catchy chorus "If you want, then call a guy over to your house. ... If you want, then sit on the verandah and smoke a 'doobie." In both videos "dating" through the app was framed as an embracing of a modern cosmopolitan lifestyle and of sexual discovery for Indian women who might choose to use the app. As I show below, the right way of "doing dating" is simultaneously structured by local understanding of international ideals of desire and sexuality.

One of TrulyMadly's aims as a dating app company was to educate Indian men on appropriate ways to "date" through its platform. When I went to speak to them in 2016 they were experimenting with plans to have a premium service where a woman would chat in real time with men and give them tips on how to become more successful in their digital interactions with women.

Describing the need for the service, a cofounder of the platform commented:

We [men] don't grow up with skills like to talk. Our purpose now is to teach them how to chat ... so now two weeks back we got this psychology major. She is just sitting and chatting with guys, telling them how to chat up, just chatting with guys telling them how to make a conversation. So if it is useful today, then, we can scale it up tomorrow and maybe even charge for it [as a premium service] the day after. $^{43}$

Dating is presented as the discovery of new ways to express intimacy, but one that needs to be taught (and one that can be commoditized in the process). Masculinity becomes tied to performances of male behavior that 
fit within stringent cosmopolitan stereotypes of male-female interactions, where cosmopolitanism operates as a sociocultural condition that enables the imaginary of a global-local hybrid that is simultaneously celebrated for its cultural creativity and feared for its perceived threat to local and national identities. ${ }^{44}$

Apart from its advertising strategies, TrulyMadly's move away from its genesis as a matrimony-oriented matchmaking services, a vestige of which remains in its official registration as TrulyMadly Matchmakers Pvt. Ltd., and its pivot toward a more cosmopolitan aesthetic have focused on constructing a user interface and corporate space incorporating a "light global millennial design." ${ }^{45}$ When developing the initial version of the application in 2013 TrulyMadly hired a UX (user experience) design firm to conduct a workshop with the key stakeholders behind TrulyMadly to help them articulate the key characteristics they hoped their platform would have. ${ }^{46}$ Keywords for the desired look/feel/structure of the platform by the organization heads were "Cool, Edgy, New Age, Clean, Visual, Intuitive, Engaging, Directional," and the characteristics of users according to corporate stakeholders were "independent, evolved, outgoing, liberal, urban, semiurban, progressive, anxious, aspirational, opinionated, influenced."

In 2017 , in downloading the II.04 MBs that comprise the digital data of the completed app, one is treated to a series of images of the interface and then asked to sign in via Facebook. Registering without Facebook appears to be impossible. After a Facebook login, a person is led to a primarily white screen and asked to enter a series of demographic information (e.g., height, city of residence, occupation). Following this, a prompt"describe yourself in at least 3 words"-pops up. These descriptions are to be presented through a series of hashtags, automatic suggestions include "\#FriendChat \#CoolDude \#LiveandLetLive." A variety of incentives to increase one's trust score is suggested-among them are the options of providing one's LinkedIn Profile, mobile number, or options direct references. The combination of carefully phrased hashtags and repeated nudges to verify both one's identity and one's intentions suggests the push and pull between ideas of liberation and protection that underlie experiences of online dating in India. In the case of TrulyMadly we see a local company aiming to tap into the allure of sexual liberation as a characteristic of cosmopolitan culture. However, in framing security (as essential to the Indian female experience) and a pedagogy of proper etiquette (as symptomatic of the Indian male condition) it suggests the contradictory imaginations of what social structures "dating" fits within the national context. 


\section{Conclusion}

Following a long lineage of examining the media and technologies' engagement with the erotic, I make a couple of different observations. First, I note how concerns surrounding the influence of new media flows repeatedly get framed in terms of gendered relationships with technologies. Yet there remain features associated with contemporary dating applications (such as geo-location and continued connective mobility) that suggest the potential uniqueness of mobile-phone-based dating platforms (compared to their web-based avatars). While this might seem an obvious point, it is worth reiterating since examination of emerging technology platforms often gets framed as either uniquely revolutionary or simply a repetition of histories, when in fact they are more often than not a combination of the two. Taking a closer look at a specific case reveals how industry lore about dating-specifically, as an expansion of sexual possibilities-comes to define both media representations and design features. Yet even as dating is constructed as a way to explore, discover, and express one's sexual desires, it remains deeply gendered and worked out within a particular app as protecting women's "safety."

\section{Notes}

I. A style of Sufi devotional music.

2. A pair of small different-sized hand drums used especially in the music of India.

3. Cofounder of TrulyMadly, interview, New Delhi, 2016.

4. "Truly Madly Presents Creep Qawwali with All India Bakchod," YouTube Video, https://www.youtube.com, accessed March I, 20 I 7.

5. Ibid.

6. Based on a database of social and leisure applications curated by the author based on App Annie Statistics as of December 2015.

7. DealStreetAsia, "TrulyMadly Secures \$5.7 Million in Series A Funding," March 4, 20I 5, https://www.dealstreetasia.com, accessed November 2016.

8. TechCrunch, "TrulyMadly Is a Tinder-Style Dating App That's Built for India," March 2, 201 5, https://techcrunch.com, accessed November 2016.

9. This feature is now available in the majority of mobile-phone-based dating applications; however, in 2009 it was a groundbreaking development.

Io. The origins of geo-locative dating apps in catering to the queer community, more specifically men desiring men, might allude to proximity as a key feature in gay male hook-up culture that was then applied to dating applications targeting users across the sexual spectrum.

I I. In 2012 OkCupid was bought by the MatchGroup, an Internet company that was to grow to become the largest aggregator of dating apps. 
I 2. Kabita Chakraborty, "Virtual Mate-Seeking in the Urban Slums of Kolkata, India," South Asian Popular Culture Io (2) (201 2): 197-2 I 6.

13. "I Tried the Tinder Dating App in India," Wall Street fournal, accessed February 26,2017 , http://blogs.wsj.com

I4. Sarah Murray and Megan Sapnar Ankerson, "Lez Takes Time: Designing Lesbian Contact in Geosocial Networking Apps," Critical Studies in Media Communication 33 (I) (2016): 53-69; Stephanie Duguay, "Dressing Up Tinderella: Interrogating Authenticity Claims on the Mobile Dating App Tinder." Information, Communication \& Society 20 (3) (2017): 35 I-67.

I 5. Group m, "Interaction," Annual Report, 2016, accessed 25, February 2017.

I6. Adriana De Souza de Silva and Jordan Frith, "Locative Mobile Social Networks: Mapping Communication and Location in Urban Spaces," Mobilities 5 (4) (2010): 485-505.

I 7. Here I draw on Benedict Anderson's I 983 definition of imaginaries as imagined communities in Imagined Communities: Reflections on the Origin and Spread of Nationalism (London: Verso Books). For a related development of the concept, also see Mica Nava, "Cosmopolitan Modernity: Everyday Imaginaries and the Register of Difference," Theory, Culture \& Society I9 (I-2) (2002): 8I-99. To see its application in relation to sexuality, see Kath Weston, "Get Thee to a Big City: Sexual Imaginary and the Great Gay Migration," GLQ: A Fournal of Lesbian and Gay Studies 2 (3) (I995): 253-77.

I8. I use the term erotic(s) to refer to ideas and practices associated with sexuality and sexual pleasure.

I9. Purnima Mankekar and Louisa Schein, Media, Erotics, and Transnational Asia (Durham, NC: Duke University Press, 2013).

20. Asa Doron and Robin Jeffrey, Great Indian Phone Book (Cambridge: Harvard University Press, 20I3).

2 I. Ibid.

22. Ravindran, Gopalan. "New Media Modernity in India." In Living the Information Society in Asia. Institute of Southeast Asian Studies, 2009.

23. "Govt Joins Chorus to Ban Cellphones on Campuses," Times of India, January I9, 2005, http://articles.timesofindia.indiatimes.com, accessed March I 2, 20 I $3 .^{2}$

24. The proliferation of cellphones and the moral panics that accompanied them in the mid-20oos also captured the imagination of Bollywood-MMS scandals became the focal plot point of Dibakar Banerjee's 2o Io Hindi cult classic Love, Sex Aur Dhoka (Love, Sex and Cheating).

25. This particular narrative applies primarily to urban India. In rural India there remains a huge gender gap between male and female users, which means issues of access are an additional layer to consider while examining the relationship between technology and intimacy.

26. Saxenian, AnnaLee. The New Argonauts: Regional Advantage in a Global Economy. Harvard University Press, 2007.

27. While these two online matrimonial platforms were not mobile phone based, they made possible the opening up of Internet-enabled technology as a space for intimacy, a space that over the years has increasingly overlapped with mobile technology. See Fritzi-Marie Titzmann, "Changing Patterns of Matchmaking: The 
Indian Online Matrimonial Market.” Asian fournal of Women's Studies I9 (4) (2013): 64-94, and Fritzi-Marie Titzmann, "Media Mobility and Convergence within India's Matrimonial Market." In New Media Configurations and Socio-Cultural Dynamics in Asia and the Arab World, edited by Nadja-Christina Schneider and Carola Richter, 242-59 (London: Bloomsbury, 20 I 5).; Kabita Chakraborty, "Virtual Mate-Seeking in the Urban Slums of Kolkata, India," South Asian Popular Culture Io (2) (2012): I97-2 I6.

28. Shoma Munshi, "Wife/Mother/Daughter-in-Law: Multiple Avatars of the Homemaker in I99os Indian Advertising," Media, Culture of Society 20 (4) (I998): 573-91.

29. Purnima Mankekar, Screening Culture, Viewing Politics: An Ethnography of Television, Womanhood, and Nation in Postcolonial India (Durham, NC: Duke University Press, I999).

30. William Mazzarella, Shoveling Smoke: Advertising and Globalization in Contemporary India (Durham, NC: Duke University Press, 2013).

3. Parameswaran, Radhika. "Global Queens, National Celebrities: Tales of Feminine Triumph in Post-Liberalization India." Critical Studies in Media Communication 2 I, no. 4 (2004): 346-70.

32. See Weinbaum, Alys Eve, Lynn M. Thomas, Priti Ramamurthy, Uta G. Poiger, Madeleine Yue Dong, and Tani E. Barlow. The Modern Girl around the World: Consumption, Modernity, and Globalization. Duke University Press, 2008.

33. Drawing conceptually on Purnima Mankekar, Screening Culture, Viewing Politics: An Ethnography of Television, Womanhood, and Nation in Postcolonial India (Durham, NC: Duke University Press, I999).

34. "How the Co-founder of MakeMyTrip Fell in Love with a Dating App," Tech in Asia, accessed August 7, 2016 (https://www.techinasia.com). Interview, TrulyMadly headquarters, June 2016.

35. Amrita Nijhawan, "Excusing the Female Dancer: Tradition and Transgression in Bollywood Dancing," South Asian Popular Culture 7 (2) (2009): 99-I I 2."

36. Ibid.

37. This refers to the brutal rape and murder of a woman, Jyoti Singh Pandey, in December 20I 2 in Delhi. The unfortunate event galvanized a series of national and global protests drawing attention to sexual violence against women. Writing about the aftermath of the event, Lodhia 2015 . Lodhia, Sharmila. "From 'living Corpse' to India's Daughter: Exploring the Social, Political and Legal Landscape of the 20 I 2 Delhi Gang Rape." Women's Studies International Forum 50 (May I, 20 I 5): 89IOI. https://doi.org/10.1016/j.wsif.2015.03.007 notes, "The severity of the attack and the inadequate response of the Indian government to the crime provoked nationwide protests and demands for legal reform. While other rapes have prompted public outcry, this particular crime inspired elevated interest, not only in India but around the world."

38. TechCrunch interview, 2015 .

39. Though not necessarily exclusive to it.

40. Stephanie Duguay, "Dressing Up Tinderella: Interrogating Authenticity Claims on the Mobile Dating App Tinder," Information, Communication \& Society 20 (3) (20I 7): 35 I-67. 
4I. Economic liberalization in India refers to a period beginning in I99 I where a set of economic policies aimed at opening up the market to foreign investment and adopting a more market capitalist approach has been often associated with the rapid economic growth of the Indian economy. Those born during the I990s (men below the age of 27) would have experienced a different sociocultural and economic landscape than the generation before. While there is not enough evidence to suggest that this generational divide is the driving force in TrulyMadly's decision it is nonetheless worth noting as it highlights how moments of socioeconomic and cultural change can generationally divide populations' perceptions toward dating and desire.

42. Caste and income are two other social indicators that are likely to be important determinants that are read by users, but not part of the sign-up process.

43. Interview, TrulyMadly headquarters, Delhi, June 2016. Reiterated public panel discussion, Godrej India, Mumbai 20 r6.

44. Steven Vertovac and Robin Cohen, Conceiving Cosmopolitanism: Theory, Context and Practice (Oxford: Oxford University Press, 2002). Also see Arjun Appadurai and Keith Breckenridge, "Why Public Culture?" Public Culture I (I) (I988): 5-9.

45. Interview, Lodhi Gardens, New Delhi, June 28, 20 I6.

46. Ibid.

\section{References}

Anderson, Benedict. (I983) 2006. Imagined Communities: Reflections on the Origin and Spread of Nationalism. London: Verso Books.

Appadurai, Arjun, and Carol A. Breckenridge. I988. "Why Public Culture?” Public Culture I (I): 5-9.

Weinbaum, A. et al. 2008. The Modern Girl around the World: Consumption, Modernity, and Globalization. Durham: Duke University Press.

Chakraborty, Kabita. 20 2. "Virtual Mate-Seeking in the Urban Slums of Kolkata, India." South Asian Popular Culture Io (2): I97-2 I 6.

De Souza e Silva, Adriana, and Jordan Frith. 20 Io. "Locative Mobile Social Networks: Mapping Communication and Location in Urban Spaces." Mobilities 5 (4): 485-505.

Doron, Assa, and Jeffrey Robin. 20I3. The Great Indian Phone Book. Cambridge: Harvard University Press.

Duguay, Stefanie. 20I7. "Dressing Up Tinderella: Interrogating Authenticity Claims on the Mobile Dating App Tinder." Information, Communication \& Society $20(3): 35$ I-67.

Havens, Timothy, Amanda D. Lotz, and Serra Tinic. 2009. "Critical Media Industry Studies: A Research Approach." Communication, Culture \& Critique 2 (2): 234-53.

Katyal, Akhil. 20 I r. "Playing a Double Game: Idioms of Same Sex Desire in India." PhD diss., University of London.

Kraidy, Marwan. 2005. Hybridity, or the Cultural Logic of Globalization. Philadelphia: Temple University Press.

Mankekar, Purnima. I999. Screening Culture, Viewing Politics: An Ethnography of Tele- 
vision, Womanhood, and Nation in Postcolonial India. Durham, NC: Duke University Press.

Mankekar, Purnima, and Louisa Schein. 201 3. Media, Erotics, and Transnational Asia. Durham, NC: Duke University Press.

Mazzarella, William. 2003. Shoveling Smoke:Advertising and Globalization in Contemporary India. Durham, NC: Duke University Press.

Munshi, Shoma. I 998. "Wife/Mother/Daughter-in-Law: Multiple Avatars of the Homemaker in I990s Indian Advertising." Media, Culture \& Society 20 (4): 57359 I.

Murray, Sarah, and Megan Sapnar Ankerson. 20r6. "Lez Takes Time: Designing Lesbian Contact in Geosocial Networking Apps." Critical Studies in Media Communication 33 (I): 53-69.

Nava, Mica. 2002. "Cosmopolitan Modernity: Everyday Imaginaries and the Register of Difference." Theory, Culture \& Society I9 (I-2): 8 I-99.

Nijhawan, Amita. 2009. "Excusing the Female Dancer: Tradition and Transgression in Bollywood Dancing." South Asian Popular Culture 7 (2): 99-I I 2.

Ramasubramanian, Srividya, and Parul Jain. 2009. "Gender Stereotypes and Normative Heterosexuality in Matrimonial Ads from Globalizing India." Asian Fournal of Communication i9 (3): 253-69.

Ravindran, Gopalan. 2009. "The Cultural Politics of New Media Modernity in India." Living the Information Society in Asia 365: 93.

Titzmann, Fritzi-Marie. 2013. "Changing Patterns of Matchmaking: The Indian Online Matrimonial Market." Asian fournal of Women's Studies I9 (4): 64-94.

Titzmann, Fritzi-Marie. 2015. "Media Mobility and Convergence within India's Matrimonial Market." In New Media Configurations and Socio-Cultural Dynamics in Asia and the Arab World, edited by Nadja-Christina Schneider and Carola Richter, 242-59. London: Bloomsbury.

"TrulyMadly Presents Creep Qawwali with All India Bakchod." 20I5. YouTube Video, https://www.youtube.com. Accessed March I, 2017.

Vertovec, Steven, and Robin Cohen. 2002. Conceiving Cosmopolitanism: Theory, Context and Practice. Oxford: Oxford University Press.

Wallis, Cara. 20 5. Technomobility in China: Young Migrant Women and Mobile Phones. New York: NYU Press.

Weston, Kath. I 995. "Get Thee to a Big City: Sexual Imaginary and the Great Gay Migration." GLQ: A Journal of Lesbian and Gay Studies 2 (3): 253-77. 


\title{
Anomalously Digital in South Asia
}

\author{
A Peri-Technological Project for Deaf Youth \\ in Mumbai
}

\section{Shruti Vaidya and Kentaro Toyama}

The proliferation of South Asian digital media, particlarly its unique forms of consumption and production, offers much to be celebrated: from aspirational romantic gestures on Facebook (Arora and Rangaswamy 2015) to grand edicts for more accessible government (Bhargava 2015), from classified ads via mobile text-messaging (Zainudeen, Samarajiva, and Sivapragasam 20I I) to martyred sex symbols on social media (Mohsin 20I6).

Into this mix, we throw in an oddball project: one in which the typical narratives of technology as savior or oppressed minority as vulnerable beneficiary are upended, all while engaging in a quasi-action-research methodology whose intervention is not gadget-focused but peri-technological. Our post hoc aim is to further stretch the already impossibly broad span of South Asian digital phenomena to its breaking point, and to ask: Does it even make sense to speak of a digital South Asia? Is there anything that coheres in the vast expanse of the subcontinent's myriad engagements with the digital?

In our study, we consider digital hearing aids for deaf young adults in Mumbai. Like deaf people all around the globe, deaf young adults in India must negotiate institutions and spaces constructed by a predominantly hearing world. Digital hearing aids may offer deaf people with moderate to severe hearing loss a chance to gain some degree of hearing ability, yet 
the use of hearing aids is a fraught issue among the deaf community, many of whom question the pressure for the deaf individuals to adapt to hearing society (Guillemin, Gillam, and Brookes 2005).

Indeed, though hearing people consider deafness to be a disability, this assumption has been frequently questioned (Padden and Humphries I990). Many deaf people do not consider themselves to have hearing loss as much as deaf gain (Bauman and Murray 2014). Deafness may confer individuals with visual acuities that hearing people may lack, and we as a global society are surely made richer by the existence of sign languages, as much as we are with spoken languages. Such gains from deafness, both as individual trait and broader cultural phenomenon, raise an analogy regarding the use of hearing aids: Could the use of hearing aids be akin to the assimilation of smaller cultural groups into majority cultures, leading to the demise of a unique language and culture?

Meanwhile, there is little doubt that the ability to hear can have advantages in a world of sound. Even deaf people—as we heard from our participants-do not deny the potential value of, for example, being able to hear an approaching vehicle, or of interpersonal communication without line of sight.

In our project, we worked with the students of a nonprofit academy in Mumbai whose mission was the education of deaf teens and young adults, and provided I4 of them with hearing aids. Our objective was both to understand how the students perceived the hearing aids (before and after receiving them), as well as to see whether there might be a way to transform the perception of the devices in both the hearing and deaf worlds. In particular, we asked half of the participants to decorate their hearing aids in a personalized way that would cause them to stand out more than the devices otherwise did. We wondered whether by having wearers own a symbol of potential stigma, it could change other people's perception of the deaf individual, as well as affect how the participants felt about their devices.

India presents an intriguing backdrop for this work for several reasons. For one, the country has an exceedingly complex relationship with what are often considered disabilities. Observers note, for example, that disabilities are commonly seen to be the fruit of karma, and therefore the result of negative actions in a previous life (Lang 200I). The disabled person is thought to deserve their inconvenience, and this shadow falls not only on the individual with the disability but also on their family who must contend with the supposed burden. Meanwhile, some communities celebrate disabled individuals as possessing special powers, often based on a religious 
interpretation (Lang 200I). The social realities of disabled people are further dependent on geography, religion, caste, and socioeconomic status. For example, families in urban areas are more likely to view disability in terms of its medical explanations, likely because of greater exposure to formal education and modern science.

Upon this complex and heterogeneous ground, the I99os witnessed the emergence of a disability rights movement (Mehrotra 20I I). This movement was intricately tied to the Indian state's engagement with disability. Historically, the Indian state has viewed disabled people through the lens of pity, rehabilitation, and charity. But the I980s saw the Indian state make a shift from a medical model to the development model, with disabled people becoming participants, not just recipients of state policy. The Persons with Disabilities Law (I995) has served as a strategic tool for disability activists to further their agenda. Nilika Mehrotra argues that unlike the women's movement, which had to stage protests in order to get laws drafted, the disability movement was mobilized around disability-related laws. At present, diverse advocacy groups, NGOs, and academics engage with disability and disabled people from the perspective of rights and services.

All of this, of course, is additionally complicated by the fact that deafness, if it is a disability at all, is not necessarily disempowering. Deaf people can and do lead independent lives without requiring routine assistance.

Another reason for India's uniqueness as a site for this study is its reputation as a digital technology superpower. India is among the leading sites for projects in "information and communication technologies for development," often abbreviated ICT4 4 D and usually implying digital technologies (Kano and Toyama 2016). The work described in this chapter can be understood in relation to that field. $\mathrm{ICT}_{4} \mathrm{D}$ projects seek to apply novel digital technologies to support socioeconomic development, and many are run by computer scientists and engineers, eager to use their technical skills to address social challenges in domains such as agriculture, education, governance, and healthcare (Unwin 2009). India's prominence as a host to these projects is likely due to a combination of its information technology (IT) prowess, its high rate of poverty, and a strong tradition of grassroots activism and charitable work. The Indian government has been a strong sponsor of such projects, hoping to spread the success of its IT sector to rural development, with large projects ranging from a universal ID card (Sathe 20I I), to rural broadband telecenters (Prasad and Ray 2012), to more recent efforts to computerize government services toward a "Digital India" (Bhargava 20 I 5). Usually, such projects highlight novel technology, but in 
the study reported here, we consider a low-tech decoration that affects how an existing digital technology is received. In a context where many deaf people have been forced to wear hearing aids in school as a child (Friedner 2015), how would a design intervention that collaboratively involves project participants affect their relationship with a digital aid?

This chapter discusses the core of our research study and concludes with a discussion of the technicolor digital kaleidoscope that is South Asia.

\section{An Aside on Terminology}

As with other researchers who have worked with the deaf community, we wrestled with terminology. Some scholars use Deaf with a capital "D" to indicate the deaf community, in recognition of its linguistic and cultural distinctness (Woodward 1972; Padden and Humphries 1990). These authors often reserve lower-case "deaf" to mean the fact of being unable to hear. We have, however, opted to keep "deaf" and its derivatives lower case, following both Friedner (2015) as well as our deaf participants, who did not adhere to the language of capital-D deaf or the idea of being a culturallinguistic minority.

Meanwhile, the word we use for hearing people is either "hearing" or "normal." Initially, and also as noted by Friedner (2015), we were taken aback by the use of the latter word by the deaf community in Mumbai, no doubt because we projected onto it an interpretation that not to be normal is to be abnormal or deviant. But, as we have come to understand through our participants, "normal" in this context implies no judgment about their or others' social rank. It indicates simply a matter of fact that hearing people outnumber deaf people, and therefore define a merely statistical majority.

\section{A Deaf Community in Mumbai}

Our research was conducted in Mumbai, India, with deaf young adults who strongly identified as deaf. We initially approached audiology clinics to see whether any would be open to a project involving their patients, but most audiologists seemed skeptical. It was explained to us that usually, much younger children came in for hearing aid fittings, while young adults who had not used hearing aids already would refuse to use them. The clinics directed us to visit deaf schools, as that was where we were most likely to meet deaf young adults. 
Soon after, we established a collaboration with a school located in a Mumbai suburb. It is a privately funded academy that was founded in the I 990 s and which has operated largely through the efforts of its principal, a normal woman. Today it is a high-functioning, elite, nonprofit organization housed in a multistoried building. As described on its official website, the school is for students with hearing impairments, multiple disabilities, and other special needs, but most of its student body is composed of deaf students. The principal of the school hoped to leave her students with an education that allowed them to lead independent, productive lives in a hearing society. She wanted more of her students to use hearing aids.

The school is managed almost exclusively by normal teachers and staff. A majority of the teachers, excluding one deaf teacher who is an alumnus of the school, impart their lessons orally along with some rudimentary sign language. The school also has one interpreter, but she must flit from one class to another and cannot accommodate all the needs of all the classes in her schedule. The participants were all students of this academy, and were composed of deaf teens and young adults.

\section{Methodology}

Our study spanned the ten-month period from November 2015 through August 20I6, with much of the first several months seeking out a group of participants interested in our project and establishing relationships with relevant stakeholders. Our overall approach was ethnographic, involving a combination of formal and informal interviews, participant observation, and simply accompanying participants as they went about their daily lives. Whenever possible, one of us (Vaidya) spent significant time at the academy, with the principal, and with the student participants, often involving eight or more hours of engagement per day straddling the school day and after-school hours. Vaidya had little prior experience with sign language at the beginning of the study, but learned it to some degree of fluency by the end of the study. She communicated with deaf participants using a combination of signing and, when necessary, interpretation via some of the school staff. The students use what could be considered a variant of Indian Sign Language that is common in Mumbai. (The quotations by participants provided here have been translated from Indian Sign Language to written English. The process of translation has involved reworking the syntax and sentence structures of ISL into English.)

We discussed our ideal set of participants with the principal. We were 
seeking an even mix of women and men who were interested in trying hearing aids but unable to afford them. The school principal then drew up a list of students who formed a larger pool from which we selected our research participants. In the end, all of our 14 participants were young adults-seven women, seven men-from 18 to 26 years of age, each of whom opted to accept a hearing aid, and who were examined by a local audiology clinic for their suitability for a hearing aid. (Many deaf people have what is medically considered "moderate to severe hearing loss"- a loss in hearing of 40-80 decibels-and some can hear sounds with a well-tuned hearing aid.)

The study was roughly divided into three phases. The first phase involved spending an extensive period of time at the school as well as other spaces the participants inhabited familiarizing ourselves with the context of their lives to the greatest extent possible. This phase also involved conversations with the participants through semistructured interviews about their general life experiences with various spaces and institutions as well as specific experiences regarding past hearing aids. In the second phase, we provided the participants off-the-shelf, behind-the-ear hearing aids along with professional fittings and return visits with a professional audiologist at no cost to them. We also interacted with them about the experiences of engaging with the new hearing aids. In the final stage, a randomly selected half of the respondents collaborated with an artist to codesign the decoration for their own hearing aid, while the other respondents continued using their regular hearing aids. The intention behind this comparative design was to explore if there were differences in the experiences of the personalized hearing aid versus the nonmodified hearing aid. This approach might be considered a kind of action research (Greenwood and Levin I998), but we are hesitant to use the term, as we had no longer-term goals beyond an understanding of how our specific "intervention" might change perceptions and behavior surrounding the hearing aids.

\section{On the Difference between Deaf and Normal}

Our initial conversations with the participants allowed us to gain a broad view of the context, histories, and affiliations of our participants. We also learned about their past experiences with hearing aids and their desires for a new one. The conversations, through semistructured interviews and over hours of participant observation at school, homes, and the sometimes meandering commute in between, were a way for us to engage with their 
opinions about deaf and normal people, families, friends, life partners, and aspirations. Below we highlight a small fraction of what emerged from these interactions, focusing primarily on what is pertinent for participant reactions to the hearing aids.

The baseline sentiment, heard over and over in our interactions, is that deaf and normal people are distinct from one another, primarily due to barriers of language. As captured concisely by Rohit (all names have been changed to preserve the confidentiality of the participants), "When normals talk, they speak. I don't understand it. When deafs sign, normal don't understand." This experience came out in stark relief when participants spoke of their schoolmates in comparison to their families. Most of the participants came from hearing families, and the dominant sentiment expressed about their families was one of alienation. In contrast, there was friendship, sharing, and collectivity experienced at school with fellow deaf students.

The communication gap was seen to have practical consequences, as well, particularly as a source of inequality between deaf and normal people. Education, especially with respect to English, was seen as being much easier for normals, which resulted in them performing better otherwise at school and in the larger Indian society. Varun, expressed this matterof-factly: "Normals can go to shop and ask for something and buy it. . . Deafs have to write it down and show it to the shopkeeper. . . Normals learn faster in school."

At the same time, there was no articulation of wanting to become normal. It was not seen as a desirable state. Many respondents talked about how boring it was to interact with hearing people because they would have to sign slowly.

\section{Family and School}

As above, familial spaces emerged as the consistent site of regular interactions with normal people. Yet this interaction only seemed to reaffirm their sense of alienation within the household. Most participants emphasized that home was a space of boredom and a desert of communication. Hrithik, describing his life at home, says, "I've tried teaching sign language at home, but they are too busy. So I just go home and sleep." Sunita, who immigrated from Nepal as a young child and lives with her hearing uncle and his family, says, "I ask my brothers 'What's happening on TV?' but they don't tell me because they can't sign." 
These vignettes highlight what deaf people perceive as the lack of effort on behalf of hearing people to learn their language, even when it is the language of a family member. Friedner (2015), who observed a similar dynamic in Bangalore, suggests that deaf young adults feel a disconnect with families, with conversation being limited to those required to satisfy physiological needs such as eating, drinking, and sleeping.

A small minority of participants had family members who could sign, and how they talk about these family members is revealing. The feeling is less gratitude and more that an expectation has been met. Something that should be happening more often has finally happened. Manisha, expressing her fondness for her brother says,

My brother signs very well. . . . I taught him and he is very good. When he was young, he would try to call me and I wouldn't be able to hear ... he used to get angry and wanted to hit me. Then Mom explained to him that I could not hear and asked him not to hit me and go tap me on the back if he wanted to talk... I love my brother. No one else signs.

But, except for a few such supportive family members who made the effort to learn sign language, families were experienced as isolating.

The school community was seen as very different from the family, but still with considerable complexity. The school we worked with represented a space to co-constitute life experiences with deaf friends, but also a site where authority still vests in hearing people.

Many painted deaf school as a site of engagement with other deaf people, contrasting it against the dull gray of their previous schools, which were for the most part taught in local (spoken) languages with teachers who did not sign at all. Rohit, recounting his experiences at previous school, said, "[My experience at the previous school was] not so good. They would speak and I wouldn't understand. I didn't understand the words. That school was in Marathi. This school is better. I am better at English and the teachers both sign and speak." Others expressed similar feelings.

But most importantly, deaf school was significant because it provided space for deaf people to meet each other, reconfirming observations by Friedner (2015). In fact, despite the assimilationist intentions of the academy's leadership, the students found it a conducive site for learning sign language and interacting with deaf peers. During our observations, we found that students were in no hurry to return home at the end of a day of 
classes, in contrast with normal students at most schools. In one case, for example, we saw young adults in the $\mathrm{s} 2$ th grade staying back, ostensibly to finish an environmental science project together. Yet even as the principal was present, helping them by hand-holding them through the material, the students engaged in signed side conversations whose content was largely nonacademic.

The close friendship among deaf students was specifically noted to be based on a common language. Friendship was not seen to be restricted to deaf people only, but our participants noticed a pattern that, as they grew older, friendship was increasingly constrained by the mutual knowledge of sign language. While some participants said they had no normal friends, others suggested that they used to have normal friends, who were now "too busy." As childhood friendships, based perhaps on physical activity, matured into an adult companionship based on communication, the distance was increasingly felt. Normal people were seen to assimilate comparatively easily into life after school into colleges and workspaces, resulting in their new found "busyness."

The occasional exceptions confirm the bond of sign language. Poornima's best friend from her neighborhood is normal. We observed that their interactions on a walk home from the train station occurred in sign language. Later, Poornima noted that they had been friends since they were children, and she taught her friend how to sign while growing up. Similarly, Rahul, a student in the i ith grade, mentioned a normal friend who lives near his house, to whom he taught sign language.

\section{Initial Perceptions of Hearing Aids}

Most of our participants had previous experiences with multiple hearing aids, and much of our interaction focused on them. They were familiar with two types of models: pocket models that require headphones and behind-the-ear (BTE) models that curl behind the ear lobe.

These conversations were dominated by problems that they had with the hearing aids: how they went bad, were lost, or were too noisy. Poornima said, "I had a pocket machine when I was young, but it became kharaab [went bad, mouthed in Marathi]. Then I got a BTE machine, but the mold used to hurt me, and that too became kharaab." It was not easy to tell whether the fact of the mold hurting her was the reason that she perceived it as going bad, or whether the two were distinct, unrelated events. In either case, though, there was no mention of a period of delight when the hearing 
aids worked. Rohit shared his experiences about the body hearing aid he used to have: "I could only hear noise with my previous pocket-machine. If there were cars or traffic on roads, I could hear it. But I never understood what the teacher was saying. I couldn't understand words or sentences." Similar stories were relayed by almost all of the other participants.

Given these negative experiences, it was not evident to us at first why our participants opted for new hearing aids in our study. The reasons varied. Poornima said, "I like riding scooters ... but without [the hearing] machine, I will not get a license." Tilakram, who is more conversant in spoken Hindi than most of the participants, said, "I want the machine to be able to hear close conversations." Based on their past experience, the participants were aware of the limitations of hearing aids as a technology, especially as determined by aid quality, which itself was determined by financial constraints. But even when those financial constraints vanish (as they did for them in our project), the participants can be seen to choose with strategic and pragmatic reasons in mind.

\section{Hearing Aids: Pragmatic and Aesthetic}

After being fitted with new hearing aids, however, reasons for use of the hearing aids sometimes changed.

For two months after the participants were fitted with hearing aids, but prior to their personalized decoration, we spent a substantial amount of time with the participants discussing their experiences with their new devices. The conversations focused on how they felt wearing the hearing aids in various spaces and others' reception. What did they think other people thought of their hearing aid? Did the perception of others affect their own perception of their appearance? Did using the hearing aid at all change the participant's perception of their own appearance? And, finally, did the design component change the experience of engaging with the hearing aid?

The reports were heterogeneous, though participants across the board cited both usefulness and problems. The usefulness was experienced on several pragmatic levels: to hear objects falling, doorbells ringing, horns blaring in traffic. Some of the participants said that the machine helped them with lipreading, listening to conversations close by, watching television, and hearing others calling out their name.

Despite these desirable outcomes, many of the participants expressed dissatisfactions, as well. A general theme that emerged along these lines was that the awaaz (sound or voice) was not clear. This caused obstacles in 
understanding full sentences, confusions between traffic sounds and other sounds, and even the direction of sound sources. Another complaint was that the mold of the hearing aid was too tight and caused physical pain (despite being offered the option to have the auditory clinic refit them at no cost). Sunita, talking about her problems with the machine, said,

It used to hurt a lot. I put some Vaseline [on] before using it. I talked to my grandmother about the machine. She tried talking to me with her mouth covered. I couldn't hear anything. I can't hear what the teacher is saying perfectly. I don't understand where the sound in traffic is coming from, or if a plane goes by.

On the whole, the participants alternated between use and nonuse, depending on the context, much as people with far-sighted vision put on glasses only to read. This differs from the medically anticipated use of hearing aids, which are designed for all-day use by manufacturers. For instance, Rohit told us that he uses the hearing aid in the school and while traveling from the station to school. He said he never uses it on the train, because the background noise becomes too loud. He also did not use it in his neighborhood, because normal people there ask him what it is and try to wear it. Over time, Rohit's engagement with the hearing aid diminished. While discussing his patterns of hearing aid usage a few months later, he said, he uses them only when there is urgency. For example, "When there is a program at school and I don't wear it, the principal scolds me. If there are guests coming to school ... I bring the machine to school and forget it in the bag until the principal scolds me." (Consistent with her desire for the students to assimilate, the principal apparently insisted to participants that they use the devices whenever possible.) Rohit's narrative illustrates how the reasons for using hearing aids can be strategic and change over time. It also shows how selective usage of the hearing aid determines who engages with the technology, in what manner, and whose reactions are finally received and interpreted by the participants.

After having provided the hearing aids, what was noticed was that the participants did not use or wear their machines all the time. In fact, they did not use the machines for the majority of the time that we were with them during school hours. At the same time, certain contexts did make the participants wear the hearing aid: in the principal's presence, in class being taught by a hearing teacher, for interviews for this study. But most often, 
when deaf young adults were interacting with each other, the devices were not used.

While discussing what wearing the hearing aids feels like, especially in terms of how it makes people feel about their appearance, the responses ranged from indifference to feeling good about it. In some cases, the hearing aid made their deafness visible, sometimes with humorous results. Sunita recalled, "Some people asked me about the machine when I went to buy milk. I had to explain to them that I cannot hear properly. Some women on the station saw me wearing the hearing aid and offered me a seat on the bench . . . they offer me the seat even when I am signing." Apparently, the person felt that deaf people required non-hearing-related physical accommodations!

At other times, these moments of recognition came with an ensuing retreat from interaction that disappointed our participants: "People sometimes come to ask things on the train. On one side I look normal. On the other side when I show the hearing aid, they understand I am deaf and say, 'Sorry."'

Yet others noted that the visibility of their deafness warded hearing people off entirely: "People on the road see the machine and they know.... When I didn't wear a machine, they would come and start talking to me. I would say I am deaf, they would say sorry and leave. When I wear the machine, people know [and don't approach]."

And still others felt comfortable with these phenomena, one way or another: "With the hearing aid, people know I am deaf. I am okay with that."

Deaf young adults conclude very quickly that the hearing world makes meaning of their deafness via the hearing aid as marker. Normal people are seen as reacting either with an acknowledgment of the deafness or guilt for not having acknowledged it in time.

Unexpectedly for us, but consonant with our other findings, none of the participants felt the least bit of shame about using hearing aids. Though there were different degrees of comfort and preference with respect to hearing aids themselves, there was no expressed complaint about the stigma of the technology. The closest thing that any of our participants said along these lines was the following by Narendra: "Before the design, people used to look at the machine and know that I am deaf. Now they look at the color. I feel nice." That is to say, he appeared to feel no stigma about the device or his deafness, but he did appreciate the shift in attention. As researchers, we had to reevaluate our starting assumption. While the participants had a 
complex relationship with the hearing aids, the technology was not experienced as a locus of stigma.

\section{Personalized Decoration}

Seven of the participants (exactly half) participated in an interactive workshop hosted by the researchers and an artist based in Mumbai. The participants were asked to draw a series of paintings about things that had meaning for them. The artist then took these portions of the paintings, digitized them, resized them, and printed them on stickers that could be applied to the hearing aid. One such design is shown in figure 6.I.

Did using these personalized designs change the experience of engaging with the hearing aids? Did it instill a sense of pride in being users of this technology? Did it have any larger impact on their self-identity as deaf young adults?

Varun was one of the people most enthusiastic about his design: "The children in the school loved it. They asked me, Who gave this to you? We want it too! My classmates also asked me where I got it. This is a really good idea!" Aishwariya had positive reactions to the design as well, saying, "All the kids asked me where I got it and they wanted it too! People at home asked me about it too. I told everyone that I made it and then your friend changed it to this size. All hearing aids look the same; this looks different. I like it." The appeal the design has to children raises a question about its appeal to young adults. The argument that the design distinguishes the hearing aid from other mass-produced hearing aids and hence is a pleasurable experience to wear illustrates how designs are intended to stand out, especially in relation to technologies that have been conventionally designed with the intention of discretion (Pullin 2009).

Yet the experience was not equally received by all participants. Virat, a college student, tried to negotiate with us from the beginning after being assigned the design group. When we met him a few weeks after he received the design, he told us that he took it off: "It made me feel like a baby! I feel that people look at me and laugh because I look like a baby. Though it is bright now, I used to like it when it was simple." Virat's comment suggests it is not a dismissal of the design's visibility as much as the playful nature of his design, which could be construed as being too childish for his tastes as a young man.

Finally, Narendra, one of the few who remarked specifically about what 


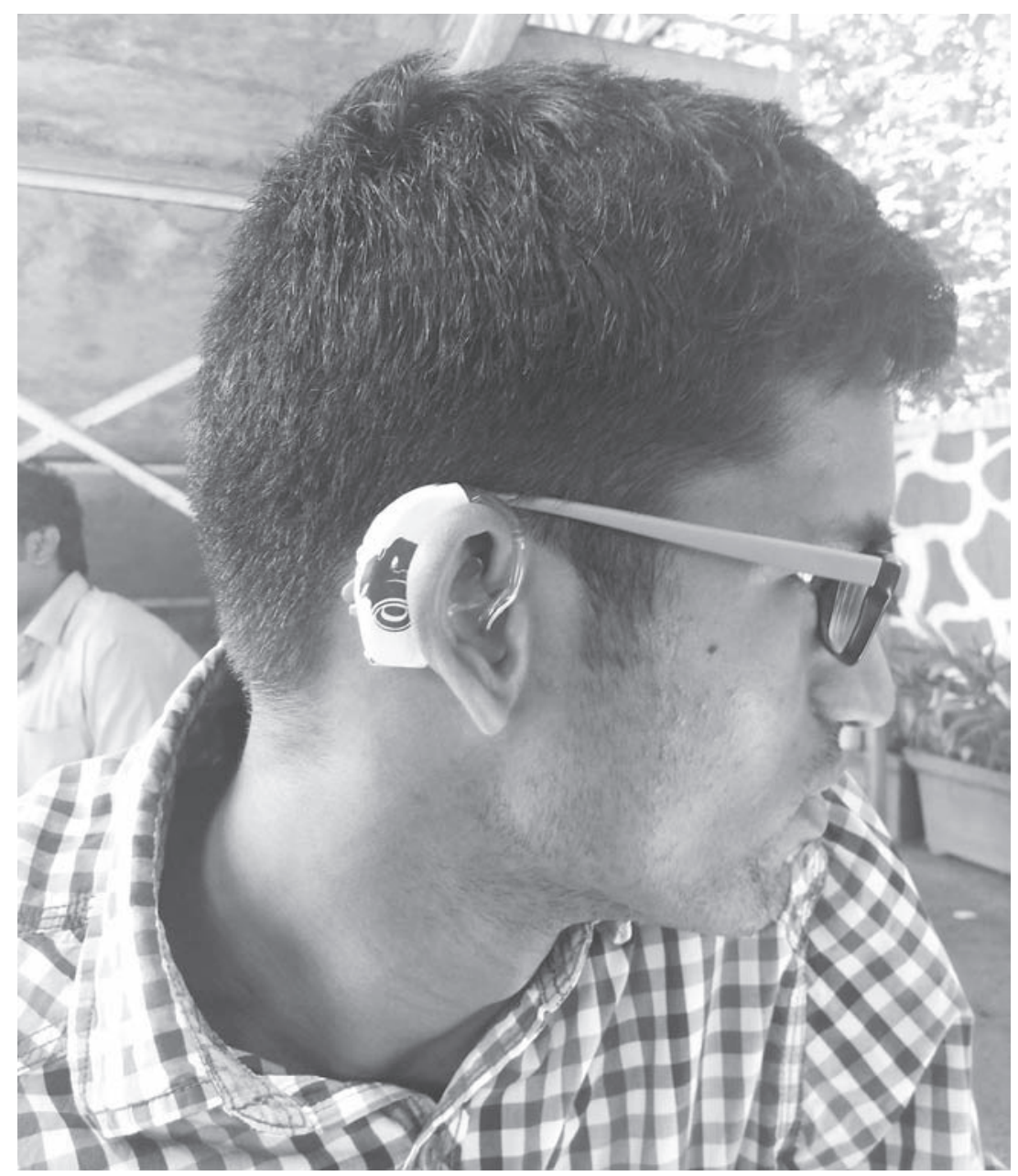

Figure 6.I. A participant wearing the hearing aid with personalized decoration, in this case of a camera.

he thought others were thinking, said, "More people look now, but I don't know what they are thinking. Nobody comes to talk to me. I would have liked the whole machine to be covered with a design. The whole machine, even the back, should have been covered with a plastic design." This, too, suggests not an outright rejection of the design, as much as a desire to improve it, possibly to extend the idea further than we allowed. 


\section{The Indian Context}

One finding that was surprising to us is the degree to which deaf youth in India have a strong identity from which they draw personal and collective strength. Among disability scholars and within the deaf community itself, it is widely accepted that there is a "Deaf culture," a dynamic set of norms and traditions that is unique to deaf people, and one which deaf people themselves readily adopt (Padden and Humphries i990; Padden and Humphries 2009).

But what is striking about the deaf community we interacted with-a community connected at least as much with deaf activists in the greater Mumbai area, as much as with their school-is how strong and proud an identity it provides for its members, especially in a larger sociocultural context in which family forces can be intense and marginalized communities tend to accept and even internalize ostracism. A long-standing debate, for example, asks why caste remains a potent force in modern India (Mahalingam 2003). Louis Dumont in his classic study of Indian caste describes the hegemony of upper-caste values, with one effect being lower-caste group's internalization of caste hierarchies in a kind of Marxist false consciousness (Dumont I970). Others, however, retort with alternate interpretations that involve less internalization and more assimilation and strategy for mobility (Appadurai i 986). Still others argue vehemently against anything other than pride in one's own caste or for a dismantling of the caste hierarchy altogether (Ilaiah r 989). But whatever the case, what is largely not in contention is a phenomenon that Indian sociologist M. N. Srinivas (I962) calls "Sanskritization"-the tendency for lower-caste people to take on the customs of the upper castes, especially as they gain socioeconomic status. That is to say, with caste, those considered lower on the hierarchy appear to feel pressures to adopt the outward appearance of those on the supposed upper rungs.

We saw no evidence of an analogous phenomenon among the deaf community in India. If anything, there is hostility toward the adoption of normal customs. At every turn, our deaf participants questioned why they should be the ones to adapt to hearing society, and not the other way around. Why shouldn't their families learn sign language? Why should they learn to read lips? Why isn't television routinely accompanied by signing?

What additionally brings this into stark relief is a casual awareness among deaf young adults that their normal peers tend to outperform them in a variety of ways. One participant, Hrithik, summed this up neatly: "Nor- 
mals do better at everything-cricket, swimming, getting jobs," presumably because of the differential opportunities to learn and hone such skills. Yet, despite acknowledging that normals have more opportunities for educational and vocational success, our deaf participants expressed no regret about being deaf. As above, all participants questioned the need to adapt to normal society. All were happiest among deaf friends. Almost all wanted to marry someone who was also deaf (with the one exception citing the practical value of having a spouse who could converse with hearing people).

This pride and confidence in spite of disadvantages is inspiring and arguably rare in India and South Asia generally among marginalized groups. Even among disabled groups, and despite activists who work toward disability pride, many nevertheless experience their situation as one of "social suffering" (Meekosha 20I I). Some see in digital technologies the potential to gain more independence, respect, and social status (Pal and Lakshmanan 20I4)-implying that those things were not theirs to begin with. Our deaf participants did not appear to feel this lack-as they might themselves explain, theirs is not necessarily a disability.

\section{As Peri-Technological Intervention}

As technology-for-development projects have proliferated since the midI990s, they have faced a range of criticism. Some of the problems cited include that projects are not appropriate for the context (Donaldson 2009); violate sociocultural norms (Hosman and Fife 2008); neglect poor infrastructure (Surana et al. 2008); ignore the local community (Swindell 2006); misunderstand user needs (Kuriyan, Ray, and Toyama 2008), and on and on. Among the reams of criticism is one that focuses on the overly technology-centric nature of the interventions (Toyama 2015). As the saying goes, "When you have a hammer, everything looks like a nail," and so, too, with technology proponents: when you have a powerful digital tool, everything looks like a problem that can be solved by it.

Our project's goal was not to add to the mounting criticism of $\mathrm{ICT}_{4} \mathrm{D}$, as much as to open the door to an entirely different class of project that we think of as peri-technological — related to or close to technology, but not strictly of it. As observers have remarked and statistics show, digital technology is pervading the world, regardless of ICT4 $\mathrm{D}$ projects and their supporters. Today, the world has more mobile phone accounts than it has people on the planet (World Bank n.d.). India alone has over I.I billion accounts, a number equivalent to over 90 percent of the total population. 
As gadgets have gone mainstream, researchers have discovered a range of peri-technological activity that is either enabled by or intended to enhance digital technology's features, but which is not itself digital in nature. For example, mobile devices are widely personalized through protective covers and key-ring-like accessories; such ornamentation is a form of selfexpression and identity reinforcement (Katz and Sugiyama 2005; Zoetewey 20IO). Usage patterns vary widely, with many households sharing devices that in other countries are considered personal and private (Sambasivan et al. 2010).

What is rarer-and possibly heretofore unseen-are intentional efforts to use peri-technological interventions to cause positive social outcomes. Several projects have developed peripheral devices to smartphones, for example, to create microscopes (Breslauer et al. 2009) or portable ultrasound devices (Mertz 20I2), but these are further digital extensions; technology is still core to the activity.

Our work provides a novel example where a nontechnological intervention was intended to make a technology more palatable, in a context where the technology might have been helpful. Indian deaf youth are somewhat isolated due to their difference; meanwhile, the deaf community can be hostile to suggestions that they should adapt to a world of normals. As a result, deaf youth might avoid hearing aids both for highlighting their deafness and for creating distance from their own community. Both of these issues, we imagined, could be mitigated by a peri-technological adaptation that draws attention to the device itself. Paradoxically, by embracing the artifact, by augmenting its visibility, by turning it into an object of selfexpression, some of the adverse social pressure could have been deflated. A peri-technological intervention could enable one to benefit from technological features without taking on the negative social impact that specific technologies might signify.

Indeed, there are other contexts in which minority communities appropriate symbols of stigma or discrimination as a way to gain control over public perception and narrative. Among the most well-known examples is the pink triangle used by the international gay community (Jensen 2002). The pink triangle was originally a badge used in Nazi concentration camps to identify homosexual inmates, but sometime in the early I970s the symbol began to be used by gay rights activists in the United States and eventually in other parts of the world. (The exact origin of its current usage is unknown [Jensen 2002].) Often juxtaposed with the equation, "silence = death," the mark has become a powerful symbol of identity and a potent 
emblem around which the gay community and its supporters rally. A related example that is more recent but lesser-known is a campaign called "It Was Never a Dress," in which a software company, Axosoft, released a reinterpreted image of the common symbol for women's bathrooms (\#ItWasNeverADress n.d.). Instead of a dress, the graphic reimagined the triangular shape as a cape on a woman wearing pants, hoping to "shift the perceptions and assumptions about women."

Yet, contrary to our expectations, our peri-technological intervention had mixed results, which, though they leaned positively, were not without detractors. In fact, we saw no sign that our participants felt any stigma attached to their hearing aids to begin with, and postdecoration there seemed to be no qualitative shift either in how they were perceived or how they responded to hearing people. If anything, the decoration merely accentuated the status quo for our deaf participants. In short, there was little expectation that the digital technology would impart an advantage, and certainly no sense that it would "repair" a problem. The result once the devices were worn was also mixed, with most responses acknowledging benefits but in a rather muted way. Our deaf participants were level-headed going into the project, and level-headed coming out. None of the typical exuberance accompanying digital technology, either as technology proponents hoping to fix an ailing society, or as anthropological observers finding a novel adaptation by "the locals," was present.

\section{Conclusion}

Our exploration of a personalized decoration intended to make hearing aids less objectionable to deaf Mumbai youth led to what were for us many unexpected findings. We found a community that had a robust sense of confidence and identity, even as they felt marginalized by the larger society and isolated from their own families. We were surprised by a tepid reaction to hearing aids-technology that normal people imagine as enabling for those with hearing loss. We saw mixed results with our peri-technological intervention that further confound narratives of tech-enabled social impact. And, all this in contradistinction to the larger geo-cultural context of South Asia where social disparities can be oppressive and where technology is frequently exalted.

For many researchers, it is the richness of digital phenomena and the cultural variety of South Asia that make them attractive as foci of scholarship. Few generalizations can be made, and seeming contradictions are 
everywhere. If so, what at first seems an outlier project might in fact be adding a new hue to a colorful spectrum, further celebrating what is the essential core of the digital in South Asia: its prodigious diversity.

\section{References}

Appadurai, A. I986. "Is Homo Hierarchicus?" American Ethnologist I 3: 745-6 I.

Arora, P., and N. Rangaswamy. 20I5. "Digital Romance in the Indian City." In Khanna, T. (ed.), The City and South Asia. Cambridge: Harvard South Asia Institute.

Bauman, H-Dirksen L., and J. J. Murray. 2014. Deaf Gain: Raising the Stakes for Human Diversity. Minneapolis: University of Minnesota.

Bhargava, Y. 20 I 5. "Digital India, Analog Setup." Hindu, July 3, 201 5. http://www. thehindu.com/business/Industry/digital-india-week-where-the-event-was-analog/article7383388.ece

Breslauer, D. N., R. N. Maamari, N. A. Switz, W. A. Lam, and D.A. Fletcher. 2009. "Mobile Phone Based Clinical Microscopy for Global Health Applications." PloS one 4 (7): e6320.

Carney, D. R., A. J. Cuddy, and A. J. Yap. 20ıо. "Power Posing Brief Nonverbal Displays Affect Neuroendocrine Levels and Risk Tolerance." Psychological Science 2 I (Io): I $363-68$.

Donaldson, Krista. 2009. "The Future of Design for Development." Information Technologies and International Development 5 (4): 97-100.

Dumont, L. I970. Homo Hierarchicus: The Caste System and Its Implications. University of Chicago Press.

Friedner, M. I. 20 I 5. Valuing Deaf Worlds in Urban India. New Brunswick, NJ: Rutgers University Press.

Greenwood, D. J., and M. Levin. I998. Introduction to Action Research: Social Research for Social Change. Thousand Oaks, CA: Sage Publications.

Guillemin, M., L. Gillam, and A. Brookes. 2005. "Technologies, Deafness, and Critical Compromise." Disability Studies Quarterly 25 (3).

Heeks, R. 2003. Most Egovernment-for-Development Projects Fail: How Can Risks Be Reduced? Vol. I4. Manchester: Institute for Development Policy and Management, University of Manchester.

Hosman, L., and E. Fife. 2008. "Improving the Prospects for Sustainable ICT projects in the Developing World." International Fournal of Media and Cultural Politics 4 (I): 5 I-69.

Ilaiah, K. I989. The State and Repressive Culture: The Andhra Experience. Hyderabad: Swecha Prachuranalu.

\#ItWasNeverADress. N.d. "About." https://itwasneveradress.com

Jensen, E. N. 2002. "The Pink Triangle and Political Consciousness: Gays, Lesbians, and the Memory of Nazi Persecution." Fournal of the History of Sexuality I I (I): 319-49.

Kano, T., and K. Toyama. 2016. "Geographic Diversification of ICTD Research.” In Proceedings of the Eighth International Conference on Information and Communication Technologies and Development, 56. New York: ACM. 
Katz, J. E., and S. Sugiyama. 2005. "Mobile Phones as Fashion Statements: The Co-creation of Mobile Communication's Public Meaning." In Mobile Communications: Re-negotiation of the Social Sphere, edited by R. Ling and P. E. Pedersen, 63-8I. London: Springer.

Kuriyan, R., I. Ray, and K. Toyama. 2008. "Information and Communication Technologies for Development: The Bottom of the Pyramid Model in Practice." Information Society 24: 93-IO4.

Lane, H. L. 2002. "Do Deaf People Have a Disability?" Sign Language Studies 2 (4): $356-79$.

Lang, R. 200 . "Understanding Disability from a South Indian Perspective." Paper presented at the I4th Annual Meeting of the Disability Studies Association, Winnipeg, Canada. https://www.ucl.ac.uk/lc-ccr/lccstaff/raymond-lang/understanding_disability_in_india.pdf

Mahalingam, R. 2003. "Essentialism, Culture, and Power: Representations of Social Class." Fournal of Social Issues 59 (4): 733-49.

Meekosha, H., 20г г. "Decolonising Disability: Thinking and Acting Globally." Disability \& Society 26 (6): 667-82.

Mehrotra, N. 20 I . "Disability Rights Movements in India: Politics and Practice." Economic and Political Weekly 46 (6): 65-72.

Mertz, L. 20 I 2. "Ultrasound? Fetal Monitoring? Spectrometer? There's an App for That! Biomedical Smart Phone Apps Are Taking Healthcare by Storm." IEEE Pulse 3 (2): I6-2 I.

Mohsin, M. 20 I6. "The Dishonourable Killing of Qandeel Baloch.” Guardian, July I 8. https://www.theguardian.com

Padden, C. A., and T. Humphries. I990. Deaf in America: Voices from a Culture. Cambridge: Harvard University Press.

Padden, C., and T. Humphries. 2009. Inside Deaf Culture. Cambridge: Harvard University Press.

Pal, J, and M. Lakshmanan. 2014. "Mobile Devices and Weak Ties: A Study of Vision Impairments and Workplace Access in Bangalore." Disability and Rebabilitation: Assistive Technology I: 9.

Prasad, R., and R. S. Ray. 20 2. "Critique of the Common Service Centre Scheme." Economic \& Political Weekly 47 (6): I8-23.

Pullin, Graham. 2009. Design Meets Disability. Cambridge, MA: MIT Press.

Sambasivan, N., E. Cutrell, K. Toyama, and B. Nardi. 2010. "Intermediated Technology Use in Developing Communities." In Proceedings of the SIGCHI Conference on Human Factors in Computing Systems, 2583-92. New York: ACM.

Sathe, V. 20 I I. "The World's Most Ambitious ID Project (Innovations Case Narrative: India's Project Aadhaar)." innovations 6 (2): 39-65.

Srinivas, M. N. I962. Caste in Modern India and Other Essays. Bombay: Asia Publishing House.

Surana, S., R. Patra, S. Nedevschi, and E. Brewer. 2008. "Deploying a Rural Wireless Telemedicine System: Experiences in Sustainability." IEEE Computer (June): 48-56.

Swindell, J. 2006. "The Village Knowledge Centres of Pondicherry." In Innovation, Education and Communication for Sustainable Development, edited by W. Leal. Frankfurt: Peter Lang. 
Toyama, K. 2015. Geek Heresy: Rescuing Social Change from the Cult of Technology. New York: PublicAffairs.

Unwin, P. T. H., ed. 2009. ICT4D: Information and Communication Technology for Development. Cambridge: Cambridge University Press.

Woodward,J. C. I972. "Implications for Sociolinguistic Research among the Deaf." Sign Language Studies I (I): I-7.

World Bank. N.d. "Mobile Cellular Subscriptions (per roo People)." http://data. worldbank.org/indicator/IT.CEL.SETS

Zainudeen, A., R. Samarajiva, and N. Sivapragasam. 20 I . "CellBazaar: Enabling M-Commerce in Bangladesh." Information Technologies \& International Development 7 (3).

Zoetewey, M. W. 20го. "A Rhetoric of Ornament: Decorating Mobile Devices in the Aesthetic Economy." Computers and Composition 27 (2): I38-57. 


\title{
The Making of a Technocrat
}

\author{
Social Media and Narendra Modi \\ Joyojeet Pal
}

In the last two decades, much work has considered ways in which digital technologies such as mobile or computing devices, sensing devices, and the communications that are enabled by them—such as social mediaintersect with a range of development issues in the Global South. Although many such technologies have been designed explicitly for use in low- and middle-income settings, others intended for other purposes have impacted human development issues because of the changing nature of technologydriven interactions that permeate society.

Social media offer one such space of inquiry whereby the sheer scope of adoption and use throughout the world have transformed interpersonal communications and power relations and agency between citizens and the polity (Bryer and Zavattaro 20I I; Loader and Mercea 20I I). Social media such as Facebook and Twitter have created a "digitally enhanced public sphere" that has become a space for political actors and citizens to exercise agency and outreach (Dutton 2009). Elections in most major democracies increasingly feature social media campaigns of key candidates in what has come to be a new normal for parts of the Global South (Lufkens 20r6). Indian Prime Minister Narendra Modi, who with more than 24 million followers on Twitter and 37 million "likes" on Facebook, is second only to Barack Obama among elected officials worldwide with social media followers. The overwhelming majority of Modi's messages on Facebook are 
"liked" more than 50,000 times apiece, and the median number of retweets of his Twitter messages is more than 2,000. As of November 2016, Modi had more than twice the number of followers on either Twitter or Facebook as any mainstream news media channel or journalist in India.

Social media are not the first or even only case of Modi using technology in some form of self-branding. Modi hired a global public relations agency that specialized in political leaders, which started a campaign of rebranding the leader as a growth-focused politician, building a Vikas Purush, literally meaning "Development Man" (Kanungo and Farooqui 2008). Through much of his campaigning in Gujarat, Modi has used technology to recraft himself as a man who appeals beyond his Hindutva roots to a leader who represents the needs of a "neo-middle class," using a range of media including a initiating a television channel called "NaMo," mobilebased outreach, an Internet campaign, and a number of public appearances through holographic shows during elections (Jaffrelot 2015).

The choice of social media is, in and of itself, not surprising. Unlike earlier means of technology-enabled outreach such as a website with downloadable wallpapers, or opt-in subscriptions for SMS messages, social media allow an unobtrusive way of connecting with the electorate and building a community (Kapoor and Dwivedi 2015). The nature of social media, in its perception as a technology of young people, came to the forefront significantly after Barack Obama's successful online campaign for his 2008 election. Modi's investment in social media is necessarily more than just the value of head count outreach to voting citizens. The symbolic value of social media emerges on two fronts-being active on social media itself suggests an embracing of modernity, but second, the tone and content of the messages on social media are also representational objects used to remind listeners of the leader's political message.

The construction of social media as a means of political outreach that spoke out against entrenched political institutions gained purchase in the aftermath of the Iranian elections of 2008 and the Egyptian prodemocracy movement (Sabadello 20I I). The popular press, in particular, played an important role in promoting the politicized social media participant as representing youthful revolution and a voice of change and decentralized empowerment (Grossman 2009). The use of short-form social media messaging was individualized yet informal, and distinct from the traditional banality of political polemic, and consequently seen as attractive to a younger tech-savvy ethic (Lenhart et al. 20 Io; Sago 2010). The election of a "giantkiller" Barack Obama, who defeated establishment candidates within his 
party to emerge on a platform of change, helped further the idea not just of a different kind of modern political leader but also of a campaign strategy that could canvas a young and idealistic population into political action. Several studies showed that politicians on social media were either younger themselves (Larsson and Kalsnes 20I4), trying to reach the young (Leng 2OI2), or looking awkward trying to act young (Baxter and Marcella 2OI2).

The flag-waving for social media as an emancipatory technology after the Arab Spring also waned as many scholars noted their potential for capture by entrenched institutions and powers (Burns and Eltham 2009; Morozov 2009; Mungiu-Pippidi and Munteanu 2009). The notion of the active social media politician as representing an alternative voice against the establishment declined with the gradual institutionalizing of social media; being active on Facebook or Twitter grew to be a given for major politicians for their campaigns as well as for citizen outreach (Hong and Nadler 20 I I). Most recently, with the U.S. 20 I 6 election, the social media political space was touted by eventual winner Donald Trump as a space offering an alternative to a mainstream media discourse, and the candidate frequently used and referred to social media as his primary means of reaching the electorate, often piggybacking on the virality of social media messaging as a means to attract mainstream media attention. More important, the postelection analysis focused on the potential for dubious social media messages to go viral.

It is also clear that participation on social media may not be dependent on the actual size of the active voting citizenry active on social media. Studies show that politicians even in the World Bank's list of poorest nations, including a vast majority of heads of government in the Global South, are directly engaging with social media (Lufkens 20I6), irrespective of scant evidence of any influence of social media on election outcomes, with even some evidence to the contrary (Leng 2012). Indeed, a number of major political figures or heads of government from the Global South engaged in social media are neither popularly elected nor have any immediate need for support from a voting electorate to stay in power, but rather use social media as a means of signaling affiliation with national or diasporic elites or presenting palatable images of themselves to the outside world (Pal and Gonawela 2016).

Political social media offer a new element in the evolution of mediatization, which refers to the mainstream media being an interlocutor between the politician and the citizen. The relationship between a politician and the mainstream media can be guided on one end by political logics, where 
a politician controls media reporting about himself or herself, or by media logics, where that politician's public actions may be driven by what a mainstream media deems newsworthy (Vergeer, Hermans, and Sams 2013). The emerging perspective on social media engagement is that of an alternative and often concurrent channel for political branding (Nilsson and Carlsson 20I4), which offers a soapbox through which to potentially control and channel a precise message that can reach those who choose to use it, but hopefully to a larger listening mainstream media as well (Fuchs 20 I 3). This has been an important strategy, which has arguably had the desired secondorder impacts-research has shown that despite not directly addressing professional journalists, Modi was able to have the mainstream print media cover his social media feed extensively (Chakraborty et al. 20I8). The resulting social media stream allows for a flow of unmediated outreach, which has been found to focus inordinately on positive, feel-good stories, ignoring tricky or controversial issues of national concern (Haq 20r6; Kohli 20I8).

\section{The Social Media "Technocrat"}

Modi's growing public image as a technocrat is not just one of folklore. Unlike the traditional definition of a technocrat who rules on the basis of their own scientific expertise, Modi's technocracy has come to be defined in not only his repeated public espousal of technology but, equally importantly, in his very public consumption of the latest technology. Narendra Modi was a relatively early starter with an interactive online presence. He had a regularly maintained website-narendramodi.in since 2007 - on which citizens could message him, set up appointments, and view a full archive of his speeches. Since 2009, he has had accounts on both Facebook and Twitter. By the eve of the 2014 general election, he had active accounts with sizable following on Google+, Instagram, Tumblr, Pinterest, and LinkedIn, and an active multimedia channel on YouTube. By 2014 Modi had reached "influencer" status on LinkedIn, an invitation program for public figures who post what are seen as influential messages on professional issues.

Modi's presence on social media must be framed within the history of his political genesis from a grassroots proselytizer and organizer for the right-wing Hindu social organization Rashtriya Swayamsevak Sangh (RSS) to a leading member of its political wing, the Bharatiya Janata Party (BJP), and eventually to chief minister for the western Indian state of Gujarat in 200I. Modi led the BJP to three election wins in Gujarat and became the 
longest-serving chief minister in the state's history. The early years of his Gujarat tenure were marred by the 2002 riots, which some news media alleged were a pogrom against Muslims. Modi was acquitted of charges, though some of his key aides were convicted and jailed for their involvement. This led to Modi's marginalization in the international community: the United States banned Modi from entry and the European Union denied him diplomatic access for several years. Modi's association with the RSS also put him at odds with the relatively liberal English-language media in India, a channel to both Indian elites and nonresident expatriates. In the years following the riots, Modi's negative coverage persisted, including interviews with antagonistic television commentators.

Although even before 2002 Modi had been known to talk about or be seen using a computer in media interviews (Shukla 2000), his investment in an aggressive public relations effort to build an image as a development icon expanded significantly after the riots (Kaur 2015; Price 2015). The "Vikas Purush" campaign featured a series of photos of him in sylvan settings, in thoughtful poses, surrounded by artifacts like an Obama biography, a financial newspaper, using technological devices like an Apple laptop and an SLR camera-proposing an image of a thoughtful, well-read, technology-embracing leader ( $\mathrm{Pal}$ 20I7). The regime highlighted industrial growth and the investment climate, avoiding mention of the riots in public fora. Modi's positive-tone messaging on Twitter that we see later has roots in the espousal of the terms asmita (common pride) as a central part of his speeches while he was chief minister, suggesting that people invest in pratiksha (aspiration) rather than ninda (condemnation) (Suhrud 20I 2). The use of asmita presented a turn-the-other-cheek style of forward-looking leadership that by encouraging its own movement to disavow ninda undercut the political opposition's attempts to bring up the riots.

Modi's use of APCO for public relations was controversial because of the firm's past campaigns with military dictators (Ahmed 20I2). On paper, though, the firm was hired by an international group of funders called "Friends of Gujarat" (Jaffrelot 20I5). In the run-up to the 2014 general election several other agencies were more closely involved in the brand campaign, including Citizens for Accountable Governance and NitiCentral, with various aspects of the outreach process (Kapoor and Dwivedi 2015; Torri 2015). ${ }^{1}$ Specifically, the 2014 election campaign had carefully managed use of technology, what British politician and head of UK-India Business Council Patricia Hewitt referred to as "having the best bits of Blair, Clinton, and Obama, but with even more modern techniques that 
even they hadn't dreamed of," including an encore of his 3-D hologram campaign (Price 2015). While Modi campaigned aggressively through public speeches throughout the country for the general election, he had very few unplanned events such as television interviews leading up to the 2014 election. Whether in person or digitally, his output was craftedallowing him to select what issues he would address, dictate the timing of such output, and precisely frame the tenor of the message, unlike the risky improvisation of a live traditional media interaction.

The social media affordances of having followers who engage with one's content offers the semblance of interactive direct communication-in Modi's case, his voice on social media is not just his flow of direct content, but also the resonance of his image and message through retweets, likes, and forwards through an active population of Indian social media users. This population is largely an aspirational and tech-savvy middle and upper class, an educated and often successful professional class whose support matters by virtue of its publicness, particularly because of its apparent distinction from his traditional base of social conservative voters. Here, communicating through Facebook or Twitter provides instrumental benefits, but doing so simultaneously dovetails a larger discourse of aspiration at a particular moment in India's history, where the political actor's embrace of the social media artifact in and of itself represents a normative positioning.

This positioning can be framed through the reframing of the middleclass voter since the 2000s. Leela Fernandes (2009) identified two discourses of development in this period: the first was marked by discussions of sustainable development and growth in policy initiatives and the second by a celebratory language of middle-class consumption as a sign of the success of these policies. This language was integral to the neoliberal movement and is referred by sociologists Pierre Bourdieu and Loïc Wacquant (200I) as the "NewLiberalSpeak." It features a plethora of buzzwords such as "globalization," "governance," and "employability"-all terms used to discuss issues of development in the mainstream to replace the erstwhile negative terminology that included "exploitation," "class," and "dominance." As we see in this research, Modi has made such languagealongside catchphrases such as "digital dividends" and "next gen"—central to his social media messaging since 2009 .

Digital technology in various human and material symbolic avatarsthe swank buildings in software special economic zones, globe-trotting IT professionals, a slew of India's cheapest computer projects, farmers checking crop prices on the Internet, or the Indian software product- 
all emerged in this period as sources of collective largesse and as objects of individual desire amid a discourse of national leapfrogging to catch up with the West ( $\mathrm{Pal}$ 2010). A vision of credentialed modernity was touted as replacing a corrupt system plagued by nepotism, reservations, and a broken educational system out of which emerged an aspirational endgame of working with technology in one of the major metros or even abroad (Radhakrishnan 2009). The heroes of this vision are the young who work with digital technology and, more important, those who allow them to get ahead-where the notion of egalitarianism rests not on leveling the number of opportunities but rather in removing the barriers to middle-class aspirants who present the possibilities of a resurgent India.

Modi is not the first major politician to highlight digital technology as central to his political branding. Since the mid-r99os, several politicians have crafted political images as tech-savvy leaders. Key among them was Andhra Pradesh's chief minister N. Chandrababu Naidu, who claimed the moniker of Cyber-Naidu, signaling his vision for a tech industry-inspired polity by referring to himself as the state's CEO (Rudolph and Rudolph 200I). In subsequent years, several politicians came to embrace both a macro-vision of technology-enabled industrial growth by explicitly promoting the tech sector or special economic zones as part of their political platforms (Banerjee-Guha 2008; Kamat 20 I I), or through a visible interaction with digital artifacts such as posing with computers for the media or incorporating technology into their public programs such as laptop giveaways around election times (Mudliar and Pal 2015). This political investment in the symbolic value of technology occurred alongside the broader expansion of the discourse of ICT $4 \mathrm{D}$ (information and communications technology for development), which saw a role for digital technology and the tech industry in a symbiotic relationship with the idea of global development (Kleine and Unwin 2009), often drawing on the work of management theories premised on a value that "Bottom of the Pyramid" markets offered growth possibilities to corporations and vice versa (Schwittay 2009). Building on Arjun Appadurai's work on the "capacity to aspire" (Appadurai 2004), several works looked at the projection or enactment of aspiration as an interim indicator of development (Ray and Kuriyan 20ro; Rangaswamy and Cutrell 2012; Ray and Kuriyan 2010).

The rise of $\mathrm{ICT}_{4} \mathrm{D}$ in India after the I99os saw an expanding affirmative discourse of technology, with images lionizing technology figures and the industry as representing "a new India." Mainstream media highlighted stories of hope from Potemkin villages where farmers used computers to 
estimate their farm inputs, or gendered bodies of low-income, low-caste women using cellphones, or a range of devices juxtaposed against users whose very presence alongside these was meant to signal the inclusive potential of digital technologies (Keniston 2003; Mazzarella 2010).

William Mazzarella, critiquing the technofetishism of the ICT $4 \mathrm{D}$ wave, noted that the problem of the social acceptance of a technocratic imaginary is further complicated because the "media that constitute the information network [are made] so organic that they become indistinguishable from the social relations they mediate" (Mazzarella 20Io). Consequently, the mainstream media's role in presenting technology as the vanguard of an alternative future for India has been profoundly political (Mazzarella 20I0). By the 2000s, even mainstream cinema saw the rise of software engineers as lead male and female characters (Pal 20IO). Politicians essentially hopped onto an aspirational language of communication that was already eminently obvious in the popular discourse.

\section{Technocracy as Political Cachet}

A large body of literature exists on the politics of technocracy in the management of complex political systems and rational planning (Banfield I959; Fischer I990). Yet ideas around the presentation of a technical/rational vision for governance, the very basis of a technocracy, have been deeply contested, with few agreements on what a technocracy is or how it exists as a system (Laird I990; Winner 1977). Much of the work on technocracy has focused on the complexities of scientific management and the role of expertise-driven direction of modern states (Silva 2009); the attention to specific personal brand management of political actors as technocrats is relatively recent (Lewandowski 20I3). Modi's self-representation as a technocrat at once uses the discourse of technology in communicated output (such as talk of the technology industry and e-governance) and the integration of technological artifacts into his persona (such as posing with computers and mobiles, appearing in 3 -D holograms, or regularly posting to social media in a first-person voice). In this, Modi goes beyond Jawaharlal Nehru or Rajiv Gandhi, in whose national political visions technology played a significant part. Modi's brand cachet as a modern, technologically oriented political actor was even greater than that of his immediate predecessor, Manmohan Singh, who was arguably the Indian political establishment's most accomplished technocrat-a widely published economics professor and former governor of the Reserve Bank of India. Modi's use of 
technology in his political branding raises the importance of the embodied technological actor in electoral politics, a subject that has largely been missing (Subramanian 2006), particularly given the long-standing perception that technocracy and populist politics have traditionally been at odds with each other (Howse 2002).

\section{Social Media in Political Branding}

The work on social media and electoral politics has been dominated by research on the Obama campaigns and its impact on campaign outreach and political communication (Hendricks and Denton 2010). In part because of his appeal among a younger, liberal electorate who are also relatively well represented on social media, Obama quickly grew in appeal as a tech-savvy "communicator-in-chief" (Miller 20I3). This association of social media success with a youthful brand image held sway through many campaigns worldwide up to the 2012 U.S. election, by which point older citizens had become a significant constituency on social media (Conway, Kenski, and Wang 2013). While Obama has served as an important example for several political leaders using social media, many of Obama team's specific social media campaign strategies, including the creation of a centralized discourse, the use of followbacks, and positive-themed messaging, were hallmarks of the Modi campaign (Pal, Chandra, and Vydiswaran 20I6). ${ }^{2}$

\section{A Brief Overview of Methods}

This is a mixed-methods study of Narendra Modi's Twitter campaign from 2009 through 2015. Twitter was selected because of a comprehensive effort on our end to record activity through periodic downloads of Modi's tweets and the activity surrounding them. Our database consists of 9,368 tweets by Narendra Modi between February 2, 2009, and October 2, 2015. Five researchers qualitatively coded a subset of 2,960 of these tweets in six phases (table 7.I).

We assigned each of the 2,960 tweets to one of nine categories such as Updates, Generic, Regards, and Confrontations; we do not discuss these here because our focus is on themes. The themes are separate from categories in that one tweet can have multiple themes, based on the subject matter. We assigned each tweet up to three thematic codes out of I6o themes, and a regional code, if relevant.

The following example helps illustrate the coding: 
Example I: Date: 05/04/20o9, Phase I

Tweet text: In Pakistan, the Taliban is inflicting its tyranny and in Pakistan, Sikhs are being persecuted, Sardars are being persecuted.

Category: Generic

Themes: International, Violence, Sikhism

Region: Pakistan

Example 2: Date: I2/II/2OI2, Phase 2

Tweet text: Congress neither has people nor issues in this election!

Addressed 3 public meetings in Ahmedabad

Category: Confrontation

Themes: Congress, Criticism, Election Campaigning

Region: Ahmedabad

We used three rounds of iteration to arrive at the r6o themes, but as the research continued we added new themes if necessary. For this paper we specifically examined the subset of themes directly related to information and communications technologies (ICTs) to analyze how often Modi talked about technology and the ways in which he did this. We created "ICTs" as a composite variable, the definition of which is as follows, from our theme legend:

Table 7.I. Tweets dated by the sampled phases $(n=2,960)$

\begin{tabular}{|c|c|c|c|}
\hline$\overline{\text { Phase }}$ & Tweet time period & Time period significance & No. of tweets \\
\hline I & Feb. I, 2009-Jan. 2 I, 2012 & Early tweets & 625 \\
\hline 2 & Aug. $3,20 \mathrm{I} 2-\mathrm{Jan} .3 \mathrm{O}, 2 \mathrm{OI} 3$ & $\begin{array}{l}\text { Tweets leading into } 2012 \\
\text { Gujarat elections }\end{array}$ & 500 \\
\hline 3 & Jan. 30, 20I $3-$ May 27,2013 & $\begin{array}{l}\text { Tweets following election as } \\
\text { chief minister }\end{array}$ & $35^{2}$ \\
\hline 4 & Apr. I3, 20I4-May I 7, 2014 & $\begin{array}{l}\text { Tweets leading into } 2014 \\
\text { general elections }\end{array}$ & $50 \mathrm{I}$ \\
\hline 5 & Dec. I 5, 2014-Feb. I 8, 2015 & $\begin{array}{l}\text { Six months after election as } \\
\text { prime minister }\end{array}$ & 486 \\
\hline 6 & Aug. I4, 20I 5-Oct. $2,20 \mathrm{I} 5$ & Six months after phase 5 & 496 \\
\hline
\end{tabular}


Mentions of science and technology, particularly digital technology. This includes scientific innovations, computers, mobile devices, and science programs (e.g., ISRO [Indian Space Research Organisation]). The theme also includes mentions of people primarily associated with technology such as scientists or industrialists (e.g., Bill Gates).

Example tweets include:

- "From making electronic goods that are globally competitive to enhancing cyber security, India must show the way." (July I, 20 I 5)

- "Tomorrow I'll address public meetings in 4 cities simultaneously through ${ }_{3} \mathrm{D}$ Projection Technology. Sharing details . . nm4.in" (November I6, 2012)

ICTs composed 9.6 percent of the total number of tweets through the entire sample of tweets analyzed. We used two forms of analyses on these tweets. First, we examined the frequency of the ICT themes through the six phases, and the reach of these tweets in terms of retweeting and favoriting. Second, we contextually analyzed the language and framing of selected tweets that characterize Modi's discourse on technology.

\section{Results}

Table 7.2 compares the thematic areas of ICTs with those of development, youth, and initiatives. Briefly, the development theme includes all tweets about economic development, the youth theme includes all specific references to young Indians or the notion of youth, and the initiatives theme includes all tweets about an initiative of the Modi government (tweets until May 2014 included Gujarat state initiatives, thereafter national initiatives). These four themes are among the most frequent themes in the entire sample of tweets. ICTs appeared consistently throughout all six phases studied, suggesting they have been part of the outreach message since the start of Modi's social media campaign. The references to youth are also an important part of the political branding, and these are tied to ICTs and development because they nudge at the aspirational discourse of the younger generations. We also found that ICTs were a major part of the discourse in the lead-up to the general election, as the single most frequent theme in 
tweets, as opposed to development, which was by far the most frequently tweeted theme by Modi while he was chief minister of Gujarat. Initiatives, which were not spoken about much in the run-up to the 2014 elections, form the single largest theme of discussion right after the 2014 election, at which point Modi started discussing a range of programs he planned to pursue as head of the government.

While development is a consistent theme, its frame changes over time. A qualitative analysis of the tweets shows that Modi's messaging uses what Bourdieu and Wacquant (200I) call "NewLiberalSpeak." We created a separate theme for "wordsmithing," which includes tweets using clever turns of phrase of business buzzwords. We found that these composed 2.0 percent of the 2,960 tweets, and were frequently applied to technology-related tweets, including the following:

- IT (Indian Talent) + IT (Information Technology) = IT (India Tomorrow)! Sharing video of my speech at \#BigTentIndia (March 2 I, 20I3; Phase 3)

Tweets related to e-governance, including the following:

- While Government is about FILE, Governance is about LIFE. If we can infuse LIFE in FILE, we will experience Governance! (April 8, 20I3; Phase 3)

Several development-themed tweets also referred to the influential expatriate Indian population in wealthy foreign nations, whose success is often

Table 7.2. Occurrences of key themes in @narendramodi Twitter text

\begin{tabular}{lcccc}
\hline Period & $\begin{array}{c}\text { ICTs } \\
(\%)\end{array}$ & $\begin{array}{c}\text { Development } \\
(\%)\end{array}$ & $\begin{array}{c}\text { Youth } \\
(\%)\end{array}$ & $\begin{array}{c}\text { Initiatives } \\
(\%)\end{array}$ \\
\hline $\begin{array}{l}\text { Early tweets } \\
\text { Tweets leading into 20 2 Gujarat } \\
\quad \text { elections }\end{array}$ & $\begin{array}{c}8.5 \\
7.0\end{array}$ & $\begin{array}{c}\text { I } 4.9 \\
\text { I I.4 }\end{array}$ & $\begin{array}{r}5.6 \\
8.8\end{array}$ & $\begin{array}{r}\text { I 5.0 } \\
6.6\end{array}$ \\
$\begin{array}{l}\text { Tweets following election as chief } \\
\text { minister }\end{array}$ & 8.3 & I 7.7 & 4.3 & 8.3 \\
$\begin{array}{l}\text { Tweets leading into 20 I4 general } \\
\text { election }\end{array}$ & I4.2 & I4.0 & 4.0 & 0.6 \\
$\begin{array}{l}\text { Six months after election as prime } \\
\quad \text { minister }\end{array}$ & I3.6 & I6.3 & 9.5 & I 8.I \\
$\begin{array}{l}\text { Six months after phase 5 } \\
\text { I I.7 }\end{array}$ & I I.I & 3.4 & 7.3 \\
\hline
\end{tabular}


discussed in the public sphere as exemplifying the potential technology offers assiduous Indians:

- A new India should focus on 3 pillars of Scale, Speed \& Skill. Sharing video of my speech at Pravasi Bharatiya Divas (January 9, 20I 2; Phase I)

The call out to the wealthy, aspirational nonresident Indian population was crafted in alliteration to signify a command over this kind of language. We find it significant that development was a frequently co-occurring theme- 19.6 percent of ICT-themed tweets were also about development. However, ICT-themed tweets were almost always phrased in positive language, unlike development-themed conversations, which at various points were also confrontational. Another aspect to the ICT-themed tweets was their high correlation to international-themed tweets. These include tweets about Silicon Valley, meetings with global tech leaders, as well as what has come to be known as "selfie diplomacy" of Modi posing on selfies with world leaders. We also found that tweets themed around ICTs tended to have more individual persons mentioned in them; in four of the phases- $\mathrm{I}$, 2, 4, and 6-there was a significant relationship between ICTs and callouts, such that if a tweet was ICT-themed, there was a higher chance than in the rest of the sample that another individual was called out in the tweet.

An example of Modi's strategic tweeting with personalities in tech came in $20 \mathrm{II}$, when he tweeted about meeting Infosys CEO N. R. Narayana Murthy. The message came at an important time-the widely respected Murthy was one of the best known names in Indian tech, a middle-class engineer turned software billionaire, and Modi had not made his national ambitions clear yet. Modi was still dogged by a generally negative media portrayal, and was once a pariah even among some sections of the industry, with the lingering memory of his criticism by leading industrialists regarding the "sense of insecurity" in the state after the 2002 riots (Jose 2012). Few major public figures had endorsed Modi at this point, so the tweet had signaling value.

WoW! What a nice light-hearted chat with Narayan Murthyji on diverse issues, so delighting (July I9, 20 I ; Phase I)

This tweet uses a respectful "ji" suffix and suggests mutual respect in their informal chat. The signaling value is also inherent in Murthy being from the tech sector, synonymous with a new tech economy built on 
talent and not nepotism, unlike other industrialists known to be close to Modi because of their Gujarat connections. Modi's style of informal tweeting using equivalence with another individual was used consistently in his tweets about several leading tech figures, even after his ascendance to the prime ministership. Over time Modi has tweeted about meetings with Dick Costolo (Twitter), Sundar Pichai (Google), Salman Khan (Khan Academy), John Chambers (Cisco), and Mark Zuckerberg (Facebook), among others. The continued style of casual association signals to his followers regarding those who have his ears, as seen in the following casual tweet to Bill Gates, in which he appears to remind the industrialist that they spoke during a meeting with the French president.

Was great meeting you @BillGates. Got to spend some time talking to you during the meeting with President @fhollande (September 28, 2015; Phase 6)

Modi used selfies very effectively in associative references. His appropriation of the selfie, typically seen as a technology for the young, in the political sphere came to further his reputation as a "Selfie Diplomat." At several points after becoming prime minister, Modi took images with world leaders, film stars, or casual citizens and tweeted them, and on a few occasions was able to create viral hashtags on selfies, including \#SelfieWithModi, an online campaign to post a selfie saying one had voted. The campaign not only highlighted the leader's apparent comfort with a contemporary means of self-expression, but it also incorporated a clever brand exercise- these tweets were typically widely retweeted because they allowed people to share a tag with their leader, creating the sense of interacting with the leader.

Never imagined such a remarkable response to \#SelfieWithModi. A big thanks. Here are some Tweets shared by friends http://t.co (April 30, 2014; Phase 4)

The SelfieWithModi hashtag is a good example of how the notion of technology reaches more broadly outside the text of the messages themselves. Modi's ubiquity on social media includes Tumblr, Instagram, LinkedIn, Pinterest, and even a curriculum vitae on LinkedIn, a shout-out to the millions of young Indians who use it for job searching. Modi was among the first politicians to use Google Hangouts and Twitter Videos, and has 
since the mid-20oos kept evolving his social media strategy alongside what was the dominant technology. His early messaging, for instance, was managed through an easy-loading website.

A Call to the Nation!Listen Narendra Modi on your mobile, configure podcast to http://narendramodi.in, For help call to 9974309240 (March 3I, 2009; Phase I)

\# Your beloved leader Narendra Modi could be just around you!! Catch him up on google maps at http://narendramodi.in (April I, 2009; Phase I)

These two tweets from 2009 signal the leader's presence across some of the newest media. We see in these tweets that he offers a range of ways to interact. We also see a strategic use of (at the time) the latest technology, Google Maps, which even early adopters had not started using widely, illustrating the leader's claim to a certain modernity. ${ }^{3}$

\section{Discussion}

In his much-cited speech at the United Kingdom parliament on November I I , 20I 5, Modi noted that his "India resides in people like Imran Khan," referring to a young man in Rajasthan who built a mobile app and donated it to his fellow citizens. The tweet created a brief tech-enabled celebrity who would trend on Twitter that same evening. The message had two implied intents-first, a Muslim man was chosen to allude to the politician's secular vision; second, the do-good technological maker in Imran signposted the prime minister's long-standing stated vision of a social order that stands on technology and the benevolence of the entrepreneurial spirit. Just as Modi rewards entrepreneurship, he condemns inefficiency.

The themes of efficiency, entrepreneurship, business-friendliness, and consciousness of the needs of the youth all repeat themselves. Their importance is in the fact that their frequent appearance sets the tone for technocratic rationality as a governing principle. The breadth of the social media campaign promotes the idea of a broadly subscribed social discourse of Modi's positions. The affordances of social technology reinforce this ubiquity. Messages across various social media channels are coordinatedFacebook statuses are coordinated with tweets, a YouTube channel features both the prime minister's radio addresses and his speeches, which in turn are 
tweeted about. To go beyond polemics and provide a guide to well-being, Modi's YouTube channel also touts speeches on yoga. Three-dimensional meetings project life-size holograms of Modi in public meetings when he is not available to speak in person. Thus, the discourse of technology and development does not stop at talk; it actively parades as action.

What we found in the consistent invocation of technology and development in Modi's social media message is that the inherent signaling crafts these as a means to remake his complicated past. Here, Modi's use of Twitter needs to be looked at not just as a case of political brand management, but as an artifact of a moment in history where technology-driven notions of development present an aspirational frame that has purchase in the media and in a broad-based middle class. Calling out to technology, rather than being elitist and misguided in a nation of great inequalities, presents a vision of patriotic optimism. Modi's self-affiliation with technocracy through this light is as much about him rebranding politically as it is about a middle-class support base seeking a secular justification for supporting him.

\section{Conclusion}

Who does a technology-centric vision of development most appeal to, and who by extension may be excluded from this vision? That Modi has successfully reframed the popular discourse surrounding him is neither new nor surprising (Colvin and Bhattacharjya 2013). What is worth examining is the appeal of this message at this historical juncture. On September 28, 2015 , a Facebook post about Modi's interaction with Facebook CEO Mark Zuckerberg was "liked" by more than I.7 million users within hours. The same day Zuckerberg changed his profile picture to a tricolor tint, prompting hundreds of thousands of Facebook users to follow. Social media were abuzz with the hashtag \#ModiInUSA, which featured meetings of the prime minister with the CEOs of Google, Microsoft, Cisco, Qualcomm, Adobe, Tesla, and Apple.

Within a month of these massively retweeted events, the Modi-led BJP lost an important election in the poor and largely rural Indian state of Bihar, despite hectic campaigning. For many who watched the surge of enthusiastic commentary about Modi on social media, the news came as a shock. Indeed, the story of Narendra Modi's social media campaign tells us little about the leader's standing in popular elections. What the story does emphasize is the ways in which the association of technology with develop- 
ment as doxa is driven home by the language and themes employed by the prime minister and by their affirmation through his followers' retweets and favoriting. The power of Modi's message is in the juxtaposition of his past as a train station tea seller with his present as a selfie-clicking leader of a strong aspirational state. The real treason on social media, it would appear, is for anyone calling herself Indian to reject that possibility.

\section{Notes}

I. Modi's own tweets have been reported as posted by staffers http://www.dnaindia.com

2. There are a number of other interesting examples of social media use in elections. For instance, in Scandinavia during nonelection cycles has shown an association between political social media communication and younger, opposition, and relatively more maverick political actors (Larsson and Kalsnes 20I4). Other work on European electoral social media has also shown distinctions in the nature and tenor of messaging based on the political culture of nation-states. Finally, social media accounts are associated with individuals; consequently, they highlight a personal style in reaching out to an electorate directly (Medina and Muñoz 20I4). This helps the branding exercise move away from the political party toward a greater focus on the individual political actor (Enli and Skogerbø 2013). There is, however, little work on media and political signaling in the Global South, and most such work revolves around the traditional image management of former (or current) strongmen through signaling neoliberal reforms, where the rebranding is often overtly tainted and separated from ostensible citizen support (Cabezas 20 I4; Fisher 20I5).

3. The same tweet does, however, have a less impressive use of a hashtag.

\section{References}

Ahmed, P. 20 2 . "The Extreme Makeover of India's (Possible) Next Leader." Huffington Post, April I 8. Accessed May 9, 20 1 8. https://www.huffingtonpost.com

Ahmed, S., and M. M. Skoric. 20I4. "My Name Is Khan: The Use of Twitter in

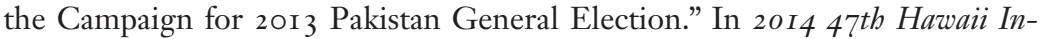
ternational Conference on System Sciences, 2242-5 I. Piscataway, NJ: Institute of Electrical and Electronics Engineers.

Appadurai, A. 2004. "The Capacity to Aspire." In Culture and Public Action, ed. V. Rao and M. Walton, 59-84. Stanford: Stanford University Press.

Banerjee-Guha, S. 2008. "Space Relations of Capital and Significance of New Economic Enclaves: SEZs in India." Economic and Political Weekly 43 (47): 5 I-59.

Banfield, E. C. I959. "Ends and Means in Planning." International Social Science fournal I I (3): 36I-68.

Baxter, G., and R. Marcella. 20 z. "Does Scotland 'Like' This? Social Media Use by Political Parties and Candidates in Scotland during the 2010 UK General Election Campaign." Libri 62 (2): I09-24. 
Berlant, L. 2006. "Cruel Optimism." Differences Bloomington I 7 (3): 20.

Bourdieu, P., and L. Wacquant. 200 I. "Notes on the New Planetary Vulgate." Radical Philosophy 105: 2-5.

Bryer, T. A., and S. M. Zavattaro. 20 I I. "Social Media and Public Administration: Theoretical Dimensions and Introduction to the Symposium." Administrative Theory of Praxis 33 (3): 325-40.

Burns, A., and B. Eltham. 2009. "Twitter Free Iran: An Evaluation of Twitter's Role in Public Diplomacy and Information Operations in Iran's 2009 Election Crisis." Record of the Communications Policy and Research Forum, November I9-20, University of Technology, Sydney, Australia, 298-3 Io.

Burrell, J. 20I2. Invisible Users: Youth in the Internet Cafés of Urban Ghana. Cambridge, MA: MIT Press.

Burrell, J., and K. Anderson. 2008. "II Have Great Desires to Look beyond My World': Trajectories of Information and Communication Technology Use among Ghanaians Living Abroad." New Media \& Society Io (2): 203-24.

Cabezas, A. L. 2014. "Between Love and Money: Sex, Tourism, and Citizenship in Cuba and the Dominican Republic." Signs 40 (I).

Chakraborty, S., J. Pal, P. Chandra, and D. Romero. 2018. "Political Tweets and Mainstream News Impact in India: A Mixed Methods Investigation into Political Outreach." Proceedings of the First Conference on Computing and Sustainable Societies (ACM COMPASS), Menlo Park, CA.

Colvin, R., and S. Bhattacharjya. 2013. "Special Report: The Remaking of Narendra Modi." South Asia News, July i I, I-8.

Conway, B. A., K. Kenski, and D. Wang. 201 3. "Twitter Use by Presidential Primary Candidates during the 2012 Campaign.” American Bebavioral Scientist 57 (I I): I 596-i6ro.

Dahlgren, P. 2005. "The Internet, Public Spheres, and Political Communication: Dispersion and Deliberation." Political Communication 22 (2): I47-62.

Dutton, W. H. 2009. "The Fifth Estate Emerging through the Network of Networks." Prometheus 27 (I): I-I 5 .

Enli, G. S., and E. Skogerbø. 20I3. "Personalized Campaigns in Party-Centred Politics: Twitter and Facebook as Arenas for Political Communication." Information, Communication \& Society I6 (5): 757-74.

Fernandes, L. 2009. "The Political Economy of Lifestyle: Consumption, India's New Middle Class and State-Led Development." In The New Middle Classes: Globalizing Lifestyles, Consumerism, and Environmental Concern, edited by L. Hellmuth and L. Meier, 2 I 9-36. New York: Springer.

Fischer, F. 1990. Technocracy and the Politics of Expertise. Newbury Park, CA: Sage.

Fisher, J. 20 I 5. "Image Management' in East Africa: Uganda, Rwanda, Kenya and Their Donors." In Images of Africa: Creation, Negotiation and Subversion, edited by J. Gallagher. Manchester: Manchester University Press.

Fuchs, C. 2013. Social Media: A Critical Introduction. London: Sage.

Grossman, L. 2009. "Iran's Protests: Why Twitter is the Medium of the Movement." Time, June I 7. Accessed April 9, 2018. http://content.time.com

Haq, Z. 20r6. "As JNU Controversy Escalates, PM Modi’s Silence Gets Louder." Hindustan Times, February 8, 2016. Accessed April 9, 2018. https://www.hindu- 
stantimes.com/india/as-jnu-row-escalates-modi-s-silence-gets-louder/storyK3OIEKkYe7xmLdshibHQZP.html

Hendricks, J. A., and R. E. Denton Jr. 2010. Communicator-in-Chief: How Barack Obama Used New Media Technology to Win the White House. Lanham, MD: Lexington Books.

Hong, S., and D. Nadler. 20r I. "Does the Early Bird Move the Polls? The Use of the Social Media Tool 'Twitter' by US Politicians and Its Impact on Public Opinion." Proceedings of the I 2 th Annual International Digital Government Research Conference: Digital Government Innovation in Challenging Times, I82-86. New York: ACM.

Howse, R. 2002. "From Politics to Technocracy—and Back Again: The Fate of the Multilateral Trading Regime." American Fournal of International Law 96 ( (1): 94-I I 7 .

Jaffrelot, C. 20 I 5. "Narendra Modi and the Power of Television in Gujarat." Television \& New Media I6 (4).

Jose, V. K. 201 2. "The Emperor Uncrowned." Caravan: $2-4$.

Kamat, S. 20 I r. "Neoliberalism, Urbanism and the Education Economy: Producing Hyderabad as a 'Global City'." Discourse: Studies in the Cultural Politics of Education 32 (2): 187-202.

Kanungo, P., and A. Farooqui. 2008. "Tracking Moditva: An Analysis of the 2007 Gujarat Elections Campaign.” Contemporary Perspectives 2 (2): 222-45.

Kapoor, K. K., and Y. K. Dwivedi. 201 5. "Metamorphosis of Indian Electoral Campaigns: Modi's Social Media Experiment." International Fournal of Indian Culture and Business Management I I (4): 496-5 I6.

Kaur, R. 201 5. "Good Times, Brought to You by Brand Modi." Television \& New Media I6 (4): 323-30.

Keniston, K. 2003 . "IT for the Masses: Hope or Hype." http://web.mit.edu/ kken/ Public/PDF/EPW_paper.pdf

Kohli, K. 2018. "Can't Find 'Vikas' or \#AccheDin? Check Narendra Modi's Twitter Timeline." Wire, May 29. Accessed May 3 I, 2018. https://thewire.in

Kleine, D., and T. Unwin. 2009. "Technological Revolution, Evolution and New Dependencies: What's New about ict4d?" Third World Quarterly 30 (5): 1045-67.

Laird, F. N. I990. "Technocracy Revisited: Knowledge, Power and the Crisis in Energy Decision Making." Organization \& Environment 4 (I): 49-6I.

Larsson, A. O., and B. Kalsnes. 20I4. "'Of Course We Are on Facebook': Use and Non-Use of Social Media among Swedish and Norwegian Politicians." European Fournal of Communication (May I6): https://doi.org/10.1177/0267323114531383

Leng, H. K. 20I 2. "Marketing Politicians on Facebook: An Examination of the Singapore General Election 20 I I." Studies in Business and Economics 7 (I): IO I-9. Lenhart, A., K. Purcell, A. Smith, and K. Zickuhr. 2010. Social Media and Mobile Internet Use among Teens and Young Adults. Millennials. Washington, DC: Pew Internet and American Life Project.

Lewandowski, A. D. 20I3. "ObamaTM: Political Branding and Participation in the 2012 US Presidential Election.” Master's thesis, Georgetown University. Accessed April 9, 20I8. http://pqdtopen.proquest.com/doc/1355174698. html=AI\&pubnum $=1536653$ 
Loader, B. D., and D. Mercea. 20 I r. "Networking Democracy? Social Media Innovations and Participatory Politics." Information, Communication \& Society I4 (6): $757-69$.

Lufkens, M. 20I6. Twiplomacy Study 2016. Geneva: Burson-Marsteller.

Mazzarella, W. 20ro. "Beautiful Balloon: The Digital Divide and the Charisma of New Media in India." American Ethnologist 37 (4): 783-804.

Medina, R. Z., and C. Z. Muñoz. 20I4. "Campaigning on Twitter: Towards the 'Personal Style' Campaign to Activate the Political Engagement during the 20 I I Spanish General Elections." Comunicación y Sociedad 27 (I): 83.

Miller, W. J. 2013. "We Can't All Be Obama: The Use of New Media in Modern Political Campaigns." Fournal of Political Marketing I 2 (4): 326-47.

Morozov, E. 2009. "Iran: downside to the 'Twitter Revolution'." Dissent 56 (4): IoI4.

Mudliar, P., and J. Pal. 201 5. "ICTD in the Popular Press: Media Discourse around Aakash, the 'World's Cheapest Tablet." Information Technologies \& International Development I I (I): 4I-55.

Mungiu-Pippidi, A., and I. Munteanu. 2009. "Moldova's 'Twitter Revolution." Fournal of Democracy 20 (3): $136-42$.

Nilsson, B., and E. Carlsson. 20I4. "Swedish Politicians and New Media: Democracy, Identity and Populism in a Digital Discourse." New Media and Society I6 (4): $655-7 \mathrm{I}$.

Pal, J. 20 го. "Rajnikant's Laptop: Computers and Development in Popular Indian Cinema." Information Technologies \& International Development 6 (2): 39-54.

Pal, J. 20 г 2. "The Machine to Aspire To: The Computer in Rural South India." First Monday I 7 (2).

Pal, J. 2017. "The Technological Self in India: From Tech-Savvy Farmers to a Selfie-Tweeting Prime Minister." Proceedings of the Ninth International Conference on Information and Communication Technologies and Development. Article no I I. New York: ACM.

Pal, J., P. Chandra, and V. Vydiswaran. 20r6. "Twitter and the Rebranding of Narendra Modi." Economic \& Political Weekly 5 I (8): 52-60

Pal, J., and A. Gonawela. 20r6. "Political Social Media in the Global South." Conference on e-Business, e-Services and e-Society, Swansea, UK, September 13-15, Proceedings, 587-93. Switzerland: Springer.

Price, L. 20 I 5. The Modi Effect: Inside Narendra Modi's Campaign to Transform India. New York: Quercus.

Radhakrishnan, S. 2009. "Professional Women, Good Families: Respectable Femininity and the Cultural Politics of a 'New' India." Qualitative Sociology 32 (2): I95-2 I 2.

Rangaswamy, N., and E. Cutrell. 20I2. "Anthropology, Development and ICTs: Slums, Youth and the Mobile Internet in Urban India." In Proceedings of the Fifth International Conference on Information and Communication Technologies and Development. New York: ACM.

Ray, I., and R. Kuriyan. 2010. "Towards Aspiration as a Development Indicator: The Case of Information and Communication Technologies." Proceedings of the 
$4^{\text {th }}$ ACM/IEEE International Conference on Information and Communication Technologies and Development, Article no. 38. New York: ACM.

Rudolph, L. I., and S. H. Rudolph. 200I. "Iconisation of Chandrababu: Sharing Sovereignty in India's Federal Market Economy." Economic and Political Weekly 36 (I 8): I 54 I-52.

Sabadello, M. 20 I I. "The Role of New Media for the Democratization Processes in the Arab World." Accessed April 9, 201 8. https://danubetech.com/download/ The-Role-of-New-Media-for-the-Democratization-Processes-in-the-ArabWorld-Presentation.pdf

Sago, B. 20I0. "The Influence of Social Media Message Sources on Millennial Generation Consumers." International fournal of Integrated Marketing Communications 2 (2).

Schwittay, A. 2009. "Taking Prahalad High-Tech: The Emergence and Evolution of Global Corporate Citizenship in the IT Industry." Fournal of Corporate Citizenship 33: 97-107.

Shukla, R. 2000. "Narendra Modi Interview on Ru Ba Ru." RuBaRu. Accessed May 9, 20 I 8. https://www.youtube.com

Silva, P. 2009. In the Name of Reason: Technocrats and Politics in Chile. University Park, PA: Penn State Press.

Subramanian, R. 2006. "India and Information Technology: A Historical and Critical Perspective." Fournal of Global Information Technology Management 9 (4): 28 46.

Suhrud, T. 20r 2. "Modi and Gujarati 'Asmita." Economic and Political Weekly 43 (I): I I-I 3 .

Torri, M. 201 5. "The 'Modi Wave': Behind the Results of the 2014 General Elections in India." International Spectator 50 (2): 56-74.

Vergeer, M., L. Hermans, and S. Sams. 20I3. Online Social Networks and MicroBlogging in Political Campaigning: The Exploration of a New Campaign Tool and a New Campaign Style. Party Politics i9 (3): 477-50 I.

Winner, L. I977. Autonomous Technology: Technics-Out-of-Control as a Theme in Political Thought. Cambridge, MA: MIT Press. 


\title{
Twitter as Liveness
}

\author{
\#ShamedlnSydney and the Paradox \\ of Participatory Live Television
}

Sangeet Kumar

The ways in which the rise of digital culture is changing older media forms (print, television, and radio) is a subject of wide scholarship (Jenkins 2008; Chadwick 20I7). In the case of television, digitization across media technologies has reshaped every dimension of the medium including its content, format, temporal structure, and audience interactivity. This chapter interrogates the ongoing ways in which live television appropriates and continues to be transformed by the growth of digital media by closely analyzing a case study about an Indian television network's attempt to garner audience interactivity through the web platform of Twitter. This incident from March 2015 is one wherein the audience for the talk show The Newshour (telecast on the news network Times Now) upended attempts by the show's anchor Arnab Goswami to peddle a critical narrative about India's defeat in the Cricket World Cup of 2015 using Twitter. They did so by creating a counter narrative by using a competing Twitter hashtag, thus intervening in the debate even as the live broadcast of the show unfolded. Through interrogating the now famous debacle, this chapter invites us to reconsider how the very nature of liveness is being transformed because of the rise of a public networked through proliferating digital devices and social networking site (SNS) platforms such as Twitter. While a networked public has allowed live television shows to appropriate and foster interac- 
tivity in unprecedented ways, thus altering the very definition of liveness and expanding the category of the audience, the precarity of liveness also risks pitfalls such as a public backlash and rebuke in real time, thus leading to an embarrassing unraveling of the very goals of interactivity.

The scramble for interactivity that this chapter analyzes can be better understood when situated within the dual context of intense competition among the Indian news networks to carve out viewership and advertising revenue as well as the widespread proliferation of networked devices and platforms in India. The deluge of news broadcast networks in the dominant languages as well as the regional ones has resulted in the contradictory effects of a culture of debate and deliberation but also a strong tendency toward sensationalism and dramatization of news events to cut through the clutter of competition. Hence, two obverse sides of the same phenomenon, media oversight over politics and authority figures in public life due to proliferation of news and opinion shows, have also raised the decibel levels of the discourse as networks bid to outcompete others with jingoism and uber-nationalism. Notably, both these aspects of being a public watchdog, on the one hand, and seeking to stand out from the clutter, on the other, rely on the use of new media platforms to foster interaction and involvement through means such as citizen journalism and live audience feedback through social media.

News television has sought to leverage this networked culture resulting from the widespread use of mobile phones and social networking sites in India to create the artifice of participatory news production with a goal toward expanding viewership and increased ratings. This phenomenon is the latest in a process of the gradual appropriation of the public by television in India through social media devices as has been evident in the invitations to call, text, or upload user videos in a wide range of shows over the past decade or so. The rise and growth of reality television (Punathambekar 2010), from Kaun Banega Crorepati to shows such as Big Brother, MTV Roadies, Indian Idol, and others that stage competition in areas ranging from quizzing to cooking, singing to dance cannot be divorced from the simultaneous growth in new media technologies that helped expand the audience of television beyond the urban metropolitan cities to include small towns and rural India. The technological changes have allowed networks to appropriate viewer input to shape the trajectory of the show by having live interactions with contestants, voting them out or giving general feedback.

Participatory interaction resulting from competition among news networks and growth of networked devices can therefore be seen as a democra- 
tizing moment within the historically contentious tussle between the hegemonic forces of mass media technologies on the one hand and the impulses of democracy, free speech, and a plural public sphere on the other. The inclusion of voiceless audiences, within the shows and programs of dominant media networks from which they have long been excluded, symbolizes the fruition of a long-held utopian dream of media critics (McChesney 2015; Bagdikian 2004). On the other hand, this drive can also be seen as a ruse to appropriate the democratic impulse and foster interactivity within a commodified format that uses the resulting audience engagement for commercial gains. This critical perspective argues that fostered interactivity, far from being some from the ground up organic expression of the demos, is invariably channeled and controlled to serve particular goals such as target ratings points (TRP) and advertising revenue. Drives to appropriate the participatory culture are visible across news shows in their invitations for viewer comments, as well as in encouraging citizens to report on local issues and conduct sting operations on corrupt officials, thus making each viewer in the audience a veritable extension of the newsroom. These changes are also an outcome of an increasingly activist role played by media institutions as they channel the anger and frustration of citizens seeking quick recourse and justice (Roy 20I6; Cody 2015). Times Now's primetime show Newshour, whose previous anchor Arnab Goswami (addressed as 'Arnab' on the show) led the show to high TRP ratings through a mix of jingoism and high decibel levels masked as the artifice of speaking truth to power, epitomized this impulse to commodify interactivity as Goswami sought to use the platform of Twitter by inviting its viewers to interact with the show by trending a chosen hashtag each evening.

Situated within these opposing motivations and consequences of interactivity, networked new media technologies have both shaped and been shaped by this attempt to appropriate the "public" within television shows. In navigating these positions, this chapter focuses on how the combined affordances of live television and new media platforms such as Twitter are leveraged to serve the goals of media institutions. Given their relationship to liveness, these media technologies can function together akin to a hybrid media apparatus (Chadwick 2017) whose combined affordances intensify immediacy, simultaneity, and reciprocity, thus amplifying the constructedness of live television (Marriott 2007; Scannell 2014). New media platforms such as Twitter allow live broadcast networks to include the flow of comments within their broadcast in real time; by urging viewers to tweet and running the tweet count on screen, the show enters into a symbiotic 
relationship akin to a feedback loop with the audience, thus amplifying and shaping the staged liveness. In analyzing how the affordances of Twitter make it particularly amenable to be appropriated by live television, this chapter focuses on the role of hashtags by news networks as a unifying tool (Rambukkana 2015), to generate and appropriate conversation about specific topics of focus each day. By creating a hashtag that encapsulates the main news event of the day and asking viewers to tweet using it as the show unfolds, shows such as Newshour try to create a feedback loop between the news studio and the ongoing conversations outside the network's studio. As they display running Twitter counts and flash chosen tweets on the screen, even reading some of them to provide the semblance of interactivity and inclusion, these news shows betray the intense pressure to create the perception of an organic involved and participatory audience.

\section{Twitter, Television, Liveness}

The case study of \#ShamedInSydney allows us to explore the connection between two distinct media technologies-Twitter and live televisionthat are tied together through their common relationship with the notion of time. The varying affordances of media technologies shape user experience differently and often evolve in ways that "developers, manufacturers and managers of particular technological forms, in other words, cannot altogether prescribe" (Marriott 2007, I3). The initial days of adoption of a media technology are often too early to predict the particular aspect that will gain traction. The unexpected growth of text messaging through a device designed primarily for voice calls (the mobile phone) is a classic instance of this phenomenon. Given this, one can argue that both television and Twitter have emerged as media technologies par excellence for capturing and enhancing the experience of liveness. Liveness is central to the phenomenon of television broadcasting and scholars have argued that the "management of liveness" is the "most fundamental task" of broadcasting (Scannell 2007, 194) and have claimed that "television is the 'live medium' par excellence" (Hammelburg 2015). In the case of Twitter, responding to speculation about the ongoing changes to the platform, its cofounder Jack Dorsey has famously tweeted, "Twitter is live. Twitter is real-time” (@Jack, February 2, 2016). The affordance of 140 characters, the publicness of the medium (the conversation is not restricted to a closed group unless one chooses to do so), and the ability to connect tweets across time and space through hashtags has allowed the platform to emerge as the go-to site for 
news updates and for participating in global conversations about issues and breaking news events unfolding in real time.

The case study analyzed here draws attention to the affordances of Twitter that enable it to emerge as an apt medium to capture the live unfolding of an event. While other SNS platforms, such as Facebook or Wikipedia, are better suited for in-depth discussions of preexisting issues that have evolved and matured, the technical and cultural architecture of Twitter, which emphasizes brevity, makes it apt for interactions that require immediacy, simultaneity, and speed. This is by no means to argue that older simmering topics of contention are not actively debated on Twitter, but that platforms other than Twitter (e.g., Facebook, which does not have limits of space) are just as appropriate, if not more, for those discussions. In fact, Twitter's own guidelines for determining trending topics underscore the value that recency has for its algorithms. In describing the criteria that its algorithms use to determine a trending hashtag, Twitter states, "This algorithm identifies topics that are popular now, rather than topics that have been popular for a while or on a daily basis, to help you discover the hottest emerging topics of discussion on Twitter." The criteria goes on to add that while the number of tweets on a topic is important, they are not the only factor that determines trends. The emphasis on the freshness of a topic rather than on a purely numerical count emphasizes the medium's affinity with liveness and explains why it remains the go-to place for facts and updates about a breaking news event.

Twitter's affinity with immediacy is shared by live television's ability to simulate the sensory experience of sharing the time and place during the unfolding of an event, which was a marked improvement (that yet remains unrivaled) over prior media technologies that preceded it. In his analysis of liveness, Paddy Scannell argues that the "management of liveness" (Scannell 20I4, I54) takes precedence over the actual experience of it. In other words, it is more important to convey to audiences that a particular broadcast is live and emphasize it through words, gestures, and other semiotics of liveness than the transmission of images and sounds in immediate real time without delay. While a slight delay (deliberate or technological) may not be immediately perceived by viewers, the absence of other markers of liveness can make the claim of a live broadcast seem suspect. The distinctness of the semiotics of liveness can be better understood by comparing footage from a surveillance (closed-circuit television) camera with the live television broadcast of an event, claims Scannell. While the former captures "soundless visual immediacy" (Scannell 2014, 99), live television provides continu- 
ous reminders that the event being witnessed is unfolding "right now" in the "here" of the correspondent reporting on the event. Marriott (2007) agrees with Scannell $(2007,2014)$ to claim that television needs to do work "to steer viewers towards the conclusion that what they were watching was live" (Marriott 2007, 2 I). Liveness therefore is not some naturally apparent phenomenon but is the "worked at, achieved and accomplished effect" (Scannell 2014, 99) that must be staged and constructed with the right indices that audiences have learned to associate with live broadcast. Scholars have identified these indices variously as direct address to the camera and remoteness (Marriott 2007, citing Vianello 1985) or immediacy and affinity (Hammelburg 2015) but always requiring preplanning and rehearsal (Scannell 2014) given that live broadcast is "intrinsically risky" (Scannell $2014, \mathrm{I} 68)$. The specifics vary according to the nature of the particular event being broadcast live, but the fact that there are formatted routines of liveness on television show its constructed and managed nature.

As they come together to simulate liveness, these media technologies also remind us of the quandary of mediation that is fated to limit one's access to the totality of the real event. The affordances of each medium limit and shape our access to it, and the immediate experience of sound and image that live television provides us is nevertheless only a representation at a distance of the actual events. It follows therefore that "no mediated encounter is going to be able to deliver anything other than a relatively thin engagement with the world" (Marriott 2007, I5). The insurmountable hurdle of space and materiality ensure that sensory experiences such as taste, touch, and smell cannot be represented live at a distance. Hence, the deployment of digital or networked media technologies along with broadcast television is often intended to complement and enhance the latter's abilities of reaction, feedback, or reciprocity. The increasing use of networked technologies (e.g., Twitter) by live broadcast shows, as in the case of Newshour's appropriation of Twitter, therefore seeks to enhance the experience of liveness for the audiences by supplementing television's limitations as primarily a one-way medium. Viewers are implored to enter into a conversation using a particular hashtag, thus allowing live shows such as Newshour to generate real-time engagement and response to compensate for the limitations of television.

This process of bringing the audience into the show through the promise of interactivity (Andrejevic 2004) that leverages the ubiquitous networked devices and SNS platforms have allowed for a new kind of intensity in creating feedback loops of participation in an ongoing conversation 
about an event. The ways in which such feedback loops can influence the coverage but also change the very nature of the event was most apparent in the live coverage of the Mumbai attacks. As trapped hostages with mobile phones revealed their locations on live telecasts, attackers and their handlers watching the same broadcast went to those locations to prey on them (Kumar 20I2). Incidents such as the coverage of the Mumbai attacks and \#ShamedInSydney share the common element of audiences cocreating the event even as it unfolds. As the particular episode of the Newshour being discussed unfolded, the mismatch between the show's narrative and the mood of the nation outside the news studio became increasingly apparent. The abysmal tweet count affected the anchor's demeanor and the show's content including the comments by the guests on the show. Through their reactions on Twitter, audiences outside the studio therefore shaped the unfolding of a live event, as I show below.

\section{The \#ShamedlnSydney Debacle}

Times Now's coverage of India's defeat in the semifinal of the Cricket World Cup on March 26, 20I 5 was similar in its format to the coverage of any other big news event. As is a usual practice among news networks in India, Times Now too attempts to trend a hashtag each evening that seeks to both predict and capture the unfolding daily zeitgeist among the Indian audience as expressed on social media. Its chosen hashtag for the said day was \#ShamedInSydney and was meant to encapsulate the public rage at India's defeat by Australia, tapping into which would have been a ratings gold for its primetime talk show, the Newshour. This is a daily routine on the show where recent hashtags such as \#TirangaTussle, \#TripleTalaqEnds, \#OneIndiaOneLaw, and \#UPTrain Tragedy have sought to coalesce conversations on the topic chosen for discussion on the show. The running tweet count using the particular hashtag on the top right corner of the screen is a marker of audience engagement that seemingly realizes the dream of a truly participatory news organization that critics of monopolistic, top-down media structures have long yearned for. A trending hashtag means that it has gained traction and crossed a certain threshold of tweets, thus marking a temporal convergence of the increasing intensity on the talk show and an equally rising number of tweets using the particular hashtag.

On a typical Newshour anchored by Goswami, as the show unfolded toward a climactic peak and the guests became increasingly inaudible (given 
the format of instigating them to speak at and over each other), the rapidly running counter of the number of tweets with the chosen hashtag signified the level of audience engagement to the guests and the audience. A high tweet count would mean that the Times Now team made the right call about the mood of the nation on a controversy or event. The choice of a hashtag therefore is a calculated gamble, and calling the bet accurately lends credence to the network's claim about being attuned to the national mood. The uncertainty about how involved the audience will be on a particular evening provides excitement but also introduces an element of risk to live broadcast. As Peters (200I) has argued, this uncertainty of liveness is akin to a gamble and fraught with danger. What will unfold in the next moment in time is unknown and while one can make educated guesses about it, watching it unfold second by second provides the thrill that makes "live" among the most used buzzwords in broadcast television (Peters 200I). In the case of the Newshour the show's anchor (Goswami) had not just sought to predict the mood of the viewers but to shape it through his tone, format, and style. As the show progressed, the decibel levels rose, with one half of the panel (that can include up to ro people) screaming at the other half. The rising passions in the studio were meant to synchronize with the rage outside, thus resulting in more tweets and a rapidly trending hashtag. The conflation of intensity in the studio with the tweet count is the digital equivalent of a passionate embrace between two competing temporalities, each egging the other on as fast moving fingers on keypads match the decibel levels on the Newshour. The ability to ratchet up the affective temperature in the Twitterverse by guessing and predicting the appropriate hashtag therefore becomes a marker of the program's success. By the standards of this successful formula repeated each night, March 26, 2015 was a day of infamy in the annals of the Newshour's success story.

As Goswami started the Newshour with the usual prologue before guests are introduced, the chosen villain for the night was the Indian cricket team. His certainty that he had, as always, accurately captured the national mood was based on a past where India's exit from any global cricket competition has been met by acrimonious attacks on the cricket team that have gone beyond protests and angry words to physical attacks including stone pelting on cricketers' homes. By betting on cricket, the holy grail of jingoistic Indian nationalism, and attacking the cricket team on a day of India's exit from the World Cup, Arnab's was a safe wager for any late night talk show host seeking to seize the affective fulcrum of its audience. Goswami started the show by proclaiming that "the results are a disaster in Sydney," adding, 
"a star-studded Indian team has collapsed like a pack of cards," "India has surrendered in the semi-final without a fight," and that was "humiliating." As he expressed his rage the hashtag \#ShamedInSydney appeared on the top-right corner of the screen with the words "India thrashed and sent packing." A few minutes into the debate Goswami was as usual, shouting down every panelist who dared to suggest that the honor was in having played a good game. However, something atypical and unpredictable was happening in the Twitterverse throughout the evening. Barring a couple of initial tweets that agreed that the Indian team had been \#ShamedInSydney, the general sentiment on Twitter seemed to be that of support and appreciation for the team, acknowledging that they had reached the semifinal without having lost a single game. Those expressing this opposing sentiment soon began using the competing hashtag of \#ShameOnTimesNow to oppose the channel's position.

Gradually, even the ambivalent emotions reflected in some of the tweets, which sought to reconcile appreciation for the team with the disappointment of the loss, soon gave way to a strong tone of appreciation and respect for the team. Critics, writing about this moment later, would mark this as a turning point in the history of India's cricket fandom-a sign of maturing spectators with realistic expectations. Sandipan Sharma (20 I 5), in an essay titled "India May Have Lost but Our Fans Have Finally Grown Up," presented a contrast from the past when "[b]ooing the team, pelting stones, setting stands on fire . . . ridiculing and humiliating players and their families" had "been typical Indian reactions to a loss." In asking the question about the maturing Indian fan, Sharma presented several reasons including the string of recent cricket victories by India that had ensured India entering the tournament as defending champions. As the show began, one of the panelists, Atul Wassan a former cricketer, reflected the popular sentiment by strongly objecting to the word "shamed" in the chosen hashtag. He claimed that the team fought hard and hence "defeated in Sydney" or "walloped in Sydney" was more accurate. "No sportsperson can be humiliated" he emphasized to Arnab, who responded in his typical combative tone with " $[\mathrm{w}]$ hat are you getting so touchy about?" It was soon clear that just like the audience outside, a majority of the seven-member panel (excluding the anchor) were in disagreement with the anchor's narrative that evening.

Instead of targeting the cricket team, as Arnab had hoped, the outrage on Twitter increasingly began to be directed toward Times Now and Arnab Goswami himself. Users blasted the low standards of televi- 
sion news in India by negatively comparing it to the press's role during the freedom struggle. Appreciation for the team and its captain contrasted with the calling out of Times Now's expedient use of the defeat to ratchet up viewer emotions. Many angry tweeters used the opportunity to deride the sensationalist nature of Indian television news specifically lambasting their desire for TRPs. In addition to tweeting with the competing hashtag \#ShameOnTimesNow many began to unfollow or block the Times Now handle on Twitter and uploaded screenshots of the blocking. One user, $M$ J Imran, shared that he had specifically searched for Times Now, followed, and then blocked their account, claiming that it "Feels good now!" Others argued that the response against Times Now was long in coming and the \#ShamedInSydney debacle represented a culmination of pent-up viewer angst against the network and its host that had just boiled over. A notable aspect of the critique was the acknowledgment of the power of social media in talking back to the dominant media institutions. One user, @nandan_jk, for instance, congratulated other users for trending the \#ShamedInSydney hashtag by proclaiming “@nandan_jk Mar 26 I'm so proud of my countrymen. ... Taught the useless media a good lesson!"

The anger also took the form of requests for an apology, for instance in this tweet by the user @raw_rak, "We need an apology on behalf of our brave team \#ShameOnTimesNow." While the majority of tweets were textual, as is often the case with a trending hashtag, other creative skills were also in full display in the form of photoshopped images and memes using the rival hashtag. There were suggestions for creating memes that were promptly taken up and published, thus pointing to the sense of momentary solidarity with distant strangers across space that a platform such as Twitter can enable. An instance of such a request from the user @Joseph_AJohn asked, "Can somebody make an animation of @msdhoni slapping @TimesNow Arnabgoswami??? \#ShameOnTimesNow." Many tweets, often from loyal acolytes of the show's anchor, reflected shock and disbelief at how horribly wrong the show's position had been. In underscoring the relationship between liveness and gambling made earlier in the chapter, one user (@halfacomic) wondered if "they flip a coin to choose the side of debate \#ShameOnTimesNow." Each of these sample tweets reflected a gross misjudgment of the nation's mood by the network. As the rival hashtag caught on, congratulatory messages began to mention the number of tweets using the hashtag \#ShameOnTimesNow, thus providing a running commentary on how Twitter users were gradually turning the tables on Times Now. One user, Swapnil Ajgaonkar (@swapnils2or I), for instance, mentioned 
the number of times the hashtag had been tweeted by saying, "I $57 \mathrm{~K}$ angry tweets and still counting." Very soon, instead of the hashtag \#ShamedInSydney it was the hashtag \#ShameOnTimesNow that was trending on Twitter and several users emphasized this in order to embolden other likeminded tweeters.

An estimate of how erroneous the Newshour's position on India's defeat had been can be gauged from the data on trending hashtags for the day of March 25, 2015, when the episode of the Newshour being discussed aired. While their chosen hashtag of \#ShamedInSydney was nowhere in contention, the rival hashtag \#ShameOnTimesNow had risen to number I7 among the trending hashtags in India and number five worldwide. While this ranking is remarkable, given that the Newshour airs late in the night (9 p.m.), leaving only a few hours before the end of the calendar date for it to count as a trend for that day, the real effect of the debacle can be sensed by the top trending hashtags for the day after the debate. Times Now's telecast had so mobilized the Twiterati that \#ShameOnTimesNow was the topmost trending hashtag in India for March 27, 201 $5^{2}$ while it was at number eight globally among the top trending hashtags. These rankings indicate that not only had the Newshour and its anchor Arnab Goswami misjudged the mood of the country but also that his position against the Indian team had functioned to further galvanize support, appreciation, and respect for the team. The show's positionality as reflected in the hashtag functioned dialectically to entrench and embolden the opposing emotion that found expression in the rival hashtag. The fact that the show's strong position was about the sport of cricket that, along with Bollywood and politics, remains among the most emotive topics within the Indian public sphere played no small a part in drawing the battle lines.

Specifics details during the telecast of the hour-long show reflected that the Newshour team, including the anchor Arnab Goswami, was gradually becoming aware of this debacle and making course corrections. With the team realizing that the tweet count for their chosen hashtag was not rising, and that too on an issue as resonant with the Indian audience as cricket, the mention of the live tweet count was conspicuous by its absence from the television screen during the show. The hashtag that appears frequently on the screen for any typical Newshour telecast only appeared once (at 2 I:43 minutes) during this particular telecast. In its place was a generic invitation to "Tweet Live Join the Debate" that kept flashing on the screen throughout the show without any particular hashtag. The anchor, Arnab, who repeatedly invokes his audience to tweet using the hashtag did so only once 
at the start of the show when the ensuing chain of events was yet to unfold. It was clear that the response from the audience had conveyed the intended message. The broadcast tried to save face (by not showing the tweet count, for example) while not doing an entire turnaround, which would have been deeply humiliating.

\section{Hashtag Wars and Networks of Simultaneity}

The \#ShamedInSydney debacle allows us to analyze the phenomenon of hashtag wars whose particular instantiation we see in this case study but which is a much wider occurrence across the global Twitter sphere. These so-called wars, which use rival hashtags to propel competing, often opposing narratives about an issue or event, epitomize what critics have called out as the divisive polarizing dimension of Twitter (Maney 2017). These wars are especially intense on political topics around elections (as was the case with the 2016 US elections) but hardly limited to them. The choice of a hashtag by Indian news networks each evening is strategic because it allows them to generate and then stake a claim on conversations about specific news events or issues that may otherwise have been diffused in the virtual realm. In enabling this yoking together of disconnected and dispersed conversations, Twitter hashtags function akin to a symbolic baton being passed around in a conversational relay, allowing each member to join an ongoing stream of conversation. As the hashtags are hyperlinked, clicking on any one of them streams all tweets on the screen in a continuous flow while the "live" button (now changed to "latest") rolls the most recent tweets from top to bottom. Twitter's ability to enable these discursive chains that cut across space and time is an affordance unique to the platform and has enabled a global alliance of users where the hashtag ties together conversations around events or ideas in real time. In the case of India, just as globally, they have also helped create alliances among reactionary and jingoistic discourses that may have been on the social fringes but now are emboldened due to Twitter's ability to erase the barriers of space and time to enable a global conversation. These emboldened reactionary discourses are most visible within India's Twitterscape, which routinely witnesses hashtag wars over competing narratives in the public sphere.

The polarizing and vitriolic nature of the Indian Twitterverse (Udupa 2017) is unique even by the global standards of the discourse on Twitter, which invariably rewards and privileges extreme positions over moderate ones. This partisanship must be contextualized against the number of Twit- 
ter users in India, which at the time the episode being analyzed aired was about 22 million, or only about 9 percent of the Internet users in India and less than 2 percent of India's total population (Hindu, January 28, 20 I 5). This number of Twitter users (since risen to 4I million in May 2016), ${ }^{3}$ while a tiny fraction of India's overall population, nevertheless makes India's Twitter population the second largest in the world after the United States. With less than half its population online (34 percent in May 20r6), India already has more Internet users ( 462 million $)^{4}$ than any other country except China; given Twitter's popularity in India, it is only a matter of time before India's Twitter population becomes the largest in the world. These rising numbers of Internet and Twitter usage provide a large base for the growth of a participatory culture in India even though Twitter users are not necessarily representative of the plurality and diversity within India's population. In fact, the relative niche and elite user base of Twitter in India mirrors global trends since the microblogging site attracts those users likely to already be invested in and more engaged with daily events and controversies than the average Internet user. This background perhaps explains the vitriolic nature of its discourse and the sobriquet of "keyboard warriors" that captures images of people with desk jobs, Internet access, and spare time to spend their entire day tweeting and sparring over issues. News networks' attempts to trend hashtags and appropriate this participatory culture must be understood against this relatively narrow base of SNS platforms in India that gives online interactivity more symbolic value than real one.

While the partisanship across political and ideological lines on Twitter has widely been acknowledged, what made the episode of \#ShamedInSydney different from the typical partisan hashtag war was also the fact that, as opposed to the typical right vs. left divide on most issues in the Indian public sphere, the \#ShameOn'TimesNow hashtag galvanized support across the political spectrum. This solidarity, cutting across political ideologies, can be understood through the unifying fandom that cricket commands in India. Moreover, the fact that the target of this solidarity was the show Newshour and its anchor Arnab Goswami, who remains a polarizing figure with doting loyal viewers as well as raging critics, further underscores how Twitter's emphasis on immediacy, simultaneity, and recency can enable new alliances between hitherto opposed sections of users. As opposed to preexisting issues and controversies where positions are already well entrenched along ideological divides, breaking news events evolve rapidly, often demanding an immediate response. While the old divides are still likely to 
shape opinions initially, the case of \#ShamedInSydney shows that the rapid spiral of tweeting and response allows its own communities of conversation to emerge, communities that are tied together in the temporal "now." The nonexistent support for Times Now's hashtag and the near unanimity in the debate on Twitter showed a clear breaking of ranks by Goswami's loyal supporters. This emphasized how the platform's affinity with the temporal now could enable a discursive momentum that weakens prior ideological loyalties in favor of the immediate emerging directional flow, which was against the channel's position. However, this emerging critical position was also informed by the prior history of anger against the channel, which unleashed itself in this particular episode. In allowing these distant users, who are strangers to each other, to be tied together in the moment, either through disagreement or alliance, Twitter enables what can be called are networks of simultaneity.

These networks of simultaneity are glued together by a spontaneous affective intensity as they are reacting viscerally to an immediate event instead of deliberating on issues over long periods. The relationship between affective intensity and the viral spread of ideas in the digital world has been studied recently (Papacharissi 2015), and the current scholarship on viral culture, for instance, emphasizes the role played by affective "arousal hierarchy" (Guadagno et al. 2013) in determining the resonance of ideas or events online. Situating this diverse range of affective responses, such as anger, curiosity/anxiety, humor, or other positive affects (Shifman 20I2), alongside conversations about the role of affect in democratic deliberations (Cody 2015) and media activism (Roy 2016) can explain why certain ideas and not others gain traction within digital cultures. The \#ShamedInSydney episode illustrates the formation of these networks of simultaneity that cut across political ideologies and were connected by an affective intensity being experienced in the moment. The fact that the hashtag continued to trend for a few days after the airing of the said episode reflects the magnitude of the network's miscalculation.

\section{Conclusion}

The case study analyzed here presents us with a snapshot of the convergence between live broadcast television and the digital platform of Twitter. It shows us the ways in which the growing interdependence between new and preexisting media technologies creates hybrid media spaces (Chadwick 20I7) where the differing affordances of each technology complement each 
other to transform the experience of mediation across space and time. The particular case of \#ShamedInSydney shows us how appropriating Twitter allows news networks to claim enhanced and interactive experiences of liveness and immediacy. It also points to the unpredictability and risks associated with a live broadcast. As Times Now's failed gamble aptly illustrates, the more enmeshed live audiences become within a live broadcast the more likely they are to begin to shape its unfolding. The resonance that liveness has with audiences (Peters 200I; Scannell 20I4) reflects an inherent longing to traverse time and space and share in the unfolding of history. By tapping into that longing and advertising their success in their ability to do so, news networks seek to exploit that longing to cut through the competition. While Times Now has been one of the leaders in this attempt, it is not the only network that seeks to do so.

While the drive to attract audiences is as old as privatized corporate media, the continuing fragmentation of audiences because of a multiplicity of media outlets has made the necessity urgent. The imperative to engage a broad range of social media outlets beyond television is a commercial compulsion as networks vie for the limited advertising revenue that is also gradually moving to the web. What the analysis above shows us is how this embrace of emerging platforms transforms the nature of news content by infusing a new temporal structure within it. While broadcast television has its own rhythms and patterns, its convergence with the "always on" social media platforms creates an entirely new dynamic that requires far speedier response time and immediate course corrections. No doubt live television has gained from this ability to tap into networks of users and audiences for crucial details about breaking news events, thus enhancing its own coverage of events and reportage. As the case study above shows, however, this reliance has also meant that it cedes control in crucial areas, such as editorial positions on issues and the direction of the narrative within news and talk shows. The ways in which networks strike the balance between incorporating live audiences into their shows while still maintaining control over key editorial aspects of news will remain a key object of study in the years to come.

\section{Notes}

I. https://support.twitter.com

2. Hashtag rankings have been sourced from trending sites including trendi nalia.com

3. https://www.statista.com

4. http://www.internetlivestats.com 


\section{References}

Andrejevic, Mark. 2004. Reality TV: The Work of Being Watched. Lanham, MD: Rowman and Littlefield.

Bagdikian, Ben H. 2004. The New Media Monopoly: A Completely Revised and Updated Edition with Seven New Chapters. 2oth ed. Boston: Beacon Press.

Chadwick, Andrew. 20 I 7. The Hybrid Media System: Politics and Power. Oxford: Oxford University Press.

Cody, Francis. 2015. "Populist Publics: Print Capitalism and Crowd Violence beyond Liberal Frameworks." Comparative Studies of South Asia, Africa and the Middle East 35 (I): 50-65.

"FAQs about Trends on Twitter." Twitter Help Center. January 23, 20I 7. https:// support.twitter.com

Guadagno, Rosanna E., Daniel M. Rempala, Shannon Murphy, and Bradley M. Okdie. 20I3. "What Makes a Video Go Viral? An Analysis of Emotional Contagion and Internet Memes." Computers in Human Behavior 29 (6): 23 I 2-I9.

Hammelburg, Esther. 2015. "\# Stemfie: Reconceptualising Liveness in the Era of Social Media." Tijdschrift voor Mediageschiedenis I 8 (I): 85-100.

"India's Twitter Users The Hindu—Google Search." N.p., n.d. Web. January 23, 2017 .

Jenkins, Henry. 2008. Convergence Culture: Where Old and New Media Collide. New York: NYU Press.

Jenkins, Henry, Sam Ford, and Joshua Green. 2013. Spreadable Media: Creating Value and Meaning in a Networked Culture. New York: NYU Press. Google Scholar. Web. August 30, 2014.

Kumar, Sangeet. 20 I 2. "The Fatal Snare of Proximity: Live Television, New Media and the Witnessing of Mumbai Attacks." South Asian History and Culture 3 (4): 532-48. Taylor and Francis+NE7M. Web.

Maney, Kevin Maney. 20I 7. "It's Time to Kill Twitter, before It Kills Us." Newsweek. January Io, 20 I 7. https://www.newsweek.com/2017/01/20/killtwitter-540656.html

Marriott, Stephanie. 2007. Live Television: Time, Space and the Broadcast Event. London: Sage.

McChesney, Robert W. 20 5. Rich Media, Poor Democracy: Communication Politics in Dubious Times. New York: New Press.

Papacharissi, Zizi. 20 I 5. Affective Publics: Sentiment, Technology and Politics. Oxford: Oxford University Press.

Peters, John Durham. 2001. "Witnessing." Media, Culture and Society 23: 707-23.

Punathambekar, Aswin. 20I0. "Reality TV and Participatory Culture in India." Popular Communication 8: 24I-55.

Rambukkana, Nathan. 201 5. "\#Introduction: Hashtags as Technosocial Events." In Hashtag Publics: The Power and Politics of Discursive Networks, edited by Nathan Rambukkana, I-Io. Bern: Peter Lang Publishing.

Roy, Srirupa. 2016. "Angry Citizens: Civic Anger and the Politics of Curative Democracy in India." Identities 23 (3): 362-77.

Scannell, Paddy. 2007. Media and Communication. London: Sage.

Scannell, Paddy. 2014. Television and the Meaning of "Live": An Enquiry into the Human Situation. Cambridge: Polity. 
Sharma, Sandipan. 20 I 5. "World Cup 20 I 5 : India May Have Lost, but Our Cricket Fans Have Finally Grown up." Firstpost. N.p., March 28, 2015. Web. January $23,2017$.

Shifman, Limor. 20 I 2. "An Anatomy of a YouTube Meme." New Media $\mathfrak{E}$ Society I 4 (2): $\mathrm{I} 87-203$.

"Twitter Accounts for Only I $7 \%$ of Indian Social Network Users." 201 5. Hindu, January 28, 2015 .

Udupa, Sahana. 201 7. "Gaali Cultures: The Politics of Abusive Exchange on Social Media.” New Media \& Society. https://doi.org/10.1177/1461444817698776

Vianello, Robert. I985. "The Power Politics of 'Live' Television.” Fournal of Film and Video 37 (3): 26-40. 
PART 3

\section{Publics}




\title{
The Remediation of Nationalism
}

\author{
Viscerality, Virality, and Digital Affect \\ Purnima Mankekar and Hannah Carlan
}

In February 20r6, Kanhaiya Kumar, a PhD student at Jawaharlal Nehru University in New Delhi (JNU hereafter), was arrested on charges of sedition and criminal conspiracy. Kumar was the president of the University Students' Union and had delivered a speech on campus criticizing the 2013 execution of Mohammed Afzal Guru, who had been convicted for his alleged involvement in the terrorist attack on the Indian parliament in $200 \mathrm{I}$. Kumar's arrest and subsequent release on bail created a firestorm of debates surrounding the meanings of nationalism in postcolonial India. At the center of this firestorm were digital media or, more specifically, the convergence of digital media like Twitter and video-sharing platforms like YouTube with mass media like television and print (Jenkins 2006; on the convergence of television and digital media in India, see Shanti Kumar 20IO, 20I4; Sangeet Kumar 2015; Punathambekar 20I I; and Roy 20I4).

Focusing on the proliferation of affectively charged discourses surrounding Kanhaiya Kumar, we examine how digital media, in conjunction with television, participated in the ongoing remediation of nationalism as visceral and viral. By foregrounding the generation and circulation of affect by and across media, our analysis complicates assumptions about the role of digital media in producing new means of political participation and agency on the part of nonelite actors (cf. Kumar 20I4; Punathambekar 20II, 20I5; and Udupa 20I7). ${ }^{1}$ We seek to make the following theoreti- 
cal interventions. One, by focusing on the mediatized debates surrounding Kumar, we seek to foreground the centrality of affects rather than "rational communication" in the generation of political discourse. ${ }^{2}$ Second, we argue that the convergence of mass media and digital media generate and circulate affects that proliferate with such speed and intensity as to become simultaneously viral and visceral. Third, as the affects that congealed around the figure of Kumar demonstrate, the remediation of nationalism is deeply refracted by gender and sexuality, thus underscoring the importance of feminist social critique.

What does it mean to make the apparently contradictory assertion about nationalism as simultaneously visceral and viral? The dictionary definition of visceral makes reference to that which is felt deep in the body (as if in its internal organs), instinctive rather than rational, and stems from "elemental emotions" (Merriam-Webster Dictionary 2018). In postulating nationalism as affect, however, we assert that the visceral, in this case, is also socially mediated; indeed, as Mankekar has insisted elsewhere, it is imperative that we think of nationalist affect as part of affective regimes intimately imbricated with the workings of the state, media, and other sociopolitical institutions (Mankekar 2015). As we will elaborate below, affects are not equivalent to emotions but, instead, operate on a separate register (on the "autonomy" of affect, see Massumi 2002). Our analysis of the affective regimes that relayed between media representations of Kumar and online responses to these representations draws on the premise that, unlike emotions, which are deemed to be located "within" subjects or are expressive of subjectivity, affect does not reside in the individual "psyche." Rather affects generate subjectivity. Hence, our focus on affect sidesteps binaristic assumptions of superficial utterances or performances (performances that we could take at "face value") versus inner truths. ${ }^{4}$ Theorists of indexicality have long insisted on the need to expand our analyses of language beyond a focus on mere referential content, and its purported truth value (Silverstein 1979), to the semiotic processes through which certain ways of speaking become tied to ideological structures, identities, and forms of difference. ${ }^{5}$ We add here the importance of attending to the production of affects, which are themselves continual processes of becoming; they pertain to agential capacities that are irreducible to binaries of resistance and compliance: affects reside in contingency and potentiality.

As we will argue in this paper, nationalism is neither solely imaginative (Anderson I99I) nor only discursive (Chatterjee I986; Bhabha 2013 [1990]), but is profoundly affective. It is deeply felt, as if in the very viscera 
of our bodies. It is corporeal; it is embodied. While discourses of nationalism might cohere around specific icons and symbols (such as the national flag, the tomb of the Unknown Soldier, or, in the case of India, the figure of Bharat Mata), these figures become potent when they acquire affective freight, which is to say, when they become generative of action and agency.

Nationalism, as Anderson suggested, is fundamentally translocal and transnational, and media have played a critical role in its production and circulation (I991; see also Abu-Lughod 2005, Mankekar I999, 2015; Rajagopal $200 \mathrm{I}$ for the role of television in the reconstitution of nationalism in postcolonial contexts). It is also essential to remember that affects are not located in any one site or sign: affects are intransitive in that they acquire potency through their circulation and concatenation (Ahmed 2015; Mankekar and Schein 2013; Mankekar 2015). We argue that digital media, whether through social networking sites like Twitter and Facebook or content-sharing platforms like YouTube, have played a crucial role in the creation and promulgation of nationalist affects.

We draw upon a long and rich tradition of feminist critiques of nationalism in South Asia (including, among many others, the work of Uma Chakravarti 1989, 20I4; Veena Das 2007; Malathi de Alwis 2002; Purnima Mankekar I999, 20 I 5; Nivedita Menon I998, 20 I 2; Nayanika Mookherjee 2015; Mrinalini Sinha 2000; Tejaswini Niranjana 1994, I999; Srirupa Roy 2007; Kumkum Sangari and Sudesh Vaid 1989; Rajeshwari Sundar Rajan 2003; and Susie Tharu 1996) that have variously examined how nationand state-making projects are fundamentally gendered. These processes are manifest in the nature of YouTube comments responding to Kanhaiya Kumar and JNU student protests, which combine accusations of antinationalism with violent, misogynist, and homophobic rhetoric.

Recent scholarship on digital media has interrogated the capacity of online spaces to engender a "participatory culture" (Burgess and Green 2009) where previously marginalized voices are potentially able to construct social and political counterpublics (Bonilla and Rosa 2015; Losh 20I4; Subramanian 2015). Facebook, in particular, has been identified for its role in recent political movements, facilitating new "netizens" to participate increasingly in democratic politics (Hauben and Hauben 1997). Several scholars have argued that people become "empowered through the Internet and use it to solve sociopolitical problems and to explore ways of improving the world" (Fedorak 2012, I 20). Just as the antiglobalization protests in Seattle in 1999 were organized online, grassroots social movements like the Arab Spring, Occupy Wall Street, Black Lives Matter, 
and recent protests against the Trump administration have emerged largely through Facebook and Twitter, allowing people to access news and organize direct action at increasing speeds and on unprecedented scales (Penney and Dadas 20I4; Juris 20I2; Tufekci and Wilson 20I2). We note that analyses that have emphasized the democratization of online spaces have elided the fact that digital publics are not devoid of structures of power and inequality, as both mass and social media are often sites for the reinforcement of racism, sexism, xenophobia, and, in our case, a particular form of fundamentalist Hindu nationalism that is intimately linked to gender and violence (Phillips 20r6; Lal 1999). Print and televised media in particular have been analyzed for how they operate by de- and recontextualizing sensationalist tropes that contribute to moral panics and reinforce racist and orientalist discourses (O'Hara 201 2; Briggs and Mantini-Briggs 2003; Puar and Rai 2002; Narayan 1997). This was especially true in the aftermath of the mediatization of the 20 I 2 Delhi gang rape, which exceeded the specificity of the crime as it spurred protests and activism within India for criminal justice reform and became a spectacle in the international media of India's purportedly uniquely "rape culture" (Amrute 2015; Roychowdhury 2013; Carlan 2014). Yet it was precisely on digital media platforms like YouTube that some Indian youth were able to critique the normalization of violence against Indian women through satirical and carnivalesque videos and imagery that mocked victim-blaming narratives (Carlan 2015).

In attempting to understand how a particular kind of affective nationalism was remediated by online responses to student protests at JNU, it is necessary to go beyond the content-production side of media analysis to investigate the crucial role of user reception and (re)interpretation as a central aspect of political participation (Carlan 20I4). Thus, we must attend carefully not only to content produced by actors in mediated publics, but also the "uptake formulations" (Agha 20I I) that proliferate in the form of online comments. We thus attend to different nodes in the circulation of videos portraying Kumar and other JNU students as "antinational" in order to understand how these videos produced heightened affective responses that articulated with violent and nonviolent forms of political agency (Couldry 2006; Burgess and Green 2009).

The mediatization of the JNU student protests as "antinational" is part of a long-standing historical phenomenon of "technocultural Hindu nationalism" (Chopra 2008), with technology and nationalism having converged beginning in the colonial period and being transformed with the rise of globalization and the consolidation of militant right-wing Hindu 
politics, or "Hindutva," since the I980s. This brand of militant digital nationalism has been particularly salient in the context of the North American diaspora, where the Internet has been used to mobilize supporters through the reinterpretation of Indian history as one of a unified Hindu nation (Lal I999, 2003, 2014). So-called Internet Hinduism (Udupa 2014) has often relied on abusive language online that is never mere insult but, instead, has the potential to incite offline violence (Udupa 20I7). Indeed, the register of abuse that has become characteristic of online Hindu nationalism is necessarily gendered, as it relies on and reproduces a historical formation of Indian womanhood propagated by an upper-caste male elite during the anticolonial nationalist movement. Much of the research on digital Hindu nationalism has demonstrated the strategies whereby groups collectively construct a historical narrative of Hindu unity in India, which Udupa (20I4) has described as "archiving": an epistemological battle to establish truth. We focus on a form of digital nationalism that emerged in response to mediatized events like those surrounding Kanhaiya Kumar in order to underscore a particular type of affective nationalism that is undergirded by violent misogyny and homophobia.

\section{A Space for Violence}

Analyzing how the convergence of digital and mass media enables the remediation of nationalism necessitates that we move beyond behaviorist explanations of "what happened" or draw a positivist connection between the videos, the commentary, and the violence that followed. Rather we wish to theorize the coimplication of the events surrounding Kanhaiya Kumar's arrest, the dissemination of videos that purported to provide evidence of his alleged sedition, comments posted on YouTube, and the violence threatened and enacted against him. We posit that media (digital and mass) created feedback loops of affective regimes that produce what, in another context, Pradeep Jeganathan (200I) has called a space for violence.

Jeganathan locates the space for violence as a habitus that can be learned or performed and as a culturally constituted phenomena (200I, 39, 4I) rather than (simply) as fury, eruptive acts, or "unthinking explosions" that are opposed to moments of peace or restraint or ordinariness (42). Drawing on these insights, we conceptualize the space for violence around $\mathrm{Ku}-$ mar in terms of its affective constitution, which is to say as generative intensities that refract community and identity on an ongoing basis. This space for violence was deeply affective precisely because it was transformative: it 
rendered violence perpetrated in the name of the nation legitimate, if not necessary. Furthermore, occurring as they did at a historical moment when the line between Hindu nationalism and Indian nationalism is increasingly fraught, the communal tone of the comments posted on YouTube should not surprise us. Nowhere was this slippage clearer than in the centrality of discourses of gender and sexuality. As we will thematize below, calls for violence against Kumar were frequently articulated in terms of gendered and sexual violence.

How was this space for violence produced and how did it articulate with the ongoing reconstitution of nationalism as an affective regime? On February 9, 2013, Mohammed Afzal Guru and Maqbool Butt were hanged after being convicted for the attack on the Parliament of India in $200 \mathrm{I}$. The execution occurred in secret under the code name Operation Three Star, with the families notified days after the execution and the burial of the bodies. Controversy followed surrounding the fairness of the trial and allegations of human rights violations by the Delhi police of torture and a secretive hanging. John Hutnyk has argued that there was an upsurge in nationalist affects that arose through the convergence of different media relating to Guru's trial. The trial was aired on Indian television channels soliciting participation from viewers via SMS that, in turn, led to increased calls for Guru's death. This happened despite the fact that there was no reliable evidence of Guru's involvement in the attack and that the Supreme Court had dismissed his confession video as manufactured (Hutnyk 20I4). Guru's execution spurred protests at Jantar Mantar in New Delhi, and violent clashes with police followed. Three years later, the Democratic Students Union, a student organization at JNU, planned to commemorate his execution with a cultural program to protest what they termed as his "judicial killing." The event, titled "A Country without a Post Office," was supposed to include protest through poetry, art, and music, and was scheduled to occur at the Sabarmati Dhaba on the JNU campus. In response to protests by the Akhil Bhartiya Vidyarthi Parishad (ABVP, the student wing of the Bharitya Janata Party, currently in power in India), the JNU administration withdrew permission for the event. Nevertheless, the event proceeded as scheduled, and clashes ensued between the Democratic Students Union and ABVP during which it was alleged that outsiders to the university shouted anti-India slogans (Zee Media Bureau 20I6).

The following day, Zee News, a Hindi-language news channel, telecast a video of the previous night's demonstration that was edited to include a caption suggesting that the students were shouting "Pakistan Zindabad" 
(Long Live Pakistan). Shortly thereafter, Delhi police filed a First Information Report (FIR) on the basis of this video and charged Kanhaiya Kumar and fellow students Umar Khalid, Anirban Bhattacharya, Rama Naga, Anant Prakash Narayan, and Ashutosh Kumar with sedition under Section r 24A of the Indian Penal Code. ${ }^{7}$ The video was later revealed to have been doctored by producers at the show; scrambled audio from another group of protesters shouting "Bhartiya Court Zindabad" (Long Live the Indian Court) was dubbed onto the original video, and the "Pakistan Zindabad" caption was imposed in order to suggest that this is was what students were shouting.

Processes of recontextualization added affective potency to these allegations. During the frenzy surrounding the alleged "anti-national" sloganeering by JNU students, Zee News uploaded the same footage to YouTube. This video became subject to considerable remediation through social media posts and comments. ${ }^{8}$ The uploading of the clip onto YouTube reinforced the narrative that producers at Zee News had knowingly fabricated alleging that Kumar and his colleagues had engaged in antinational acts. In the ro days following the February 9 event at JNU, Zee News uploaded dozens of videos onto YouTube that explicitly described JNU students as "anti-nationals," "criminals," "traitors," "renegades," and terrorist "sympathizers." Such accusations had both an illocutionary force and perlocutionary effects, in the Austinian sense (Austin 1962), in that the students were not merely accused of seditious, and therefore illegal, behavior, but the act of invoking such language emboldened police, other protestors, and, later, lawyers outside Delhi's Patiala House Courts Complex to violently attack Kumar. The narrative of the "antinational" students of JNU consolidated through the mediatization of doctored videos that were both circulated and commodified by Zee News (Agha 20 I I) thus articulated (in both senses) a visceral and viral affect with state-sponsored violence.

One of the earliest videos Zee News uploaded was entitled "JNU Shouts Anti-nationalist Slogans; Nation Questions Intent," and the 87 online comments that followed highlight how passions had been ignited on all sides. Commenter Kulsum Fatima suggested that those who shouted antiIndia slogans at the cultural program on February 9 may have been ABVP activists "masquerading as others." But the majority of the posts called for the violent punishment of Kumar, often offering to mete out the punishments themselves. For instance, one poster responded: "However many Afzals emerge from home, we will hound each one of their homes and kill them. Jai Hind" ("Jitne bhi Afzal ghar ghar se niklenge, hum utne Afzal 
ghar ghar me ghus kar marenge Jai Hind"). This poster claimed to intend to personally pursue Afzal Guru, who had been hanged a year ago, but was essentially articulating an exhortation against all individuals engaging in antinational activities. Thus, without naming Kumar and his colleagues, the poster was calling for their death. This post ended with the slogan, "Jai Hind ("Victory to India)," thus remediating a frequently used nationalist salutation with an exhortation to violently pursue, hound, and kill traitors.

\section{Gender, Sexuality, and Nationalist Affect}

Theorizing the affective potency of these exhortations necessitates that we underscore the primacy of gendered and sexualized violence in the formation of hypernationalist affect. These virulent responses to Kumar and his colleagues did not stop with the exhortation to kill them. They slid into violent gender-based abuse as suggested, for instance, in the response from commenter Azad King, who wrote: "Hang Umer and Kanhaiya for supporting those motherfucking terrorists" ("Ye madarchdo terrorist ko support karne wale umar or kanbiya ko bb fadi [sic] de do"). This post was followed by another that highlighted the centrality of sexual violence to Hindu nationalism: "What is new about this? Most people are antinational (deshdrobi). But it is we Hindus who are cunts (chutiye) because we don't unite the way they do ... . arise, friends ... Jai Hind." Azad King was drawing on a strategy typically deployed by RSS activists to reprimand Hindus for not uniting against a common enemy (Muslims). Other posters agreed, arguing that "we" Hindus are not united, with one poster going further: "If one we will unite we can $\mathrm{f}^{* *} \mathrm{k}$ them [sic]."

Gendered and sexualized violence were the primary modalities for the articulation of the threats to Kanhaiya Kumar and his colleagues (cf. Udupa 2017). For instance, when commenter Shwetank Seth pleaded (in vain) for reason, arguing that these students were not antinational and that it was important to get "complete information," commenter Prasanna Chitnis would have none of it, and responded that they were indeed antinational; after all, they were not shouting Bharat Mata ki fai ("Victory to Mother India"). At this point, commenter Bharadwaja Bidadi responded, "What is it that these sister-fuckers want freedom from?" and proceeded to abuse a woman in the video portrayed shouting these alleged slogans: "Who is the bitch shouting over vocal cord [sic]?"

The creation of a space for violence against Kanhaiya and other "traitors" recalls a moment in the United States when, after the events that we 
have now memorialized as "September I I, 200I," similar exhortations to violence were made against terrorists and those who allegedly "looked like" terrorists, in particular, men from the Middle East and South Asia. While this is not the place to parse out the differences between those calls to violence and the ones that appeared in the posts against Kumar on YouTube, certain discursive continuities are striking. Muneer Ahmad has pointed out that, in the United States after September i ith, hate crimes were often framed as crimes of passion. He argues: "The passion in question here is love of nation, the crimes a visceral reaction born out of patriotic fervor" (2002, 9, emphasis added). Likewise, the exhortations to violence against Kumar and other students were also articulated in terms of passion and, since the object of passion was the nation, this violence was rendered legitimate rather than morally reprehensible. Drawing on a deeper genealogy of tropes of the feminized Hindu-Indian nation who must be protected from sexual violation, the exhortation to violence may be interpreted as calls for honor killings on behalf of the betrayed/violated nation against Kumar and his colleagues who, by protesting the circumstances surrounding the conviction and killing of Afzal Guru, were represented as terrorist sympathizers or terrorists themselves (cf. Ahmad 2002).

Muneer Ahmad draws our attention to flyers that circulated in New York after the destruction of the World Trade Center depicting Osama Bin Laden being sodomized by the World Trade Center with the caption, "You like sky scrapers, bitch?" (Ahmad 2002, IO). In addition, the Associated Press distributed a picture of a bomb intended for Afghanistan on which an American sailor had written, "Hijack this, faggots!" (Ahmad 2002, Io). As we have noted above, the calls for sodomistic rape as punishment for Kanhaiya Kumar and his colleagues were also saturated with misogyny and homophobia. For instance, N. Jain wrote, "Put a stick up the arses of the motherfuckers at JNU and make them parade naked . . . those bastards" (“jnu ki madarchodo ki gand mai danda dalke nanga ghumne chabiye . . . haramkoro ko"), while another poster exhorted: "Put a stick up their arses and shoot them and give them freedom" ("inki gand mai goli mar ke do azadi").

As calls for violence became ubiquitous in response to the ongoing recirculation of the doctored video first published by Zee News, public discourse surrounding Kumar became increasingly polarized. Debates on television channels like Times Now devolved into shouting matches between guest speakers who charged Kanhaiya Kumar and his colleagues with antinational activities. In a series of feedback loops, the affects generated by these television programs converged with those generated by 
several digital platforms, including YouTube. When, on February i 2, 20 16, another video was uploaded alleging that the previous one portraying JNU students (including Kumar and Umer Khalid) shouting "antinational" slogans was false and doctored, 784 commenters responded. Many of these comments consisted of affectively charged responses that were equally exhortative in their calls for violent punishment to "anti-national traitors." Again, almost all of them called for gendered and sexual violence against Kumar and his colleagues. One poster, Pratik Tulsyan, exclaimed: "Kill evry [sic] student who loved Pakistan, let's make a bomb and kill all these motherfuckers." Another commenter, Manish Agarwal, responded that the person who uploaded this video was a "chutiya" (cunt) and "jihadi." This sexually violent language was reiterated in several posts that followed, such as "Internet jihadi ... Madarchod [motherfucker]." These posts were countered by j. blin who wrote: "Kill all motherfucking ABVP supporters ( $m a-$ darchod bhakts). Time for a revolution to kill cunt (chutiya) fascists in India." However, a majority of the posts were against those who allegedly shouted anti-India slogans and used similarly violent language (for instance, "Fuck him in the pulic [sic] with Bitch donkeys Dick. Wtf" posted by Aswartha Ashu, and "Shame on u jnu students ... u live in this country ... india feeds $\mathrm{u}$ and today $\mathrm{u} \mathrm{r}$ thinking about destroy it . . . if u want to go to pakistan u can go ... u deserve to lick pakistani asses u mother fucker Afzal guru's asses" by Lucky Indian. The Thinker added, "Shame on you anti-national horse shit go fuck yourself." Exhortations to sexual violence thus remediated older Hindu nationalist demands that Muslims and others deemed to be traitors be "sent back" to Pakistan. Furthermore, in one fell swoop, all JNU students were castigated as traitors irrespective of their political leanings: they were told that they deserved to "lick Pakistani asses."

Following his arrest, Kanhaiya Kumar was placed in judicial custody for three days while the other five students went underground. Thousands of students, faculty, and staff at JNU protested the arrest and stopped classes at the university for several days. Tensions mounted further, when, on February 14, 2016, Zee News republicized the same doctored video that purported to depict students shouting "Bharat ki barbadi" and "Pakistan zindabaad" ("Destruction to India" and "Long Live Pakistan"). ${ }^{9}$ This video became viral as it was quickly relayed across various digital media platforms. Its virality was also manifest in how it rapidly and repeatedly sparked calls for violence against Kumar and his colleagues. For instance, one poster commented on YouTube, "Anti national deserve on bullet in their forehead [sic]." This was followed by a post by Arrow Straight who, 
reverting to exhortations to sodomistic rape by previous posters, went one better with "Put a bullet in their butt and make them suffer!"

\section{Contagious Affects}

These calls to violence spread like a contagion. Vishwanath Hindustan posted, "If got gun I will kill him," and John Cena Wwe, "Hang them to death." Vivek K let loose a spate of sexually violent abuses on Kanhaiya Kumar: "maakichut, madarchod, madarchod," (all synonyms for motherfucker) and "bhenchod" (sisterfucker), with 48darklord suggesting, "All these guys need to be rounded up and beaten wih [sic] sticks in between their legs" This theme of sodomistic rape continued unabated with Di John exhorting: "All those motherfuckers who participated in the JNU cultural event should have a hot rod shoved into their arses . . . son of a prostitute do you think we the public are cunts?" ("Randi ke aulad chutiya samajbte hai public ko?").

On February 15, when Kanhaiya Kumar appeared for his hearing at the Patiala House Courts Complex, several lawyers physically attacked him and the journalists who were present, as the police stood by passively. The Delhi court extended Kumar's judicial custody by two days and rescheduled the hearing for February i 7 . That day, Kumar was attacked a second time by bystanders. Journalists inside the courtroom captured footage of the attack. This footage became viral on different digital media platforms, including YouTube. The district court further postponed Kumar's hearing until March 2, and he was taken to Tihar Jail. Kumar filed a petition to the Supreme Court for bail the following day, and an investigative report was submitted to the Supreme Court showing that the district court had allowed the judicial protection order to be violated when Kumar was assaulted.

On February 22, Vishwa Deepak, one of the producers of Zee News, released a statement admitting, "Our biases made us hear Bhartiya Court Zindabad as Pakistan Zindabad" ("Long live Indian courts" as "Long live Pakistan"). Deepak resigned from the channel after expressing reservations over its "biased coverage." He stated that the network had a bias in favor of Narendra Modi, and that it had "abetted a riot-like situation." An investigation was ordered by the government of India, and the forensic company Truth Labs found that two out of seven different videos shot at JNU on February 9 and I I had been altered and, in particular, that the audio containing "Pakistan Zindabad" was inserted. ${ }^{10}$ On February 
23, Umar Khalid and Anirban Bhattacharya surrendered to police and were held at Tihar Jail; they were subsequently granted bail on March I 7, 20I6. On March 2, Kanhaiya Kumar was granted a six-month interim bail by the Delhi High court and, immediately after his release on March 3, gave an impassioned speech on the need for justice and, attacking Prime Minister Modi and the BJP government, appealed for freedom within India rather than from India.

Angry responses against Kumar again went viral on digital media. For instance, 6,98 I comments were posted on YouTube, most of which reiterated previous exhortations to violence with ever-increasing fervor. As before, these calls to violence were rendered legitimate because they purported to be on behalf of the nation: therein lay their affective charge. For instance, on March 3, one poster wrote, "I'm gonna kill this bastard the moment I see him," to which Arshdeep Singh responded: "What an idiot [!] I am ready to go to jail after killing him!" Significantly, some posters also heaped gender-based abuse on Barkha Dutt, the celebrity NDTV journalist who interviewed Kumar after his release, calling her a prostitute ("Randi barkba").

On March Io, Kanhaiya Kumar was physically assaulted by one Vikas Chaudhary who claimed that he was a traitor who had to be taught a lesson. Kumar responded to the threats against his life thus: "You can kill me, you can silence me but you cannot scare me. But before you kill me, think about Rohith Vemula. When you killed one Rohith, several Rohiths came forward. If you kill someone else now, many others will stand up." ${ }^{11}$ In the days that followed there were four attacks on Kumar. On March 28, Uttar Pradesh Navnirman Sena's national president, Amit Jani, posted a threat on Facebook that his organization would storm the JNU campus and gun down Kumar and Umar Khalid unless the two left Delhi by the end of the day.

The usage of particular hashtags online has been tied to the formation of new subjectivities, and can become what Sanjay Sharma has called "affective contagions" (2013, 6I). As the YouTube clip purporting to show students shouting slogans praising Pakistan and calling for the destruction of India circulated, it was continuously subject to an iterative and citational process that shifted and transformed its meaning. The production of the original video from the cultural program, with doctored audio, and a written caption that read "Pakistan Zindabaad" meant that this video was already a complex, intertextual product that then became subject to further reinterpretation. Intertextuality and citationality are foundational features 
of human communicative practice, and are similarly integral to the decontextualization and recontextualization of videos online that make them mutable and continuously reinterpretable (Rymes 20 I 2; Agha 20 I I).

We wish to reiterate the cautionary note with which we introduced our analysis of the inseparability of "events" from online comments posted about Kanhaiya: far from attributing positivist causality to these comments, we underscore instead their affective freight. Affect, as Spinoza (1985) reminds us, is about the generative capacity for action. Blurring the boundaries between emotion, cognition, and corporeality, at once ambient and viscerally felt, and spanning the private and the public, affect is the name we give to that intensity that enables us to navigate the world: it is that which enables us to affect others and to be affected by them. As we have noted above, affects do not reside in individuals; nor are individuals the loci for affects. Instead, affects leave their traces on and generate subjectivity. We have pointed to the virality of nationalist affects as they spiraled out from the relay between mass and digital media. The February 9, 20 I 6 public memorial to Afzal Guru and Maqbool Butt, the protests and counterprotests surrounding it, Zee TV's coverage of this event, its subsequent release of footage that purported to portray the seditious acts of Kanhaiya and his colleagues, the constant relay of this footage across mass and digital media, the posting of comments that ricocheted across multiple platforms including YouTube and, last but not least, the confusion surrounding the veracity of this footage and, indeed, about what had "really" occurred-all converged with and amplified each other to produce nationalist affects that were familiar in their reliance on gender-based and sexual violence, but also unfamiliar because of the speed with which they fed each other and spread though the body politic like a contagion. This was a remediated nationalism that was, at once, old and new.

\section{The Remediation of Nationalism}

On February 19, the day after Kanhaiya Kumar was taken to Tihar Jail, classes were canceled at JNU as a solidarity movement broke out across the city with thousands of people marching in the streets in his support. JNU faculty launched a series of public lectures on nationalism that were covered by television news and uploaded onto YouTube. These public lectures were remarkably effective in generating critiques of different connotations of patriotism and nationalism, the relationship between the state and civil society, the role of dissent in Indian democracy, and the implications of the 
increasing privatization of higher education in India for academic freedom. These debates were also uploaded on YouTube and generated passionate commentary. In most comments, these faculty members were condemned as "anti-national." While we do not have the space to engage either the crucial and powerful acts of resistance by JNU faculty, journalists, and other public intellectuals or the responses to them, it is important that we remind ourselves of the political and discursive significance of their interventions.

In scholarship on digital media, remediation has come to refer to intertextual relationships between different media and to processes by which digital technologies articulate to reconfigure and refashion mediation (for instance, Bolter and Grusin 2000). Remediation, therefore, refers not to ruptures or radically new forms of mediation but, instead, to the remixing of "new" and "old" media. Certainly, as we learned through our analysis of the feedback loops spanning Zee News, the videos uploaded on YouTube, and the online commentary, digital media relied on "older" media like television even as it produced new forms of identification and, most pertinent to our argument, affective regimes surrounding Hindu-Indian nationalism.

Indeed, we extend the concept of remediation not simply to emergent articulations between "old" and "new" media but to how Hindu-Indian nationalism was itself reconfigured through the generation and circulation of affective regimes surrounding Kanhaiya Kumar and his colleagues. We have suggested above that these affective regimes drew upon older forms of Hindu nationalism (as in the ways in which they deployed misogyny and homophobia to call for the protection of a feminized nation [Bharat Mata] or the calls to "send back" Muslims to Pakistan) and, at the same time, produced a belligerent nationalism that was at once old and new. As these remediated forms of nationalism became viral through their relay across different media platforms, the contagious nature of these affects, their intertextuality and citationality, and their centrality to the production of a space for violence were precisely what rendered them visceral. Put simply, as in the case of the remediation of media, the form of these nationalist affects (quite literally, their mediation) refracted their content: it was their virality, their simultaneous immediacy and expansiveness that rendered them both familiar and unfamiliar.

In closing, we return, once again, to the importance of feminist social critique for understanding the work of digital media in South Asia, particularly with regard to their role in the production of public spheres, emergent forms of political participation, and the remediation of nationalism. Feminist critique is never simply about sexual difference but insists that gender 
is itself constituted —often violently—by other axes of inequality, including caste, class, religious difference, and discourses of sexuality. We wish to recall the discursive and ideological contexts in which digital media have proliferated in India by pausing to reflect on the very term "Digital India" and the political uses to which it has been harnessed: Digital India has been assumed to be indexical of Emergent India. All the more reason, we insist, that we need to foreground the role of digital media in the production of a space for gendered and sexual violence in the name of the nation.

\section{Notes}

I. It is important that we note that the viscerality and virality of nationalism remediated by digital media has extended beyond South Asia to many other parts of the world from the United Kingdom, France, and the United States to Turkey and Egypt.

2. There is, by now, a voluminous body of scholarship critiquing Jürgen Habermas's original theorization of the public sphere in terms of rational communication, most notably the pathbreaking work of Nancy Fraser (I990) and Michael Warner (2005) These conceptions of the public sphere have been vigorously interrogated in the South Asian/Indian context; see, for example, Appadurai (1996), Appadurai and Breckenridge (I988), Breckenridge and Van der Veer (I993), Cody (201 I), and Rajagopal (2009). It is beyond the scope of this chapter to debate the viability of prevalent conceptions of the public sphere in contemporary India.

3. Merriam-Webster Dictionary. "Visceral." Accessed May 21, 2018. https:// www.merriam-webster.com

4. We hence align our conceptions of performance and performativity with poststructuralist theories of subject formation, for example, Judith Butler 2006, 2 OI I.

5. When analyzing digital speech in particular it is imperative to reject the ideological assumption that online speech is fundamentally different from offline speech and, in particular, that the anonymous nature of online discourse thus requires skepticism when analyzing its contents. Rather than belabor questions of commenters' "true" identities or feelings (which could be raised in the context of face-to-face interaction as well), we focus on the semiotic processes through which certain discourses surrounding "anti-nationalism" became mediatized and amplified alongside particularly violent, gendered affects. For more on the methodological questions and ideologies surrounding mediated language, see Gershon 20 го.

6. The event, originally conceived as a poetry reading session, shares its title with a poem written by Agha Shahid Ali about Kashmiri rebellion against Indian rule.

7. This law, first implemented by the British colonial government, makes any "attempts to bring into hatred or contempt ... towards the Government" punishable with life imprisonment.

8. Zee News. February I0, 20I6. "JNU Shouts Anti-nationalist Slogans; Nation 
Questions Intent," YouTube video. Accessed May 2 I, 2018. https://www.youtube. com

9. Prashant V. Singh, "From 'Pakistan Zindabad' to 'Bharat ki barbaadi'Slogans that were raised by 'anti-nationals' in JNU," Zee News, February I4, 20 I6. Accessed May 2 I, 2018. http://zeenews.india.com

Io. India Today "India Today Impact: Tests Confirm 2 out of 7 Kanhaiya Sedition Videos Doctored," March I, 2016. Accessed May 2 I, 2018. http://indiatoday. intoday.in/story/india-today-impact-tests-confirm-2-out-of-7-kanhaiya-seditionvideos-fake/1/609162.html

I I. In 2015 , the Hyderabad University administration decided to withhold the scholarship funds of Rohith Vemula, a Dalit PhD student, due to his involvement in the Ambedkar Students' Association, a Dalit rights student organization that was branded "anti-national" by the ABVP. The ABVP used the fact that Vemula had participated in a demonstration against the death penalty for a convicted terrorist, Yakub Menon, as evidence of his antinational activities. Vemula was also physically assaulted by ABVP students in his hostel. Subsequently, Vemula and four other students were suspended from the university for participating in allegedly "antinational" activities, and after his suspension was confirmed in January $20 \mathrm{I} 6$, Vemula committed suicide. Vemula's death sparked massive student demonstrations across the country condemning discrimination against Dalit students and the stifling of free speech, which became another rallying point in the JNU student movement against the criminalization of Kanhaiya Kumar and other student activists.

\section{References}

Abu-Lughod, Lila. 2005. Dramas of Nationhood: The Politics of Television in Egypt. Chicago: University of Chicago Press.

Agha, Asif. 20 I I. "Meet Mediatization." Language \& Communication 3 I (3) (20I I): I63-70.

Ahmad, Muneer. 2002. "Homeland Insecurities: Racial Violence the Day after September I I." Social Text 20 (3): IOI-I 5.

Ahmed, Sara. 20 1 5. The Cultural Politics of Emotion. 2nd ed. New York: Routledge.

Amrute, S. 201 5. "Moving Rape: Trafficking in the Violence of Postliberalization." Public Culture 27 (2): 33 I-59.

Anderson, Benedict R. I991. Imagined Communities: Reflections on the Origin and Spread of Nationalism. London: Verso.

Appadurai, Arjun. 1996. Modernity at Large: Cultural Dimensions of Globalization. Minneapolis: University of Minnesota Press.

Appadurai, Arjun, and Carol A. Breckenridge. I988. "Why Public Culture?" Public Culture I (I): 5-9.

Austin, John L. I962. How to Do Things with Words. Oxford: Clarendon Press.

Bhabha, Homi K., ed. (I990) 2013. Nation and Narration. New York: Routledge.

Bolter, Jay, and Richard Grusin. 2000. Remediation: Understanding New Media. Boston: MIT Press.

Bonilla, Yarimar, and Jonathan Rosa. 20 15. "\#Ferguson: Digital Protest, Hashtag 
Ethnography, and the Racial Politics of Social Media in the United States." American Ethnologist 42 (I): 4-I 7 .

Breckenridge, Carol A., and Peter Van der Veer. 1993. Orientalism and the Postcolonial Predicament: Perspectives on South Asia. Philadelphia: University of Pennsylvania Press.

Briggs, Charles L., and Clara Mantini-Briggs. 2003. Stories in the Time of Cholera: Racial Profiling during a Medical Nightmare. Berkeley: University of California Press.

Burgess, Jean, and Joshua Green. 2009. YouTube: Online Video and Participatory Culture. Malden, MA: Polity.

Butler, Judith. 2006. Gender Trouble: Feminism and the Subversion of Identity. New York: Routledge.

Butler, Judith. 20 I I. Bodies That Matter: On the Discursive Limits of Sex. New York: Routledge.

Carlan, Hannah. 20 I4. "Debating Rape as 'Culture': Interacting Virtually on Social Media in India." MPhil diss., University of Cambridge.

Carlan, Hannah. 20 I 5. "Dented, Painted, and Proud': Satire on Indian Social Media after the 2012 Delhi Gang Rape.” Texas Linguistic Forum: Proceedings of the 23rd Symposium about Language and Society 58: I I-22.

Chakravarti, Uma. I989. "Whatever Happened to the Vedic Dasi? Orientalism, Nationalism and a Script for the Past." In Recasting Women: Essays in Indian Colonial History, edited by Kumkum Sangari and Sudesh Vaid. New Brunswick: Rutgers University Press.

Chatterjee, Partha. 1986. Nationalist Thought and the Colonial World: A Derivative Discourse. London: Zed Books.

Chopra, Rohit. 2008. Technology and Nationalism in India: Cultural Negotiations from Colonialism to Cyberspace. Amherst: Cambria Press.

Cody, Francis. 20 I I. "Publics and Politics." Annual Review of Anthropology 40: 3752 .

Couldry, Nick. 2006. Listening beyond the Echoes: Media, Ethics, and Agency in an Uncertain World. London: Routledge.

Das, Veena. 2007. Life and Words: Violence and the Descent into the Ordinary. Berkeley: University of California Press.

de Alwis, Malathi. 2002. "The Changing Role of Women in Sri Lankan Society." Social Research 69 (3): 675-791.

Fedorak, Shirley A. 201 2. Antbropology Matters. 2nd ed. North York, Ontario: University of Toronto Press, Higher Education Division.

Fraser, Nancy. I990. "Rethinking the Public Sphere: A Contribution to the Critique of Actually Existing Democracy." Social Text 25/26: 56-80.

Gershon, Ilana. 2010. "Media Ideologies: An Introduction." Fournal of Linguistic Anthropology 20 (2): 283-93.

Hauben, Michael, and Ronda Hauben. 1997. Netizens: On the History and Impact of Usenet and the Internet. Los Alamitos, CA: IEEE Computer Society Press.

Hutnyk, John. 2014. "NDTV 24x7 Remix: Mohammad Afzal Guru Frame by Frame.” In Channeling Cultures: Television Studies from India, edited by Biswarup Sen and Abhijit Roy, I77-200. New Delhi: Oxford University Press. 
Jeganathan, Pradeep. 200 I. "A Space for Violence: Anthropology, Politics and the Location of a Sinhala Practice of Masculinity." Subaltern Studies I I : 37-65.

Jenkins, Henry. 2006. Convergence Culture: Where Old and New Media Collide. New York: NYU Press.

Juris, Jeffrey S. 201 2. "Reflections on \#Occupy Everywhere: Social Media, Public Space, and Emerging Logics of Aggregation: Reflections on \#Occupy Everywhere." American Ethnologist 39 (2): 259-79.

Kumar, Sangeet. 201 5. "Contagious Memes, Viral Videos and Subversive Parody: The Grammar of Contention on the Indian Web." International Communication Gazette 77 (3): 232-47.

Kumar, Shanti. 20Iо. Gandhi Meets Primetime: Globalization and Nationalism in Indian Television. Urbana: University of Illinois Press.

Kumar, Shanti. 2014. "Spaces of Television: Rethinking the Public/Private Divide in Postcolonial India." In Channeling Cultures: Television Studies from India, edited by Biswarup Sen and Abhijit Roy, 8I-IO3. New Delhi: Oxford University Press.

Lal, Vinay. I 999. "The Politics of History on the Internet: Cyber-Diasporic Hinduism and the North American Hindu Diaspora." Diaspora 8 (2): I 37-72.

Lal, Vinay. 2003. "North American Hindus, the Sense of History, and the Politics of Internet Diasporism." In Asian America.net: Ethnicity, Nationalism, and Cyberspace, edited by Rachel C. Lee and Sau-ling Cynthia Wong, 98-I 38. New York: Routledge.

Lal, Vinay. 2014. "Cyberspace, the Globalisation of Hinduism, and Protocols of Citizenship." In Indian Transnationalism Online: New Perspectives on Diaspora, edited by Ajaya Kumar Sahoo and Johannes G. de Kruijf, I 2 I-43. London: Routledge.

Losh, Elizabeth. 2014. "Hashtag Feminism and Twitter Activism in India." Social Epistemology Review and Reply Collective 3 (3): I I-22.

Mankekar, Purnima. I999. Screening Culture, Viewing Politics: An Ethnography of Television, Womanhood, and Nation in Postcolonial India. Durham, NC: Duke University Press.

Mankekar, Purnima. 20 I 5. Unsettling India: Affect, Temporality, Transnationality. Durham, NC: Duke University Press.

Mankekar, Purnima, and Louisa Schein, eds. 2013. Media, Erotics, and Transnational Asia. Durham, NC: Duke University Press.

Massumi, Brian. 2002. Parables for the Virtual: Movement, Affect, Sensation. Durham, NC: Duke University Press.

Menon, Nivedita. I 998. "State/Gender/Community: Citizenship in Contemporary India." Economic and Political Weekly 33 (5): PE3-PEı。.

Menon, Nivedita. 20 I 2. Seeing Like a Feminist. New Delhi: Penguin.

Mookherjee, Nayanika. 20 I 5. The Spectral Wound: Sexual Violence, Public Memories, and the Bangladesh War of I97I. Durham, NC: Duke University Press.

Narayan, Uma. I 997. "Cross-Cultural Connections, Border-Crossings, and 'Death by Culture': Thinking about Dowry Murders in India and Domestic-Violence Murders in the United States." In Dislocating Cultures: Identities, Traditions, and Third World Feminism, 8 I-I I 7. London: Taylor \& Francis. 
Niranjana, Tejaswini. I 994. "Integrating Whose Nation? Tourists and Terrorists in 'Roja." Economic and Political Weekly 29 (3): 79-82.

Niranjana, Tejaswini. I998. "Left to the Imagination': Indian Nationalisms and Female Sexuality in Trinidad." In A Question of Silence? The Sexual Economies of Modern India, edited by Mary E. John and Janaki Nair. New Delhi: Kali for Women.

O'Hara, S. 20I 2. "Monsters, Playboys, Virgins and Whores: Rape Myths in the News Media's Coverage of Sexual Violence." Language and Literature 2 I (3): 247-59.

Penney, Joel, and Caroline Dadas. 20I4. "(Re) Tweeting in the Service of Protest: Digital Composition and Circulation in the Occupy Wall Street Movement." New Media \& Society I6 (I): 74-90.

Phillips, Whitney. 2016. This Is Why We Can't Have Nice Things: Mapping the Relationship between Online Trolling and Mainstream Culture. Cambridge, MA: MIT Press.

Puar, Jasbir K. 2006. "Mapping US Homonormativities." Gender, Place \& Culture I3 (I): $67-88$.

Puar, Jasbir K., and Amit Rai. 2002. "Monster, Terrorist, Fag: The War on Terrorism and the Production of Docile Patriots." Social Text 20 (3): I I 7-48.

Punathambekar, Aswin. 20I I. "Reality TV and Participatory Culture in India." Popular Communication 8 (4): 24I-55.

Punathambekar, Aswin. 20 I 5. "Satire, Elections, and Democratic Politics in Digital India." Television and New Media i 6 (4): 394-400.

Rajagopal, Arvind. 200 I. Politics after Television: Hindu Nationalism and the Reshaping of the Public in India. Cambridge: Cambridge University Press.

Rajagopal, Arvind, ed. 2009. The Indian Public Sphere: Readings in Media History. New Delhi: Oxford University Press.

Rajan, Rajeswari Sunder. 2003. The Scandal of the State: Women, Law, and Citizenship in Postcolonial India. Durham, NC: Duke University Press.

Roy, Abhijit. 20I4. "TV after Television Studies: Recasting Questions of Audiovisual Form.” In Channeling Cultures: Television Studies from India, edited by Biswarup Sen and Abhijit Roy, I 7-40. New Delhi: Oxford University Press.

Roy, Srirupa. 2007. Beyond Belief: India and the Politics of Postcolonial Nationalism. Durham, NC: Duke University Press.

Roychowdhury, Poulami. 2013. “'The Delhi Gang Rape': The Making of International Causes." Feminist Studies 39 (I): 282-92.

Rymes, Betsy. 201 2. "Recontextualizing YouTube: From Macro-Micro to MassMediated Communicative Repertoires.” Anthropology \& Education Quarterly 43 (2): 2 I4-27.

Sangari, Kumkum, and Sudesh Vaid, eds. I989. Recasting Women: Essays in Indian Colonial History. New Brunswick: Rutgers University Press.

Sharma, Sanjay. 201 3. "Black Twitter? Racial Hashtags, Networks and Contagion." New Formations 78 (July): 46-64.

Silverstein, Michael. I 979. "Language Structure and Linguistic Ideology." In The Elements: A Parasession on Linguistic Units and Levels, edited by Paul Clyne, William Hanks, and Carol Hofbauer, I93-247. Chicago: Chicago Linguistic Society. 
Sinha, Mrinalini. 2000. "Refashioning Mother India: Feminism and Nationalism in Late-Colonial India." Feminist Studies 26 (3): 623-644.

Spinoza, Benedictus de. 1985. The Collected Works of Spinoza. Edited by E. M. Curley. Princeton: Princeton University Press.

Subramanian, Sujatha. 201 5. "From the Streets to the Web: Looking at Feminist Activism on Social Media." Economic \& Political Weekly 50 ( I 7): 7 I-78.

Sundar Rajan, Rajeshwari. 1993. Real and Imagined Women: Gender, Culture, and Postcolonialism. London: Routledge.

Sundar Rajan, Rajeshwari. 2003. The Scandal of the State: Women, Law, and Citizenship in Postcolonial India. Durham, NC: Duke University Press.

Tharu, Susie. I996. "The Impossible Subject: Caste and the Gendered Body." Economic and Political Weekly 3 I (22): I 3 I I-I 5.

Tufekci, Zeynep, and Christopher Wilson. 201 2. "Social Media and the Decision to Participate in Political Protest: Observations from Tahrir Square." Fournal of Communication 62 (2): 363-79.

Udupa, Sahana. 20 I4. "Online Archiving as Claims to History: New Media and Religious Politics in India." MMG Working Papers I4-IO. http://www.mmg.mpg. de

Udupa, Sahana. 20 1 7. "Gaali Cultures: The Politics of Abusive Exchange on Social Media." New Media and Society 20 (4): I 506-2 2.

Warner, Michael. 2005. Publics and Counterpublics. New York: Zone Books.

Zee Media Bureau. 2016. "JNU Row: Provocative Slogans Were Shouted by Outsiders, Says University's Probe Panel." Zee News, March I6. Accessed May 2 I, 2018. http://zeenews.india.com 


\title{
Clash of Actors
}

\section{Nation-Talk and Middle Class Politics \\ on Online Media}

\author{
Sahana Udupa
}

The resurgence of nationalism as a popular sentiment on online media in the last decade has sparked a wide discussion of digital media's centrality to exclusionary populism. Right-wing populism has been on the rise after formal politics in liberal democracies started moving toward a stifling "consensus at the center" (Mouffe 2005, 66), but the debate intensified in Europe, North America, and Australia under global conditions of migration. In the wake of arrivals of refugees escaping war and poverty, longer patterns of immigration are also radically reframed to portray them as inimical to the national interest. The paradoxical rise of nationalism in the age of global connections confirms the fears expressed by globalization scholars as early as in the I990s, and their prescient caution that global mobilities may lead to an "even deeper trough of defensive exclusivism" (Hall I997, 25).

That online media have emerged as the staging ground for nationalist sentiments is evident in the recent surge of vituperative speech aimed against migrants on social media. Studies of nationalism in Europe, for instance, have drawn attention to the "neo-nationalist rhetoric" expanding on social media platforms such as Facebook and Twitter (Fuchs 20I6). The demands to seal the national boundaries have combined assertions of "cultural fundamentalism" with "biological racism," causing concern about the 
spread of xenophobic "hate speech" on online media (Gingrich and Banks 2006; European Commission 2016).

If neonationalism has emerged as an isolationist response to global and regional migration in the Global North, digital media in India reveal a complex landscape of warring narratives and divergent claims, which has fueled, with all its contradictions, a rambunctious discourse around nation and national belonging. Neither reducible to exclusivist populism nor to "benign" patriotism, digitally mediated national imaginaries reveal a zone of confrontation among the middle classes in urban India. Based on ongoing ethnographic fieldwork among online users in Mumbai, Bangalore, and Delhi, and a close reading of tweets around the hashtag "ModiInsultsIndia" on the microblogging platform Twitter, I delineate this zone of confrontation with two interlinked observations.

First, the acrimonious debates on nation and national belonging are shaped by a disjunctive discursive field of two prominent groups active on political social media in urban India-those who fashion a post-Nehruvian model of liberalism and those who declare allegiance to Hindu nationalism. Although the two groups spar over a variety of issues, a common trope of anticorruption and notions of technological modernity run between the subfields, both fueled by overlapping sets of online users using similar informational tactics, and both feeding the aspiration of "New India."

Second, the peer-to-peer network architecture of social media is significant in shaping renewed ideas about nationhood among young online users in urban India. It has set in motion a culture of verbal confrontations fanning hypervocality to debates on national belonging. The proliferation of social media discourse on national belonging through confrontational verbal cultures of self-confessed "liberals" and "Hindu nationalists" could be best captured as "online nation-talk." By terming it as "nation-talk," I signal the fleeting and blurring sentiments that ride on online speech acts (including visual material). Online nation-talk provides the conditions for nationalism to develop as a hard-boiled exclusivist ideology, as the squabbling publics together compose the quotidian infrastructure to (re)produce nation as a legitimate frame of belonging. This is especially significant for the resurgence of Hindu nationalism and its particular formation of "enterprise Hindutva" in digital India (Udupa, forthcoming). As Victoria Bernal $(2015,4)$ suggests, "Websites [and online media more broadly] are sites of conflict that make dominant nationalist discourses and alternative perspectives visible and legible as ordinary people articulate to each other 
what things mean to them in their own words and collectively construct accounts and analysis of the nation."

Social media nation-talk in India is important for many reasons, not least that the number of online users in India, at $35^{\circ}$ million, is next only to China and the United States. India's Internet users are expanding as a consumer market for the private sector and also as a constituency to be captured and appeased for political gains and ideological production for political parties. The efforts of the market and political interest groups to establish online allegiance continue apace, even as online users engage in practices that exceed both market calculations and political strategies. The irreducible diversity of cultural contexts that shape middle class online users and their divergent approach to political participation defy an easy summary. However, amid all the cultural and linguistic diversity, I suggest, the disjunctive discursive field of "liberals" and "religious nationalists" has given rise to a vibrant form of online nation-talk.

Social media nation-talk runs counter to a significant body of literature that has argued that the transnational technologies of Internet media and its peer driven content cultures enable global civic consciousness and global civil society (Dahlgren 2015). Even the sobering narratives that critique digital enlightenment have emphasized that the market and technological features of digital media undermine national territorial boundaries and nation-states as political-juridical entities. Aneesh (2006) has coined the term "algocracy" to define the rule of algorithms that upsets the national boundaries and the very paradigm of territorial governance through the logics of computer code universalism and programmability. Although the potential to transcend national boundaries is without doubt a key feature of the Internet-enabled media, the unfolding social and political cultures of new media reveal that the postnational postulation is challenged once again in the digital age.

In her critique of the postnational thesis of globalization theorists, Leela Fernandes (2000, 6 12 ) reveals that India's economic reforms of the I99os saw the emergence of the "discourse of globality" that was "invented through the deployment of nationalist narratives." I have argued elsewhere that the local-global dialectic in the media fields of postreforms India yoked together the seemingly unrelated discourses of commodity consumption, civic activism, cultural ascent, and social mobility as a legitimate aspiration of "New India" epitomized by globalizing cities such as Bangalore $(2015, \mathrm{I} 7-\mathrm{I} 8)$. Key here is the aspirational construct of the nation in direct 
relation to media modernity and emerging forms of globality. Equally important in this mediated discourse of "desire-as-aspiration" is the critical role of the urban middle classes imagined as the key actors of aspirational new India ( 17 ). The aspirational construct of New India resulted in part from commercial media's efforts to expand audience markets in the liberalizing economy, but the hegemonic sensibility of India as an emerging global power increasingly enlisted middle class audiences in ways that they could actively participate in the aspirational discourse. I suggest that it is in this context of mediated national imagination of postreforms India and the historical formations of religious nationalism (van der Veer 1994) that online nation-talk could be more fully delineated. Far from being passive recipients of national imagination-which was not the case even with the presumably monological print media ${ }^{1}$ - middle class media users started to make direct claims on what the nation should mean and to whom through a growing number of web-based media. The vast expansion of mobile Internet after 2010 broadened the class base of online usage (Doron and Jeffrey 20I3; Tenhunen 20I8), taking its political formations (including nation-talk) beyond the middle class. The vibrant landscape of Internet memes in India testifies to this expansion. However, the protoagentic privilege of middle class users and the representation of their voices on mainstream media as public opinion continued to magnify the symbolic salience of this online user group. The microblogging site Twitter represents an important site to understand the dynamic of new media technologies intersecting with the nationalist imagination of the middle class. In the rest of the chapter, I will focus on this platform and home in on the hashtag ModiInsultsIndia, to examine the clash between self-fashioned liberals and Hindu nationalist sympathizers as a cantankerous form of new media fed nation-talk.

\section{Twitter Is for "Serious People"}

Compared to the vast reach of the social networking site Facebook and mobile media messenger service Whatsapp, the user volume for Twitter in India is not very large. The social networking site had a share of only I 7 percent of social media users in India and 8 per cent of all Internet users in $2015 .{ }^{2}$ Twitter's 22 million users comprise just r. 8 per cent of the Indian population. ${ }^{3}$ In 2017 , India became the fastest growing market for Twitter in terms of the number of active online users. ${ }^{4}$ However, Twitter's influence stems partly from mainstream commercial media's privileging of Twitter 
debates as a lively channel for citizens voice. This practice is especially prominent among television news channels because of the interrelated agendas of interactive news making and market driven models of monetizing audiences. Twitter debates thus resonate beyond their limited reach, as commercial television news and print media present Twitter updates as direct news feed from common citizens and political elites.

Twitter entered major cities in India at a time when online users had grown familiar with and quite "addicted" to Facebook and LinkedIn where they could reactivate, maintain, and expand their personal friendship groups, familial ties, or professional networks, and also satisfy, in some measure, their "insatiable nosiness about what other people are doing" (Miller 2OI I, IOI). It was not surprising then that Twitter, despite its emphasis on short messages sans images and an imposed restriction of I4O characters, was initially used as an extension of personal networks, and yet another online gateway for "real-world" socializing and snooping. Typically, people on Twitter would update on what they ate, which film they watched, or where they went shopping. In just a year from Twitter's foray into the Indian market, tweeters grew enough in number to encourage some enterprising tweeters to take the next step and invite these tweeters for "offline" gatherings. In cities like Mumbai, tweeters assembled for offline tweet meets, calling them "coffee tweet up" and "dinner tweet up" for socializing or discussing common business interests. By 2010 , Twitter experienced a transition. Although routine updates and the impulse to organize tweeters for social cause or business interests did not disappear, Twitter came to be perceived more as a platform to share information, opinionate, and remain up-to-date on "hard" news. This transition coincided with Twitter's official branding in later years of its inception as a "real time information network" where one can "have access to the voices and information surrounding all that interests her/him.” The rapidly changing new media landscape and new smartphone applications in the market were crucial for this branding since Twitter had to distinguish itself from more fun-driven new media services. Soon, Twitter users commenting on politics and news events or tagging stories on "current affairs" were more common. Twitter became a high ground for opinion exchange, as opposed to what many users described as "frivolous" Facebook—a result of assigning "political moralities" to different media technologies (Miller 20I I). Many online users I met in Mumbai had little doubt when they said, "Facebook is time pass. Twitter is for serious people." ${ }^{5}$ Although the list of Twitter users with the largest following continued to be dominated by cinema actors and 
sports celebrities, active profiles of political elites on Twitter, and expanding volumes of political debates testified to Twitter's reception as a forum for public debate on publicly relevant matters. It was indeed the supposed public character of Twitter with its potential to open up channels of anonymous connections through hidden or open handles that confirmed its status as a "serious forum for serious people."

In practice and in corporate branding, Twitter mimicked the repertoire of news and its claims to public opinion shaping, wrapped as such in the tiny packets of 140 characters. This perception continued in India, even as the U.S.-based company struggled to retain its global user base and increasingly turned to "emerging markets" such as India and the Philippines for future growth through advertisement-led revenue strategies (Rajan 20I6).

The perception of Twitter as a public medium for serious debates is at once generative and reflective of the vibrant online discussions on the Indian nation and what it means to belong to the nation. Tweets around the hashtag ModiInsultsIndia are one among the several instances of online nation-talk, illustrating the distinct features of new media and aspects of online work among warring factions that together provide the conditions for nation-talk to flourish. While no hashtag is representative of the entire gamut of discussions on social media, influential hashtags that stirred media events (Couldry 2002) provide a window to the broader cultures of online discourse by illustrating the content and tenor of debates set in a milieu explored through ethnographic methods.

\section{Clash of Actors}

The hashtag ModiInsultsIndia appeared on Twitter in 2015 to express anger at what a section of online users saw as an insult to India's pride when the Indian prime minister made a statement during a foreign visit that Indians abroad need no longer feel ashamed about being born in India. More than 80,000 tweets surfaced on Twitter within just two days, criticizing the "insensitive" remarks of the nation's highest executive. The hashtag top trended nationally and also globally for a brief period in May 2015. The sudden invention of the hashtag and the spurt of tweets condemning the prime minister's statement was ironic. The hashtag that spiked on the national and global Twitter charts was an unexpected affront to a leader who had cultivated a strong Twitter following precisely with the dream of a corruption-free India and the pride of Hindu India as a global power. 
Modi had filled the need for a strong leadership figure-a need that had stemmed from a host of factors, including the perceived weak leadership of the incumbent government and an ambient mediated culture to legitimate "celebrity icons" to take charge of new India. ${ }^{6}$ Tech-savviness was one of the key elements of the cultivated public image of Modi, as he actively participated in the microblogging platform of Twitter to amass a large following (at 42 million followers in May 2018). The adulation for the leader on Twitter invoked the sobriquet of "bhakt" community online, who would, as a devout to the deity, hold the leader in awe and unremitting reverence. The hashtag ModiInsultsIndia thus came as a surprise. The messiah of netsavvy young India surging ahead to free the country from old world politics had to confront a tide of critical tweets, all the more caustic because of the hashtag that implicated him in a no-holds-barred style typical of Twitter clashes. "The dam broke this morning," announced the English language news daily the Telegraph, "digital fire and brimstone fell mercilessly upon the unchallenged poster-boy politician of the Twitter age."

The hashtag embodied the claim that a serving prime minister should not disrespect the country and its people with a casual and critical portrayal of the nation, especially during foreign visits. With punching irony, the hashtag signaled the intriguing sway of online nation-talk for which even Modi was an insufficient icon. Hence, contrary to the interpretation that the hashtag brought to light a contested cyberspace that came out in unequivocal terms for the first time to challenge a hegemonic figure, I intend to show that the hashtag signaled online nation-talk as a highly charged emotional discourse that, with all contradictions, seeks to normalize national pride as an ethical attribute of a proper citizen in the digital age.

In the days between May I9 and June 4, 2015, a total of 84,762 tweets attached to the hashtag ModiInsultsIndia were collected using the Twitter Archiving Google Sheet (TAGS) Hawksey tool. ${ }^{8}$ The application revealed a Twitter rate of 10.6 tweets per minute for the hashtag during this period. The tweet pool was later analyzed for the highest retweeted tweets, prominent themes, links embedded in the tweets, and other hashtags cited in the hashtag pool. A close reading of the impassioned tweets filled with humor, anger, and satire, alongside plain mimesis and retweets, revealed a vibrant and acrimonious discourse of national pride. Of the total sampled items, posts that were retweeted more than 20 times were chosen for a close reading.

Before a detailed analysis of the tweets, a few meta-analytical points are in order. Similar to other Twitter clashes in the Indian public domain in re- 
cent times, the tweet pool around \#ModiInsultsIndia illustrated the highly intertextual nature of online debates. Online sites or printed stories of commercial news media were frequently cited in the tweets to authenticate or debunk propositions. News companies for their part made the trending hashtag-proxy for "popular voice"—a regularly updated news story. The influence of news organizations was evident not only in a direct sense of posting the themes for discussion but also in a more complicated manner of injecting circularity into the discourse. On the list of top ro tweets in the sample was a post by @BBCtrending that announced that over 80,000 tweets had used \#ModiInsultsIndia to react to the prime minister's comments. This post was retweeted 426 times. Another highly retweeted post came from Huffington Post India: "RT @HuffPostIndia: \#ModiInsultsIndia Trends worldwide as furious Indians slam PM's overseas remarks." The evidentiary effects of social media trending and the staging of trending as news by organized media influenced tweeters' participation. Tweeters enthusiastically shared the trendometer readings and confirmed to themselves and others that the trending hashtag stood for something significant and authentic. A tweeter exclaimed, "Oi teri! 68000 Aaj Sanghi aatmahatya karenge bhai" [oh its 68000 ! Sanghis will commit suicide today bro]. ${ }^{9}$ Another updated: "\#ModiInsultsIndia has just crossed roo K tweets. The massive shame this $\mathrm{c}^{*} \%$ has brought to his own party." 10

Politicians drew upon both the sources- "popular tweets" and news entities-to advance their claims. It was hard to distinguish where the "unmediated popular voice" ended and commercial media messaging began, or where the top-down political propaganda converged with the seeming spontaneity of nation-talk. Moreover, as tweeters absorbed the messages coming from various quarters, they discussed the possibility of manipulation of hashtags by political forces. The shades of suspicion and critical awareness added yet another layer of mediation to an already charged intertextual field. The tweets in the sample revealed the practice of mutual references for authenticating or discrediting argumentative positions, and the undercurrent of suspicion that all these might be orchestrated by the political parties after all. A post retweeted 365 times wondered: "How much money BJP paid to @TwitterIndia to remove \#ModiInsultsIndia from Trends List and replace it [with] another."11 This suspicion gathered steam when a new hashtag "ModiIndiasPride" surfaced on the Twitter trending charts just when \#ModiInsultsIndia had started to trend globally and nationally. ${ }^{12}$ The flattering and congratulatory hashtag was construed as an engineered tweet coming out of the party's social media campaign 
managers. The post: “\#ModiInsultsIndia propaganda exposed by @X\#ModiIndiasPride," which was retweeted I,027 times in the sample, was at the center of this discussion. The post showed the images of newspaper reports of Modi's speech, arguing that the original message was misrepresented and that it was yet another instance of false media propaganda. It became the second most retweeted post in the hashtag pool, inching closer to the first position after some hours of undisputed trending of \#ModiInsultsIndia. Many tweeters joined the simmering sentiment of suspicion, while others alleged this was without doubt a case of buying out Twitter's silence:

Is it true??? @twitter has removed \#ModiInsultsIndia?? (Io I counts)

The suspicion prompted a tweeter to give a heroic call against TwitterIndia succumbing to political pressure:

RT @nesoron: I say guys, beat @twitterIndia. And how. RT \#ModiInsultsIndia a million times. C'mon. Let's beat 'em. Please do. (97 counts)

Amid the suspicion that such tweets were coming out of the propaganda machinery, challenges to the PM's statement in the Twitter debate were advanced by prominent spokespersons of the Indian National Congress Party. Two of the top ro tweeters in the sample, for instance, were official spokespersons of the Congress Party. Presenting Twitterati as a bold group of conscientious citizens, one of the spokespersons hailed their valor:

Glad that twitterati hs given a fitting reply to prime minister. Enough of tolerating his barbs at the country\&countrymen. (288 counts)

Spokespersons of the Communist Party of India (Marxist) were also active, albeit further below the list of top retweets. Tweets by official spokespersons of political parties as well as suspected dummies represented attempts to assuage or malign online stardom for overt political gains by major political parties such as the Indian National Congress and the BJP. Mindful of the political wrangling that had entrenched the hashtag, tweeters conjectured in a variety of ways, and one of the top ro tweets surmised:

BJP has good opportunity to take revenge for \#ModiInsultsIndia by claiming \#RahulInsultsHinduism. (347 counts) 
In the later tweets \#ModiInsultsIndia started to appear with other unrelated hashtags such as \#PrayforPhillipines, inducing clutter into the debate. A Twitter handle (now defunct) stood out in the pool for its repetitive attacks on the prime minister's statement, inserting harsh metaphors at regular intervals throughout the trending period.

Intertextuality, remediation, and political propaganda qualify claims of unmediated popular voice bursting out on social networking sites, and online nation-talk is no exception. However, the sheer volume of tweets and the number of unique Twitter handles in \#ModiInsultsIndia indicate that the tweets cannot be reduced to a discourse that was fully engineered top down. It is precisely in the remediated intertextual field, including conjectures about manipulation, that online actors emerge and collide, thereby experiencing new forms of political expression and new ways of laying claims to public discourse. That nation-talk remained on the top of such claims was evident in the various themes marshalled around the hashtag ModiInsultsIndia. These could be analyzed as "discursive themes," which refer to strategies and content of texts "as instantiations of discourse" (Barthes i972).

In the sample, the highest retweeted posts made a direct reference to "nation," with allegations of disgrace and dishonor to the country, and assertions of national pride. These tweets/retweets constituted 54 percent of the total sample (table I0.I). Others (9 percent) staged a direct confrontation between major political parties and still others ( 9 percent) simply relayed information from organized media networks.

Category I: Critical of the prime minister's speech with direct or implicit reference to "nation" and "national pride"

Table ro. r. Thematic categories of \#ModiInsultsIndia tweets May-June 2015

\begin{tabular}{lccc}
\hline Category & $\begin{array}{c}\text { No. of unique } \\
\text { tweets }^{*}\end{array}$ & Tweet count & $\%$ \\
\hline I & 3 I I & 20, I 49 & 54 \\
2 & I 87 & I0,278 & 28 \\
3 & 4 I & 3,292 & 9 \\
4 & 26 & 3,035 & 8 \\
5 & I6 & 540 & I \\
\hline *Each unique tweet is repeated at least 20 times. Tweet count includes retweets.
\end{tabular}


Category 2: Critical tweets with distinct themes but with no direct or implicit reference to "nation"

Category 3: Tweets that shared information from news sources

Category 4: Tweets defending the prime minister's statement and challenging opposition parties

Category 5: Tweets critical of the speech with references to the opposition party in positive terms

How was the idea of "nation" invoked, asserted, and expressed in the hashtag pool? What were the elements of the national imaginary and how did the themes cluster around \#ModiInsultsIndia?

\section{Theme 1: Failed Symbol of National Pride}

"Speak for yourself Sir. Strictly Yourself," a tweeter posted insistently, and others joined the debate, declaring that they were "not ashamed" of being born in India. Some tweeters capitalized the phrase to announce their indomitable stance and others resorted to retweeting as many posts as they could. Still others found satire and cynicism to be effective:

Congratulations India on having a Prime Minister who was ashamed of his origin till we made him the Prime Minister. (with slight variations, 78 counts)

Stirred up by the maelstrom, thousands of tweeters joined to condemn the PM's statements as "disgraceful" and "distasteful" that to them insulted, offended, or embarrassed the people of India. "Most controversial part of Modi's speech was 'People were born in India due to sins of past life," complained a tweeter, and another added in jest that his frequent foreign trips could be because he felt ashamed of being born in India. Ad hominin attacks on Modi in the hashtag pool expressed tweeters' anguish at the faltered symbol of national pride, resulting in all manner of name calling—liar, illiterate, uneducated, selfie-driven, self-obsessed-and deriding hashtags such as GappuInIndia and Feku (liar). Some expressed disappointment that the PM didn't know the "basics of public speak[ing]" and more important, he was not "nationalist" and "patriotic" enough. His "poor knowledge" was to be questioned, since he had a tendency to get "carried away by his own rhetoric." Fueled also by political mudslinging, the tweets derided his failure to embody the national spirit and properly represent its 
strengths and achievements. A tweet by a political party spokesperson saying that the PM's statement had "offended the sensibilities of every Indian" was retweeted more than $35^{\circ}$ times. A sense of betrayal underwrote a large number of tweets, and the promise before the election of a proud nationalist dissipating after gaining power:

Before Election: Proud chaiwala [tea vendor], Proud Hindu, Proud Nationalist. After Election: Ashamed to be born in India. (I69 counts, with some variation was retweeted again 79 times)

[T]his was when I felt ashamed . . a ashamed of your fake nationalism! ( 153 counts)

\section{Theme 2: Taxpayers Money}

For many tweeters, "nationalism" and the failure to embody it meant definite material consequences. One of the key complaints in the hashtag was that the prime minister was wasting taxpayers' money on foreign trips and the deriding comments just added to the wound.

We elected a PM who travels the world at our expense just to tell the world how ashamed we are to born in India. Pathetic ... (83 counts; with slight variations, IO2 counts)

Foreign visits and residence by ordinary citizens, on the other hand, were for actual life opportunities-studies, jobs, and suchlike. Going abroad would no way mean they were any less nationalist:

Ppl may dislike many things happening in India. Go abroad for better opportunities. But they're NOT ashamed of being Indian. . . . ( 150 counts)

People may go abroad for further studies or jobs, but no sir, they aren't ashamed of being an Indian. (44 counts)

\section{Theme 3: Glory and Sacrifice}

The materiality of taxpayers' money merged with the symbolic resonance of the nation as a space of belonging. Claiming that "no individual is big- 
ger than the motherland," tweeters emphasized that India's unbroken and glorious tradition went well beyond the short-term regimes of political leaders. Even those that came to the defense of Modi reiterated that the nation was indeed not insulted and the prime minister's statement had been twisted by "media propaganda." India as Bharat was timeless, abundant, and magnificent, and no mortal leader measures up to its glory-no prime minister now or before:

PM's may come and go-but our proud and illustrious National Identity as Indians will endure for time immemorial. Jai Hind! ( I Io counts)

Dear PM, India is not getting importance abroad bcoz of you, infact u $r$ getting importance abroad bcoz of India only. (retweeted with slight variations over 70 times)

Our proud and pride about India is nothing to do with someone becoming PM of India. (66 counts)

Mujhe Bharatiy hone par tab bhi garv tha jab aap pradhaan mantra nabi the aur tab bhi hoga jab aap pradhaan mantra nahin honge (I was proud of being an Indian even before you became the Prime Minsiter [sic]. I will be proud even after you are no longer the Prime Minister) (49 counts)

India made you PM. ... You haven't made India. Just a reminder you are the 15 th PM of this great country. (39 counts)

The default idioms to assert India's excellence centered on the symbolic and mythological repertoire of Hinduism. The top tweet in the entire hashtag pool invoked Brahma, the creator of the world in Hindu mythology, as the ultimate arbiter to settle the matter. In a half-jesting tone, it declared:

RT @The'TweetOfGod: Just talked to Brahma. He's not ashamed to have been born Indian either. ( 1,182 counts)

Together with Brahma, a large number of historical figures were parleyed to assert India's glorious past. Most of them were heroic warriors during 
India's liberation struggle and none of them-asserted the tweeters with a tinge of sarcasm-were ashamed of being an Indian. A tweeter stated sarcastically: "Maharana Pratap was ashamed being an Indian until Modi became PM!" On the publicly shared profile page, this tweeter called himself "Biologically, Emotionally, Financially, intellectually ... Indian." A slew of tweets illustrated that there were indeed many such "multifaceted" patriots active in the hashtag pool:

Samrat Ashok felt ashamed to be born in India. He died in shameful state as Modiji declined to take birth then. (I 66 counts)

Tab to Bhagzwan Ram ko bhi badbi sharm aayi hogi Ayodhya mein paida bone mein (By that token God Ram might also have felt ashamed to be born in Ayodhya)

so swami vivekananda was ashamed of being called Indian before modiji became PM. (34 counts)

Are you ashamed of Gandhi, Nehru, Sardar Patel, Vivekananda? (32 counts)

My apologies to Bhagat Singh, Rajguru, Sahdev and numerous young men who sacrificed lives so tht I day a PM can shame them. (26 counts)

The valor and sacrifice of these heroes illustrated, according to a tweeter, that "India is more, much more than you can ever understand."

Together with historical figures came the image of Indian soldiers fighting battles on the borders. Soldiers were cited repeatedly to signify the gravity of national belonging:

If "Indians were ashamed of being Indians" why did soldiers sacrifice their lives at the border? (with variations, 34 counts)

Those who laid down their life for BJP's failure in Kargil, Acc to Modi they were ashamed of India. (IoI retweets)

I was ashamed wen China had d audacity to show wrong map of India during @narendramodi’s visit! (26 counts) 
Following these tweets, an image of the prime minister not applauding when a martyr's wife received a salutation from the president at a public event circulated swiftly, with one tweeter complaining that the minister didn't show "a single percent respect for a martyr's wife." The territorial and militarized narrative of the nation melded with "sacrificial citizenship" in which "citizenship is expressed through sacrificing for the nation" (Bernal 2005,7 ). Shaped by a long history of popular representations of sacrificial citizens in cinema as well as in state media, social media narratives brought the related symbols of territory, soldier, and sacrifice as a coherent account of the nation.

The hard side of territorial defense and heroic sacrifice inspired a swelling of emotions. The nation for these tweeters was not a distant, abstract concept but a personalized community composed of forefathers, parents, and sons yet to be born. The insult, thus, was personal:

A PM while representing the whole country in the foreign soil insults our parents, forefathers. ( 76 counts)

I am \& will always be proud to be Indian because our forefathers routed the mighty British empire through non-violence. ( 27 counts)

Can Anybody Be Ashamed of One's Own MOTHER? Yes, an emotional ... (7 I counts)

Modi is ashamed of being born to Indian Mother! . . (with minor variations, 2 I counts)

After this tweet I feel \#ModiInsultsIndia and the Pride of the country I am born in. This is not Done Mr PM. (50 counts)

Proud of India's Culture Farmers : Scientists . . . ( I 77 counts, retweeted with slight variations 57 times)

Yeh hai mera [This is my] Hindustan and we are proud Indians and will never feel ashamed to be born here. (43 counts)

The emotional appeal of national pride and belonging was not limited to those who were critical of the prime minister's statement. It was just as 
striking among tweeters who defended the statement. Some tweets were cynical of the Congress Party leader Rahul Gandhi (named as Yuvrraj) and accused him of not knowing how to salute the national flag, and other tweets dismissed those standing behind the hashtag as pernicious traitors feigning national pride.

Yuvrraj does nt know how to salute our national flag; @INCIndia says \#ModiInsultsIndia. Morons of the highest order.

Shayad yeh iss \#ModiInsultsIndia hashtag aur trend ka bi asar bai, ki kuch gaddar bhi Bharat mata ki jai bolne lag gaye hey, dikbawe! [Perhaps it is the effect of this hashtag that even traitors have started to hail Mother Bharat, show-offs!]

Caustic as they were, the tweets squabbled to show who was a better nationalist and who was just a fake. Supporters of the ruling party were dubbed as "bhakts" (religious devotees) busy in the "bhakt photoshop factory" and those critical were derided as "AAPtards" (supporters of the Aam Aadmi Party_Common Man's Party), "Congi” (Congress Party supporters), and "AdarshLibrals" (ideal liberals in a cynical portrait). Despite their wrangling, and indeed through this wrangling, tweeters kept alive online nation-talk as a legitimate discourse, with all the terms of the argument firmly in place.

\section{Theme 4: Corruption}

The blurring of boundaries between the two seemingly oppositional camps becomes stark on the issue of corruption. Those who defended the PM's statement asserted that if one should be ashamed of anything, it should be "rampant corruption" and the corrupt political class. A tweeter declared, "Even thou it cud hav been articulated better, there is NO case for \#ModiInsultsIndia; We were shamed due to rampant Corruption." Several anticorruption tweets condemned the hashtag:

FACT: Supporters of all corrupt leaders in India are trending \#ModiInsultsIndia against @narendramodi’s development. (9I counts)

If Booting out big corruption, Presenting India as a global power, Development etc is insult ... then Yes \#ModiInsultsIndia. . . . (2 I 2 counts) 
Tweeters who supported the hashtag and condemned the PM's statement were equally critical of the political class as "corrupt" and formal politics as "dirty." "We Are Not Ashamed Of Born Indian, But Are Ashamed Of Our Politicians!" declared a tweet, and others said:

Prime Minister should maintain the dignity of the post and should not try to play dirty politics everywhere. (84 counts)

So even patriotism was a jumla! [jumla is an empty, vapid political promise] (55 counts)

The anti-political-class rhetoric in the tweets combined with a sense of responsibility and ownership as citizens. This was illustrated in the tweets that lectured that no country was perfect, but it should be made perfect with hard labor. Others were more direct:

It's my job as a citizen to keep my country on her toes, but unlike \#NaMo I've never been ashamed of being Indian. . . (57 counts)

Responsibilized citizenship and anti-political-class sentiment constituted a new middle class sensibility in postreforms India that was reflected as well as fed by mass media organizations (Udupa 2015). Insult and pride were thus inseparable from the emerging sense of responsibilized and angry citizens eager to experience and assert India as a global power. It was not surprising that a large number of tweets expressed discontent not so much about the content of the speech as the fact that it was delivered "on foreign soil." It was unpardonable, according to these tweeters, that "Indians were insulted abroad." PM made "a joke out of India abroad," decried a tweeter in Hindi [Bharat ka duniya mein Mazak], while others urged:

Modi should immediately cancel all future foreign tours. He is doing nothing but insulting our country on foreign soil. (4I counts).

Respected PM, when you are on a foreign tour, do remember that you are representing a nation, not your political party. $(238$ counts, retweeted with slight variations 40 counts)

No world leader goes abroad to trash talk his own country. (34 counts) 
Vidheshi bhoomi par desh ko badnam karne vale Modiji pable Pradhan mantri bane [Modiji became the first prime minister to defame a country on foreign land]. (I 24 counts)

Going on foreign tours and insulting his own country. . . has any $\mathrm{PM}$ in history does this before? (29 counts)

Mr. Modi ... Ur remark has let Indians down on foreign land, nd it's a national disgrace. We $\mathrm{r}$ proud Indians. (2 7 counts)

Can u ever imagine, Cameron/Obama, etc go abroad \& say 'We/ Our citizens $r$ ashamed of being born British/American, etc'!?

Next time when Modi speaks abroad, this disclaimer may be shown. "All my views are personal and not of my employer, India." ... ( ( 60 counts)

These tweets illustrate that aspirational restlessness in a globalizing milieu is an important element of online nation-talk. Other themes in the hashtag pool included historical references to Nazi Germany as well as the controversies around the role of the Rashtreeya Swayam Sevak Sangha in the Indian national struggle.

The variety of themes marshalled in the name of "nation" through rhetorical confrontation, joking, cynicism, and evidencing do not reveal a clearly formulated friend/enemy schema or a sharp "us/them" distinction identified by many scholars as the key discursive tool for online nationalism (Fuchs 2016). While the framing of religious minorities as "the other" is a common occurrence in online debate cultures in urban India, what this hashtag reveals is the process "emotionalization" of nation-talk (Fuchs 20I6, I8I) even as these emotions were subjected to strategic use by major political parties. The case of \#ModiInsultsIndia illustrates that the emotional confrontation between "liberals" and "Hindu nationalists" on online media is generative of a revived and vibrant form of online nation-talk. Although the divide between the self-proclaimed liberal tech-moderns and Hindutva (Hindu nationalist) volunteers appear irreconcilable, the common discourse of national pride that runs between them reveals the blurred boundaries of ideology that constitute middle class politics of online deliberation in urban India.

How do we understand the mediatic elements of social media shap- 
ing this nation-talk? I conclude with a provisional argument to address this question, adding that social media's mediations can be separated only analytically while in practice a host of factors go into making online nation talk.

\section{Social Media Nationalism}

In his well-known thesis on imagined communities, Benedict Anderson (I99I) posits a distinct sociality emerging from the mass ceremony of reading newspapers. There are several well-accepted critiques of Anderson's Euro-centric assumptions of linguistic standardization, homogenous empty time, and the "unbound seriality" of the nationalist imagination idealized as the ethical universal. But what is significant, at least in the limited sense of the technological mediation of print, is the idea of simultaneity and a cognitive capacity to imagine others even though physically distant, through the ritual of reading that unfolds in "silent privacy" or "the lair of skull," as Anderson describes it (35). How does this compare with social media, after we accept, contra Anderson and following Partha Chatterjee (1999) that the nation as a conflictual political community moves in heterogeneous time-space?

Gerald Kane and colleagues (2014) describe four constitutive features of the users of social media: ( $\mathrm{I}$ ) users have a unique user profile that is constructed by the user, by members of their network, and by the platform; (2) access digital content through, and protect it from, various search mechanisms provided by the platform; (3) can articulate a list of other users with whom they share a relational connection; and (4) view and traverse their connections and those made by others on the platforms. Manuel Castells (2009) and Christian Fuchs (2016) emphasize "permanent input and activity" as the specific features of web 2.0 shaped by the market imperatives of data analytics. The "upload of user-generated content and permanent communicative flows" (Fuchs 2016, I38-39) underlie "self-work" in the mass self-communication models of social media. I suggest that these features of traversing and articulating a list of concrete users-even when they have pseudonyms - as well as the market inflected generation of continuous user data in terse prose cocreate peer-to-peer verbal confrontations as a constitutive aspect of online nation-talk. In the hashtag pool, tweets illustrate the cultures of word play, irreverence, satire, and verbal clashes among users. And, therefore, distinct from the cognitive and temporal mediation of print, social media shape the conditions for the utopia of nationalism 
through discursive, seemingly voluntary, continuous, confrontational, and peer-to-peer networks in quasi-public forms. I have argued elsewhere that this should be analyzed in terms of "fun as a meta practice" (Udupa, "Nationalism," forthcoming) that brings "hot nationalism"-_a psychology of extraordinary emotions" (Mihelj 20I I) and the banality of repetition, habit, staging, and signaling (Billig I995) into a co-constitutive relation on digital media. Online nation-talk composes the daily materialities of nationalism (Postill 2006) beyond the state apparatus and political craft, yet it is encouraged and solicited by these structures in a market-augmented culture of "self-work" in new media.

If technological mediation calibrates group power via communities of practice, the growing acrimonious debates between "liberals" and "Hindu nationalists" point to the layered nature of online political media in India, signaling that the "high political debates" concerning nation and nationalism are increasingly negotiated by the online work of middle class sector with access to social media. Online political media revives and reproduces the historical legacy of the middle class as the nationalist vanguard (Fernandes 2000), aligning the debates along the fragile divide between liberals and religious nationalists who together advance a rambunctious discourse of hypernationalism. Contradictory and contentious as it may be, online nation-talk provides an important condition for exclusivist nationalism to coagulate around it.

\section{Notes}

I. An extended argument on the production of interactivity in print news media in post reforms India is available in Udupa 2015.

2. http://www.huffingtonpost.in, accessed November 2 I, 20 I 6.

3. http://www.huffingtonpost.in, accessed November 2 I, 20 I 6.

4. https://economictimes.indiatimes.com/opinion/interviews/india-becameour-number-one-market-in-daily-users-twitters-new-india-director-taranjeetsingh/articleshow/58601906.cms, accessed May I, 2018,

5. The perception, however, changed in other cities like Bangalore where Facebook's more regional language friendly usage worked well for regional commentaries on politics.

6. The link between celebrity saviors of New India and personalization of news in the media industry is significant in creating the ambient culture of celebrity saviors of New India (Udupa 2015).

7. http://www.telegraphindia.com, accessed May 20, 2015.

8. https://tags.hawksey.info. Tweets that were posted prior to the data collection period are out of this sample. All the Twitter handles are removed to protect anonymity, except the handles of mainstream media. 
9. "Sanghis" refer to the volunteers of Rashtriya Swayamsevak Sangh, the foremost right-wing Hindu nationalist organization in India.

Io. Tweets are retained in their original style and grammar to stay close to the colloquial argumentative styles and casual disregard for grammatical rules in online debates.

I I. Tweets are retained in their original style and grammar to stay close to the colloquial argumentative styles and casual disregard for grammatical rules in online debates.

I 2. http://zeenews.india.com, accessed May 27, 2015 .

\section{References}

Anderson, B. I99. Imagined Communities: Reflections on the Origin and Spread of Nationalism. London: Verso.

Aneesh, A. 2006. Virtual Migration: The Programming of Globalization. Durham, NC: Duke University Press.

Barthes, R. I972. Mythologies. London: Cape.

Bernal, Victoria. 2005. "Eritrea On-Line: Diaspora, Cyberspace, and the Public Sphere." American Ethnologist 32 (4): 660-75.

Bernal, V. 2014. Nation as Network: Diaspora, Cyberspace, and Citizenship. Chicago: University of Chicago Press.

Billig, M. 1995. Banal Nationalism. Thousand Oaks, CA: Sage.

Castells, M. 2009. Communication Power. Oxford: Oxford University Press.

Chatterjee, P. I993. The Nation and Its Fragments: Colonial and Postcolonial Histories. Princeton: Princeton University Press.

Chatterjee, P. I999. "Anderson's Utopia.” Diacritics 29 (4): I $28-34$.

Couldry, N. 2002. "Playing for Celebrity: Big Brother as Ritual Event." Television and New Media 3 (2): 283-93.

Dahlgren, P. 201 5. "The Internet as a Civic Space." In Handbook of Digital Politics, edited by S. Coleman and D. Freelon, I 7-34. Cheltenham, UK: Edward Elgar Publishing.

Doron, A., and R. Jeffrey. 2013. The Great Indian Phone Book: How the Cheap Cell Phone Changes Business, Politics, and Daily Life. Cambridge: Harvard University Press.

European Commission. 20i6. "Code of Conduct on Countering Illegal Hate Speech Online: First Results on Implementation.” https://ec.europa.eu/information_society/newsroom/image/document/2016-50/factsheet-code-conduct-8_40573.pdf

Fernandes, L. 2000. "Nationalizing 'the Global': Media Images, Cultural Politics and the Middle Class in India." Media, Culture and Society 22 (5): 6 I I-28.

Fuchs, C. 2016. "Racism, Nationalism and Right-Wing Extremism Online: The Austrian Presidential Election 20 I6 on Facebook." Momentum Quarterly 5 (3): I $72-96$.

Gingrich, Andre, and Marcus Banks, eds. 2006. Neo-Nationalism in Europe and Beyond: Perspectives from Social Anthropology. Berghahn Books.

Hall, S. I997. "The Local and the Global: Globalization and Ethnicity. In Culture, 
Globalization and the World-System: Contemporary Conditions for the Representation of Identity, edited by A. King, I9-40. Minneapolis: University of Minnesota Press.

Kane, G. C. 20I4. "What's Different about Social Media Networks? A Framework and Research Agenda." MIS Quarterly 38 (I): 275-304.

Mihelj, S. 20 I I. "Nationalism and the Media, East and West." In Media, Nationalism, and European Identities, edited by M. Sükösd and K. Jakubowicz, 203-26. Budapest: CEU Press.

Miller, D. 20 i . Tales from Facebook. Cambridge: Polity.

Mouffe, C. 2005. The Return of the Political. London: Verso.

Postill, J. 2006. Media and Nation Building: How the Iban Became Malaysian. New York: Berghahn Books.

Rajan, N. 20I6. "Twitter Looks to Countries Like India for Growth, but Damn Those Feature Phones" Indian Express, August 2. Accessed November 2 I, 2016, http://indianexpress.com

Tenhunen, S. 2018. A Village Goes Mobile: Telephony, Mediation, and Social Change in Rural India. New York: Oxford University Press.

Udupa, S. 2015. Making News in Global India: Media, Publics, Politics. Cambridge: Cambridge University Press.

Udupa, S. Forthcoming. "Enterprise Hindutva: Five Prototypes in Urban India." Contemporary South Asia.

Udupa, S. Forthcoming. "Nationalism in Digital India: Fun as a Meta-Practice in Political Discourse." International fournal of Communication.

van der Veer, P. I994. Religious Nationalism: Hindus and Muslims in India. Berkeley: University of California Press. 


\title{
Private Publics
}

\author{
New Media and Performances of Pakistani Identity \\ from Party Videos to Cable News
}

Mobina Hashmi

Two stories from Pakistan dominated my Twitter feed in early 2017. Several prominent bloggers and activists from Islamabad and Lahore went missing, presumably abducted. ${ }^{1}$ The uncertainty around their absence created an opportunity for another iteration of critique of the Pakistani political and military classes' ongoing intimidation of journalists and activists and debate over the possibility of an independent public sphere. ${ }^{2}$ The other story was that of Tayyaba, a Io-year-old girl who was repeatedly severely physically abused by her middle-class professional "employers." This story developed on social media when pictures of the child's badly bruised face circulated along with the fact that her employer was actually a district judge. As interest built, the police were forced to investigate, and a case was opened against her abusers.

These two stories together illustrate parallel concerns about the nature and scope of media publics in Pakistan today. The story of the abducted bloggers was inserted into public discourse as the latest skirmish in the struggle to establish independent institutions that can hold the state accountable for its actions. Tayyaba's story, on the other hand, feeds an appetite for scandal, but it also shows how the boundary between domestic private spaces and media publics is porous in a way that historically has not been the case. Domestic workers from rural or poor urban families are 
intimate witnesses to the private lives of urban middle-class and elite families. These private lives had been protected by class privilege from public scrutiny, but the growth of new media publics-on news and talk channels as well as on digital media-have created spaces where aspects of these private lives are made selectively available for broader audiences. That is, the domestic private is quite literally made public, made visible, and thus available for scrutiny.

The emergence of these new publics brings with it new norms for public performances of Pakistani identity, norms that combine elements of private conversation and interaction with already established rules for public behavior. Unlike the state-centric productions of Pakistani identity that dominated electronic media for almost the first 50 years of the nation's existence, the last Io to I 5 years have seen the emergence of the varied and conflicted media publics that we see today in dozens of television channels, radio stations, and of course, digital media. These media publics express a range of interests, logics, and practices such as journalistic identities, social codes of interactions, visual codes for set design and live coverage, and developmental discourses.

In this chapter, I focus on social codes of interaction to trace how private conversational norms are remediated in a range of media publics on YouTube, ranging from news outlets to informal and amateur videos of weddings, dance parties, and encounters with sex workers. These online spaces publicize more informal and intimate spaces of conversation, contestation, opinion, and socializing, and are a fascinating space of performance of Pakistani identity. The desires, anxieties and frustrations, and humor on display here give us a window into a Pakistan that is, I would argue, closer to the one that many of us live than the one we see performed and produced on more official channels.

I call these spaces the "private publics" of digital life in Pakistan in order to bring out the texture of online interactions that easily slide from sociability to hostility and back again. In contrast with the attempts to impose order, security, and civility in official media publics, these overlooked private publics reveal the untidy experiences of national attachment. Recent scholarship on media publics departs from the Habermasian investment in rational civic discourse and instead explores the practices, affects, and attachments at play in digital publics. I build on this scholarship to suggest that Pakistani identity is one of several rhetorical devices used in "acts of citizenship" rather than a steady attachment. $^{4}$ 


\section{Official Digital Publics: State and Activist Calls for Censorship and Regulation}

Pakistan's digital cultures register on the international news radar largely in relation to censorship. For example, the government's $20 \mathrm{I} 2$ ban on YouTube following the distribution of the film Innocence of the Muslims (2OI2) on that platform was widely reported. ${ }^{5}$ Pakistan Electronic Media Regulatory Authority, the main regulatory body for television, and the Pakistan Telecommunication Authority, which regulates the Internet, are both charged with censoring content in the name of national security and protecting Islamic values. ${ }^{6}$ A number of activist groups challenge this frame for regulation of digital spaces. Bytes For All, which advocates for transparency, freedom of expression, and action against cyber harassment and bullying, was one of the main groups that objected to the Prevention of Electronic Crimes Ordinance, enacted in August 2016. The ordinance was supposed to deter hate speech and harassment, but contained sweeping language that could be used to suppress critique as well. ${ }^{7}$ The tension between media activist groups and the state over the line between protection and censorship is evident in the small, but growing, research corpus on hate speech, harassment, and censorship that is gradually taking shape. Largely consisting of reports from domestic and foreign NGOs, this body of research focuses on the online harassment of women as well as on instances of physical violence against women in retaliation for their use of digital media. ${ }^{8}$

Much of the discourse on public/private distinctions centers on the movement of women across boundaries that are themselves mobile and mediated by class, region, and religiosity. ${ }^{9}$ Thus, it is no surprise that some of the most visible contestations over older and newer conceptions of modernity take place in relation to women's bodies and public appearance. For example, Girls at Dhabas, which started around 2015 , is a movement of mostly elite women who unapologetically enter traditionally male spaces such as dhabas (roadside teashops) and public parks or organize group bike rides on public roads as a way of protesting the harassment of women. ${ }^{10}$ While Girls at Dhabas has received extensive news coverage in the English press, rural and working-class urban women who navigate male public spaces on a daily basis remain deeply vulnerable. They make the news only in the context of violence, as in the case of Tayyaba or that of four women killed in a village in northern Pakistan because a video of them enjoying themselves at a wedding was circulated on social media. ${ }^{11}$ 
In contrast to the official discourse on modesty, surveillance, and privacy, Pakistani YouTube videos reveal a messier reality. For example, a poor-quality undercover style video of a roadside pickup spot for sex workers in Karachi had almost 220,000 views as of mid-2018. ${ }^{12}$ All we see is the occasional conversation between burqa-clad women and the driver of a car, motorbike, or rickshaw that ends when one of the women walks off the screen. The comments are almost all in Urdu in either naksh script or transliterated into Latin script, and are light-hearted in tone. One person wrote, "Yar me yahan ata bun to mujby to milti he nahi hai han I mili the par wo bekar the. Usny kaha. K baki achi achi gai v hai. Biking par." (Man, I never find any when I come here. I did find one a week ago but she was useless. She said all the good ones have gone biking.) Another offered the tip, "Tariq road ka mqrkit mein achi wali hain." (Tariq Road market has the better ones.) The joking, informal tone of these comments is typical of the mode of talk in the thousands of comments on other similar YouTube videos. Such talk is expressive of modes of public life in Pakistan that display little concern for religious morality, social welfare, or any of the other concerns we see in state or NGO discourses on the Internet.

\section{Theorizing Pakistani Digital Media Publics}

By now, scholarship on digital publics has moved well beyond the analytic constraints of public sphere theory developed for a different medium and context to research the nature of conversation and interaction in these digital publics; the dynamics of their formation and persistence; and, the potential of these spaces to nurture, direct, intensify, or practice political affinities, affects, and actions. For example, Mimi Sheller and John Urry's call for a "sociology of mobilities" that asks us to recognize "relationships that involve the complex and fluid hybridizing of public-and-private life" is much better for understanding Pakistani identity than any attempt to neatly contain politics and dynamics of citizenship within distinct "public" and "private" spheres of action and thought-even if only as analytic constructs. ${ }^{13}$ Not only has the state variously been in the hands of the military, the industrial elite, and the landowning elite, these sectors are often united by kinship and business ties. The interlocking military-feudal-industrialbureaucratic alliances in Pakistan are crafted, cemented, and negotiated in ways that cut across governmental, public, private business, and familial interests. The state, civil society, and the media, in their institutions and practices, are best understood as the sedimentation of these relationships. ${ }^{14}$ 
Thus, only an understanding of the social that recognizes mobility and fluidity can accommodate publics constituted by the crisscrossing movement of media, bodies, actions, and affects evident in either the case of the young women who were killed because a video of them at a wedding was leaked, or in the mediated construction of Girls at Dhabas as the feminist face of Pakistan. These multilayered entanglements also shape the formal structures of media publics in Pakistan. The performance of Pakistani identity we see in talk shows, television dramas, news programs, and so forth is also, I argue, shaped by the remediation of private norms of gendered and classed behavior.

In addition to challenging the spatial segregation of public and private, digital media publics also require a reconsideration of the modes and norms of reasoned public conversation. Instead of assuming rational debate as the only legitimate form of public talk, it is necessary to recognize the different modes of conversation, interaction, and, simply, presence in digital publics such as those of YouTube. As Zizi Papacharissi notes in her work on affective publics, democratic participation needs to be civil, but need not be polite: "The distinction drawn defines politeness as etiquette-related, and civility as respect for the collective traditions of democracy." ${ }^{15}$ While this does open up room for taking trolling and other forms of online vitriol as part of political speech rather than disruptive noise, Papacharissi remains interested in assessing these spaces for their political potential. ${ }^{16}$ Liesbet Van Zoonen, Farida Vis, and Sabina Mihelj offer a useful corrective to this approach in their analysis of responses to an anti-Islam video. Focusing on the multiplication of viewpoints in relation to the video's original provocation rather than on dialogue and close networks of interaction, they argue for YouTube as a digital public in which new "acts and practices of (unlocated) citizenship" emerge. ${ }^{17}$ These scholars open up room to consider sentiments such as anger, provocation, satire, or amusement as legitimate political affects. They show how the political dimension of digital publics can include discrete performances or acts of citizenship rather than the expressions of citizen selves. Finally, I draw on Aswin Punathambekar who brings out the temporal dimension of media publics when he asks:

Instead of arguing endlessly about whether popular culture can serve as a staging ground or a terrain for learning and practicing skills that can then, in some stagist fashion, be applied in the realm of formal politics, another way to think about "entertaining politics" is to ask, "How do people entertain political matters?" To pose the 
question this way is to wonder how talk about political matters gets woven into the rhythms of everyday mediatized lives. ${ }^{18}$

\section{Tehzeeb, Ikhlaaq, and Takalluf: Norms of Civility on Pakistani Television}

News and public affairs programming as well as television drama are, I argue, structured by shared understanding of the etiquette of public conversation. In this section, I outline the two discourses on the norms of public conversation that have shaped Pakistani television. The first is Ganga-famani tebzeeb (north Indian, Muslim, Urdu-speaking elite culture) with its elaborate norms of takalluf (deference, politeness) and $i k b l a q$ (manners, morals), and the second is that of the journalistic conventions of the 24-hour news channel that have supplanted these norms in the multichannel era.

The hegemony of elite north Indian Urdu culture had always been challenged in Pakistan by regional cultures, notably by a very popular vision of rural Punjabi culture articulated in a series of films in the late I970s and I980s. These films featured the character Maula Jatt who "marked the emergence of a new type of a hero, one who was rural, loud, hypermasculine, unabashedly violent, fluent in colloquial Punjabi, and had very little to do with the nation or state."19 Further, this character marked the popularity of new filmic conventions that, instead of prioritizing socially conscious stories, celebrated "vulgar comedy, 'dirty' dancing and charismatic Punjabi villainy." ${ }^{20}$

PTV's (Pakistan Television) hour-long Urdu dramas, drawing on a tradition of zannana literature and often written by leading Urdu playwrights, continued to use the Urdu-speaking elites' norms of tebzeeb (culture) to frame their depictions of domestic spaces and lives and their intersections with public life well into the $1990{ }^{21}{ }^{21}$ Eventually, intrusions from outside the hegemonic national space forced a change. Satellite television and videocassette tapes introduced Pakistanis to foreign media in the I980s, and the penetration of these media accelerated in the r 990 .

Some of the old norms persisted in the news publics crafted by privately owned channels like Geo News and Aaj TV in the early 2000 in the use of what I call "uncle talk." This masculine version of women's talk relies on the comfort of familiar norms and spaces. In particular, it reproduces the conversational norms of elite drawing rooms and semiprivate spaces where men who hold positions of public importance meet in private (social or 
familial) contexts and hold forth on issues of public import. It is marked by elaborate codes of politeness and verbal markers of deference to those of higher status. Despite the growth of regional language channels, increased class diversity in on-air reporters and on talk shows, and freedom from direct state supervision, these new publics still largely reproduce the conversational norms of elite Urdu-speaking culture, especially in the use of linguistic markers of respect for status. ${ }^{22}$

However, public figures and politicians have developed a greater repertoire of performance styles that blend private conversational modes, uncle talk, and formal address and allow a more confrontational attitude. For example, in 20r6, during a session of the National Assembly, Khwaja Aziz, the defence minister, admonished Shireen Mazari, a leading opposition politician, to "make her voice more feminine." An unidentified government backbencher chimed in, saying "Keep quiet, aunty!," illustrating how social norms of politeness and respect are used even as the speaker is telling Mazari that she belongs in a different—private—space. Mazari's party's spokesman responded that "Khawaja Asif should be hung upside down for his vulgarity and misbehavior, and should be beaten with a shoe 25 times in the morning and 25 times in the evening." Mazari herself also drew on familial, even feudal, norms by calling Asif "besharam and behaya" (lacking in shame or a sense of propriety) in a tweet. ${ }^{23}$

A more promising trend for challenging elite hegemony over televisual norms comes from the introduction of elements from the repertoire of 24-hour news channels around the world. Live reporting on location, person-on-the-street interviews, investigative journalism, and reality programs introduced a range of voices and locations not seen before on television. As television journalists sought to define their professional identities in relation to international norms of objectivity and reasoned debate, they began to distance themselves from the modes of "uncle talk." In its place, we now see the emergence of a more confrontational style that articulates elements of elite Urdu-speaking tehzeeb with vernacular performance styles and global norms.

For example, Sar e Aam, a popular weekend television program on ARY News, takes a sensationalist approach to investigative reporting. The name of the program means "in public" or "something done openly in public." Each episode is structured as an exposé of a social issue or problem that has traditionally been kept private and unseen. In an episode from 2017 , shot entirely on location, the host Iqrar-ul-Hassan invites viewers to accompany him into a beauty parlor, a back alley in a poor neighborhood, 
and a "respectable" private residence to see the realities of prostitution in Karachi. ${ }^{24}$ We hear Hassan negotiate a meeting and rates with the woman who runs a sex work business from a beauty parlor. More disturbingly, we see the visible and sustained distress of the women when Hassan and his camera crew burst into their space. Under loud, dramatic music, we can hear women crying as they cower on the floor and even grab Hassan's feet, begging him to stop. One woman implores Hassan to stop, saying that her husband will kill her, but he continues to demand the women uncover their faces and talk with him. The only concession he makes is to, impatiently, assure them that their faces will be blurred on television. However, his confrontational manner alters radically when he meets with a sex worker who has a more exclusive clientele. This woman, who is presented as young, educated, and middle class, is treated with compassion and Hassan's tone is polite and even mildly flirtatious. The episode ends in her bedroom with Hassan addressing the viewers asking them to make the changes in social norms needed to end this kind of exploitative sex work.

On the show's YouTube channel, this episode has over I.5 million views and over I, Ioo comments as of May 20I8. Many of the commenters chide Hassan for his rough behavior: "Iqrar Bhai I respect you and ur programe. If $\mathrm{u}$ can do programe then do on Poverty which is the main root of 80 $\%$ problemes. Why u are teasing these innocent women." Another person asked "why don't you raid in five star hotels," and yet another noted "All faces are visible enough. Not sure what they are blurring." Other commenters, though, were simply fans: "Bhai iqrar I am big fan of you. . . . please I want meet you" and "I just love ur shoe u and ur show amazing, fabulous, brilliant, fantastic e.g u have a great sene of humour." Yet others expressed disapproval in religious terms, but the overall tone of the comments was one of distressed compassion: "Think some things are better not to be revealed or exposed so he should have just stayed away from exposing brothels; no point in making these poor women feel even more embarrassed about their lives...."

The negotiations between religious beliefs, gendered ideologies about protecting women, class critiques, fandom, and disapproval of the host's techniques showcase the range of ways in which ordinary Pakistanis think and talk about uncomfortable issues. There is nothing remarkable about these responses except for their utterance in a shared public space. Like the talk shows on Geo News, family dramas on PTV, or politicians' tweet wars, Sar e Aam and the comments it elicited on YouTube remediates private norms in different ways for different audiences. In the collective, read 
as acts of citizenship, these comments show a more nuanced version of private and public life in Pakistan than that revealed, for example, by the government's attempts to create a sanitized Internet.

Bickering between politicians, long-standing skepticism toward state media, and newer disillusionment with the urban and sensationalist bias of commercial media has contributed to the growing importance of social media such as Twitter and Facebook as important sources of breaking stories, leaks, comments by politicians, and so forth. For example, the efforts undertaken by cricketer-turned-politician Imran Khan, who became Prime Minister in 2018, to mobilize public support are reported and debated in social media platforms such as Twitter as much as they are in news channels or newspapers. The dynamics of the digital publics that take shape around formal politics is beyond the scope of this chapter, but it is a necessary complement to the analysis offered here.

\section{The Private Publics of Digital Pakistan on YouTube}

I stumbled upon the vast and varied world of Pakistani party, dance, and "sexy" videos while doing research for another project and was immediately fascinated. Following a trail of links, starting with documentary videos exploring Pakistan through either the eyes of either a white or Pakistani-British traveler, it took only a few clicks to reach a different set of "documentary" videos. Unlike diasporic narratives of return and discovery $^{25}$ that reproduce the aesthetics of documentary video, these party and "sexy" videos display all the signifiers of unauthorized, amateur videos captured on a camera phone: poor lighting and focus, uneven sound levels, jerky camera movements, and hastily composed framing. They are mostly uploaded to YouTube by ordinary users, but also by aggregator channels that specialize in subgenres such as mujras (erotic dances by women or $\mathrm{bi}$ jras performed almost exclusively for all-male groups at parties, weddings, and so on), party videos, videos of college girls, and so forth. The videos that meet the criteria of a "private public" can be grouped into five categories by subject matter:

- private videos of dance recitals or performances by school or college girls that have circulated beyond their intended context; ${ }^{26}$

- illicit recordings of mujras;

- recordings of video sex chats or sexual encounters that are almost certainly circulated without consent; 
- amateur videos of "underground" dance parties in elite homes or clubs;

- news or documentary clips that have been recoded for sexual content.

The descriptions for many of these videos explicitly state the desire to make private spaces available in public. When directed toward elites-coed groups or women-this impulse undermines the privilege that have kept elites protected from public scrutiny. In other instances, such as videos of private dances for all-male crowds, the videos reinscribe gendered hierarchies by inviting a shared voyeurism. The comment spaces are overwhelmingly male-judging by names and the language in the comments that use a mixture of everyday Urdu, English, regional languages, and, sometimes, Hindi. Urdu comments are sometimes written in naqsh script but are more often transliterated in Latin script.

What we see in the unofficial "private publics" of YouTube videos is a significantly different vision of Pakistan. The topics are actually quite similar to those discussed in more official spaces: the use of women's bodies to draw national, ethnic, religious, and class boundaries; the airing of ethnic or national rivalries and resentments; debates over women's rights couched in the opposition between Islamic values and Western modernity, and so forth. The difference lies in tone and in the presence of two other categories of comments: critiques of the aesthetic and technical quality of the video and brief, strangely poignant requests for contact with the subjects of the video (e.g., simply "plz numbe"). The comments I analyze below were in response to three You Tube videos: a private mujra, ${ }^{27}$ an amateur documentary about an underground nightclub in Karachi, ${ }^{28}$ and a video of a young woman practicing a dance in a classroom at the University of Lahore. ${ }^{29}$

I argue that the version of Pakistan expressed here is characterized by fragmented attachments, local desires and concerns, lazy provocation, and casual sociability and not the desire for legitimacy, civility, or accountability expressed in official discourses-statist or activist. For example, people looking for evidence of political activity might find it difficult to know what to make of the following exchange on a video of dance practice at the University of Lahore:

kuch Khuda ka khuff khao yaar. ... (Man, have at least some fear of God) (ItsKKJ)

You're boring. (aqib2000) 
These comments are performative acts of citizenship with such diffuse motivations and ambitions that to look for any kind of indication of potential for political affiliation let alone action seems perverse. Nonetheless, I argue that the utterances and interactions in these spaces tell us as much about what it means to be Pakistani as any official discourse. More so, they help us understand the everyday experience of living citizenship as one form of attachment among many.

Even though most comments focused on drawing national, ethnic, religious, and class boundaries, often using the videos either as examples of "Western" or Indian contamination of a Muslim society or as illustrations of progress toward social tolerance, the tone was rarely serious or coherent. The pair of comments on the nightclub video below are, respectively, stream of consciousness and ritual condemnation:

i dont see whats so disgusting about this i think Pakistan should tone it down a bit. remove currupt asshole ... i mean government officials. like come on ... youth culture will always thrive this isnt a scandal its a revolution LONG LIVE FREEDOM (qaesaro9)

\section{lanat ho kutay ki naslon yahan janay walon par bc apna deen imaan bhool} kar apnay bappoon ko follow kar rhay ho Doob maro Allah karay ya tm logo k liay sharam ki bat honi chyan haram khooron Allah karay asa azaab nazill ho jis s tum logon k hosh thikhanay ajain!:@ ("curses on the descendants of dogs who go [to] these clubs because they have forgotten their faith and follow their fathers. You should drown of shame. This should be a source of shame for you bastards. May God punish you in such a way that it brings you back to your senses!") (someone 501 )

An equal number of commenters mocked the young people shown in the video as "wannabees." Yet others asked for the location of the club, "anyone who knows the location of this place should post it immeidiately ... It looks fab for couples... I would be a regular goes so anyone who knows about the location. ... Please do post . . . thanks." Another strand of comments was more reflective, wondering, "[h]aving night clubs is not a big deal but the thing is that what we gonna do with our life, imitating west by doing all wrong things that never ever being considered good even in noble western families."

While the comments on the nightclub focused on anxieties about au- 
thenticity, the comments on the dance practice at the University of Lahore were split between ethnic insults targeting Punjabis (Lahore is the largest city in Punjab) and contesting the location of the performance by decoding the accents and the furniture in the room. One person declared, "its fake video. I am study in university of Lahore and we not have that kind of class...." Several others claimed the young women could not be Pakistani because of their accents:

@tamsadeas this is either in america or britain, listen to their accent at the start you idiot.

WTF. .. . do u really think this fuckin accent can be from any pubjabi girl. . . f fuck u uploader!!!!!!!!!!!!!!!!!!

A small group of people voiced the same concerns about violating the young women's privacy as did commenters on the Sar e Aami episode. For example, one person both countered criticism from others and critiqued the uploader: "man come on ease up its just a dance for fun and sum stupid fck uploaded it. dont get angry pakistani brothers girls these days $r$ changin." Some of the angriest and most violent comments were on the video of the mujra. For example, one person left two comments: "Punjabi girls are all cheaters. Never marry them" and "these bitches are on the increase ... FUCK YOU BITCHES!" On the other side of the affective and political spectrum was this dispassionate observation on an older version of the nightclub video, "Bad upload. No sound after about 3 minutes."

In lieu of a conclusion, I'll end with a sequence of comments on the University of Lahore video that illustrates the range of emotions, opinions, desires, and provocations that are, I argue, typical of the comments on this genre of video:

punjabi Randi.... (gulfam khan)

Once in Pakistani universities and other educationak institutes students were practicing for educational debates and other developmental activities. ... May ALLAH protects us (Syed Akhtar)

clumsy steps (Abhi Jeet)

She can come over to India and have a peaceful life away from Talibans. (LoveALL) 
She needs more practice. (slickr48)

i want to marry that girl so $i$ get her to dance for me every night for free lol (Sajid Ali)

What should we make of lazy insult, despair over decline, deliberate needling, aesthetic critique, and (ironic?) patriarchal humor in close textual (but not necessarily spatial or temporal) proximity? Artists, social commentators, and scholars have long lamented the underimagined nature of Pakistan. Filmmaker Sabiha Sumar says in relation to a lack of a "tradition of filmmaking" in Pakistan that it cannot develop "unless we can ask, what is Pakistan about, what is our vision, what is our self-image; unless Pakistan can define its dreams; unless Pakistan can define this very clearly and bring on board the majority of this country to agree to that vision - that dream, that self-image-we cannot create anything successfully. We do not have a nation." ${ }^{30}$ In the face of such longing for identity, it is tempting to resolve the messiness of these digital private publics into neat social and political positions. But it might be more productive to instead spend some time in these spaces and, as Aswin Punathambekar suggests, entertain the political, "to give attention to, carefully consider, contemplate, think about, give thought to, support, and at times, tolerate an idea, a suggestion, and, of course, feelings (the affective dimensions of the political). ${ }^{{ }^{31}}$ In the process, we might discover a way of being that comes closer to the experiences of citizenship, belonging, and disaffection in Pakistani digital publics.

\section{Notes}

I. "Pakistan: Bloggers Feared Abducted," Human Rights Watch, January I I, 2017. https://www.hrw.org

2. The targeted killing in 2015 of social activist Sabeen Mahmud, who had worked to create, both literally and figuratively, a public space for liberal critique and expression, was a turning point for the urban liberal class.

3. Awais Yousufzai, "Tayyaba Case: Judge, Wife Deny Torturing Child," Geo News, January I6, 201 7. https://www.geo.tv

4. Liesbet Van Zoonen, Farida Vis, and Sabina Mihelj. "Performing Citizenship on YouTube: Activism, Satire and Online Debate around the Anti-Islam Video Fitna," Critical Discourse Studies 7 (4) (2010): 252.

5. See for example, Ali Sethi, "Banistan: Why Is YouTube Still Blocked in Pakistan?" New Yorker, August 7, 2013. https://www.newyorker.com

6. Editorial, "Electronic Media Code of Conduct 2015: Regulating the Media," Dawn, August 25, 201 5. https://www.dawn.com

7. "Freedom on the Net 20r6: Pakistan," Freedom House, accessed February 2, 2017. https://freedomhouse.org 
8. "Freedom on the Net 20r6: Pakistan"; Gul Bukhari and Furhan Hussain, “Technology Driven Violence against Women," Research Report, Bytes for All, Pakistan, 20I4. https://bytesforall.pk

9. Bukhari and Hussain, "Technology Driven Violence against Women."

ı. "Women Pedal en Masse in Karachi, Lahore and Islamabad," Geo News, April 2, 2018 . https://www.geo.tv

I I. "Global Information Society Watch 2013: Women's Rights, Gender and ICTs," Association for Progressive Communication and Hivos, I88, accessed February $2,2017$. https://www.apc.org

I 2. Jawed Rafi, "Prostitution at Back of Mazar-e-Quaid," YouTube video, I I:58, May 28, 2013. https://www.youtube.com

I 3. Mimi Sheller and John Urry, "Mobile Transformations of Public and Private Life," Theory, Culture \& Society 20 (3) (2003): 108.

I4. Ayesha Siddiqa, Military Inc.: Inside Pakistan's Military Economy (Karachi: Oxford University Press, 2007).

I 5. Zizi Papacharissi, "Democracy Online: Civility, Politeness, and the Democratic Potential of Online Political Discussion Groups," New Media \& Society 6 (2) (2004): 260.

r6. Zizi Papacharissi, "Affective Publics and Structures of Storytelling: Sentiment, Events and Mediality," Information, Communication o Society I9 (3) (2016): 3 IO. http://dx.doi.org

I 7. Van Zoonen, Vis, and Mihelj, "Performing Citizenship," 260.

I8. Aswin Punathambekar, "Satire, Elections, and Democratic Politics in Digital India," Television \& New Media I6 (4) (20 I 5): 394.

I 9. Iqbal Sevea, “'Kharaak Kita Oi!': Masculinity, Caste, and Gender in Punjabi Films," BioScope 5 (2) (20I4): I 3 I-32. DOI: IO. I I 77/o97492 76I 4548645.

20. Wajiha Raza Rizvi, "Visual Pleasure in Pakistani Cinema (I947-2014)," International Fournal of Asia Pacific Studies Io (2) (2014): 77. https://papers.ssrn.com/ sol3/papers.cfm

2 I. Shuchi Kothari, "From Genre to Zanaana: Urdu Television Drama Serials and Women's Culture in Pakistan," Contemporary South Asia I4 (3) (2005): 289-305.

22. For a detailed analysis of how the host of the very popular religious talk show Aalim Online embodied a modern, cultured version of this persona, see Shumaila Ahmed, "Islam, Media and the Construction of Religious Authority in Pakistan: The Case of Aamir Liaquat Husain," master's thesis, University of Wollongong in Dubai, 20I4. http://www.academia.edu

23. Raza Khan, "Khawaja Asif's 'Vulgar' Outburst against Shireen Mazari Angers PTI," Dawn, June 8, 20 I6. http://www.dawn.com

24. Sar e Aam, "Karachi Ke Tariq Road Mein Chalta Hua Ghaleez Karobar?Iqrar U1 Hassan," YouTube video, 34:23, May 5, 201 7. https://www.youtube.com

25. For examples, see the British Royal Society for the Encouragement of Arts, Manufactures and Commerce's "Pakistan Calling" collection of videos. https:// www.thersa.org

26. Sahar Habib Ghazi, “Innocent Home Videos Are Becoming Pakistani 'Porn' on YouTube and Destroying Lives," Public Radio International: Global Voices Online, October I I, 20 I 3. https://www.pri.org 
27. DesiFun4, "PrivateVIPmujra_20 I 2,"YouTube video, 2:29, January 3 I, 20 I 2. https://www.youtube.com

28. Naima Chudrey, "Karachi Night Club," YouTube video, 9:38, October 2, 2009. https://www.youtube.com

29. Saknofear, "Universty of Lahore Dance Practice in Class Room," YouTube video, 3:09, February 2 2, 2009. https://www.youtube.com

30. Ali Nobil Ahmad, "Independent Filmmaking in Pakistan: An Interview with Sabiha Sumar," transcribed by Sophia Anjum, BioScope 5 (2) (20I4): I6I. DOI: I0.I I 77/0974927614550756.

3. Punathambekar, "Satire, Elections, and Democratic Politics in Digital India," 398.

\section{References}

Ahmad, Ali Nobil. 20I4. "Independent Filmmaking in Pakistan: An Interview with Sabiha Sumar." Transcribed by Sophia Anjum. BioScope 5 (2): I 53-62. doi: IO. I I 77/0974927614550756.

Ahmed, Shumaila. 20 14. "Islam, Media and the Construction of Religious Authority in Pakistan: The Case of Aamir Liaquat Husain.” Master's thesis, University of Wollongong in Dubai. http://www.academia.edu

Bukhari, Gul, and Furhan Hussain. 2014. "Technology Driven Violence against Women." Research Report, Bytes for All, Pakistan. https://bytesforall.pk

Chudrey, Naima. 2009. "Karachi Night Club." YouTube video, 9:38. October 2. https://www.youtube.com

DesiFun4. 20I2. "PrivateVIPmujra_20r2." You'Tube video, 2:29. January 3 I. https://www.youtube.com

Editorial. 201 5. "Electronic Media Code of Conduct 201 5: Regulating the Media." Dawn, August 25. https://www.dawn.com

"Freedom on the Net 2016 : Pakistan." 20 I 7. Freedom House, accessed February 2, 201 7. https://freedomhouse.org

Ghazi, Sahar Habib. 20 1 3. "Innocent Home Videos Are Becoming Pakistani 'Porn' on You'Tube and Destroying Lives." Public Radio International: Global Voices Online, October I I. https://www.pri.org

"Global Information Society Watch 20I3: Women's Rights, Gender and ICTs." 2017. Association for Progressive Communication and Hivos, I88, accessed February 2, 201 7. https://www.apc.org

Khan, Raza. 20 I6. "Khawaja Asif's 'Vulgar' Outburst against Shireen Mazari Angers PTI." Dawn, June 8. http://www.dawn.com

Kothari, Shuchi. 2005. "From Genre to Zanaana: Urdu Television Drama Serials and Women's Culture in Pakistan." Contemporary South Asia I4 (3): 289-305.

"Pakistan: Bloggers Feared Abducted." 20I7. Human Rights Watch, January I I. https://www.hrw.org

Papacharissi, Zizi. 2004. "Democracy Online: Civility, Politeness, and the Democratic Potential of Online Political Discussion Groups." New Media \& Society 6 (2): $259-83$.

Papacharissi, Zizi. 20r6. "Affective Publics and Structures of Storytelling: Senti- 
ment, Events and Mediality." Information, Communication \& Society I9 (3): 30724.http://dx.doi.org

Punathambekar, Aswin. 20 I 5. "Satire, Elections, and Democratic Politics in Digital India." Television \& New Media I6 (4): 394-400.

Rafi, Jawed. 20 I 3. "Prostitution at Back of Mazar-e-Quaid." You'Tube video, i I:58. May 28. https://www.youtube.com

Rizvi, Wajiha Raza. 2014. "Visual Pleasure in Pakistani Cinema (r947-2014)." International Fournal of Asia Pacific Studies Io (2): 73-105. https://papers.ssrn.com/ sol3/papers.cfm

Saknofear. 2009. "Universty of Lahore Dance Practice in Class Room." YouTube video, 3:09. February 22. https://www.youtube.com

Sar e Aam. 20 I 7. "Karachi Ke Tariq Road Mein Chalta Hua Ghaleez Karobar?Iqrar Ul Hassan.” YouTube video, 34:23. May 5. https://www.youtube.com

Sethi, Ali. 20I3. "Banistan: Why Is YouTube Still Blocked in Pakistan?" New Yorker, August 7. https://www.newyorker.com

Sevea, Iqbal. 20 14. "'Kharaak Kita Oi!': Masculinity, Caste, and Gender in Punjabi Films.” BioScope 5 (2): I 29-40. doi: IO. I I 77/09749276I 4548645.

Sheller, Mimi, and John Urry. 2003. "Mobile Transformations of Public and Private Life." Theory, Culture \& Society 20 (3): 107-25.

Siddiqa, Ayesha. 2007. Military Inc.: Inside Pakistan's Military Economy. Karachi: Oxford University Press.

Van Zoonen, Liesbet, Farida Vis, and Sabina Mihelj. 20Io. "Performing Citizenship on YouTube: Activism, Satire and Online Debate around the Anti-Islam Video Fitna." Critical Discourse Studies 7 (4): 249-62.

"Women Pedal en Masse in Karachi, Lahore and Islamabad." 20i8. Geo News, April 2. https://www.geo.tv

Yousufzai, Awais. "Tayyaba Case: Judge, Wife Deny Torturing Child.” 20 I7. Geo News, January i6. https://www.geo.tv 


\section{The Man on the Moon}

\section{A Semiotic Analysis of Scopic Regimes in Bangladesh}

\section{Muhammad Nabil Zuberi}

On March 3, 20I3, a large number of people in Bangladesh claimed to see the face of Allama Delwar Hossain Sayeedi on the moon. ${ }^{1}$ Sayeedi, a popular and charismatic Islamic orator and vice-president of the largest Islamic political party in Bangladesh, Jamaat-e-Islami, was sentenced to death by the government on February 28, 2013 for war crimes committed during the 1971 Bangladesh Liberation War. As the sun went down the next day, an image of Sayeedi's face on the moon began to circulate on Facebook with a caption claiming it as divine proof of his innocence. While the majority of the urban educated population was busy mocking the "absurdity" of the image, it continued to be shared through texting to those without Internet access, and through loudspeakers in mosques and word of mouth to those without a cell phone. Finally, that "manipulated" image became "real" when, after the Morning Prayer on March 3, scores of people throughout the country managed to see Sayeedi on the moon with their naked eyes. Apparently assuming it was a Karāmā $b^{2}$ or an omen indexing his innocence, they took to the streets protesting the verdict. By the end of the day, 67 people were dead, making it "the worst day of political violence in Bangladesh in decades" (Ethirajan 2013).

Nothing could have prepared the sector of the urban middle class for the shock they received from the unexpected and inexplicable rage and violence that the images and the sighting generated. The same was true for 
people who believed in the images and the sighting, as they were equally appalled by suggestions that all these divine signs were part of an elaborate Jamaat-e-Islami scheme to deceive them. The image, therefore, squarely divided the public into two groups: some could not comprehend how such a charade cannot but be retorted to with sarcasm and contempt, while others could not fathom how such divine signs can be responded to with anything other than devotion. The actual sighting of Sayeedi on the moon further removed these "realities" from each other. For people on one extreme, the entire atmosphere in which the sighting occurred was imbued with signs of divine intervention. For people at the other end, nothing could have been more bizarre, more antithetical to their sense of reality. All they saw in the entire ploy-accomplished through this-worldly acts of manipulation of images and rumors-was treachery and deviousness of mortals.

How did a population with a common language, history, and religion manage to see and experience such contrasting phenomena? What made the "manipulation" behind the image visible to some, and Sayeedi's face on the moon visible to others? How did these different appearances come about and acquire such contrasting meanings and political weight that an absurd matter to some became so significant to others that they were prepared to sacrifice their lives? In this chapter, I argue that these distinct visual experiences expose the contested nature of a seemingly homogenous "Bangladeshi" ocular culture, making it possible to discern the presence of two conflicting yet intimately related scopic regimes: a disembodied, positivist regime versus an embodied, deictic mode of vision (Jay I999, 3). Here, instead of reducing the visual either to the effects of an universal, innate faculty or to manifestations of fixed, isolated, homogenous cultures, I locate its political significance in the interlocked histories of technologies and ideologies that constantly destabilize the boundaries of what can be shown and seen, opening them up for manipulation (Jay 2002, 275; Pinney 2004,8$)$. In other words, I argue that the power to define visual and political possibilities operates not just through these preexisting scopic regimes, but through the workings of distinct semiotic ideologies on constantly mutating technologies of vision that reshape those regimes (Keane 2003, 4I9). This chapter, therefore, along with developing a critique of the positivist model of visuality dominant in Bangladesh, attempts to chart the ways distinct semiotic ideologies of efficacy and indexicality opened up the "manipulated" images and sightings of Sayeedi to different interpretations and political actions.

Moreover, I also argue that while these scopic regimes played a signifi- 
cant role in creating these distinct visual experiences, in the South Asian context these regimes do not constitute "incommensurable" or "unbridgeable" ocular fields (Jay 2002, 268). In other words, at least in this postcolonial setting, neither of these regimes completely rejects or replaces the other. Rather, their relationship is marked by a complex coexistence where they simultaneously resist and reproduce each other. In this chapter, I therefore illustrate how in staying true to the "polyscopic" and "interocular" nature of South Asian visuality, these ways of seeing not just coexisted, but merged with each other in producing different readings of Sayeedi's images and sightings.

\section{Seeing with/out the Body: Syncretism in South Asian Visualities}

A productive ground to start this inquiry comes from a range of interdisciplinary works that examine diverging modalities of vision in the South Asian postcolonial context and their relation to Western modernity (Davis 1999; Freitag 2007; Jain 2007; Pinney 2004). While being cautious in not reifying South Asian visualities, these studies elucidate the presence of two different scopic regimes: a decarnalized, disengaged mode associated with the Cartesian tradition and inculcated mostly during colonial periods, against an embodied, deictic mode of vision, with a deeper history dating back at least to precolonial times (Jay I999, 3; Nandy 1995, 2 I; Pinney 2002, 356). Corresponding to Norman Bryson's distinction between gaze and glance, ${ }^{3}$ the crucial difference between these two is that the former reduces vision to a static point, fetishizing the image through conflating it with objective reality, whereas the latter requires a carnal body, conscious of the viewing process and the representational status of the image being viewed (Bal I991, I42; Bryson I986, 95; Jay 1999, 7).

In the South Asian context, two key examples of such an embodied mode of viewing are darshan (Eck 1998) and nazar (Bhatti 20I2), where the viewing process is conscious and corporeal, not needing the viewer to privilege vision over other senses, or to assume the existence of the viewed object independent from the viewing process. In darshan, the key is the intersubjective relation between the subject of the image and the viewer, which gets established through the reciprocation of gaze (Gell I998, I I 7). Similarly, nazar denotes the potency of a fixated, penetrating gaze that mixed with the affective force of love or envy can affect the object or the person viewed, either through transference of bad luck or through signi- 
fying intimate physical interaction (Bhatti and Pinney 201 I, 228; Taylor 2002, 297). Both darshan and nazar therefore require the active and embodied engagement of the viewer through the habituated use of senses, emotions, and imagination.

A corollary to understanding South Asian visualities as embodied is that instead of aesthetic and semiotic aspects of images or how they "look," their efficacy or what they "do" for their viewers becomes important (Pinney 2004, 8). Critiquing Kantian approaches to aesthetics that depend on objective evaluation of the image by separating it from the viewer, Pinney proposes the concept of "corpothetics" to understand the corporeal aesthetics that unites the image and the viewer through mobilizing a certain poetics of the body in order to make the images efficacious, that is, to access their power to intervene in this-worldly affairs (Pinney 2004, I90). ${ }^{4}$ Kajri Jain (2007, I2-I3) also critiques the positivist tradition for privileging the authority of the visual and argues for incorporating the efficacy of images in an account. Jain terms this approach to images as forensicjuridical, as instead of analyzing images as circulating objects, it primarily engages and values the semiotic and ethical status of the images as evidence (true/false, real/fake), ${ }^{5}$ focusing on the representational capacities inherent in the images to be understood solely through visual engagement. Jain's work, on the other hand, puts forward other "vernacular" modes of valuing and engaging with images that depend on the power of faith and the ability of images to be efficacious.

Along with charting the presence of these modes, these studies put forward two characterizations of the complex and intimate ways South Asian visualities cohabit in the postcolonial space. First is the polyscopic nature of South Asian visual experiences, where instead of the dominance of one visual order, multiple visualities operate in eccentric yet complementary ways (Jay I 994, 592). The second characteristic of South Asian visualities, conceptualized by Appadurai and Breckenridge $(1992,52)$ as "interocularity," points to the fluidity of visual fields, where meanings, scripts, and symbols from one visual field cycle ceaselessly into other fields. Thus, while darshan has been viewed as an archetypal "Hindu" mode of vision, the idea of mutuality of sensual engagements at its heart transcends Hinduism, spilling into the everyday practices of visiting holy persons, political figures, or viewing cinema (Freitag 2007, 307). Similarly, nazar, with its roots in the Persianate religiously devotional poetic tradition, has made its way into the mundane and profane life, especially in romantic Urdu and Hindi literature and commercial films (Taylor 2002, 302). 
In certain ways, Sayeedi's images and sightings exemplified these characteristics of South Asian visualities. Different interpretations of Sayeedi's images not only showed the complex interaction between an embodied, efficacious regime and a disembodied, positivist one, but they also became the sites of fusion of ocular experiences and ideologies, making it difficult to box them in dichotomous understanding of visualities (corpothetics/ aesthetics, juridical/vernacular) and corresponding binaries like secular/ Islamic, modern/traditional, urban elites/rural mass (Sinha 2007, I93). For example, those who refused to believe in Sayeedi's image did not always do so on the basis of secular positivist logic. Conversely, many tried to present scientific explanations of how Sayeedi can be seen on the moon. In other words, neither the believers nor the skeptics of Sayeedi's images and sightings were strongly wedded to any one of these scopic regimes. Rather, in drawing their conclusions they subscribed to different semiotic ideologies embedded in those regimes on what images, sightings, and realities are, how to access them, and how they are related. In the next sections, I turn to the workings of these semiotic ideologies in different interpretations of Sayeedi's images and sightings, illustrating how, when confronted with the technology of manipulation, different ideologies of the efficacy and indexicality of the images ultimately led to these diverse interpretations.

\section{Image as Evidence: Competing Ideologies of Efficacy and Indexicality}

While the specific source and time of Sayeedi's image appearing on the Internet is debated, everyone agrees that it became viral after being posted on the pro-Jamaat-e-Islami Facebook page called Basherkella,${ }^{6}$ which had over Ioo, oo followers at that time. The urban educated class started noticing the image on March 2, most of them mocking the idea of Sayeedi being seen on the moon. In rejecting the image, the skeptics drew from two sources of authority embedded in two different scopic regimes: the secular argument that deemed the image as "unscientific" and "irrational" was entrenched in a disembodied, positivist mode of seeing, while the Islamic argument, with its claim that the image should be denounced as a "bid'ah," had its roots in an embodied mode of vision. However, in spite of their differences, these two modes did not cancel each other out; rather, they intensified each other polyscopically in rejecting the viability of Sayeedi's image.

Catering to this polyscopic nature, most press reports that came out next day were composites of these two arguments. The Daily Star, the most 
circulated English daily newspaper in Bangladesh, reported how the "absurd," "bizarre and cheap photo manipulation" drew "condemnation from Islamic scholars and ridicule from regular Facebook users":

Several Islami scholars termed the use of this fake picture "a JamaatShibir ploy" to cheat ordinary believers and exploited their religious sentiments. According to scholars, such an act is a "great sin." They note that such "sighting" of the moon can never happen in the light of the Quran and the Hadith. ...

The picture also prompted online bloggers and activists to make equally absurd jokes using Sayedee's pictures. In one, for instance, Sayedee was shown as one of the three astronomers to have landed on the moon in 1969. In this picture, Neil Armstrong's face has been replaced by Sayedee's face. ${ }^{8}$

Clearly, while there was little doubt in both Islamic and secular quarters about the "inauthenticity" of the image, their grounds of rejecting it were quite different. For the Islamic scholars, the main message was a cautionary one about what the image can $d o$. From their perspective, the image was efficacious in an adverse way, as its potency comes from its ability to do harm to believers. The secular skeptics, on the other hand, were fixated on the "look" of the image. However, as the report summed up, these modes spoke in each other's support, and many skeptics refused to believe in the image for both reasons, illustrating the polyscopic nature of their vision.

Nevertheless, as the secular skeptics of the image flooded the Internet with numerous absurdly manipulated, satirical images of their own, the tone of their primary reaction remained sarcastic. While these mocking images functioned as vehicles of moral criticism (Dadlez 20I I), one of their key purposes was to establish the secular skeptic claim to intellectual superiority. This claim stood on the perceived inability of the masses to understand the most rudimentary aspect of the image: that it is a "fake," and therefore has no divine power or evidentiary force. These skeptics, therefore, were shocked for a second time upon encountering people who, despite knowing all the "facts," wanted to believe in the image. In the comment section of a Prothom $A l^{9}$ report, Aminul Islam recounted his experience of the night before:

A person from my village woke me up calling in the early morning to look at the moon to see Sayeedi. Many people in my village have 




Figure I2.I. Image mocking Sayeedi's sighting on the moon

gathered in the field for this reason. I know that the image they are seeing is a fake. If I want, I can photoshop his image on a tiger. I tried to make him understand that. But someone already managed to see Sayeedi on the moon. "Let me see if I can see him also" were his last words before hanging up. He was clearly excited!10

While the skeptics at first were surprised by this inability of the believers to see the "visible," soon they identified a specific "way of seeing" as the problem. In another comment section, Adil Mahmood wrote:

The believers live in a world where Allahu Akbar can be seen on the image of a pregnant cow, trees grow in a design to show Allah's name, angels can be seen on kaba in lailatul qadar... how can they doubt Sayeedi's sighting on the moon? ${ }^{11}$

Soon, the key target of the skeptics became this specific kind of "blindness," which lacks ability to see cheap manipulation, but sees miracles and magic instead. With the moral insight that they are the one with the cure, the main aim of their flooding the Internet with images mimicking and mocking Sayeedi's image was to treat that blindness by showing that the "original" is a "fake."

In this regard, their approach to the image is similar to Jain's explication of the forensic-juridical approach as it also engages images based primarily on their status as "evidence" or their ability to represent the truth or reality. As such, the approach located the authority of the images in their representational capacities, that is, in the meaning of signifiers to be apprehended through visual engagement, without properly addressing the "efficacy of images as circulating objects or of viewers as embodied beings" (Jain 2007, I2). Yet, as Aminul's comment on the Prothom Alo report illustrated, for the 
believers the key question was not the truth or falsehood of the image, but the ability of the image to intervene in this world and the next. Members of Jamaat-e-Islami also stressed the potency of the image, as according to newspaper reports that came out next day, they circulated the image with a warning that those distrusting the image will commit a $\sin \left(\right.$ Gunaab) ${ }^{12}$ People therefore kept sharing the image fearing that, otherwise, grave consequences would be waiting for them both in this life and in life after death.

However, while the efficacy of the image became a key determinant in its circulation, it did not end the debate on the status of the image as evidence. Rather, for the majority, the question of efficacy became intimately tangled with the truth-value of the image. In this regard, while both parties subscribed to the notion of the "truth claim" of images in the sense that they are representations of the real, ${ }^{13}$ each came with a very different idea of what it means. The secular skeptics rejected Sayeedi's image based on a particular semiotic ideology ${ }^{14}$ of photographic indexicality that rendered some images as "image juste" or just/correct images at the expense of others. This indexicality of photographs results from the conviction that as photographs are physical impressions on the silver emulsion resulting from the unmediated reflection of light from the photographed object, they are free from human intervention and produce absolute visual accuracy and truthfulness. Thus, the quality of indexicality becomes tied to photography's truth claim, making it key in identifying images that are unjust, artificial, and misrepresentations of reality. This ideology of indexicality therefore not only provided the standard that Sayeedi's image failed to meet but it also laid bare the "blindness" of those who believed in Sayeedi's image and their inability to understand the indexical nature of a photograph.

However, believers in the image made it clear that their belief came not just out of the fear of committing sin, but because they consider the image to be true, suggesting that they shared a different idea of how the truth claims of images work. The difference between these semiotic ideologies becomes clear from the fact that in contrast to the skeptics' idea of indexicality, which demands a fixed, definitive, universally observable connection of the image with reality, the believers circulated multiple and radically different images as proof of Sayeedi's sighting on the moon. The most circulated one simply showed a photograph of Sayeedi's face on a photograph of the moon followed by a caption:

From late Friday night to early Saturday, many people were able to see Sayeedi's face on the moon including his prayer cap, glasses, and 


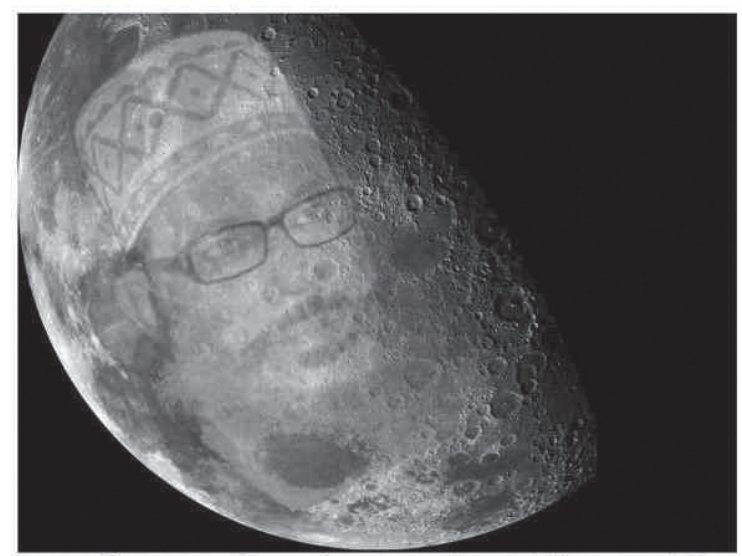

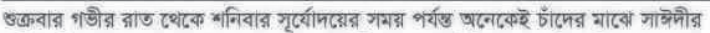
প্রতিচ্মিবি দেথতে পেয়েছেন। বাংনাদেশ, লৌদিআরবসহ বিভিন্ন হানে বিষয়টি মানুষ পথমে

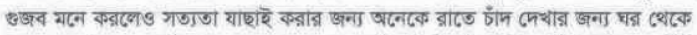

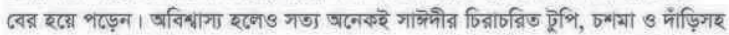

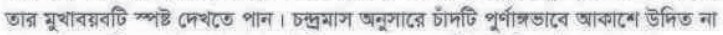

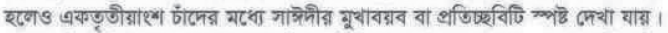

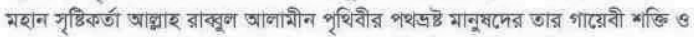
কের্রারতি দেখালোর জন্য যুগে যুগে এমন অনেক नিদর্শন মানুষকে দেখিয়েছেন। এছাড়া তার পতের অনুসারী অনেক লেক্বান্দাকেও তিनि অলৌকিক ভাবে गহযোগিত করেছেন।

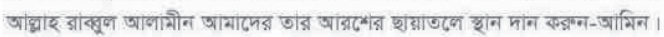

Figure I 2.2. Most circulated image of Sayeedi

beard. . . . Throughout history, god has shown his divine power and Karāmāh through such phenomena. He has also helped his true followers in miraculous ways. May god grant us mercy-Amen.

Absent in this description is any mention of the image or claim that it is an actual photograph of the event. The image was more a call to look at the moon than a proof of the event, depending rather on the text to testify to the trueness of the event through describing the details of the sighting in different places.

In contrast, two other less circulated images were presented more explicitly as evidence of the event. In the second one, two photographs of the moon and Sayeedi's face are shown side by side, with a shape similar to Sayeedi's face sketched on the moon. The caption reads: "I hereby pledge in the name of Allah, that I took this image last night, and has not edited it, just traced the shape of the blessed face of Allama Sayeedi." The third image was also a composite of two photographs of the moon and Sayeedi's face juxtaposed with each other, with a caption that says "Allama Sayeedi can be seen in moon in this shape." In spite of their differences, in all three 
images a different semiotic ideology of indexicality can be seen working in a paradoxical way as they tried to remove ambiguity with a concurrent resistance to semiotic closure. In other words, the use of these images as evidence was impeded by the excess of their "intertwined indexical and iconic aspects," requiring either the assistance of text or specific photographs of Sayeedi's face and outlining to index the resemblance (Gunning 2004, 43). Thus, these etchings done by Sayeedi's supporters illustrates Tom Gunning's argument that digital manipulation and indexicality do not always oppose each other, but that manipulation is required to remove the iconic excesses of the image to make indexicality apparent, and to make the images usable as evidence or proof.

However, contrary to the notion of indexicality active in the skeptics' rationale, this indexicality did not depend on any sort of semiotic closure. That is, while all these composite images tried to remove ambiguity by making the indexical work, that did not preclude the emergence of other meanings and possibilities. Rather, their simultaneous circulation suggested that there was no consensus among the believers on a specific way to see Sayeedi on the moon, and any way of seeing Sayeedi on the moon is valid. In that sense, like darshan and nazar, neither the image nor the object indexed existed outside of the viewing process, but required the active engagement of the viewer to materialize. The images here acted in a translucent way described in Davis's (I 999, 23) discussion of Indian images of god. Davis argued that while images of gods have substantive presence in themselves, they allow viewers with a devotional eye to see beyond their reality to the transcendent reality of gods. This translucency of Sayeedi's images is also similar to the emptiness or hollowness of deictic indexicality described by Charles Sanders Peirce (Doane 2007, 2). While both indexicalities are defined by a physical, material connection with the signified, in contrast to the photographic indexicality that partakes iconicity because of resemblance (footprint, death masks), deictic indexicality partakes the symbolic, forcing meaning to be opened to the spatiotemporal instance of signification. As Richard Davis illustrates, when translated to the realm of the images of gods, this means that each devotional eye may produce a different transcendent reality that it sees through the image. Therefore, in contrast to the photographic indexicality operative in skeptics' arguments, for the believers, indexicality resisted semiotic closure.

Moreover, as Aminul's comment on the Prothom Alo report above illustrates, the images did manage to stimulate their duplicates, and people in Aminul's village were able to see Sayeedi on the moon after seeing the 
image. As such, it violated another cardinal rule of photographic indexicality, which stipulates that the trace and the contact must belong to different temporal planes. In other words, the trace must come after, retrospectively providing the proof of a contact that does not exist anymore. Therefore, once photographs are perceived as mirrors of a different reality, the existence of that reality cannot be denied. Roland Barthes $(2006,76)$ points to this understanding when he claimed that a photograph mechanically reproduces to infinity what can never be reproduced existentially. For Barthes, this double constriction or imposition of reality and past, absolute and deferred presence, manifestation and separation is the very essence or noeme of photography: "the thing that has been." In a way, Sayeedi's images destabilize this sequential constriction as in many cases people managed to see Sayeedi on the moon after seeing the image. In other words, contrary to the noeme of photography, the manifestation here occurred without separation: the images not only mirrored the past but also mediated future actions and, in doing so, asserted the reality of the event.

Therefore, for many believers, the truth claims of the images were not located in their photographic indexicality. Rather, their trust in Sayeedi's images illustrate Gunning's $(2004,42)$ argument that truth claims are not integral to an image, but are rather "a claim made for it." Gunning separates truth claims from indexicality, arguing that, in order to speak the truth, the photograph must be integrated into a statement and subjected to rules of discourse. Following Charles Sanders Peirce, Keane (2003, 4I 9 ) also makes a related point that since icons and indexes in themselves assert nothing, their social power depends on semiotic ideologies to make them apparent by opening up the material properties of objects like photographs to signification. In a similar vein, Strassler's (2014, I 23) concept of auratic indexicality elucidates the culturally mediated nature of indexicality in her ethnographic study of the images of a spirit queen named Ratu Kidul in Indonesia. Strassler illustrates how, on the one hand, indexical claims of contact with this unseen queen imbue her paintings with supernatural powers, and on the other, due to a culturally mediated semiotic ideology of indexicality, these images are conceived not as traces of a "past but now absent present," but as media for "transmitting an ongoing but otherwise invisible presence," making them potent, efficacious objects.

Similarly, the "reality" effect of Sayeedi's image differs significantly from the idea of truth claims and indexicality that the secular skeptics used to criticize the image. Rather, the semiotic ideology of indexicality that connected the images physically to the signified worked in a deictic and 
translucent way, differing in three important ways. First, unlike photographic indexicality, it did not depend on establishing an objective, universally observable connection to reality, but kept open the possibility of other connections. Second, the believers did not see the images as traces of a past event that is absent now, but as mediums of an ongoing event. Lastly, in contrast to photographic indexicality, which is contingent on iconicity to signify, this deictic indexicality depended on the sketches, text, and collages to allow the believers to actually see Sayeedi on the moon. In other words, these tracings and texts embedded in the images support Strassler's argument against Gunning, illustrating that culturally mediated ideologies of indexicality can play a presence-conjuring role along with the visual excesses of iconicity.

\section{Believing the Body: The Semiotic Ideology of Karāmāh}

In general, people's responses to Sayeedi's images and sightings followed similar trajectories. Like the images, people drew from both secular and Islamic worldviews in a polyscopic and interocular way to reject the news of Sayeedi's sighting because it is both "unscientific" and "un-Islamic." Nevertheless, many rejected the news because it contradicts the sharia, and argued that the believers are committing bid'ab (innovation) at best and shirk (idolatry or polytheism) at worst. As they all believed in the miracles performed by the prophets and described in the Quran, it was not the sighting itself that was in question here. Rather, they challenged Sayeedi's sanctity, arguing that no mortal except the prophets is holy enough to be seen on the moon.

However, this question of Sayeedi's sanctity was irrelevant for the secular skeptics, and they rejected it for completely different reasons: because seeing someone on the moon is not objectively observable and scientifically possible. For example, Dipen Bhattacharya, an astrophysicist, tried to fathom the impossibility of the news mathematically:

I was doing a quick back-of-the-envelope calculation for the amount of energy to create a visible image on the moon. The numbers are astronomical, because to put an image on the moon that would be visible from here, you have to match the solar flux at the moon. ${ }^{15}$

Bhattacharya went on to calculate that it could be done only if someone projected a beam using Io,ooo terawatts of energy. That is impossible, he 
explains to the reader, since the total power output of the entire world is 2.3 terawatt, and even that is enough to vaporize everything around the projector, let alone the Io,ooo terawatts needed. He concluded, "but when people believe in divine intervention, all these calculations are beside the point."

At the center of skeptics' arguments like these was the positivist metaphysical foundation that depended on the existence of two separate but interdependent entities: an observable, systematic, external reality and an impartial observing subject (Kember I 998, 25). Coupled with the Platonic mistrust of mimesis explained by Jain (2007), this ideology makes some realities more "just," true, and believable than others. Here, instead of an image, it is the viewer's mind that becomes the location of mimesis. Therefore, for skeptics like Bhattacharya, the explanation of why so many people were able to see Sayeedi on the moon resorted either to a backward mindset or to mass hallucination. As Jiten Roy commented on Bhattacharya's post:

In my view, the culprit is religion; it's a faith, which stunted the development of normal psyche; probably brain cells as well. Examples of such immature psyche among religious people is present everywhere. $^{16}$

Another blogger, Golam Dostagir, argues that the science behind the unconscious mind is key in explaining the sighting:

Human mind has limitless power. It will believe what it wants to believe. We already know about mass hysteria in girl's school. . . . if such physical symptoms occur according [to] the suggestions of other people, then is it hard to imagine a face on the moon because of that? We need to understand it is a mass psychogenic illness. ${ }^{17}$

Just like the "manipulated" images, the reality here is distorted by this pathological collective psyche, which tricks the otherwise "objective" vision into seeing things that the mind wants to see. As another blogger wrote, "You are imagining Sayeedi on the moon with your mind, your eyes are just seeing that." 18

However, very different answers to what constitutes reality and how it is accessed become apparent in the statements of the people who defended Sayeedi's sighting on the moon. To explain the fact that not everybody who 
tried to see Sayeedi on the moon was able to see him, they argued that this transcendental reality is not accessible to all. The dominant argument was that it was mostly pious (dindar), righteous (parhezgar) persons who were able to see Sayeedi on the moon. Abu Zaowad, who wrote a booklet on the event titled "Karāmāt al-awliyā," argued:

Following their morning prayer, countless honest (imāndaar) Muslims have seen Sayeedi's face on the moon when they exited the mosque and looked at the sky. People who do not support famaatShibir but are truthful also acknowledged seeing Sayeedi's face on the moon.

Most accounts of Sayeedi's sighting included testimonies by people who reportedly have never lied in their life, and who are believed by everybody in the village. The "reality" in these statements was not objective and accessible to all, but is transcendental), which can only be accessed through the vision of a righteous person. A blogger named Usama Yusuf argued: "My uncle saw Sayeedi on the moon, and nobody in this area including me has the power to doubt what he saw. Just because I have not seen it . . does not mean I have ability to deny his vision." 19

While this embodied intersubjective mode of vision was significant in producing the reality effect of Sayeedi's images and sighting, it was not the only one to play a crucial role. Rather what rationalized the entire phenomena through opening up the qualities of the moon to such signification was the semiotic ideology of Karämāh, or the belief in the miracles performed by Awliya' Allah (the friends of god), seen as signs of dignity bestowed upon them by god (Dabashi 1989). While all Muslims believe in Mojaja or miracles performed by the prophets and described in the Quran, followers of Sufis strongly believe that the gift has passed down to the Sufi saints. As Islam spread into South Asia through Sufi tradition, the Islamic worldviews here were molded through these stories of divine intervention. Therefore, people here are accustomed to and equipped with semiotic ideologies and forms of embodiment to read and feel the presence of this divine order in everyday life.

The significance of the context in which the Karämāh took place also played a role in the reality effect of Sayeedi's sighting. In most instances, it happened after the Morning Prayer in a liminal time known as Subb$e$-Sadiq, the importance of which was established in the Quran and the Hadith numerous times. The selection of the moon as the background 
of Sayeedi's apparition was by no means an accident either. The Quran has a chapter on the moon, where Allah awarded the miracle of splitting the moon to Prophet Mohammad to establish the truthfulness of his messengerhood to the people of Mecca. Moreover, Iranian and South Asian Muslims are not unfamiliar to the idea of seeing Karāmāh on the moon, as people like Ayatollah Ruhollah Moosavi Khomeini in Iran and Abul Al'a Moududi and Riaz Ahmed Gohar Shahi in Pakistan have claimed divinity based on their being sighted on the moon.

In addition, the descriptions of almost involuntary bodily responses of people when they saw Sayeedi on the moon provided another important cue to the reality of the event as a Karämāh. For example, in one of the interviews of people who saw Sayeedi on the moon done by the writer of the booklet, an imam narrated his experience:

I saw the face of Allama Sayeedi floating on the moon with his usual prayer cap and glasses. I saw it myself, and the minute I saw it, god's praise spontaneously came out of my mouth. I felt my senses heightened and shivers ran through my body.

Such unintentional physical reactions (becoming unconscious, screaming, numbness) following the sighting also helped in establishing the reality effect of the sighting, since such reactions only come when people face something extraordinary, indexing the status of the event as Karāmāh.

Moreover, these somatic experiences were not limited in seeing Sayeedi on the moon, but involved feeling changes in the physical world, too, which also worked as signs of divine intervention. The imam in the interview went on to explain the situation on the day he saw Sayeedi on the moon:

The situation was eerily still . . . to tell you the truth, the day on which the verdict was announced . . . it was uncannily silent ... I haven't seen such uneasy silence on earth in my life ... the entire world seemed to be mute from shock ... the sky and the air seemed dazed and shaken up ... everything everywhere was traumatized.

The most frequent among those changes was the transformation that happened in the object that was at the center of discussion: the moon. Those who saw Sayeedi argued that for the duration the moon was not in the normal state that can be seen in ordinary times. In another interview from the same series, a madrasah teacher recounted his experience: 
When I looked at the moon, I saw the shape of Allama Sayeedi's face imprinted like negative film.... it stayed like that for approximately two-three days, but started fading after that. . . the mark does not appear like that anymore, now you can see a map like thing on the moon, not that mark.

Another youth from the same series of interviews stated: "I am not sure whether it is Sayeedi or not, but I have seen a face on the moon . . . and the shape of the moon is different also, it is not the normal moon we see every day."

Therefore, the mode of vision that enabled the believers to see Sayeedi on the moon was completely different from the one the skeptics were equipped with. Instead of the model with an impartial coherent observer and a universally accessible objective reality, in this mode of vision the reality is not the same for all; rather, different layers of reality become accessible and visible to viewers depending on their subjectivity. Moreover, vision was not the only way to access that reality; rather, it was open to be interpreted through other senses also. It is the semiotic ideology of Karāmāh that enabled the believers to read and interpret these signs in the narratives, bodies, context, and physical environment involved in the sighting. In other words, the semiotic ideology of Karāmāh did not simply make these signs recognizable and interpretable to them, it enabled them to instigate certain political responses and actions. The skeptics, without the semiotic ideology of Karāmāh, failed to see and understand that call to action.

\section{Conclusion}

In analyzing the distinct visual phenomena that the skeptics and the believers of Sayeedi's images and sightings experienced, I suggested that two scopic regimes underlie these experiences: one based on the idea that reality is objective and external to the viewer and can only be accessed in a disembodied and impartial way though vision, while in the other, reality does not exist outside the viewer but becomes accessible through embodied engagement with the subject. However, instead of considering their discrepancies, I here argue that these two modes were applied in a polyscopic and interocular way, as the viewers used different semiotic ideologies in believing or rejecting Sayeedi's images and sightings. For the skeptics and believers who subscribed to the ideology of efficacy, the debate was not about the visual signifiers in the images or how the images looked, but about their 
ability to intervene in this world and the next. In terms of the sighting, it was not the probability of seeing someone on the moon that was contested. Rather, skeptics questioned whether Sayeedi is righteous enough to be seen on the moon, while the believers tried to prove his sanctity. On the other hand, the secular skeptic argument revolved around the semiotic ideology of photographic indexicality, and not only eschewed the efficaciousness of the images but also ignored the discursive nature of the truth claim of the image and the multiple ways indexicality can be formed. It therefore went unnoticed that, for the believers of Sayeedi's images, the truth claim came from a semiotic ideology of indexicality that established the connection of the images to the signified in a deictic and translucent way, premised on a transcendental reality. Similarly, for the event of Sayeedi's sighting, the idea of an objectively observable reality played a key role in the secular skeptic argument, ignoring the semiotic ideology of Karammāh that the believers employed in experiencing and interpreting the sighting of Sayeedi on the moon, taking direction for future actions.

\section{Notes}

I. While the phrase "the man on the moon" has been widely used to refer to the shape of a human face in the moon familiar to people around the world, it was used in the Bangla blogosphere to refer to the event of Sayeedi's sighting on the moon.

2. In Islamic theology, Karāmāt al-awliya $\bar{a}$ refers to the belief that Allah can bestow or reveal miracles on behalf of a wäli (a pious person/a friend of Allah) (Amanullah 2003).

3. Bryson argued that Western painting suppresses deictic markers like brushstrokes, encouraging a disembodied gaze that sees images as objective realities. In contrast, Chinese paintings display the strokes through which they materialized, requiring the intimate involvement of a carnal body.

4. Pinney $(2004,18)$ situates this bodily praxis against the mathematically ordered, disinterested aesthetics by invoking the similarity of this dichotomy with two others: Susan Buck-Morss's proposition to apprehend aesthetics as somatic experience that can't be subsumed by the mind and therefore resists "predatory reason"; and Jean-François Lyotard's oppositional understanding of "figure" and "discourse," as contrary to the closure of meaning in discourse, the figural defies the demands of meaning through constituting "a space where intensities are felt" (Carroll 1987, 30; Kester 1997, 43).

5. Jain argues that within this ocularcentric formation of knowledge, which also draws from Platonic mistrust of the image and the mimesis, the authority of the images comes from their adequacy or inadequacy in representing the truth or reality

6. Basherkella (bamboo fort) alludes to the fort built by Titumir, who led a peasant uprising against the British colonial authorities in the nineteenth century. 
7. In Islamic theology, bid'ah refers to matters without precedence and in opposition to the Quran and Sunnah.

8. https://archive.is.mtAYT desh.

9. The Prothom Alo is a daily newspaper with the largest circulation in Bangla-

Io. https://archive.is/41DHk

I I. https://archive.is/SNLuq

I 2. https://archive.is/MOf3 1

I3. While the ideology has a complex genealogy, in general, it conceptualizes images as tied to "reality" through the natural force of mimesis, and hence closer to "reality" than symbols or words, which lack any necessary connection with the signified as arbitrary signs (Jay 2002, 269).

I4. Semiotic ideologies are basic assumptions about what signs are and how they work, and they scaffold different modes of signification across apparently distinct social fields by interpreting and rationalizing them (Keane 2003).

I 5. https://archive.is/FZ11Q

I6. https://archive.is/FZ11Q

I 7. http://archive.is/TlzNt

I 8. http://archive.is/ $1 \mathrm{kF} 17$

I9. http://archive.is/MQgLt

\section{References}

Amanullah, Muhammad. 2003. "Debate over the Karāmah of Allah's Friends." Arab Law Quarterly i 8 (3-4): 365-74.

Appadurai, Arjun, and Carol A. Breckenridge. r992. "Museums Are Good to Think: Heritage on View in India." In Museums and Communities: The Politics of Public Culture, edited by Ivan Karp, Christine Mullen Kreamer, and Steven Levine. Washington, DC: Smithsonian Books.

Bal, Mieke. I991. Reading Rembrandt: Beyond the Word-Image Opposition. Cambridge: Cambridge University Press.

Barthes, Roland. 2006. Camera Lucida: Reflections on Photography. Edited by Richard Howard. New York: Hill and Wang.

Bhatti, Shaila. 20 I 2. Translating Museums: A Counterbistory of South Asian Museology. Walnut Creek, CA: Routledge.

Bhatti, Shaila, and Christopher Pinney. 201 I. "Optic-Clash: Modes of Visuality in India." In A Companion to the Anthropology of India, edited by Isabelle ClarkDecès, 223-40. Hoboken, NJ: Wiley-Blackwell.

Bryson, Norman. 1986. Vision and Painting: The Logic of the Gaze. New Haven: Yale University Press.

Carroll, David. I987. Paraesthetics: Foucault, Lyotard, Derrida. London: Routledge.

Dabashi, Hamid. 1989. Authority in Islam: From the Rise of Mubammad to the Establishment of the Umayyads. New Brunswick, NJ: Transaction Publishers.

Dadlez, Eva M. 20 i r. "Truly Funny: Humor, Irony, and Satire as Moral Criticism." Fournal of Aesthetic Education 45 (I): I-I 7. 
Davis, Richard H. I999. Lives of Indian Images. Princeton: Princeton University Press.

Doane, Mary Ann. 2007. "Indexicality: Trace and Sign: Introduction." Differences I8 (I): I-6.

Eck, Diana L. I998. Darsan: Seeing the Divine Image in India. 3rd ed. New York: Columbia University Press.

Ethirajan, Anbarasan. 2013. "Bangladesh War Crimes Verdict Sparks More Violence.” BBC News, March I. http://www.bbc.com

Freitag, Sandria B. 2007. "South Asian Ways of Seeing, Muslim Ways of Knowing." Indian Economic \& Social History Review 44 (3): 297-33 I.

Gell, Alfred. 1998. Art and Agency: An Anthropological Theory. Oxford: Oxford University Press.

Gunning, Tom. 2004. "What's the Point of an Index? Or, Faking Photographs." Nordicom Review I-2 (25): 39-50.

Jain, Kajri. 2007. Gods in the Bazaar: The Economies of Indian Calendar Art. Durham, NC: Duke University Press.

Jay, Martin. I994. Downcast Eyes: The Denigration of Vision in Twentieth-Century French Thought. Berkeley: University of California Press.

Jay, Martin. I999. "Scopic Regimes of Modernity." In Vision and Visuality, edited by Hal Foster. Seattle: Bay Press.

Jay, Martin. 2002. "Cultural Relativism and the Visual Turn." Fournal of Visual Culture I (3): $267-78$.

Keane, Webb. 2003. "Semiotics and the Social Analysis of Material Things." Language \& Communication 23 (3): 409-25.

Kember, Sarah. I998. Virtual Anxiety: Photography, New Technologies and Subjectivity. Manchester: Manchester University Press.

Kester, Grant H. I 997. "Aesthetics after the End of Art: An Interview with Susan Buck-Morss." Art Journal 56 (I): $38-45$.

Nandy, Ashis. 1995. The Savage Freud and Other Essays on Possible and Retrievable Selves. Princeton: Princeton University Press.

Pinney, Christopher. 2002. "The Indian Work of Art in the Age of Mechanical Reproduction Or, What Happens When Peasants 'Get Hold' of Images." In Media Worlds: Anthropology on New Terrain, edited by Faye D. Ginsburg, Lila Abu-Lughod, and Brian Larkin. Berkeley: University of California Press.

Pinney, Christopher. 2004. Photos of the Gods: The Printed Image and Political Struggle in India. London: Reaktion Books.

Sinha, Ajay J. 2007. "Visual Culture and the Politics of Locality in Modern India: A Review Essay." Modern Asian Studies 4I (I): I 87-220.

Strassler, Karen. 20I4. "Seeing the Unseen in Indonesia's Public Sphere: Photographic Appearances of a Spirit Queen." Comparative Studies in Society and History $56(\mathrm{I}): 98-\mathrm{I} 30$.

Taylor, Woodman. 2002. "Penetrating Gazes: The Poetics of Sight and Visual Display in Popular Indian Cinema." Contributions to Indian Sociology 36 (I-2): 297322 . 


\title{
Media and Imperialism in the Global Village
}

\author{
A Case Study of Four Malalais
}

\section{Wazhmah Osman}

Since the events of $9 /$ I I and the start of the "War on Terror," debates pertaining to Muslim women's rights have been reverberating globally. Particularly in the West, Muslim women have been put under the popular culture spotlight, evident in the proliferation of media such as fiction films, television programs, documentaries, books, and news that focus on their plight under repressive Islamic regimes. The resultant media attention has been critiqued by scholars from a variety of disciplines concerned with the overwhelming portrayal of women as victims, without accounting for their actual or potential agency, thereby perpetuating stereotypes of women under Islam that have gained new currency since $9 /$ I r. Yet while this type of media continues to proliferate, little attention has been given to the cultural productions that constitute local gender subjectivities and social movements. Likewise, little attention has been given to how local activists and human rights groups "talk back" to this discourse.

In this chapter, I trace and contextualize the trajectory of iconic figures and their role in key contemporary moments of activism and reform in Afghanistan and Pakistan. In particular, I will focus on the four Malalais (Malala Yousafzai, Malalai Joya, Malalai Kakar, and Malalai of Maiwand) in order to highlight the various ways in which Af-Pak women's activism gets selectively recognized and appropriated by neoimperial agendas. Through 
tracing how Malala achieved such global stature, I hope to underline the ways in which particular aspects of her activism were deemed more legitimate than others in order to justify neoimperial agendas in Afghanistan and Pakistan. The backlash against Malala in her native Pakistan also reveals how the global media and the Western exaltation of her ended up privileging a particular type of activist that obscured the many other Pakistani and Afghan women who had been advocating for political and social change for decades before. In doing so, this chapter engages with a broader set of questions: Why have some of these local heroines like Yousafzai become global phenomena, winning accolades such as the Nobel Peace Prize, while others have had a hard time crossing their localized boundaries? What is the role of political economy, imperial ideologies, and disparities in media infrastructures in their circulation or lack thereof? What does the politics of recognition that surrounds them tell us about the ways in which digital media are implicated within structures of empire?

In order to begin to answer the aforementioned questions, I interrogate the international celebration of Malala Yousafzai and, during select moments, the celebration of the other Malalais, but also the moments when they became persona non grata within media and government discourse. The goal is not to question the worthiness of people like Malala's accomplishments, but rather to critique the workings of empire in not generating platforms for those equally worthy female activists in the Af-Pak region. I am not the first person to draw attention to the incredible global scope of Malala Yousafzai's recognition and critique it as a tool of imperial agendas. In fact, Yousafzai herself has reflected on the pull of forces casting her singularly as just a victim: "In Swat, I studied in the same school for Io years and there I was just considered to be Malala. Here I'm famous, here people think of me as the girl who was shot by the Taliban. The real Malala is gone somewhere, and I can't find her."' Thus, one of my main goals is to situate Yousafzai within a broader history of progress, reform, and activism in South Asia. This chapter also situates this issue of gender and iconicity in relation to a post-9/I I context marked by new media developments including the emergence of dozens of new television and radio stations, hundreds of publications, a fledgling movie industry, and an Internet infrastructure with funding from foreign and domestic sources.

At a time when numerous other human rights activists from the region have also risked their lives to fight local and foreign injustices in ways both spectacular and ordinary, it is critical to understand not only what makes their efforts less worthy of global recognition but what their contributions 
are in the first place. I argue that when celebrated women activists, who bravely fight for modern signifiers of human rights, equality, and justice, also question and challenge U.S. imperialism and hold U.S. foreign policy accountable for the rise of extremism in their region, they become dangerous figures. They can no longer be easily subsumed into the simplistic narratives of victimhood into which imperial discourses slot them. Their circulation must be managed and controlled, and it is here that the role of global and digital media acquires significance.

\section{Colonial and Neoimperial Feminism: Giving and Taking Voice}

In order to understand why certain instances of resistance to the social and political order among women from South Asia and the Middle East are celebrated and others are left out of the contemporary record, it is important to consider how both colonial administrations and discourses view women as a proxy for how effectively a broader political agenda is being implemented. This colonial history is by no means a relic of the past. The regimes of knowledge production that are endemic to colonial forms of power continue today in the guise of neoimperial nation-building and development projects and more outward forms of militarization, such as the systematic drone attacks that are specific to the U.S.-led War on Terror (Khalili 20I2; Grewal 2017; Parks and Caplan 2017; Packer and Reeves 2017; Tahir 2017), and their place in the genealogy of U.S. warfare. The ways in which the media mobilize visual representations cannot be detached from war, militarization, and humanitarian and development discourse (Chadha and Kavoori 2015; Chrisman 2013; Solomon 2007). When grappling with a figure like Yousafzai, it is crucial, then, to keep in mind how imperial projects have mobilized gender as a weapon of conquest, regime-building, and the governance of colonial subjects.

A key way that imperial powers have used women to further their agendas is by creating a narrative in which there is a righteous "us" (read the West) and a morally bankrupt "them" (read the "East" or "The Muslim World"). In Samuel Huntington's classic piece "The Clash of Civilizations," which has been disgraced in academia but is still alive and well in policy circles, sets up false binaries between religiosity and secularism and between progress and religious extremism. This modernist rhetoric was used to justify Western rule in the name of liberating Muslim, Hindu, or Pagan women from their "repressive" societies. As prominent postcolonial 
scholars have noted, these false binaries obscure the complexities of the residues and social configurations of the colonial encounter (Asad I986, 2003; Chatterjee 1997; Gole 2006; Mahmood 2005).

Yet in order to maintain the fiction of being bastions of democracy, human rights, and freedom for all, the Western ruling elite needs to do more than erase their regressive records; they also have to erase the agency of progressive reform in South Asia. Anyone who is familiar with Afghan history knows that the long struggle for women's rights (and sexuality) has been an ongoing battle between modernist state policies and the more restrictive and repressive interpretations of Islamic and tribal laws dictated by religio-tribal elders. Put simply, there is a long history of Western colonial and more recent neoimperial discourse that deliberately distorts and erases histories that do not neatly fit within its narrative and geopolitical agenda. Mainstream Western media, including television networks and films, even independent ones, tend to perpetuate this dominant ideology.

Therefore, when some people from the Global South and East are handpicked for public consumption and celebrated globally, we must be suspicious. Upon close analysis of the media coverage of the four Malalais as well as other Afghan and Pakistani women who have spoken truth to power at home and abroad, it becomes clear that there is a logic to choosing who gets media coverage and who does not. In the digital age, there are certainly more spaces for disjuncture from the dominant discourse and self-representation. However, as we shall see in the discussion of the four Malalais in the next section, ultimately media forms play less of a factor in who gets covered than ongoing colonial agendas.

\section{The Four Malalais}

The four Malalais I will be presenting are Malala Yousafzai, Malalai Joya, Malalai Kakar, and Malalai of Maiwand. First, it is important to note that while only one of them, Yousafzai, has achieved an iconic global stature, all of them are well-known public figures in the Af-Pak region, and Joya and Kakar are figures I know personally through my activist work in the region. Additionally, it is important to highlight that most of the Afghan and Pakistani women's rights groups and activists I have met and worked with actively seek to expand their reach outside of the local and into the global public sphere. The fact remains that international attention can bring allies, clout, and funding to enact local change, and local activists are keenly 
aware of the power differentials. Yet, for a variety of reasons, which I will elucidate in this chapter, most of them have been unable to tap into global networks of media, funding, and activism.

\section{Malala Yousafzai: The Celebrity vs. the Activist, and the Censoring of Drone Warfare}

In the discourse on iconic global women activists, Malala Yousafzai is now a household name. Having graced the covers of books, women's rights brochures, and been the subjects of several documentaries, the name Malala evokes not only an individual but a symbolic figure. Malala Yousafzai was born in 1997 in the Swat Valley in Pakistan near the border of Afghanistan, where as a child my family and I spent time as refugees during the Soviet Occupation. At the age of I I, in 2008, she started writing a blog for BBC Urdu about life under the Taliban, which gained attention in Pakistan. Adam Ellick from the New York Times picked up on the story and made a documentary about her the next year called Class Dismissed: The Story of Malala. ${ }^{2}$ She became a regional symbol of resistance to the Taliban, which of course put her in danger in the Taliban-dominated region where she lived. Yet it was in 2012 , when she was shot at I 5 years of age by the Taliban on a school bus, that she became a global figure. Following the shooting and her subsequent recovery in a Birmingham, UK hospital, Malala was offered multiple book deals, speaking engagements, and became the subject of additional documentaries, which culminated in her winning the Nobel Peace Prize in 20I4. In fact, the UN General Assembly declared her I6th birthday "Malala Day."

Following her recovery, Malala's speeches were primarily focused on the power of education to equip girls, no matter where they lived, with the tools to move beyond their economic and cultural circumstances. In fact, Malala herself emphasized the global relevance of her message by noting in her 2013 speech to the UN: "Malala Day is not my day. Today is the day of every woman, every boy and every girl who have raised their voice for their rights." And when accepting the Nobel Peace Prize, she noted, "I tell my story not because it is unique but because it is not. It is the story of many girls." While Malala herself attempted to draw attention to the tragically ordinary fact that girls like her suffer disenfranchisement every day at the hands of corrupt governments, the media persisted in promoting a narrative that emphasized her extraordinary 
quality as a women's rights activist who embodied resilience, bravery, and heroism. With the publishing of her memoir, I Am Malala, which sold I. 8 million copies worldwide, ${ }^{5}$ Malala became a ubiquitous name in the global consciousness.

On the one hand, Western media outlets, NGOs, and public schools mobilized Malala's image and her writing and speeches as a kind of extraordinary aberration-as a unique story of female bravery that one does not often see in places like Pakistan or Afghanistan. On the other hand, Pakistani media outlets and public figures were quick to say that she had "sold out," and that in fact the global embrace of her as an extraordinary heroine erases the heroism of thousands of Pakistani women who resist the dominant social and political order every day, and who do suffer while doing so-if not through suffering a bullet to the head, then through other forms of gender-based violence. In fact, the global embrace of Malala sparked outrage and skepticism among the Pakistani middle classes. ${ }^{6}$ While her blog and the rapid proliferation of social media platforms at the time of her shooting certainly contributed to the transnational circulation of the shooting, there are deeper forces at play. ${ }^{7}$

The ways in which the United States has used Pakistan as a battleground for its ongoing War on Terror in Afghanistan is widely known. The status of women has functioned in critical ways for the ongoing justification of militarization and development projects (which often go hand in hand, as noted by scholar Jennifer Fluri [20 2 2]). The shooting of Yousafzai was also mobilized by U.S. government branches in order to justify ongoing drone strikes in Pakistan, which the Obama administration ramped up in 2009 under the U.S. military and the Central Intelligence Agency in order to destroy the Taliban and al Qaeda leadership. ${ }^{8}$ In fact, even the Pakistani liberal elite have used Yousafzai's shooting to encourage U.S. intervention in Pakistan. Following the shooting, one Pakistani citizen at a vigil held up a sign that said "Drones kill so Malala can live," a statement that bought into sharp focus the neoimperial logic that drone attacks against the Taliban are the most effective mechanism to protect children like Malala. What the sign did not point out was that as of 2014, between three to four thousand people have been killed by drones in the Af-Pak region. ${ }^{9}$ Time magazine columnist Joe Klein defended drone attacks on MSNBC's Morning foe, shortly after Malala's shooting, ${ }^{10}$ stating that these attacks were preemptive ways to protect "our" children, adding, "The bottom line is: In the end, whose four year old gets killed?" The shooting of Malala then, was also a 
way for the U.S. global media infrastructure to justify the ongoing use of drones in Pakistan by pointing to the brutality of a force like the Taliban.

It is notable that Malala herself has vehemently spoken out against the U.S. drone campaign. In meeting with President Barack Obama in 20I4, she noted in a statement, "I thanked President Obama for the United States' work in supporting education in Pakistan and Afghanistan and for Syrian refugees. I also expressed my concerns that drone attacks are fueling terrorism. Innocent victims are killed in these acts, and they lead to resentment among the Pakistani people." ${ }^{11}$ Despite this honest plea for the United States to reconsider its drone program, the White House statement on the meeting left out this part of the discussion. ${ }^{12}$

Rather, the statement focused on Malala's activism around girls' education. ${ }^{13}$ In more recent years, Malala has also spoken out against global political violence, including the Israeli state's targeting of Gaza, having pledged $\$ 50,000$ to rebuild Gaza schools. ${ }^{14}$ She has also spoken out about the injustices faced by Rohingyan refugees and Palestinian children, having tweeted in December 2017, "Today I am thinking of Palestinian and Rohingya children - and all around the world still struggling to achieve Anne [Frank]'s dream of freedom. \#HumanRightsDay." And in more recent years, she has condemned the Taliban for their ongoing persecution of civilians in Afghanistan. ${ }^{15}$ In more recent months, Malala has publicly critiqued the Trump campaign's remarks about implementing a Muslim travel ban, calling it prejudiced, noting, "Well that's really tragic that you hear these comments which are full of hatred, full of this ideology of being discriminative towards others." ${ }^{16}$ And yet these statements, as much as they remain couched within the more humanitarian language of education, freedom, and children's wellbeing, were only given coverage by a handful of news sources.

I seek to critique the global perception of Malala's work not to discredit it. In fact, the Malala Fund and other initiatives she and her family run have made impressive contributions to the construction of girls' schools in Pakistan. The Malala Fund, for example, provides educational opportunities to former domestic workers, children fleeing conflict, and provides school supplies for girls' schools affected by flooding. ${ }^{17}$ In 2014 , the Ministry of Finance of Pakistan signed an agreement with the UN Educational Scientific and Cultural Organisation that would allot $\$ 7$ million from the Malala Fund toward an education project that would focus on rural areas of Pakistan. ${ }^{18}$ What I am interested in disaggregating is why it is that only 
a sliver of Malala's work is being given global media attention and along what lines are certain types of activism distinguished from each other to the point where recognition and access to resources shift? The case of Malala also draws our attention to the ways in which a particular victimhood subjectivity is a precursor for getting educational, professional, and medical benefits from Western powers. It is certainly no coincidence that, as of 20I 7, Malala began studying at Oxford University and she and her family are now living in Birmingham. The fact that she and her family retained Edelman, a top PR firm that has represented companies like Microsoft and Starbucks, to help in managing media requests, and that she regularly gives speeches and interviews, and meets with world leaders, have all contributed to what some media experts call "The Malala Machine."19

Therefore, it would be a misreading of Yousafzai's advocacy to say that it has been completely subjected to the misappropriation and misuse of the U.S. military industrial complex and the global media infrastructure to which it is tied. It is important to acknowledge her incredible agency when explaining her advocacy, postshooting. She has made the decision to accept media requests, and has figured out a way to remain connected to Pakistan and expand her message globally while still living in the United Kingdom. Nevertheless, in addition to the dangers of the hypermilitarization stance that Yousafzai's shooting has been mobilized toward, it is also important to see how she has been treated as more of a persona and less as a person. In other words, her activism has been mobilized to further the trope of the Muslim woman victim rather than as part of a longer life history of enacting social change.

Malalai Joya: A Critical Voice in the War on Terror and

Afghanistan's Puppet Regimes

Tracing the trajectory of how Joya's activism was perceived by Western political and social institutions reveals stark similarities but also important differences with her counterpart. Comparatively, Joya's messages remained underrecognized by Western media outlets, but when they were, they were seen as threatening and overly political. Joya was born in 1978 in Farah Province, near the border of Iran, where, as a child, she and her family became refugees during the Soviet-Afghan War. Joya gained international recognition after making an impassioned and daring three-minute speech ${ }^{20}$ 
denouncing the crimes of Afghan warlords during a 2003 Loya Jirga (or public assembly) to ratify Afghanistan's new post-9/I i constitution. As a 24-year-old elected female delegate, she committed a politically and socially subversive act by denouncing mujahedin leaders for killing thousands of civilians during the Civil War following the Soviet exit in 1989. The video captured on cellphone cameras and professional cameras by journalists was broadcast on almost all Afghan television and radio stations and went viral on social media platforms in countries with high Internet use. In the video, we can see and hear the warlords become increasingly outraged as they forcibly remove Joya. The chief of the Loya Jirga, Sibhatullah Mojaddedi, a U.S. and Saudi government funded Islamist leader, also makes a vitriolic rant against her in which he calls her an "infidel and a communist." ${ }^{21}$ Shortly after this speech, he also made a statement that women are not suited for public office.

Joya's speech resulted in national and regional recognition, garnering her both praise among Afghan women's activists and disdain from male warlords and government officials who sought to uphold the status quo. In 2005, she was elected as an official member of Afghanistan Parliament, representing Farah Province. In 2007, the same warlord MPs voted to suspend her after she continued to question their legitimacy to serve in public office and demanded they be tried for their war crimes. Following this speech, Joya also gained global recognition, as she became the subject of multiple media requests and documentaries. In 2009 she published her book, A Woman among Warlords: The Extraordinary Story of an Afghan Who Dared to Raise Her Voice.

The political force of her work also appears in how she explains what true self-determination would mean for Afghanistan, which did not always sit well with mainstream media outlets. In one interview with $\mathrm{CNN}$ in 2009, Joya responds to an interviewer's question as to why she was expelled from Parliament by highlighting that she simply told the truth about the US-backed regime which is just a "carbon copy" of the Taliban, but under the guise of "democracy," and that the government was being run by warlords who were no better. The interviewer, Heidi Collins, eventually took issue with Joya's calling the U.S. presence in Afghanistan an "occupation," and continued to press Joya on how effectively Afghan security forces have defended the people, implying that the U.S. presence was necessary for Afghanistan's security. Joya responded by saying that even in Kabul, where 
there is an abundance of foreign troops, safety has not been realized. I want to suggest that there is a ceiling to how much recognition Joya's activism received internationally - that while the United States and Western media have lauded her efforts to speak against Afghan politicians and the legislature, at a certain point her critique crossed a threshold, which resulted in very material consequences. In 2007, Joya publicly blamed the United States for civilian deaths in Afghanistan and for allying with corrupt regimes in Afghanistan that have actively sought to silence Afghan women.

The consequences of her public statements were drastic. In 20 I I, Joya was sponsored by two New York City-based organizations, the War Resistors League and the South Asia Solidarity Initiative, to promote the launch of her U.S. book tour, but she was denied visas multiple times. On the eve of what was supposed to be a three-week speaking tour, Joya was denied a visa to enter the United States. The U.S. embassy officer noted the following reasons: "She is 'unemployed' and lives 'underground," failing to recognize that her living underground is a result of her having to hide from possible assassination attempts by the various religio-tribal forces from the Taliban to U.S.-backed warlords to various Islamic extremist sects.

The proliferation of social media, political blogs, and other digital platforms over the past io years has not necessarily translated into greater exposure for people like Joya, at least in the Euro-American context. Here, the stark differences between Joya and Yousafzai are explicit-while one could not even get a visa to enter the United States for a temporary stay, the other has been given permanent protection by the United Kingdom and the opportunity to study at Oxford University, as well as investment of multiple forms of economic and social capital to get her message across. Meanwhile, Joya's lack of interest in promoting girls' education within a corrupt political system in the name of women's liberation has led to her fading from the Western media spotlight.

\section{Malalai Kakar: An Unrecognized Advocate for Afghan Women's Rights}

Malalai Kakar was a lieutenant colonel and head of the Crimes Against Women Unit in the police department of Kandahar, a conservative southern province in Afghanistan, which, like the North-West Frontier Province in Pakistan, is a Taliban stronghold. She came from a family of police of- 
ficers and investigators. She took a stance against traditional patriarchal and misogynist practices such as child marriages and domestic abuse in a region known as a hotbed of religious and tribal extremism. As a result, major national media institutions and women's rights organization picked up on her work, and she became an iconic and respected figure throughout the Af-Pak region for her bravery. Globally, she achieved a limited amount of exposure only after the Taliban assassinated her outside of her home in September 2008. Prior to Kakar's death, there were only a few Western and international reports about her work, hence she had not crossed over globally in the way Yousafzai or even Joya have. After her death, there were more international stories and reports commemorating her short life's work including two short documentaries, but they did not circulate in established mainstream venues as did Yousafzai or Joya's films and books. She did not travel much outside of Kandahar, which is a difficult area for international and even local journalists to travel to. The few video stories and news stories have circulated solely in online venues with limited "clicks" and "hits."

Yet Kakar's image, one in which she is seen wearing a blue burqa and pointing a gun, was used by the far right U.K. group Britain First for one of their many Islamophobic, anti-immigrant, and prowar campaigns and gained much traction online. The image is overlaid with a warning in red, "Terror attack: Severe. An attack is highly likely." A right-wing Australian senator subsequently used the altered Britain First image for a "ban the burka" campaign. The poster equates Islam with terrorism.

According to Laura Slezic, the photographer, she took the picture as Kakar was preparing to rescue a teenager who had been kidnapped. She readied her pistol and threw on her burqa over her national police uniform. Slezic, who was moved by Kakar's strength and compassion, was horrified by the appropriation of her image: "To see an image of her and all she represents used this way is such an insult to her and her family and all the women in Afghanistan. I don't even have the words to describe it." Yet, despite copyright laws, she has little recourse as the poster has been shared over 50,000 times on Facebook. As Haras Rafiq, outreach officer at the Quilliam Foundation, a counterextremism think tank, has stated, "Social media is playing a key role in radicalizing both Islamists and the far right. In order to attract more followers and get more "hits," "clicks," and "likes," these groups will appeal to the basest human desires inciting misplaced fear, violence, and revenge. ${ }^{22}$ 


\section{Malalai of Maiwand: A Figure within the Rubble of Erased Women's Histories}

The final Malalai also known as "Mother Malalai" or "Malalai of Maiwand" is a folkloric ethno-national hero among Afghans and Pakistanis. Malalai played a pivotal role in the second Anglo-Afghan War in $\mathrm{I} 88 \mathrm{o}$ in the Battle of Maiwand, in Kandahar Province, which was under the control of then British India. Although there are various accounts of her exact role in the battle, the general consensus in oral stories and Afghan history books is that she rallied a demoralized Afghan army on the verge of retreat and near surrender to retain their honor as enshrined in the codes of the Pashtunwali (or Pashtun ethical code) and continue to fight. She raised the Afghan flag and proclaimed that dying under the fire of the British artillery was an honor. She was killed in battle by the British army, but the Afghan army emerged victorious in that battle. In some versions, her role in the battle is more active as she participates in directly fighting the British army. My primary school in Kabul, where my mother was a teacher, was also named Malalai after this venerated figure. Her name has been enshrined within many institutions like schools and hospitals in Afghanistan as well as in folklore and poetry. In fact, Malala Yousafzai has stated that she is named after this historical heroine, and cites her struggle against the British in her biography I Am Malala. Her grave has become a shrine where people visit from near and far to pray. Not surprisingly, she does not appear anywhere in the fastidious archives of the British. While Malalai of Maiwand is a historical figure, her story reminds us of the fact that the erasure of strong, politically active Afghan women who attempted to resist the status quo is not unique to U.S. imperial discourses. This erasure was a key tool that British colonial forces used in order to make the case that Afghanistan was a backward country whose women were oppressed and, more significantly, did not have the tools to liberate themselves.

\section{Conclusion}

The case of the four Malalais is one window into understanding the politics of recognition that operate in the media's consumption of Afghan and Pakistani women's activism, in an age of war, militarization, and development. It is clear that each Malala(i) comes from a set of different conditions of possibility, economic, social, and political, and these all contribute toward 
producing different outcomes in the ways their activism get recognized and circulated locally and transnationally. However, they all share the quality of having been co-opted by U.S. government discourse and officials as well as American media as embodying the oppressed Muslim woman who is victimized by her native culture, and made more rescuable by outside powers and occupying forces.

Gender has always been a contentious issue in Afghanistan and Pakistan. As this chapter has illustrated, there is an equally long history of internal cultural contestations between progressive reformers and conservative elites. It is often through gendered contestations that attempts at setting and defining national/cultural/ social identity, often in the singular, occur. Yet during the "War on Terror" era it has become challenging for human rights activists from South Asia to challenge religious extremism, specifically the rise of Islamism in Afghanistan and Pakistan. As the case study of the four Malalais shows, activists from the region are often co-opted as spokespeople to support Islamophobic and xenophobic agendas that spur hypermilitarization and hate mongering against their own fellow South Asian immigrants in the West and innocent civilians in the east.

Thus the goal of this chapter is not to hide issues of gender and sexuality that people in Afghanistan and Pakistan grapple with. It is important for the local and international activist and development aid community to continue to support gender-based projects and fight discriminatory practices and violence against women and other marginalized groups in the region. Despite the accelerating drumbeat of war to free and liberate Afghan, Pakistani, and Muslim women, since the start of the longest running U.S. war, there has been little media coverage of these issues, which have persisted. Indeed, it was only during the precursor and lead-up to the "War on Terror" that the Western media floodgates opened, evident in the proliferation of fiction films, television programs, documentaries, books, and news that focus on women's plight under purportedly repressive Islamic regimes.

To be sure, digital media have played a central role in the circulation of the dire situation and plight of Afghan and Pakistani women. Malala Yousafzai would have never become the icon she is without her blog. Malalai Joya's historic speech went viral after it was captured on cellphones. The death of Farkhunda Malikzada, an Afghan woman publicly beaten and killed by a mob in Kabul in 2015, also went viral because of bystanders and perpetrators recording events on their mobile phones, thus 
launching a movement to curb fanatical and misogynistic mullahs and religious leaders. The members of RAWA (Revolutionary Association of the Women of Afghanistan) and T2 T (The Second Floor) have directly credited social media as the platform that helped them reach wider allies locally and internationally.

Yet we also have to interrogate the celebratory claims that digital media has created a global village that evens out power imbalances and gives a platform to the marginalized and disenfranchised. At the same time that digital media have been foundational to the rise of these human rights movements, they are far from the empowering panacea that allows for independence and self-presentation. Digital media are as entangled in the infrastructures of empire as traditional media networks.

To begin with, we must take into account lack of Internet penetration and the fact that the vast majority of Afghans and Pakistanis do not have the literacy or financial means to access the limited digital media infrastructure. In Afghanistan, Internet penetration and infrastructure is at a mere 5 percent. ${ }^{23}$ It is also important to highlight the dominance of the English language on the Internet. More than 50 percent of websites in the world are in English. This also causes problems in self-representation and crossover of information to the broader global public sphere. While more Pakistanis than Afghans speak English, the vast majority of both countries' people do not speak English. Moreover, during the early years of the Taliban regime, even for those transnational feminist organizations who genuinely sought to help, their overreliance on digital media as a portal to understanding the on the ground situation of Afghan women often precluded their endeavors. Lacking cultural access, Western feminist organizations directed their attention to and gathered their information from the same few websites of Afghan women's organizations that were available in English. Digital media indeed served as a cross-cultural bridge, yet it was a very narrow bridge with limited access to a wider cross-section of Afghan society.

Finally, it is worth noting that established media institutions and circuits remain just as crucial, if not more so, than social media. Joya is redeemed by the success of the international journalist reports, films with high crossover in the international film festival and broadcast markets, and subsequent books. Traditional networks of activism and methods of promotion, such as film festivals and book tours, are still very effective in building a base, solidarity, and recognition nationally, regionally, and across cultures. 


\section{Notes}

I. Kamila Shamsie, "Interview: Malala Yousafzai: 'It's Hard to Kill. Maybe That's Why His Hand Was Shaking," Guardian, October 7, 2013. https://www. theguardian.com

2. "The Making of Malala," NY Times Documentaries, October 8, 20I3, https:// www.nytimes.com/2013/10/08/world/asia/the-making-of-Malala.html

3. Mirren Gidda, "Malala Yousafzai's New Mission: Can She Still Inspire as an Adult?," Newsweek, January I I, 20I 7. http://www.newsweek.com/2017/01/20/ exclusive-malala-yousafzai-interview-davos-540978.html

4. Ibid.

5. Will Kerry, "Malala Is a Millionaire Who Has Donated More Than \$IMillion," Huffington Post, October 26, 20 I6. https://www.huffingtonpost.com

6. Shamsie, "Malala Yousafzai: 'It's Hard to Kill."

7. "Malala Inc: Global Operations Surrounds Teenage Campaigner," AFP, October I I, 20I3. https://www.dawn.com

8. Greg Bruno, "US Drone Activities in Pakistan," Council on Foreign Relations, July i 9, 20IO. https://www.cfr.org

9. Micah Zenko, "America's 50oth Drone Strike," Council on Foreign Relations, November 2 I, 20I4. https://www.cfr.org

ı. Glenn Greenwald, "Joe Klein's Sociopathic Defense of Drone Killings of Children," Guardian, October 23, 20I 2. https://www.theguardian.com

I I. Zack Beauchamp, "Don't Forget Malala Yousafzai's Appeal to Obama: End the Drone War," VOX, October ı, 20I4. https://www.vox.com

I 2. Tonya Somanader, "President Obama Congratulates Malala Yousafzai and Kailash Satyarthi on Winning the 2014 Nobel Peace Prize," White House Archives, October Iо, 20I4. https://obamawhitehouse.archives.gov

I3. Ibid.

I4. "Malala Yousafzai Donates Prize Money to Rebuild Gaza School," Associated Press, October 3 I, 20I4. https://www.nytimes.com/2014/10/31/world/middleeast/ malala-yousafzai-nobel-gaza-school.html

I 5. "Malala Speaks to the UN in Defiance of Taliban, Calls for Universal Education," TOLO News, July I4, 20I3. https://www.tolonews.com

I6. Jack Moore, "Malala Condemns Donald Trump's Muslim Ban Proposal in U.S," Newsweek, December I6, 201 5. http://www.newsweek.com

I 7. "About Us." The Malala Fund. https://www.malala.org

I8. Ghumman, Khawar. "\$7 million from Malala Fund for Education Project in Remote Areas," Dawn, April I 2, 20 I4. https://www.dawn.com

I9. "Malala Inc: Global Operations Surrounds Teenage Campaigner," AFP, October I I, 20I3. https://www.dawn.com

20. Defense Committee for Malalai Joya, "The Brave and Historical Speech of Malalai Joya in the LJ," July 2, 2007. https://www.youtube.com

2 I. Carol Riphenburg, "Women's Prospects in Afghanistan: Oppression or Opportunity?," Middle East Institute, April I 2, 20 I 2. http://www.mei.edu

22. https://www.theguardian.com

23. See InternetWorldStats, Usage and Population Stats at http://www.inter networldstats.com/stats.htm 


\section{References}

Ahmed, Leila. 20 I I. A Quiet Revolution: The Veil's Resurgence, from the Middle East to America. New Haven: Yale University Press.

Asad, Talal. I986. "The Idea of an Anthropology of Islam." Qui Parle I 7 (2): I-30.

Asad, Talal. 2003. Formations of the Secular: Christianity, Islam, Modernity. Stanford: Stanford University Press.

Chadha, Kalyani, and Anandam Kavoori. 20 I 5. "The New Normal: From Media Imperialism to Market Liberalization: Asia's Shifting Television Landscapes.” Media, Culture, and Society 37: 479-92.

Chatterjee, Partha. I997. "Our Modernity." Lecture organized by the South-South Exchange Programme for Research on the History of Development and the Council for the Development of Social Science Research in Africa, Rotterdam/ Dakar.

Chrisman, Robert. 2013. "The Role of Mass Media in U.S. Imperialism." Black Scholar 43 (3): 56-60.

Cloud, Dana L. 2006. "To Veil the Threat of Terror': Afghan Women and the (Clash of Civilizations) in the Imagery of the US War on Terrorism." Quarterly Journal of Speech 90 (3): 285-306.

Fabian, Johannes. I 986. Time and the Other: How Anthropology Makes Its Object. New York: Columbia University Press.

Fluri, Jennifer. 20 I 2. "Capitalizing on Bare Life: Sovereignty, Exception, and Gender Politics." Antipode 44 (I): 3 I-50.

Göle, Nilüfer. 2006. "Europe's Encounter with Islam: What Future?” Constellations I $3(2): 248-62$.

Grewal, Inderpal. 2017. "Drone Imaginaries: The Technopolitics of Visuality in Postcolony and Empire." In Life in the Age of Drone Warfare, edited by Lisa Parks and Caren Kaplan, 343-66. Durham, NC: Duke University Press.

Khalili, Laien. 20 I 2. "Fighting over Drones." Middle East Report 264 (Fall): I 8-2 I.

Mahmood, Saba. 2005. Politics of Piety: The Islamic Revival and the Feminist Subject. Princeton: Princeton University Press.

Mahmood, Saba, and Charles Hirschkind. 2002. "Feminism, the Taliban, and the Politics of Counterinsurgency." Anthropological Quarterly 75 (2): 339-54.

Minh-ha, Trinh T. I991. When the Moon Waxes Red: Representation, Gender and Cultural Politics. New York: Routledge.

Mitchell, Timothy. 2002. "McJihad: Islam in the US Global Order." Social Text 20 (4): I-I 8.

Packer, Jeremy, and Joshua Reeves. 20 I 7. "Drones, Media/Weapons, and the Coming Humanectomy." In Life in the Age of Drone Warfare, edited by Lisa Parks and Caren Kaplan, 26I-8I. Durham, NC: Duke University Press.

Parks, Lisa, and Caren Kaplan. 201 7. "Introduction." In Life in the Age of Drone Warfare, edited by Lisa Parks and Caren Kaplan, I-22. Durham, NC: Duke University Press.

Rashid, Ahmed. 2000. Taliban: Militant Islam, Oil, and Fundamentalism in Central Asia. New Haven: Yale University Press.

Roy, Arundhati. 2004. An Ordinary Person's Guide to Empire. Boston: South End Press. 
Shohat, Ella, and Robert Stam. 2013. Unthinking Eurocentrism: Multiculturalism and the Media. New York: Routledge.

Solomon, Keith. 2007. "The Spectacle of War and the Specter of 'The Horror.'” Fournal of Popular Film \& Television 35 (I): 22-3 I.

Spivak, Gayatri Chakravorky. I988. "Can the Subaltern Speak?" In Colonial Discourse and Postcolonial Theory: A Reader, edited by Patrick Williams and Laura Chrisman, 66-I I I. New York: Columbia University Press.

Tahir, Madiha. 20 I 7. “The Containment Zone.” In Life in the Age of Drone Warfare, edited by Lisa Parks and Caren Kaplan, 220-40. Durham, NC: Duke University Press. 


\section{Contributors}

Daniel Arnaudo is Cybersecurity Fellow at the University of Washington's Jackson School of International Studies, where he has worked on projects in Brazil, Myanmar, and the United States. Concurrently, he is a Senior Program Manager in the governance department of the National Democratic Institute (NDI) in Washington, DC, and a Research Fellow with the Igarapé Institute of Rio de Janeiro.

Payal Arora is an Associate Professor at Erasmus University Rotterdam and Founder of Catalyst Lab, a center that reignites relations between academia and the public through social media campaigns. Her expertise lies in data economies, activism, and digital cultures in the global South.

Hannah Carlan is a $\mathrm{PhD}$ candidate specializing in linguistic and sociocultural anthropology at UCLA. Her doctoral dissertation analyzes how the politics of language and multilingualism impact the everyday practices of rural development workers in Himachal Pradesh, India.

Vishnupriya Das is a PhD candidate and Barbour Scholar at the University of Michigan, Ann Arbor. Her research explores how young people experience intimacy across geographic distance through communication technologies such as mobile phones, social media, and wearables.

Mobina Hashmi is Assistant Professor of Television and Radio and affiliate faculty with the Women's and Gender Studies Program at Brooklyn College, where she teaches undergraduate and master's courses in media criticism, gender and sexuality in the media, and new media. 
Sangeet Kumar is Associate Professor in the Department of Communication at Denison University, Ohio. His current research is focused on exploring the interplay of power and agency in relation to global digital platforms.

Shanti Kumar is an Associate Professor in the Department of RadioTelevision-Film at the University of Texas-Austin. He is the author of Gandhi Meets Primetime: Globalization and Nationalism in Indian Television (2006).

Purnima Mankekar is a Professor of Gender Studies, Asian American Studies, and Film, Television, and Digital Media at the University of California, Los Angeles. She is the initiator and convener of an international and interdisciplinary consortium of scholars working on a collective project, Publics on Edge, that seeks to examine how transnational regimes of affect shape politics in Asia, Australia, and Europe.

Sriram Mohan is a $\mathrm{PhD}$ candidate in the Department of Communication Studies at the University of Michigan, Ann Arbor. His research examines the cultural politics of digital media and technology use in South Asian contexts.

Rahul Mukherjee is the Dick Wolf Assistant Professor of Television and New Media Studies in the Cinema Studies Program at the University of Pennsylvania. His areas of interest include critical infrastructure studies, digital media technologies, and environmental humanities.

Wazhmah Osman is an assistant professor in Temple University's Department of Media Studies and Production. Her work analyses the impact of international funding and cross-border media flows on the national politics of Afghanistan, the region, and beyond.

Joyojeet Pal is an Associate Professor at the School of Information at the University of Michigan, Ann Arbor, and a Senior Researcher at Microsoft Research India. He works on the intersection of technology and global development, and has been researching the role of social media use by mainstream politicians in India. 
Aswin Punathambekar is an Associate Professor and Founding Director of the Global Media Studies Initiative in the Department of Communication Studies at the University of Michigan, Ann Arbor. He is the author of From Bombay to Bollywood: The Making of a Global Media Industry (2013).

Kentaro Toyama is W. K. Kellogg Professor of Community Information at the University of Michigan School of Information, a fellow of the Dalai Lama Center for Ethics and Transformative Values at MIT, and author of Geek Heresy: Rescuing Social Change from the Cult of Technology (2015).

Sahana Udupa is professor of media anthropology at the Ludwig Maximilian University, Munich, and senior research partner at the Max Planck Institute for the Study of Religious and Ethnic Diversity, Germany. She researches and teaches journalism cultures, digital media, and urban politics.

Shruti Vaidya is a $\mathrm{PhD}$ student in the Department of Comparative Human Development at the University of Chicago. Her current research is an ethnographic project that focuses on the intersection of disability and queer movements in the Indian context. Her research interests include disability studies, queer studies, and medical anthropology.

Muhammad Nabil Zuberi is a PhD candidate in the Department of Anthropology at the Graduate Center of the City University of New York. His areas of interest include ethno-psychology, media technologies, and social movements. His doctoral research analyzes the roles that people's ideas and beliefs about the media play in the circulation and interpretation of "manipulated" images and "fake" news in times of crisis and violence. 


\section{Index}

Note: Page numbers in italics refer to the illustrations and tables.

Aadhaar, 65, 67-68, 69

ABVP (Akhil Bhartiya Vidyarthi Parishad), 2 I 8 n i I

Academic freedom, 2 I 6

Accountability, 2 I

Activism, I 8, 26, Iо0-Iо I, 247, 280-8 I

See also specific activists

Advertising, 79-83, 81, 90, I 30, 228

Affect, nationalist, 2 I 5

Afghanistan, 288-89, 292

Af-Pak Women's Rights Movement, 26, $280-89$

Afzal Guru, Mohammed, 203, 208, 2 Iо, 2II, 2 I 5

Agency, 40

AIB. See All India Bakchod

Airtel, 80, 8I, 83, 87, 90

Akhil Bhartiya Vidyarthi Parishad. See ABVP

Algocracy, 225

Algorithms, I I , 39-42, I 88, 225

Alienation, deafness and, I48-49

Allah, 267, 274, 275, 277n2

All India Bakchod (AIB), 90

All India Radio, $5^{8}$

Anderson, Benedict, 24I

Anglo-Afghan War, 29I
Anonymity, 48-49

Anonymous, I I I

Anticorruption, 224

Antinationalism, 209-IO, 2 I 2 , 2 I 8n I I

Apps, 91, Iо8, I 29-30, I38n27

See also Dating apps

Arab Spring, I65

Armstrong, Neil, 266

Ashok, Samrat, 236

Authentication, 67

Avatars, I6

Axe audio player, 85

Axosoft, I 59

Bandwidth, in India, 60-6I

Bangladesh, 25, 26I-63

Bangladesh Liberation War, 26I

Banking, digital, 67

Barthes, Roland, 27 I

Basherkella, 265, 277n6

Basu, Jyoti, 76

Behind-the-ear (BTE), I 50

Bharat Broadband Network Limited, 55

Bharatiya Janata Party (BJP), I66-67

BharatNet, 55

Bhattacharya, Dipen, 272-73 
Bid'ah (innovation), 272, 278n7

Big Data, $3^{8-42}$

Bin Laden, Osama, 2 I I

Biological racism, 223-24

Biometric authentication, 68

Biometric identity, 38, 42-44, 55, 65, 69

Biometric Identity Project, 38, 42 See also Aadhaar

Biometric surveillance, 42

BJP. See Bharatiya Janata Party

Blink Hacker Group, I I I

Blogs, 7

Bluetooth, 84, 86

Bollywood, 23, 77, 79-80, 90, I 32

Bots, of political, 4I

Branding, I64, I69, I 7 I-73, I 78, I $79 \mathrm{n} 2,228$

Britain First, 290

British Empire, 96

Brown, Gordon, 285

BTE. See Behind-the-ear

Buck-Morss, Susan, 277n4

Burma, 96

activism in, IOO-IOI

birth and unresolved ethnic conflicts in, $97-98$

censorship in, I IO, I I 2 , I I 3

censorship laws of, I03

coding in language of, IO2-4

cyber cafés in, IOI

democratic and virtual space in, IO5

dictatorship and media in, 98-100

digital literacy of, Io9

8888 Revolution in, Iо०

freedom of information in, 105

GDP of, I07

gender in, I I 2

government in, 99-100, 103

human rights in, I I I

ICTs in, IO3-4

Internet in, IOO-IO2, I I 3

language in, $\mathrm{IO}^{-4} 4$

literacy in, Io6

media in, I I 3

media independence in, 105

Media Law in, I05-6 migration in, IO4

minorities in, I IO

national identity of, 97

newspapers in, 98-99

political parties in, 98, го9-го

political prisoners of, IO5

press in, 98-99

privacy in, I09

radio in, $\mathrm{IO} 2$

socialism of, 98

surveillance in, IO I, I I 2 , I I 3

television in, 99, го , , Iо6

Twitter in, I I I

See also Myanmar

BurmaNet, Ioo

Butt, Maqbool, 208, 2 I 5

Bytes For All, 247

Cable Television Networks (Regulation) Amendment Act, 53

Cablewallabs, 56-57

Caldwell, John, ıo

Capitalism, 8, I 5

Caste, I6, 22, 42, 69, I 40n42

biometric identity and, 43-44

classification of, 48

customs and, I 56

gender and, 43

hierarchies, I 56

marriage and, I 57

politics and, 43

socioeconomic status and, ${ }_{5} 6$

Celebrity, activism and, 284-87

Cell antenna cluster, 89

Cellphones

advertising, 81,82

bandwidth, $77-78$

Bollywood, 79-80, 90

culture and, 77

dating apps and, I 37, I37ng

electromagnetic field and, 88, 94n 36

environment and, 78

equality and, $82-83$

friendship and, 78,83

gender and, 80 , I 70

India, I 29, I $57-58$ 
inequality and, 83

infrastructures, 77, 84, 87-90

intimacy and, $8 \circ, 82$

life changing impact of, 83

lifestyle and, 9I

Myanmar, Io6-7

perception of, 82

prepaid, 37

radiation, $88,94 n_{3} 6$

recharge shops, 86

regulations, 88

revolution in India, 76

sexuality and, I 29

smartphones, 3

subaltern-popular and, 83-87

towers, $76,79,87-88,90$

usage patterns, I 58

users, 23

Censorship, 23, 84

Burma, I IO, I I 2, I I 3

digital, 45

drone warfare and, $284-87$

Internet and, 96

laws in Burma, I03

self-censorship, Io6

by state, I 7

Chandrasekhar, Rajeev, 69

Chatrooms, I 27

China, r96, 236

Cinema, I 70

Citizen journalism, I 85

Citizenship, I4, 2 I

acts of, 246, 249, 253, 255

big data and, 38

dynamics of, 248

media and, 86

politics and, 239

sacrificial, 237

UID and, 38

Civic engagement, 2 I

Civility, norms of, 250-53

Civil society groups, I9

Class

Pakistan, 249

Class Dismissed: The Story of Malala, 284

Coding, 4I, IO2-4, IO8-9, I 32
Cold War, 2 7ng

Colonial feminism, 282-83

Colonialism, 38, 42-44, 45

Committee for the Restoration of Democracy in Burma, Ioo

Commodification, of social interactions, I 8

Communal dynamics, 22

Communal politics, 42-44

Communication

infrastructures, $5, \mathrm{I}_{3}$

Internet, 89

long-distance, 6

platforms, I 9

politics and, 22, 44, 47

public sphere and, 2 I $7 \mathrm{n} 2$

social media and, I63, 24I

Compliance, 204

Computers, 2 7n9, I69-70

Computer Science and Development Law, Iо I, Iо3, Iо6, I Iо

Connectivity, 4, 54-55

Conquest, gender and, 282

Consent, 253-54

Consumer products, imitation, 84

Consumption, digital media, I42

Conversation, I 35

Corporate branding, on Twitter, 228

Corpothetics, 264, 265

Corruption, 42, 87, I69, 238-4I

Counterextremism, 290

“Creep Qawwali," I 2 5, I 32, I 34

Cricket World Cup, I90-95

Cuba, 93 n29

Cultural belonging, 9

Cultural dynamics, global, io

Cultural fundamentalism, 223-24

Cultural production, 3

Culture

cellphones and, 77

curation of, I I

definition of, 4

globalization and, I I

homogenization of, I I

media and, I 6

Twitter and, 24I 
Customs, caste and, I 56

Cyber cafés, 76, 86, ı I

Cyberpublics, I 8

\section{Darshan, 263-64, 270}

DAS. See Digital Addressable System

Data connectivity, 88

Data consumption, I 2

Data democracy, 66

Datafication, I8, 37, 42, 47, 48

Data mining, I I

Data speeds, I 6

Dating apps, I6, 23-24, I25-26, I 37 n I

cellphones and, I37, I37ng

education through, I35

history of, I $27-3$ I

India, I 26 , I 27

intimacy and, $135^{-36,} \mathrm{I} 38 \mathrm{n} .27$

location and, I 28 , I 37 nio

marriage and, I 27

morals of, 129

queer community and, I 37nio

social networking and, I 27

Deaf community, I 45-47, I 59-60

Deafness

alienation and, I48-49

as disability, I 43

family and, $148-50$

friendship and, I 50

guilt and, I 53

hearing aids and, I 53

Indian context of, I 56-57

marriage and, 157

normal and, I $47-48$

school and, $148-50$

society and, I 48

stigma about, I43

terminology for interfacing with, I 45

Deaf young adults, 24, I42-43. See also

Hearing aids

Death penalty, 2 I $8 \mathrm{nI}$ I

Deepak, Vishwa, 2 I 3

Delhi Gang Rape, I32, I39n37

Democracy, 2 I 5-I6, 249
Democratic Voice of Burma, I I I

Democratization, of online spaces, 206

Department of Telecommunication Services, I 28

Desire, I 35

Dictatorship in Burma, 98-roo

Digital Addressable System (DAS), 22 , $53-60,70$

Digital culture, 2, I I, I 84

Digital divide, 6, 96

Digital dividends, 6o-63

Digital hearing aids. See Hearing aids

Digital India, 54, 55, 58, 63-70, 78, 9I, I 44-45

Digital India Foundation, 68

Digital inequality, 27n6

Digital infrastructure, 3, 5

Digital intermediaries, I 5, I 7

Digital literacy

Burma, Io9

Digital media, 7

consumption, $\mathrm{I}_{42}$

feminism and, 2 I 6

infrastructures, 293

media and, ro

media convergence and, I 8

Myanmar, Io9

nationalism and, 2 I $7 \mathrm{n} \mathrm{I}$

political culture and, 26

politics and, I9

production, I 42

publics in Pakistan, 248-50

scholarship, 2 I 6

technology, 3

television and, 203

use, 2O-2 I

Digital monitoring, of refugees, 40

Digital music, mapping of, 84, 86

Digital speech, 2 I $7 \mathrm{n}_{5}$

Digital studies, 4, 7-8, 23

Digital terrestrial television (DTT), $5^{8}$

Digitization, 48, I 84

Direct to home (DTH), 57-58, 67

Disability, I43-44

Discrimination, $4 \mathrm{I}-42$, I 58

Dish TV, 67-68, 70 
Dissent, democracy and, 2 I 5-16

Diversity, 40, I60

Divine intervention, 273, 274, 275

Domestic abuse, 290

Doordarshan, 58

Dostagir, Golam, 273

DPS MMS Scandal, I 29

Drones, 282, 284-87

DTH. See Direct to home

DTT. See Digital terrestrial television

Economy, 66, 67, 84, I40n4I, I 75-76

Education, of women, 285, 286-87, 289

Efficacy, 265-72

Egalitarianism, I69

E-KYC (Know Your Customer), 6567,68

Elections, 96, Ioo, I 79n2

Electromagnetic field, cellphones and, $88,94 n_{3} 6$

Electronic Transactions Act, $\mathrm{IO}_{3}$

Ellick, Adam, 284

English language, 293

Entrepreneur networks, I 29

Entrepreneurship, I 77

Equality, 282

Eroticism, I26, I28, I32, I38nI8, 253

Ethnocentrism, $27 n 8$

EU General Data Protection Regulation, 49

Europe, 223

Exceptionalism, in political culture, $47-48$

Exclusivism, 223

Facebook, 80, г 88, 253

addiction, 227

language and, 242n 5

minorities and, I Io

Modi, I63-64, I68

Myanmar, I09, I I I

nationalism and, 205

TrulyMadly and, I 34, I 36

Zero, , $о 8$

Fake grassroots support, 46-47

Fake news, 79, 266
Family, deafness and, I48-50

Farmers, computers for, I69-70

Feedback loops, interactivity, I 89-90

\#Feku, 233

Feminism, 25, 4I, 204, 2 I 6-I 7, 282-83, 293

Feminist bots, $4 \mathrm{I}$

File sharing technology, 86

Film, I6, 264

Fingerprinting, 38, 42, 65

Flashmobs, I Io

Four Malalais, 28I-92

Free Burma Coalition, I I

Freedom of expression, in Pakistan, I 7,2 I

Freedom of information, in Burma, I05

Friendship, 78, 83, I 50

Fundamentalism, 45, 206, 233

Gandhi, Rahul, 238

Gandhi, Sonia, 46

\#GappuInIndia, 233

Gay community, I 58-59

Gender, I6, 69, 204, 2 I0-I3, 28 I

Afghanistan, 292

Burma, I 2

caste and, 43

cellphones and, 80, I 70

conquest and, 282

divide, I 2

feminist bots, $4 \mathrm{I}$

Pakistan, 249

sexuality and, 24

subjectivity and, 8I

technology and, I 37

violence and, 208, 2 Io, 2 I 2,2 I 5,2 I 7

Generational divide, TrulyMadly and, I4On $4 \mathrm{I}$

Geography, social theory and, 8-9

Geography agnostic, I

Geopolitics, 28n23

Girls at Dhabas, 247, 249

Global, local and, I6

Global connectivity, 4

Globalization, 4, I I, I 29, 206-7, 223 
Global media studies, 4

Global mobility, 2

Glory, 234-35

Gmail, Io8-9

God, 270

Google, Io8

Goswami, Arnab, I90-95, I96-97

Governance, 22, 64, 225

Government

Burma, 99-I00, I03

corruption and, 87

Digital India and, 65

hatred toward, 2 I $7 \mathrm{n} 7$

Internet and, $37-38$

Myanmar, I09-IO, I I 3

social media and, 37

Grassroots social movements, 205-6

Grindr, I 27

GSM Association, 6o-6 I

Guilt, deafness and, I 53

Habermas, 20, 28, 2 I $7 \mathrm{n} 2$

Hacker News, I 2

Harassment, 247

Harmonization, 59-63

Digital India, 63-69

telecommunications policy, 69-70

Hashtags

corruption and, 238-4I

hyperlinking of, I95

of Modi, I 76-77, 224, 226, 228, 237

in news, 190

patriotism and, 236

trending, I90

of Twitter, 187-88, 190-97, 224, 226, 228

violence and, 2 I 4

wars, I 95-97

See also specific hashtags

Hate mongering, 292

Hate speech, 224, 247

Headphones, I 50

Hearing aids, 24, I42 appearance of, I 53

deafness and, I 53

design of, I $54-55$ discretion of, I 54

dissatisfaction with, $15 \mathrm{I}-5^{2}$

financial aspect of, I 5 I

identity and, I 54

initial perceptions of, $150-5 \mathrm{I}$

peri-technological intervention,

I $57-59$

personalized decoration, I 54-55, I55

physical pain from, ${ }^{2} 2$

pragmatic and aesthetic, I $5 \mathrm{I}-54$

relationship with, I 54

in school, I45-47, I 52-53

television and, I 5 I

types of, I 50

Hinduism, 235-36, 264

History of media, 97

Homogenization, of culture, I I

Homophobia, 205, 207, 2 I I

Honor killings, 2 I I

Hotel Supreme, 89

Human bodies, infrastructures and, ${ }_{23}, 88$

Human rights, 26, I I I , 28 I-82, 283 , 293

Hutnyk, John, 208

Hybridity, I 6

Hybrid media spaces, I $97-98$

Hyperlinks, hashtags as, I95

Hypernationalism, 242

I Am Malala (Yousafzai), 285, 29 I

ICTD. See Information and communication technologies for development

ICTs (Information and communication technologies), I03-4, I 72-74, I 75

Identity biometric, 38, 42-44, 55, 65, 69

hearing aids and, I 54

of India, national, 235

language and, 2 I 7 n 5

national, 25

Pakistan, 246, 249

racial, 4I

religious, 69

state-sponsored identity projects, 22 
Ikblaq (manners, morals), 250-53

Images

darshan, 270

as evidence, $265^{-72}$

fake, 266, 267, 269

fetishizing, 263

of God, 270

indexicality of, $265-72,277$

manipulation of, 26I-62, 266, 267, $267,269,270,273$

mistrust of, $277 \mathrm{n}_{5}$

nazar, 270

objectivity and, 263,272

photoshop, 267

reality and, $27 \mathrm{I}, 272$

Imperialism, I I , I 5, 282

Inclusion, 40

Income, I40n42, I63

Indexicality, 265-72, 277

India

bandwidth in, 6o-6I

cellphone revolution in, 76

cellphones in, I 29, I 57-58

cyber cafés in, 76, 86

dating apps in, I26, I 27

deafness in context of, $156-57$

development of, 78

Digital Addressable System in, $55-60$

digital revolution of, $\mathrm{I}-2$

disability in, I43-44

economy of, 66, I40n4I

elite of, 49

eroticism in, $\mathrm{I} 26, \mathrm{I}_{3} 2, \mathrm{I} 38 \mathrm{n} \mathrm{I} 8$

independence, 96

inequality in, 178

Internet in, 55, 225

liberation of, 236

mobile network infrastructure in, 6o-62

money in, 66

national identity of, 235

national pride in, 237

platforms of, 66-67

political parties in, 238

sexuality in, I 29
SNS in, 196

television in, 53, 55-60, I 84

Twitter in, I95-97, 226-28

women, 132

Indian Department of Telecommunications, $88,93^{n} 6$

Indian Idol, I9-20

Indian Sign Language, 146

IndiaStack, 64-70, 66, 70

Indus Towers, 76

Inequality, $27 \mathrm{n} 6,37,83, \mathrm{I} 78,206$, 217

Information and communication technologies. See ICTs

Information and communication technologies for development (ICTD), 6, 9, 27n5, I44-45, I 57, I69-70

Information flow, 20

Information justice, 44

Infrastructures, I 2-I 4

cellphones, 77, 84, 87-90

colonialism and, 42-44

communication, 5 , I3

definition of, 13

digital, 3, 5

Digital Addressable System, 55

digital media, 293

human bodies and, 23, 88

IndiaStack, 68

Internet, 89, 28 I

Internet as, I $3-\mathrm{I} 4$

media, I 3, I 4, 22

politics and, I4

scholarship on, I 3

surveillance, IO I

telecommunications, 6o-6I

values and, 4I

Innocence of the Muslims, 247

Interactivity, I 84-90

Interference, signal transmissions and, 62

Intermedia framework, 8-I I

International Telecommunications

Union (ITU), 53, 59-60, 62, 63,

69-70, Iо I 
Internet, 3, 4-5

bandwidth, 89

Burma, IOO-IO2, I I 3

censorship and, 96

communication, 89

cost of, $27 \mathrm{nI} 3$

culture, 23

demographics of, $27 \mathrm{n} 2$

government and, $37-38$

India, 55, 225

infrastructures, 89, 28 I

as infrastructures, I $3-\mathrm{I} 4$

language and, 207, 293

media and, Io

memes, 226

Myanmar, 97, 107

regionalized traffic flow of, 27 nio

studies, 7

as technology, $27 \mathrm{n}_{5}$

uses, $27 \mathrm{nI} 3$

violence and, 207-I 5

YOY, $28 \mathrm{ni} 4$

Internet Protocol television (IPTV), $57-58$

Interocular visuality, 263-64, 272, 276

Interpreters, 146

Intimacy, 80, 82, I 35-36, I38n .2 7

IPTV. See Internet Protocol television

Iris scans, 69

Islam, Aminul, 266-67

Islam, terrorism and, 290

Islamophobia, 292

ISpirt, 64-65, 68

ITU. See International Telecommunications Union

Jamaat-e-Islami, 26I-62, 265, 268

Jan Dhan Yojana, 67

Journalism, 46

citizen, 185

Joya, Malalai, 283, 287-89

July Boys, I, 2

July Systems, I

Justice, 282

Kakar, Malalai, 283, 289-90
Karāmāh, 2 72-77

Karma, I43

Khan, Imran, I 77

\#KholoBC, I 7

Know Your Customer. See e-KYC

Kumar, Kanhaiya, 203-5, 209-I 5, 2 I 8 n I I

Language, 28n23, 48

abusive, 207, 2 IO

Burma, IO2-4

Facebook and, 242n 5

identity and, $2 \mathrm{I} 7 \mathrm{n} 5$

Internet and, 207, 293

of Modi, r 68

Myanmar, IO2

politics and, 44

sign, I46

standardization of, 24I

television and, $25 \mathrm{I}$

Lava Mobiles, 8I

Law for the Registration of Printers and Publishers, 99, I05

Laws, I03, I44

See also specific laws

LCOs. See Local cable operators

Liberal democracy, 223

Lifestyle, 9I, I 30

LinkedIn, 227

Literacy, I06, 293

Literature, 250, 264

Liveness of television, $187-90$ of Twitter, I $87-90$ uncertainty and risk in, I9I, I98

Local, global and, r6

Local cable operators (LCOs), 57

Locality, 9

Localization, 16

Location dating apps and, I 28, I 37 n 10

Twitter and, I90

Long-distance communication, 6

Lyotard, Jean-François, 277

Mahmood, Adil, 267 
Mahmud, Sabeen, 2 I, $257 \mathrm{n} 2$

Malala Fund, 285, 286-87

Malalai of Maiwand, 283, 29I

Malikzada, Farkhunda, 292-93

Marginalization, of women, 4I

Marginalized groups, 40

Market forces, state and, 2 I

Marriage, I 2 7, I 29-30, I 34, I38n2 7,

$$
\text { I } 57,290
$$

Masculinity, I 35-36

Mass media, 44-47, 49, 204

Mecca, 275

Media

activism and, 247

blackouts, I 4

Burma, I 3

capitalism and, 8

citizenship and, 86

context of, 9

convergence, 18,22

culture and, I 6

dictatorship in Burma and, 98--100

digital media and, Io

digitization of, 184

drones in, 286

eroticism and, 128

genres, I I

globalization and, 4

global mobility in, 2

history of, 97

imperialism, I I

independence in Burma, I05

infrastructures, I3, I4, 22

Internet and, Io

mass, 44-47, 49

middle-class and, 226

misogyny and, 292-93

nationalism and, 205

Pakistan, 25

pirate culture of, $27 \mathrm{nI} 2$

politics and, I 5

private ownership of, ro

propaganda, 235

studies, 28ni 8, 28n23

Yousafzai in, 287

See also Digital media; Television
Media Law, in Burma, I05-6

MeitY. See Ministry of Electronics, Information and Technology

Memory card, 85, 93n29

Memory sticks, 93n29

Mewati videos, 84

Micromaterialization, of music, 84,86

Micropolitics, 39

MicroSD cards, 76, 84, 86

Microsoft, Io8

Microsoft Word, IO4

Middle-class, 25, I 30, 226, 242, 285

Migration, I04, 223

Mimesis, 273, 277n5, 278n I 3

Ministry of Communications, Post and Telegraph (MPT), , о6

Ministry of Electronics, Information and Technology (MeitY), 64

Ministry of Information and Broadcasting, 54

Minorities, I IO, I 58

Miracles, 274, 277n2

Misogyny, 205, 207, 2 I I , 290, 292-93

Miss World, I 30

Mobile network infrastructures, 6 , $60-62$

Mobile phones. See Cellphones

Mobility, 249

Modernity, I 30, I69, 224, 263

Modernization, 5

Modesty, 248

Modi, Narendra, 54, 64 APCO, I67

buzzwords and wordsmithing of, I 74 campaign of, I68, I 7 I

economy and, $175-76$

Facebook of, I 63-64, I68

hashtags of, $176-77,224,226,228$, 237

hologram of, I68, I 70

ICTs and, I $72-74, \mathrm{I} 75$

Kumar and, 2 I 4

language of, $\mathrm{I} 68$

meetings of, 176

Murthy and, I $75^{-7} 6$

Muslim community and, I67 
Modi, Narendra (continued) public image of, I66, 229 public relations of, 167

RSS and, I66-67 self-branding of, I64, I69, I 70, I 78 selfies of, I 76 , I 79 social media and, 46, I63-64, I66, I 68, I $77-78$

technology, I 70-7 I, I 72, I 78

Twitter of, 46, I64, I67, I68, I 7 I-79, I 72, I74, I 79n I

website of, I66

younger generation and, $\mathrm{I} 73^{-74}$

YouTube channel of, I 78

Zuckerberg and, ${ }_{7} 8$

\#ModiIndiasPride, 230-3 I

\#ModiInsultsIndia, 25, 224, 226, 228 $33,232,238,240$

Mojaddedi, Sibhatullah, 288

Money, in India, 66

Moon, 275

See also Sayeedi, Allama Delwar Hossain

Morals, I 29, 227

Morning Prayer, 274-75

MPT. See Ministry of Communications, Post and Telegraph

MTV, i6

Multi system operators (MSOs), 57

Mumbai, deaf community in, $145-47$, I 59-60

Mumbai attacks, I90

Murthy, Narayana, I 75-76

Music, 84, 86

Music video circulation, 84

Myanmar, 96 apps used in, Io8 cellphones in, 106-7

Facebook in, Io9, I I I government in, I09-10, I I 3

Internet in, 97, I07

language in, $\mathrm{IO}_{2}$ online ecosystem of, Io8-9

platforms of, 97

radio in, 99-I00

website for, IO I
NaMo ChatBot, 47, I64

National e-governance plan, 64

National identity, 25, 235

Nationalism, 25, 203, 204

antinationalism, 209-IO, 2 I 2 , 2 I 8 n I I

digital media and, 2 I $7 \mathrm{n} \mathrm{I}$

Europe, 223

Facebook and, 205

feminism and, 2 I6-I 7

forms of, 2 I 6

hypernationalism, 242

media and, 205

religion and, 226

remediation of, 2 I $5^{-1} 7$

resurgence of, 223

social media and, 24I-42

taxpayers money and, 234

Twitter and, 205, 234

violence and, 2 I O, 2 I 2

YouTube and, 205, 208, 2 I 2 ,

$$
\text { 2 I 5-I } 6
$$

Nationalist affect, 2 IO-I 3, 2 I 5

National League for Democracy

(NLD), 97, I00, I02, I05, I I 3

National pride, 233-34, 237

Nation-talk, 224-2 5, 240-4I

Nazar, 263-64, 270

Nazi Germany, 240

Neoimperial feminism, $282-83$

Nepotism, I69

Netflix, 39

Net neutrality, 79, 89-90

Networks of simultaneity, 195-97

New India, 242n6

New Indian Woman, I 30

New Light of Myanmar, Io I

New media, 22, 60, I 86, 242

New media publics, $245-46$

News, 20, 25, I66, I 85, I90, I98, 250

Newshour, г86, г87, I89, г90-92, г96

New Telecom Policy (NTP-99), I 29

NGOs. See Nongovernmental organizations

Nilekani, Nandan, 66

9/I I , 26, 2 I I, 280 
NLD. See National League for Democracy

Nongovernmental organizations (NGOs), 6, 39, 247

Normal, deafness and, I $47-48$

NTP-99. See New Telecom Policy

Obama, Barack, 37, 46, I63-65, I67, I $7 \mathrm{I}, 240,285,286$

Objectivity, 263, 272, 274, 276

Official Secrets Act, I I 2

Omar, Adil, I 7

OnGrid, 68-69

Online debates, 230

Online ecosystem, of Myanmar, Io8-9

Online spaces, democratization of, 206

Open Society Institute, Ioo

Operation Three Star, 208

\section{Painting, 277n3}

Pakistan

class in, 249

digital media publics in, $248-50$

eroticism in, 253

freedom of expression in, I 7, 2 I

gender in, 249

identity in, 246, 249

media in, 25

middle-class in, 285

news in, 250

politics in, 245

poverty in, $25^{2}$

sexuality in, 253-54

status in, $25 \mathrm{I}$

television in, 250-53

on YouTube, private publics of, 253-57

YouTube in, I6-I 7

Pakistan Telecommunication Authority, 247

Pakistan Television Corporation. See PTV

Pangalong Agreement, 97

Participation. See Interactivity

Patriotism, 2 I I, 2 I 5, 236

Paul, Amit, 20
PCOs. See Public call offices

Peer-to-peer networks, 224

Peirce, Charles Sanders, 270, 27 I

Perception, of cellphones, 82

Peri-technological intervention, hearing aids as, $157-59$

Personalization, Big Data and, 39

Persons with Disabilities Law (India), I 44

Photography, 268, 27 I

See also Images

Photoshop, 238, 267

Piety, 26

Pir, Ali Gul, I 7

Pirate media culture, $27 \mathrm{nI} 2$

Pirate networks, 23

Planet Romeo, I 27

Platforms, I4-I9, 66-67, 86, 97, I 84

Pluralism, 2 I, 40

Political audiences, 39-42, 43, 46-47, 50

Political culture, 26, 47-48

Political ideology, 44-47

Political institutions, 44

Political movements, I 8-I9

Political orientation, 39

Political participation, 37, 203-4, 225

Political parties, 39, 45, 87, 98, I 79n2, I 96, 208, 23 I-32, 238

Political prisoners, of Burma, I05

Politics, 7

algorithms and, 40

branding and, I 79n2

caste and, 43

citizenship and, 239

Cold War, 27 ng

communal, 42-44

communication and, 22, 44, 47

datafication of, 42, 47

digital media and, I 9

infrastructures and, I4

language and, 44

liberal democracy and, 223

media and, I 5

morals and, 227

Pakistan, 245 
Politics (continued)

publics and, 249

social media and, I8, I63-66, I 7 I-

73 , I 79n2

technocracy and, I 70-7 I

Twitter and, 227

WhatsApp and, 9I

zones of participation and, 20

Polyscopic visuality, 263-66, 272, 276

Popular culture, 249

Popular tweets, 230

Populism, 223, 224

Postmodern politics, 40

Poverty, 37, 223, 252

Power relations, I4, I6 3

Prasar Bharati Corporation, $5^{8}$

\#PrayforPhillipines, 232

Press Scrutiny and Registration Department, I05

Press Scrutiny Board, 99

Prevention of Electronic Crimes Ordinance, 247

Printers and Publishers Act, IO3, IO5-6

Privacy, 40, 48-49, 68, I09, 248

Private ownership, of media, Io

Private publics, 246, 253-57

Private sector, 225

Private space, publics and, $245-46$

Privatization, 44

Production, digital media, I42

Progressive ideals, 2 I

Promiscuity, I 26

Propaganda, 230-32, 235

Prostitution, 252

Protests, 206, 209

Psyche, 273

PTV (Pakistan Television Corporation), 25,250

Public behavior, in Pakistan, 246

Public call offices (PCOs), 20

Public office, women in, 288

Public opinion, 4I

Public perception, 79

Publics, I 8-2 I, 28n2 2, 245-46, 249, $25 \mathrm{I}-5^{2}$

Public sphere, I I, 2 I 7 n 2
Public sphere theory, 248

Public telephone booths, 6

Public values, I 5

Al Qaeda, 285

Qawwali, I25, I $27 \mathrm{nI}$

Queer community, dating apps and, I 37 nio

Quran, 272, 274-75

Racial identity, 4I

Racial stratification, $27 \mathrm{n} 8$

Racism, 40, 206, 223-24

Radiation, 23, 88, 94n36

Radio, 99-I00, I02, 28I

\#RahulInsultsHinduism, 23 I

Ram, 236

Rape, I32, I39n37, 2 I 3

Rashtriya Swayamsevak Sangh (RSS), I 66-67, 240

RAWA (Revolutionary Association of the Women of Afghanistan), 293

Reality, 27I-74, 276, 278nI 3

Reality television, I9-20, I85

Recharge shops, 86

Recontextualization, of videos, 209 , $2 \mathrm{I} 5$

Reform, 280

Refugees, digital monitoring of, 40

Regulations, cellphones, 88

Reliance Industries, 68, 70

Reliance Jio, I 2, 68, 82, 87

Religion, 69, I43-44, 226, 273, 282-83

Remediation, of nationalism, 2 I 5-I 7

Reserve Bank of India, 66

Resistance, 204

Reuters, 99

Revolutionary Association of the Women of Afghanistan. See RAWA

Riots, 79

Rothenbacher, Franz, 62-63

RSS. See Rashtriya Swayamsevak Sangh

Rumors, 79, 91 
Sacrifice, 234-37

Safety, I 32-37

Saffron Revolution, I03-4

San Francisco, 9

Sanskritization, I 56

Satellite television, 59, 250

Sayeedi, Allama Delwar Hossain, 2526, 26I-62, 265, 267, 269, 272-77, $277 \mathrm{nI}$

Scholarly organizations, 4

Scholarship, I 3, 2 I 6

Schools, I 45-47, I48-50, I 52-53

The Second Floor (T2T), 2 I, 293

Secularism, 2 I , 282

Sedition law, 49

Self-branding, I64, I69, I 78

Self-censorship, Io6

Self-expression, 78 , I 58

Selfhood, 24

Selfies, of Modi, I 76, I 79

Self-image, 257

Self-presentation, 24

Semiotic ideologies, $278 \mathrm{nI} 4$

Sexism, 206

Sexuality, I 6, 69, 204, 2 I I , 2 I 3

Bollywood, I 32

cellphones and, I 29

discovery, I 35

gender and, 24

India, I 29

Pakistan, 253-54

safety and, I 32

TrulyMadly and, I 3 I -35

violence and, 208, 2 I0, 2 I 2,2 I 5, 2 I 7

women, 283

Sex workers, 248, 25 I-52

\#ShamedInSydney, I 87, I 90-98

\#ShameOn'TimesNow, 193-94, I96

Sharing music, 86

Shirk (idolatry or polytheism), 272

Signal transmissions, interference and, 62

Sign language, I46, I49, I 50

Silicon Valley, I, 9

Silicon Valley, 2

Sin, 268
Singh, Manmohan, I 70-7 I

Sinha Le, I9

Skepticism, 266, 272-73, 276

Slezic, Laura, 290

SLORC. See State Law and Order Restoration Council

Slums, 77

Smartphones, 3,78

SMS, 6

SNS. See Social networking site

Social codes, 246

Social inequality, 37

Social interactions, commodification of, $\mathrm{I} 8$

Socialism, of Burma, 98

Social justice, 40,48

Social media, 24

branding and, $\mathrm{I} 7 \mathrm{I}-73$

communication and, I63, 24I

elections and, I 79n2

government and, 37

Modi and, 46, I63-64, I66, I68, I $77-78$

nationalism and, 24I-42

news and, I66

politics and, I8, I63-66, I 7 I-73, I 79n2

television and, 198

of Trump, i65

urban environments, 25

videos, 90

Social networking, 7, I 27

Social networking site (SNS) platforms, I 84, I 89-90, I96

Social spaces, 2 I

Social theory, geography and, 8-9

Society, deafness and, 148

Sociocultural norms, I 57

Socioeconomic status, caste and, ${ }_{5} 6$

Sound studies, 28n 8

South Asia Solidarity Initiative, 289

Soviet Union, computer network of, $27 n 9$

Spectrum consolidation, Airtel and, 87

Spectrum distribution, 9I

Spectrum licenses, 87 
Spectrum wars, of Reliance Jio, 87

Spontaneous affective intensity, on Twitter, I97

Sri Lanka, I9

Standardization, 58, 63, I92-93, 24I

Start-up culture, 90

State

censorship by, I 7

market forces and, 2 I

State Law and Order Restoration Council (SLORC), Ioo

State-sponsored identity projects, 22

Status, in Pakistan, $25 \mathrm{I}$

Stereotypes, 80, 280

Stigma, I 43, I 58

Subaltern-popular, cellphones and,

$$
83-87
$$

Sufi tradition, 274

Sumar, Sabiha, 257

Surveillance, 48, 68, 70, IOI, I I 2, I I 3 , 248

Synchronization, 62-63

Syncretism, visuality and, 263-65

System design, 67

T2 T. See The Second Floor

Tabla, I 2 5, I 37n2

TAGS. See Twitter Archiving Google

Sheet Hawksey tool

Takalluf (deference, politeness), 250-53

Taliban, 284, 285, 286, 288, 290

Target rating points (TRP), I 86

Taxpayers money, 234

Technocracy, politics and, I 70-7 I

Technology, I69

companies, I 5

digital media, 3

file sharing, 86

gender and, I 37

Internet as, $27 \mathrm{n}_{5}$

Modi's use of, I 70-7 I, I 72, I 78

new, 23

wealth and, ${ }_{3} 8$

Techno-nationalism, 5

Tebzeeb (culture), 250-53

Telecom market, I 2
Telecommunications, 6o-62, 63, 69-70

Telecommunications Law, I Io, I I 2

Telecommunications Regulatory Authority of India (TRAI), 53-54, 56, 57,6 I, 67, I 29

Telecom policies, 90

Telephones, 5, 6 See also Cellphones

Television, 4, Iо, I6, 60-63, 70, 28 I

audience, I $84-85,227$

Burma, 99, I0 I, I 06

buzzwords, I9I

color, I4

digital media and, 203

DTH channels, 57-58, 67

DTT, $5^{8}$

evolution of, 22

hearing aids and, I $5 \mathrm{I}$

in India, 53, 55-60, I 84

interactivity and, $185-86$

IPTV, $57-5^{8}$

language and, $25 \mathrm{I}$

licensing, 99

limitations of, I 89

liveness of, $187-90$

media convergence and, 22

national television network, 45

new media and, I 86

news, I 85

norms in, $25 \mathrm{I}$

Pakistan, 250-53

political parties and, 45

private control of, Io6

providers, $57^{-} 5^{8}$

publics and, $25 \mathrm{I}-52$

reality, I9-20, I 85

resolution of, $5^{8}$

satellite, 59,250

sex workers on, $25 \mathrm{I}-52$

SNS and, I 89-90

social media and, I98

standardization of, 58,63, I $92-93$

TRP on, I 86

Twitter and, 24, I84-90, I97

See also Digital Addressable System

Television and Video Law, ıо , Io6 
Terrorism, Islam and, 290

Texting, I 87 See also SMS

Times Now, I92-94, I97, I98

Tinder, 23

TRAI. See Telecommunications Regulatory Authority of India

Travel ban, 286

Trending, I88, I90

TRP. See Target rating points

TrulyMadly, 23, I 25-26

age on, I34

campaigns of, I 35

definition of dating, I 33

demographics, I 33

Facebook and, I 34, I 36

generational divide and, I4On4I

headquarters, I 3 I

keywords of, ${ }_{1} 36$

marketing of, $132-33, \mathrm{I} 36$

marriage and, $\mathrm{I} 34$

peeping toms and, $132-33$

privacy and, 132

safety of, I 32, I 34-35

sexuality and, I 3 I -35

sign-up process, I4On 42

social indicators on, I $40 \mathrm{n}_{4} 2$

verification on, 133

Trump, Donald, 37, I65, 206, 286

Truth, photography and, 268

Twitter, 24, 253

algorithm of, 188

bots, 50

Burma, I I I

China, I96

clashes on, 228-33

corporate branding on, 228

culture and, 24I

fake followers on, 46

grammar and, 243nio-i I

guidelines of, $\mathrm{I} 88$

hashtags of, 187-88, 190-97, 224, 226,228

Hindu mythology and, 235-36

India, I 95-97, 226-28

IndiaStack, 68-69 interactivity and, I 84-90

liveness of, I 87-90

location and, I9o

of Modi, 46, I64, I67, I68, I 7 I-79,

I 72, I74, I 79 n I

nationalism and, 205, 234

networks of simultaneity, I95-97

Newshour, I 89, I9I-92

perception of, 228

polarizing dimension of, I95

political parties and, I 96

politics and, 227

popular tweets, 230

seriousness of, $226-28$

\#ShamedInSydney, I 87, I 90-98

\#ShameOnTimesNow, I93-94, I96

spontaneous affective intensity on,

I97

television and, 24, I84-90, I 97

trending on, I 88

users of, 196

videos and, 203

YouTube and, 203

Twitter Archiving Google Sheet Hawksey tool, 229

Twitter India, 23 I

UID. See Unique identification number

Unbound seriality, 24I

Unconscious mind, 273

UN Human Rights Commission, I I I

Unicode, IO2-4, IO8

Unified Payment Interface (UPI), 65-66

Union of Burma, 97-98

Union Revolutionary Council, 98-99

Unique Identification Authority, 65, 67

Unique identification number (UID), $38,65,67-69$

United Nations, 62-63, I I I

United States, 2 IO-I I, 289

Universities, 3-4

"Unsilencing Balochistan," 2 I

UPI. See Unified Payment Interface

Urban environments, social media in,

25 
Values, infrastructures and, 4I

Van Dijck, José, I4-I 5

VCRs. See Videocassette recorders

Vemula, Rohith, 2 I 8n I I

Videocassette recorders (VCRs), I4

Videos

doctoring, 209, 2 I 2-I 3

of protests, 209

recontextualization of, 209, 2 I 5

social media, 90

Twitter and, 203

Violence, 205

contagious affect, 2 I $3^{-\mathrm{I}} 5$

gender and, 208, 2 IO, 2 I 2,2 I 5, 2 I 7

hashtags and, 2 I4

honor killings, 2 I I

Internet and, 207-I 5

against Kanhaiya Kumar and other students, 2 I I

nationalism and, 2 I O, 2 I 2

normalization of, 206

sexuality and, 208, 2 I , , 2 I 2, 2 I 5, 2 I 7

space for, 207-I 5

against women, 206, 245, 247, 292

You Tube and, 207

Viral rumors, 79, 9I

Visuality

Bangladesh, 262-63

darshan, 263-64

Hinduism and, 264

interocular, 263-64, 272, 276

nazar, 263-64

objectivity and, 276

polyscopic, 263-66, 272, 276

syncretism and, 263-65

Vivekananda, Swami, 236

Vodafone, 82

War on Terror, 280, 282, 287-89, 292

War Resistors League, 289

Wealth, technology and, $3^{8}$

Web 2.o, I 5

Welfare, 42-44

WhatsApp, 76, 79, 80, 90, 9I, I 25, 226

White technoculture, $27 \mathrm{n} 8$
Wikipedia, I 88

Windows, IO2

A Woman among Warlords (Joya), 288

Women

activism of, $280-8 \mathrm{I}$

domestic abuse, 290

education of, $285,286-87,289$

imperialism and, 282

India, I 32

liberation of, $282-83,289$

marginalization of, $4 \mathrm{I}$

Muslim, 280

in public office, 288

religion and, $282-83$

rights of, 253-54, 283, 289-90

safety of, I32, I34-35, I 37

sexuality of, 283

stereotypes of, 280

violence against, 206, 245, 247, 292

Yousafzai and, 285

World Trade Center, 2 I I

World War II, 62-63, 98

Xenophobia, 206, 224, 292

Yang, Guobin, 3

Year over year (YOY), 28ni 4

Younger generation, $\mathrm{I} 73^{-74}$

Yousafzai, Malala, 28 I, 283

background of, 284

blog of, 284, 292

documentaries on, 284

drones and, $285-86$

education of, 287

Malala Fund, 285, 286-87

in media, 287

memoirs of, 285

Nobel Peace Prize of, 284

shooting of, 284,287

women and, 285

YouTube

comments, 207, 2 I I , 248, 254-57

Kumar and, 2 I 4

localized implementation of, I 7

of Modi, I 78 
nationalism and, 205, 208, $2 \mathrm{I} 2$, 2 I 5-I 6

Pakistan, I6-I7

private publics of Pakistan on, 25357

publics and, 246

sex workers and, 248
Twitter and, 203

violence and, 207

YOY. See Year over year

Zawgyi, I02-3, го4, Iо8

Zones of participation, I9-20

Zuckerberg, Mark, I I I, I 78 
